\title{
Untersuchung von Proteinkomponenten der ER-Golgi- Recycling-Maschinerie von Hefe
}

\author{
Dissertation \\ zur Erlangung des Doktorgrades \\ der Mathematisch-Naturwissenschaftlichen Fakultäten \\ der Georg-August-Universität zu Göttingen
}

vorgelegt von

Tanja Neumann

aus Göttingen

Göttingen 2000 
D7

Referent:

Prof. Dr. A. Zeeck

Korreferent:

Prof. Dr. H. Laatsch

Tag der mündlichen Prüfung:

31.01.2001 
für Christian 


\section{Inhaltsverzeichnis}

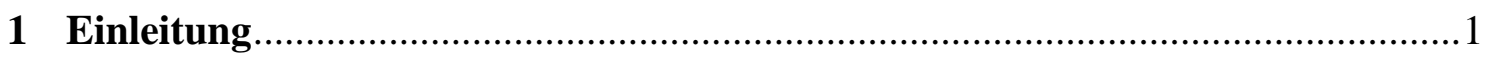

1.1 Der vesikelvermittelte Transport ..............................................................

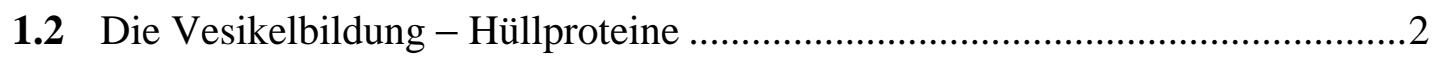

1.2.1 COPII-Vesikel - anterograder Transport vom ER zum Golgi..................3

1.2.1.1 Bildung der COPII-Hülle..................................................... 3

1.2.1.2 ER-Export Signale ............................................................

1.2.2 COPI-Vesikel - retrograder Transport vom Golgi zum ER ...................6

1.2.2.1 Bildung von COPI-Vesikeln................................................6

1.2.2.2 Signale des ER-Rücktransports und der ER-Retention ............. 7

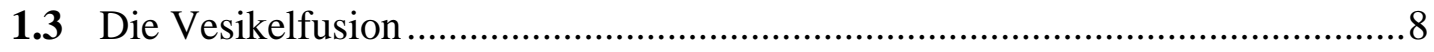

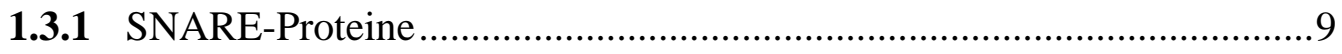

1.3.2 Modulatoren der SNARE-Proteine ................................................... 10

1.4 SNARE-Proteine der ER-Golgi-Recyclingmaschinerie in Hefe …....................12

1.5 Zielsetzung und Konzept dieser Arbeit ........................................................ 14

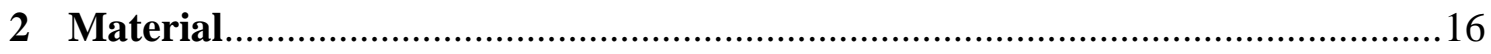

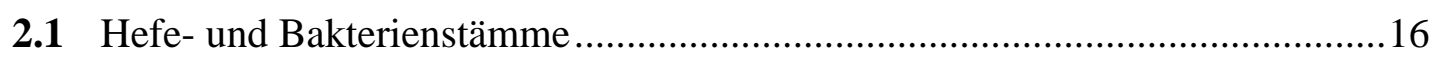

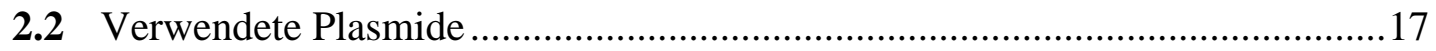

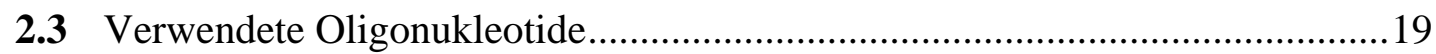

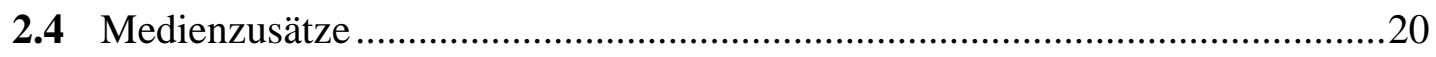

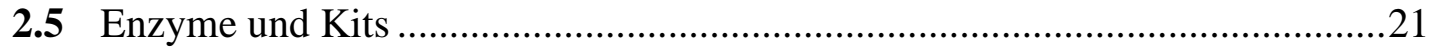

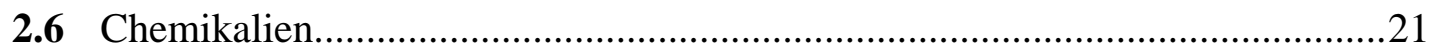

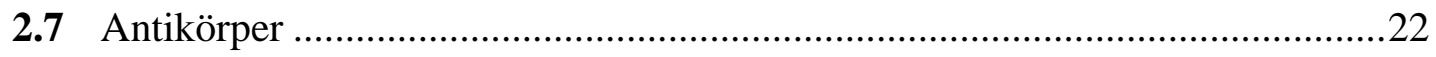

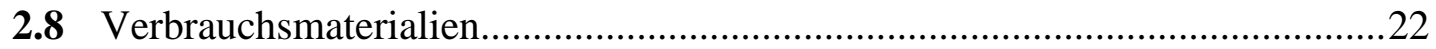

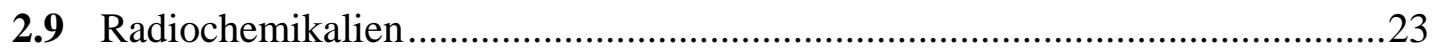

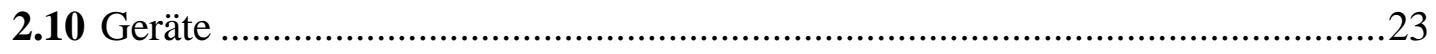

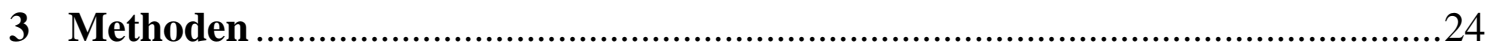

3.1 Kulturbedingungen für Escherichia coli ....................................................24

3.1.1 Nährmedien für E. coli ...................................................................24

3.1.2 Anzucht von E. coli-Kulturen ........................................................25 
3.2 Kulturbedingungen für Saccharomyces cerevisiae ........................................25

3.2.1 Nährmedien für Hefe Kulturen ........................................................25

3.2.2 Anzucht von Hefekulturen ...............................................................26

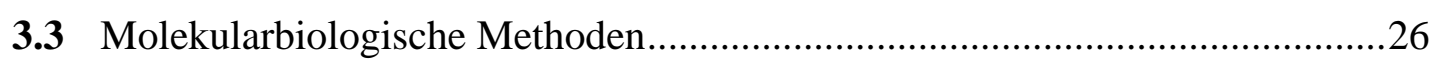

3.3.1 Präparationen von DNA ...........................................................26

3.3.1.1 Analytische Plasmidisolierung aus E. coli-Zellen ...................26

3.3.1.2 Präparative Plasmidisolierung aus E. coli-Zellen ...................27

3.3.2 Photometrische Bestimmung der DNA-Konzentration ........................28

3.3.3 Enzymatische Behandlung von DNA ..............................................28

3.3.3.1 Fragmentierung von Doppelstrang-DNA mit Restriktions-

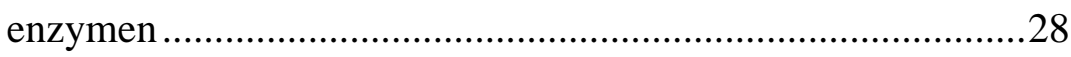

3.3.3.2 Behandlung von linearisierter DNA mit alkalischer

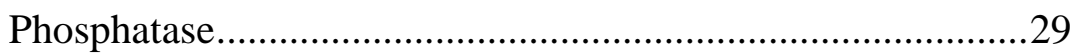

3.3.3.3 Auffüllen von 5'-überhängenden DNA-Enden .......................29

3.3.4 Gelelektrophoretische Auftrennung von DNA ....................................30

3.3.5 Analytische und präparative Agarose-Gelelektrophorese......................30

3.3.6 Isolierung von DNA aus präparativen Gelen ........................................31

3.3.7 Klonierung rekombinanter DNA in $E$. coli ...........................................31

3.3.7.1 Ligation von DNA-Doppelstrang-Fragmenten ........................32

3.3.7.2 Herstellung transformationskompetenter E. coli-Zellen...........32

3.3.7.3 Transformation von E. coli-Zellen.........................................33

3.3.8 DNA-Amplifikation mit der Polymerase-Kettenreaktion.......................33

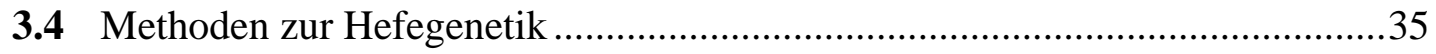

3.4.1 klassische Transformation von Hefezellen ..........................................35

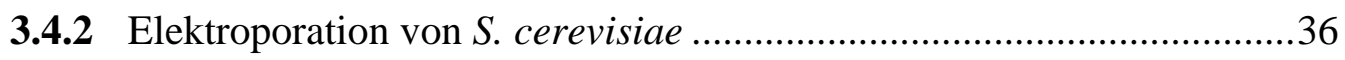

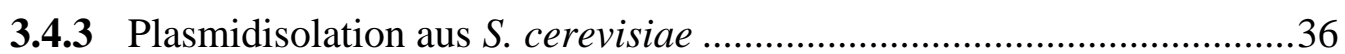

3.4.4 Präparation von genomischer Hefe-DNA ..............................................37

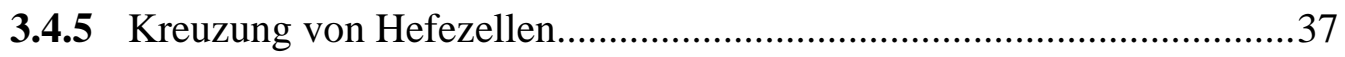

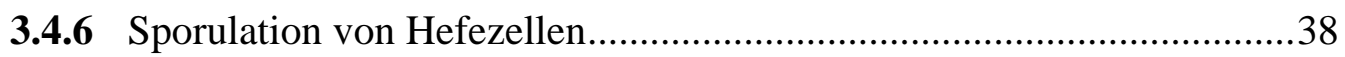

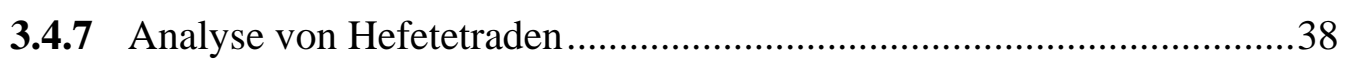

3.4.8 Nachweis von sekretiertem $\alpha$-Pheromon durch den „Halo“-Test...........39

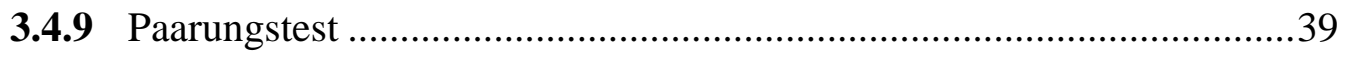

3.4.10 Bestimmung des Wachstums von Hefezellen auf Agarplatten..............40

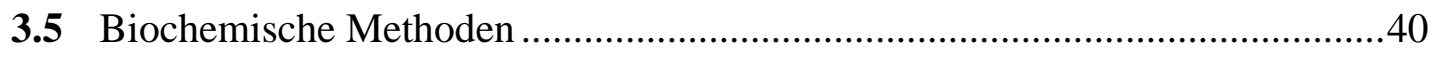

3.5.1 Alkalischer Aufschluß von Hefezellen und TCA-Präzipitation der Proteine

3.5.2 Messung der Proteinkonzentration 
3.5.3 Trennung von Proteinen durch SDS-PAGE........................................41

3.5.4 Nachweis von Proteinen auf Nitrozellulose-Filtern..............................43

3.5.4.1 Transfer von Proteinen auf Nitrozellulose-Filter

$$
\text { (,Westernblot“-Verfahren) ..................................................43 }
$$

3.5.4.2 Ponceau-Färbung von Nitrozellulose-Filtern...........................43

3.5.4.3 Immunologischer Nachweis von Proteinen auf Nitrozellulose-

Filtern (Immunoblot-Analyse) .............................................44

3.5.5 Expression von GST-Fusionsproteinen in S. cerevisiae ........................45

3.5.6 Aufreinigung von GST-Fusionsprotein-Komplexen

(GST-,,pull-down“-Experiment) ...

3.5.7 Immunpräzipitation von radioaktiv markierten Proteinen aus Zellextrakten (,Pulse-Chase“-Experiment).............................................46

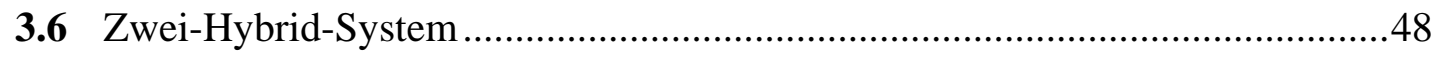

3.6.1 Transformation einer c-DNA-Genbank ............................................49

3.6.2 X-Gal-Filtertest zur Identifizierung interagierender Proteine.................50

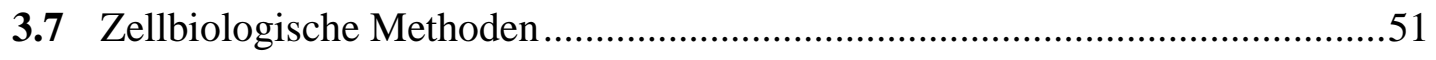

3.7.1 Immunfluoreszenzanalysen von Hefezellen.......................................51

3.7.2 Subzelluläre Fraktionierung von Hefekompartimenten mittels Sucrose-

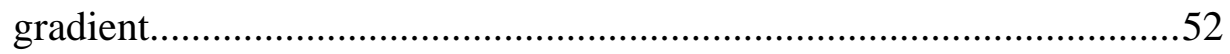

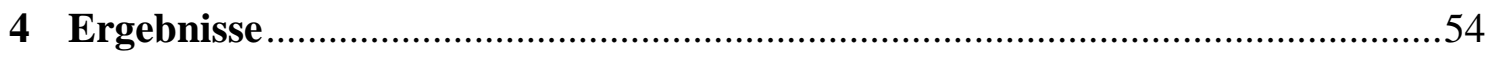

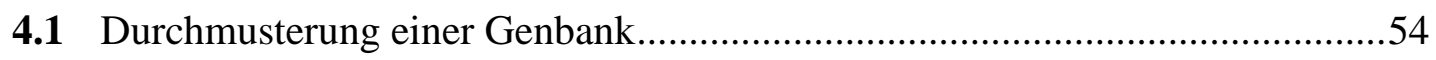

4.1.1 Verwendung des Ste2-Wbp1p-Reporters............................................54

4.1.2 Verwendung des Sec22- $\alpha$ Reporters.................................................59

4.2 Einfluß von SNARE-Proteinen auf die ER-Golgi-Recyclingmaschinerie ........61

4.3 Weitere Effekte der Überproduktion von Sed5p ........................................65

4.4 Die Suche nach Genen, deren Überexpression die negativen Effekte einer Überproduktion von Sed5p ausgleichen kann...............................................66

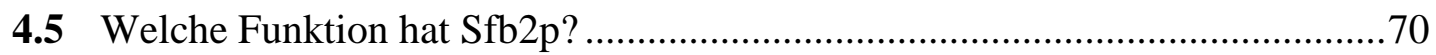

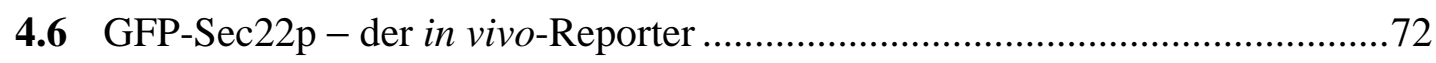

4.7 Die Suche nach direkten Bindungspartnern von Sec22p mittels Zwei-Hybrid-

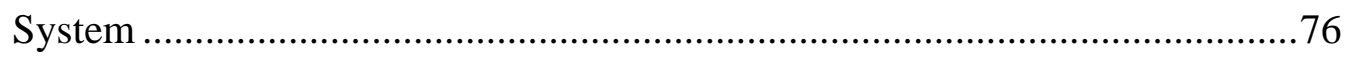

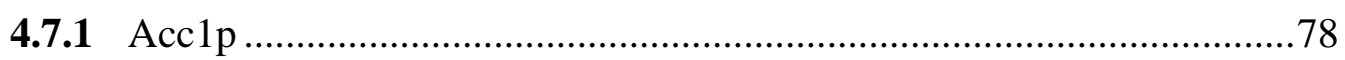

4.7.2 Untersuchung der Interaktion zwischen Acc1p und Sec22p.................81

4.7.3 Untersuchung der Interaktion zwischen Acc1p und weiteren SNAREs 
4.7.4 Genetischer Zusammenhang zwischen SEC22 und ACC1 86

4.7.5 Lokalisation von Acc1p in Hefemutanten des vesikulären Transports...... 88

4.7.6 Regulation der Aktivität von Acc1p und Auswirkungen auf die Interaktion mit $\operatorname{Sec} 22 \mathrm{p}$ 91

5 Diskussion . .94

5.1 Die Recycling-Maschinerie von Sec22p 94

5.2 Überproduktion von Sed5p stört das Recycling von Sec22p 95

5.3 Sfb2p - ein Gegenspieler des Sed5p? .98

5.4 Acc1p und der vesikuläre Transport. 100

6 Zusammenfassung 106

7 Literaturverzeichnis 108

8 Anhang 122 


\section{Einleitung}

Die eukaryontische Zelle enthält eine Anzahl von Kompartimenten, sogenannte Organellen, die durch intrazelluläre Membranen umgeben sind. Beispiele hierfür sind der Zellkern, das endoplasmatische Retikulum (ER), der Golgi-Apparat sowie Endosomen und Lysosomen. In solchen intrazellulären Kompartimenten finden unterschiedliche metabolische Prozesse statt. Zusammen mit der Plasmamembran bilden sie ein funktionelles Netzwerk aus, welches für die Biosynthese, Modifizierung und Lokalisation von Proteinen und Lipiden, für die Sekretion sowie für die Endozytose verschiedenster Proteine und Verbindungen verantwortlich ist.

\subsection{Der vesikelvermittelte Transport}

Durch die Sekretion von Molekülen und durch die Aufnahme von extrazellulärem Material steht die Zelle mit ihrer Umgebung in Verbindung. Gleichzeitig muß aber auch die strukturelle und funktionelle Organisation der einzelnen intrazellulären Kompartimente aufrecht erhalten werden. Dazu muß die Zelle sowohl alle synthetisierten Proteine und Lipide als auch aufgenommene Moleküle zielgerichtet und korrekt zu ihrem Bestimmungsort bringen. Dies geschieht zu einem erheblichen Teil mit Hilfe von Transportvesikeln, kleinen membranumschlossenen Strukturen, die von einem Kompartiment, dem Donorkompartiment, abschnüren und mit einem anderen, dem Akzeptorkompartiment, fusionieren (Palade, 1975). Dabei kann ein Vesikel sowohl lösliche Fracht in seinem Innern transportieren als auch in seiner Lipiddoppelschicht inkorporierte Transmembranproteine und Lipide. Alle vesikulären Transportprozesse stehen in einem dynamischen Gleichgewicht miteinander (Abb. 1).

Bei den zahlreichen Transportprozessen innerhalb der Zelle stellt sich die Frage nach dem Organisationsmuster dieser Vorgänge. Viele Faktoren, die für die Spezifität und Direktionalität des vesikulären Transports verantwortlich sind, konnten in den letzten Jahren isoliert und charakterisiert werden. Dabei stellte sich heraus, daß diese Komponenten von der Bäckerhefe bis zum Mensch hochkonserviert sind (Bennett und Scheller, 1993; Ferro-Novick und Jahn, 1994). 


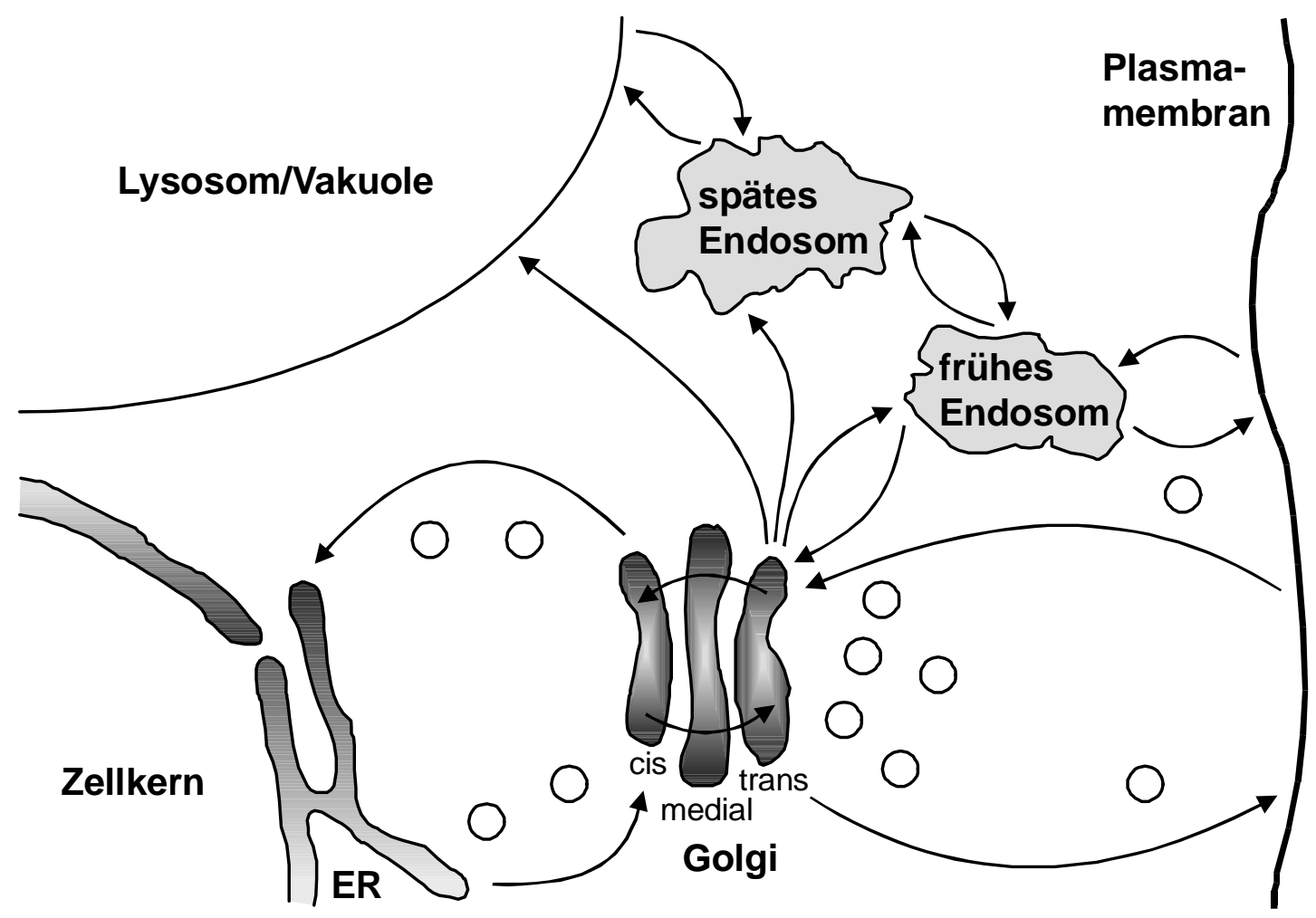

Abbildung 1: Schematische Darstellung vesikulärer Transportprozesse innerhalb einer eukaryontischen Zelle.

\subsection{Die Vesikelbildung - Hüllproteine}

Die Mehrzahl der Transportvesikel entsteht aus spezialisierten Membranbereichen, deren dem Zytosol zugewandte Oberfläche durch ein besonderes Gitter aus Proteinen bedeckt ist. Man glaubt, daß durch die Zusammenlagerung dieser Hüllproteine (englisch: coat proteins) die Energiebarriere der Vesikelknospung überwunden wird. Die Vesikelhülle wird vor der Verschmelzung mit der Akzeptormembran abgeworfen, damit die beiden Membranen in direkte Wechselwirkung treten können.

Es sind drei verschiedene Hüllproteinkomplexe bekannt: 1) Clathrin umhüllte Vesikel bestehen aus einem Adaptorkomplex, einer kleinen GTPase und Clathrin. Sie schnüren zum einen an der Plasmamembran ab (Endozytose) und zum anderen am trans-Golgi-Netzwerk (Transport zu Endosomen). Diese Hüllproteinkomplexe unterscheiden sich wiederum je nach Ort ihrer Bildung und ihrem Ziel in der Zusammensetzung ihrer Adaptorkomplexuntereinheiten. 2) COPI-umhüllte Vesikel bestehen aus sieben Proteinuntereinheiten und eben- 
falls einer kleinen GTPase. Sie bilden sich im Golgi und sind sowohl für den Transport innerhalb des Golgi als auch für den retrograden Transport vom Golgi zum ER verantwortlich. 3) COPII-umhüllte Vesikel werden ausschließlich am ER gebildet. Der COPII-Hüllproteinkomplex besteht aus fünf Untereinheiten, darunter wiederum eine GTPase.

Das Zusammenlagern der Hüllproteine auf der Membran scheint einem generellen Mechanismus zu folgen und wird immer durch die Bindung der kleinen GTPase an die Membranoberfläche in ihrer GTP-gebundenen Form initialisiert. Da die beiden zuletzt genannten Hüllproteinkomplexe COPI und COPII in ihrer Funktion im ER-Golgi-Transport für diese Arbeit eine entscheidende Rolle spielen, sollen diese im folgenden näher beleuchtet werden.

\subsubsection{COPII-Vesikel - anterograder Transport vom ER zum Golgi}

\subsubsection{Bildung der COPII-Hülle}

Die Komponenten der COPII-Vesikelhülle wurden mit Hilfe von sec-Mutanten (sec für Sekretion) aus Hefe, welche unterschiedliche Defekte in verschiedenen Schritten des intrazellulären Vesikeltransports aufwiesen, charakterisiert (Kaiser und Schekman, 1990). Dies führte zu der Identifizierung von drei löslichen Proteinkomponenten in Hefe: dem Sar1p, dem Sec23p-Komplex und dem Sec13p-Komplex (Tab. 1). Sar1p ist eine GTPase, die Sequenzhomologie zur Familie der Ras GTPasen aufweist (Barlowe et al., 1993; Nakano und Muramatsu, 1989). Der Sec23p-Komplex ist $400 \mathrm{kDa}$ groß und setzt sich aus zwei Proteinen Sec23p und Sec24p zusammen, während der Sec13p-Komplex ein Molekulargewicht von $700 \mathrm{kDa}$ aufweist und aus Sec13p- und Sec31p-Untereinheiten besteht (Pryer et al., 1993; Salama et al., 1997; Salama et al., 1993). Beide Proteine des Sec13p-Komplexes weisen sogenannte WD 40-Motive auf, von denen angenommen wird, daß sie generell Protein-Protein-Wechselwirkungen vermitteln (Neer et al., 1994).

Durch in vitro Rekonstitutionsexperimente mit gewaschenen Membranen konnten die einzelnen Schritte der Vesikelbildung aufgeklärt werden (Salama et al., 1993). Der erste Schritt stellt wie bereits erwähnt das Rekrutieren der GTPase Sarlp an die Membran dar. Dazu muß die GTPase von der GDP-gebundenen Form, die zytosolisch ist, in die GTP-gebundenene Form, die membranassoziiert ist, überführt werden. Dies wird durch einen Nukleotid-Austauschfaktor Sec12p, ein Transmembranprotein des ER, katalysiert (Barlowe und Schekman, 1993). 
Danach kann zunächst der Sec23p-Komplex binden, dessen Bindung die Voraussetzung für die Bindung des Sec13p-Komplexes darstellt. Nach dem Abschnüren des Vesikels werden die Hüllproteine durch die Hydrolyse des an Sar1p gebundenen GTP wieder entfernt, damit das Vesikel mit seiner Zielmembran fusionieren kann. Letztere Reaktion wird durch eines der Hüllproteine selbst, Sec23p, welches eine GTPase aktivierende Domäne besitzt und somit als GAP (GTPase aktivierendes Protein) fungiert, stimuliert (Yoshihisa et al., 1993). Das Abdissoziieren der Hüllproteine kann durch die Anwesenheit des nicht hydrolisierbaren GTP-Analogons GTP $\gamma$ S inhibiert werden, wodurch das Vesikel fusionsinkompetent wird (Barlowe et al., 1994).

\begin{tabular}{cccc}
\hline COPII & Hefe & Säuger & Größe \\
\hline \hline Sec13-Komplex & Sec13p & hSec13p & $\sim 34 \mathrm{kDa}$ \\
& Sec31p & hSec31p & $\sim 150 \mathrm{kDa}$ \\
Sec23-Komplex & Sec23p & hSec23p & $\sim 85 \mathrm{kDa}$ \\
& Sec24p & hSec24p & $\sim 105 \mathrm{kDa}$ \\
GTPase & Sar1p & Sar1 & $\sim 21 \mathrm{kDa}$ \\
\hline COPI & Hefe & Säuger & Größe \\
\hline \hline Coatomer & Ret1p & $\alpha$-COP & $\sim 140 \mathrm{kDa}$ \\
& Sec26p & $\beta$-COP & $\sim 107 \mathrm{kDa}$ \\
& Sec27p & $\beta^{\prime}$-COP & $\sim 102 \mathrm{kDa}$ \\
& Sec21p & $\gamma$-COP & $\sim 97 \mathrm{kDa}$ \\
& Ret2p & $\delta$-COP & $\sim 57 \mathrm{kDa}$ \\
& Sec28p & $\varepsilon$-COP & $\sim 35 \mathrm{kDa}$ \\
& Ret3p & $\zeta$-COP & $\sim 20 \mathrm{kDa}$ \\
& Arf1/2p & ARF1 & $\sim 20 \mathrm{kDa}$ \\
\hline
\end{tabular}

Tabelle 1: Übersicht über die Hüllproteine von COPI- und COPIIVesikeln; die Größe in kDa wurde durch die Aminosäurezusammensetzung bestimmt

Die soeben beschriebenen fünf zytosolischen Proteine reichen in vitro aus, um ein funktionelles COPII-Vesikel zu produzieren. In vivo sind jedoch noch zwei weitere Proteine bekannt, die beim Abschnüren von Vesikeln am ER eine Rolle spielen. Dies ist zum einen Sec16p, ein $240 \mathrm{kDa}$ Protein, welches peripher an das ER assoziiert ist, und Sed4p, welches eine starke Homologie zu Sec12p aufweist (Espenshade et al., 1995; Gimeno et al., 1995). Es konnte gezeigt werden, daß Sec16p mit Sec23p und Sec24p interagiert, worauf ihm eine mögliche Funktion 
als eine Art Stützwerk für die Membranassoziation der zytosolischen Hüllproteine zugeschrieben wurde. Es könnte jedoch auch eine Rolle bei der Proteinsortierung spielen, da in temperatursensitiven Mutanten von Sec16p nur bestimmte Frachtmoleküle nicht in die COPII-Vesikel verpackt werden (Campbell und Schekman, 1997). Obwohl Sed4p homolog zu Sec12p ist, katalysiert es nicht den GDP-GTP-Austausch an Sar1p. Es bindet an Sec16p und könnte so in einem multimeren Proteinkomplex seine noch nicht eindeutig geklärte Funktion in der Vesikelknospung haben.

Erst kürzlich konnte anhand zweier dem Sec24-Protein sehr ähnlichen Proteine in Hefe gezeigt werden, daß die Zusammensetzung der COPII-Hülle variiert und es somit Subpopulationen von COPII-Vesikeln geben kann, die unterschiedliche Frachtmoleküle transportieren (Roberg et al., 1999; Peng et al., 2000; Higashio et al., 2000; Kurihara et al., 2000).

\subsubsection{ER-Export Signale}

Proteine, die vom ER, dem Ort ihrer Synthese, zu anderen Organellen transportiert werden sollen, müssen in COPII-Vesikel verpackt werden. Lange Zeit glaubte man, daß der Weitertransport vom ER zum Golgi-Komplex dem „bulkflow"-Modell folgt, das besagt, daß grundsächlich alle Proteine zunächst weitertransportiert werden und nur solche Proteine, die ein spezifisches Recycling- oder Retentionssignal besitzen, anschließend vom Golgi wieder zurückgeführt werden (Pfeffer und Rothman, 1987). Dies würde bedeuten, daß keine Konzentrierung der Frachtmoleküle bei der COPII-Vesikelknospung erfolgt. Für einige Proteine, die in großen Mengen sezerniert werden, trifft dies zu (Warren und Mellman, 1999). Einige weniger stark synthetisierte Frachtmoleküle scheinen dagegen spezifische Rezeptoren zu benötigen, um sich in COPII-Vesikeln anzureichern (Balch et al., 1994). Auch die Tatsache, daß in einigen Hefemutanten nur bestimmte Frachtmoleküle einen Transportdefekt aufweisen, spricht für einen aktiven Sortierungsprozess beim ER-Export (Schimmöller et al., 1995). Es konnte erst später durch die Isolierung eines Proteinkomplexes, der sich während der Assoziation der Hüllproteine an die Membran bildet, gezeigt werden, daß ein Teil der COPII-Hüllproteine, nämlich der Sec23/24p-Komplex, mit den zu transportierenden Frachtmolekülen interagiert (Kuehn et al., 1998; Aridor et al., 1998). Es wurde nach spezifischen Proteinsequenzen innerhalb der Frachtmoleküle gesucht, die von den Hüllproteinen als Sortierungssignal erkannt werden. Das vollständige Signal ist zur Zeit noch unbekannt, jedoch scheinen die 
am C-Terminus gelegenen Phenylalaninreste in dem Säugerprotein ERGIC-53 für die COPII-Interaktion verantwortlich zu sein (Kappeler et al., 1997). Da diese beiden Aminosäuren nicht für einen ER-Export ausreichen, sind sie wahrscheinlich Teil eines größeren Exportsignals. Diese beiden Aminosäurereste sind im Hefehomologen Emp47p gegen zwei Leucin ausgetauscht.

Des weiteren kommt im zytoplasmatischen Teil einiger Transmembranproteine ein ER-Exit-Motiv vor, daß zwei saure Aminosäuren enthält, die durch eine beliebige Aminosäure getrennt sind (D/EXD/E-Motiv) (Nishimura und Balch, 1997). Eine direkte Interaktion des zuletzt genannten Motivs mit den COPII-Hüllproteinen konnte jedoch noch nicht gezeigt werden.

\subsubsection{COPI-Vesikel - retrograder Transport vom Golgi zum ER}

\subsubsection{Bildung von COPI-Vesikeln}

Die in vitro Generation der COPI-Vesikel von isolierten Golgi-Membranen aus Säugerzellen machte die biochemische Charakterisierung der COPI-Hüllproteine möglich (Ostermann et al., 1993; Serafini et al., 1991b). Die Vesikelhülle besteht aus der zytosolischen GTPase ARF1 und „coatomer“, einem heteroheptameren Proteinkomplex, bestehend aus stöchiometrischen Anteilen $\alpha_{-}^{-}, \beta_{-}^{-}, \beta^{\prime}-, \gamma_{-}^{-}, \delta_{-}, \zeta_{-}$, und $\varepsilon$-COP (Serafini et al., 1991a; Waters et al., 1991). Zu allen Säugerproteinen sind Hefehomologe bekannt (siehe Tabelle 1). $\beta-, \beta^{\prime}-, \gamma-$ und $\varepsilon$-COP aus Hefe sind die Genprodukte von SEC26, SEC27, SEC21 bzw. SEC28 (Duden et al., 1994; Hosobuchi et al., 1992; Duden et al., 1998). Zur Isolierung dieser Gene wurden zum Teil Hefemutanten verwendet, die einen Defekt im sekretorischen Transportweg zeigen. Die anderen drei „,coatomer“-Untereinheiten wurden mit Hilfe eines genetischen „screens“ identifiziert, bei dem Mutanten selektiert wurden, die einen Defekt in der Rückführung eines ER-residenten Proteins aufweisen. So wurden die Gene RET1(COP1), RET2 und RET3 (Ret für ,retrieval“) kloniert, die für $\alpha-, \delta$ - und $\zeta$-COP in Hefe kodieren (Letourneur et al., 1994; Cosson et al., 1996).

Die Bildung der COPI-umhüllten Vesikel verläuft ähnlich der COPII-umhüllten Vesikel. Sie wird durch das Rekrutieren der zytosolischen GTPase ARF1 an die Golgi-Membran initiiert (Palmer et al., 1993; Donaldson et al., 1992). Die Bindung und Aktivierung von ARF1 wird durch den Austausch von GDP zu GTP ausgelöst. Es wird vermutet, daß der myristoylierte N-Terminus des Proteins durch die GTP-Bindung seine Konformation ändert und somit die Membran- 
bindung erlaubt (Kahn et al., 1992). Die Reaktion wird ebenfalls wie im Falle COPII durch einen Nukleotid-Austauschfaktor katalysiert. Im Gegensatz zu dem Transmembranprotein Sec12p sind alle charakterisierten Nukleotid-Austauschfaktoren für ARF1 zytosolische Proteine (Chardin und McCormick, 1999). Nach der Bindung von ARF1 erfolgt die Bindung der ,coatomer“-Untereinheiten, wobei dies wie bei COPII in zwei Schritten erfolgt: zunächst Bindung des Subkomplexes $\beta$-, $\gamma-, \delta$ - und $\zeta$-COP und anschließend die Bindung von $\alpha-, \beta^{\prime}-$ und $\varepsilon$-COP (Faulstich et al., 1996). Nachdem das Vesikel abgeschnürt ist, bewirkt die Hydrolyse von ARF1 gebundenem GTP die Freisetzung der Hüllproteine. Im Gegensatz zum COPII-System, bei dem die GTP-Hydrolyse von Sar1p durch das Hüllprotein Sec23p katalysiert wird, müssen alle bisher isolierten ARF-GTPase aktivierenden Proteine (ARF GAPs) zunächst aus dem Zytosol rekrutiert werden (Poon et al., 1999). Die funktionelle Analyse eines ARF1-ARF GAP-Komplexes ergab, daß durch Anwesenheit von ,coatomer“-Untereinheiten die GTP-Hydrolyse um einen Faktor von 1000 erhöht wird (Goldberg, 1999). Dies läßt die Vermutung zu, daß ein Komplex bestehend aus ARF1, ARF GAP und „coatomer“ bereits während der Vesikelbildung auf der Membranoberfläche existiert.

Die genaue funktionelle Analyse der COPI-Vesikel im Membrantransport vom Golgi zum ER gestaltet sich als sehr kompliziert, da COPI-Vesikel sowohl eine entscheidende Funktion in der Strukturerhaltung des Golgi als auch im intraGolgi anterograden Transport haben.

\subsubsection{Signale des ER-Rücktransports und der ER-Retention}

Eine Funktion des retrograden Transports ist das Zurückführen von Proteinen, die normalerweise im ER lokalisiert sind, jedoch im Vesikelfluß des anterograden Transports in den Golgi gelangt sind. Für viele solcher Proteine weiß man, daß ihre Sortierung in retrograde COPI-Vesikel durch Aminosäuresequenzmotive vermittelt wird.

Das am besten charakterisierte ER-Rücktransportsignal ist die KDEL-Sequenz in Säugern bzw. die HDEL-Sequenz in Hefe (Munro und Pelham; 1987; Pelham, 1990). Dieses Sequenzmotiv befindet sich am C-Terminus von überwiegend luminalen löslichen Proteinen. Die Genprodukte von SED4 (vgl. Kap. 1.2.1.1) und SEC2O in Hefe sind bisher die einzigen bekannten Transmembranproteine mit diesem Motiv. Der Rücktransport zum ER ist rezeptorvermittelt. Der im Golgi lokalisierte, transmembrane Erd2p-Rezeptor in Hefe (KDEL-Rezeptor in Säugern (Lewis und Pelham, 1990; Scheel und Pelham, 1996)) bindet 
die HDEL-markierten Proteine und wird zusammen mit seiner Fracht durch COPI-Vesikel zum ER transportiert (Semenza et al., 1990; Townsley et al., 1994). Man glaubt, daß durch die veränderten physiologischen Bedingungen innerhalb des ER die Bindung zwischen Rezeptor und Protein aufgehoben wird und der Rezeptor daraufhin über den anterograden Transportweg erneut in den Golgi gelangt (Lewis und Pelham, 1992). Die Unterbrechung des ERD2-Gens in Hefe ist letal; es konnten aber Gene isoliert werden, durch deren Überexpression die Zellen wieder lebensfähig wurden (Lewis et al., 1990). Eines dieser Gene ist das eben genannte $S E D 4$, ein weiteres ist SED5, dessen Genprodukt ein t-SNARE im Golgi darstellt (vgl. Kap. 1.4).

Für Typ-I-Transmembranproteine konnte gezeigt werden, daß ein C-terminales Di-Lysin-Motiv (K(X)KXX-Motiv) als Rückführungssignal dient (Jackson et al., 1990; Nilsson et al., 1989). Die Tatsache, daß der COPI-Proteinkomplex an dieses Signal binden kann, belegt auch die Beteiligung von COPI-Vesikeln am retrograden Transport (Cosson und Letourneur, 1994). Cosson und Letourneur benutzten hierbei ein Hybridprotein, welches aus dem $\alpha$-Faktor Rezeptor Ste2p und dem C-Terminus von Wbp1p besteht. Wbp1p ist eine Untereinheit der Oligosaccharyltransferase in Hefe und besitzt ein KKXX-Motiv. So konnte gezeigt werden, daß alle COPI-Mutanten mit Ausnahme von sec28-Mutanten ( $\varepsilon$-COP) nicht in der Lage sind, dieses Hybridprotein im frühen sekretorischen Transportweg zurückzuhalten (Letourneur et al., 1994; Duden et al., 1998). Für den COPI-Proteinkomplex aus den „coatomer“-Mutanten sec27-1 und ret1-1 $\left(\alpha-\mathrm{COP}\right.$ und $\beta^{\prime}$-COP) konnte zudem in vitro nachgewiesen werden, da $\beta$ die Bindung an das KKXX-Motiv verloren geht (Letourneur et al., 1994).

Ähnlich dem Erd2p-Rezeptor wurde ein Gen kloniert, dessen Genprodukt Rer1p zwischen Golgi und ER zirkuliert und für die Retention des Typ-II-Transmembranproteins Sec12p zuständig ist (Boehm et al., 1994; Boehm et al., 1997; Sato et al., 1995). Dieser Rückführungsmechanismus ist maßgeblich von der Transmembrandomäne des Sec12p abhängig. Daß bestimmte Bereiche der Transmembrandomäne für die Retention eine Rolle spielen, wurde auch für andere Proteine gezeigt (Letourneur und Cosson, 1998; Rayner und Pelham, 1997).

\subsection{Die Vesikelfusion}

Es gibt drei Proteinklassen, die eine generelle Schlüsselrolle bei der zellulären Vesikelfusion spielen: die SNARE-Proteine (SNAP receptor), die kleinen 
GTP-bindenden Proteine der Ypt/Rab-Familie und die Proteine der Sec1-Familie. Des weiteren wurden sogenannte, ,tethering“-Faktoren gefunden, die für die Direktionalität des Vesikels verantwortlich sind. Sie gehören jedoch keiner bestimmten Proteinklasse an und agieren in großen Komplexen oder als Oligomere.

\subsubsection{SNARE-Proteine}

SNARE-Proteine lassen sich in zwei Klassen unterteilen: Sie sind entweder Typ-II-Transmembranproteine und gehören den Proteinfamilien der Synaptobrevine bzw. Syntaxine an oder sind durch Acylreste in der Membran verankert und gehören der SNAP-25-Familie an (Weimbs et al., 1998). Sie wurden als Rezeptoren für SNAPs (soluble NSF attachment proteins) identifiziert, die wiederum einen Komplex mit der ATPase NSF (NEM-sensitive-factor) bilden können (Malhotra et al., 1988; Söllner et al., 1993). Die entsprechenden Hefeproteine zu SNAP und NSF sind Sec17p und Sec18p (Wilson et al., 1989). Alle SNAREs können $\alpha$-helikale Strukturen ausbilden, die sich zu sogenannten „coiled-coils“ zusammenlagern und während der Vesikelfusion stabile Komplexe ausbilden. Die Komplexe können durch die ATP-Hydrolyse von NSF (Sec18p) reversibel aufgelöst werden (Hayashi et al., 1994). Zu welchem Zeitpunkt der Vesikelfusion die ATP-Hydrolyse stattfindet ist umstritten.

Rothman und seine Mitarbeiter postulierten nach der Identifizierung der SNAREs einen generellen Mechanismus für die Vesikelfusion, die sogenannte SNARE-Hypothese (Söllner et al., 1993; Rothman, 1994). Sie besagt, daß die spezifische Anlagerung an die Zielmembran (,docking“) und die anschließende Fusion eines Transportvesikels abhängig von den beteiligten v- und t-SNAREs sind, die sich dabei entweder auf dem Vesikel, wo sie nach dem Abstreifen der Hüllproteine für potentielle Bindungspartner zugänglich sind, oder auf der Zielmembran (,target membrane“) befinden. Dabei ist jedes SNARE nur für einen bestimmten Transportschritt verantwortlich. Diese Annahme ist jedoch zunehmend auf Widersprüche gestoßen, z. B. sind manche SNAREs bei mehreren unterschiedlichen Fusionsprozessen involviert. Die SNARE-Hypothese in ihrer ursprünglichen Form kann heute nur noch als ein sehr stark vereinfachtes Modell des Fusionsprozesses angesehen werden. Trotzdem werden auch heute noch SNARE-Proteine als v- und t-SNARE klassifiziert.

Der exozytotische SNARE-Komplex, der an der Fusion von Vesikeln mit der Plasmamembran beteiligt ist, ist am besten charakterisiert. Mittels Elektronenmikroskopie konnte die parallele Anordnung der $\alpha$-helikalen Struktu- 
ren der SNAREs im neuronalen SNARE-Komplex und im exozytotischen SNARE-Komplex von Hefe nachgewiesen werden (Hanson et al., 1997; Katz et al., 1998). Vom neuronalen SNARE-Komplex ist inzwischen die Raumstruktur des sogenannten Kern- oder ,core“-Bereiches mit Hilfe von Röntgenstrukturanalyse bestimmt worden. Sie setzt sich tatsächlich aus vier parallel ineinander gewundenen $\alpha$-Helices zusammen, die ein sogenanntes Vier-Helix-Bündel bilden (Sutton et al., 1998). Aus diesen Ergebnissen ging die Vorstellung hervor, daß durch die Ausbildung des SNARE-Komplexes die Vesikelmembran so dicht an die Zielmembran herangezogen wird, daß die Energiebarriere der Membranfusion überwunden wird.

Mit Hilfe der Kristallstruktur des neuronalen SNARE-Komplexes konnten die Aminosäuresequenzabschnitte der einzelnen SNAREs, welche die $\alpha$-helikalen Strukturen ausbilden, in Bezug auf ihre Raumstruktur neu verglichen werden (Fasshauer et al., 1998). Diese Sequenzabschnitte von ungefähr 60 Aminosäuren werden auch als das SNARE-Motiv bezeichnet. Die Analyse ergab, daß die zentrale Aminosäure, die sich strukturell in die Mitte des SNARE-Komplexes richten würde, fast immer (mit nur wenigen Ausnahmen) entweder ein Glutamin (Q) oder ein Arginin (R) ist. Deswegen wurden alle SNAREs zwei neuen Proteinklassen, den R-SNAREs und den Q-SNAREs zugeordnet (Fasshauer et al. 1998). Die Autoren behaupten weiterhin, daß alle fusionskompetenten SNARE-Komplexe aus einem Vier-Helix-Bündel bestehen, das sich aus drei Q-SNAREs und einem R-SNARE zusammensetzt. Dies ist jedoch noch nicht bewiesen.

\subsubsection{Modulatoren der SNARE-Proteine}

Die eben beschriebenen SNARE-Proteine sind essentiell für die Vesikelfusion. Darüber hinaus werden keine Faktoren benötigt, um in vitro künstlich hergestellte Liposomen, in denen SNAREs inkorporiert sind, zur Fusion zu bringen (Weber et al., 1998). Dieser Fusionsprozess ist allerdings viel zu langsam, um die realen Prozesse in der Zelle widerzuspiegeln. SNAREs können jedoch nicht die Direktionalität und Spezifität des Vesikeltransportes garantieren, da Ergebnisse von in vitro-Experimenten mit aufgereinigten Proteinen zeigten, daß SNAREProteine unspezifisch zum Teil relativ stabile Komplexe ausbilden können (Yang et al., 1999; Tsui et al., 2000). In der Zelle würde dies zur unkontrollierten Verschmelzung von ganzen Organellen führen. Der Zeitpunkt und der Ort in der Zelle, an dem die SNARE-Komplexe gebildet werden, hängt von den bereits er- 
wähnten Proteinen der Ypt/Rab-Familie, den Proteinen der Sec1-Familie und den „tethering“-Faktoren ab. Es sollen hier stellvertretend nur einige Beispiele aus Hefe aufgezeigt werden.

Der erste Vertreter und Prototyp der Ypt/Rab-Proteinfamilie, Ypt1p, wurde in Hefe entdeckt (Gallwitz et al., 1983). Nach der Sequenzierung des Hefegenoms konnten elf Vertreter der YPT-Genfamilie gefunden werden (Lazar et al., 1997). Jedes Ypt ist funktionell auf einen bestimmten vesikulären Transportschritt spezialisiert. Es ist bekannt, daß die kleinen GTPasen einen Katalysezyklus durchlaufen, bei dem sie zum einen zwischen einer GTP-gebundenen aktiven und einer GDP-gebundenen inaktiven Form wechseln und zum anderen zwischen einer membrangebundenen und einer zytosolischen Form (Lazar et al., 1997; Fig. 2). Es wird vermutet, daß sie dabei am „,docking“-Prozeß des Vesikels an die Zielmembran beteiligt sind. Evidenzen dafür gibt es aus Untersuchungen der homotypischen Vakuolenfusion und aus einem ER-GolgiTranportassay (Mayer und Wickner, 1997; Cao et al., 1998). Eine weitere mögliche Funktion der Ypt-GTPasen ist die Entfernung von Inhibitoren der SNARE-Komplexbildung, den Proteinen der Sec1-Familie (siehe unten). Diese Rolle der SNARE-Aktivierung wurde Ypt1p, das seine Funktion im ER-Golgi Transport ausübt, sogar für v- und t-SNARE zugeschrieben (Lian et al., 1994; Lupashin und Waters, 1997). In diesen Arbeiten konnte jedoch die zeitliche Abfolge des Fusionsprozesses nicht so gut aufgelöst werden wie in dem ER-Golgi in vitro Transportsystem (Cao et al., 1998).

Die Proteine der Sec1-Familie binden an Syntaxine (t-SNAREs). In Hefe sind vier Vertreter der Sec1-Familie und sieben Syntaxine bekannt. Aufgrund dieses Ungleichgewichts ist es unwahrscheinlich, daß diese Vertreter die Spezifität aller Vesikelfusionen garantieren. Sly1p wurde als Suppressor des Verlustes der Ypt1-Funktion isoliert und ist im ER-Golgi Transport involviert (Dascher et al., 1991; Ossig et al., 1991). Slylp bindet mit hoher Affinität an das im Golgi vorliegende t-SNARE Sed5p (Grabowski und Gallwitz, 1997; Kosodo et al., 1998). Es wird vermutet, daß die Sec1-Proteine die t-SNAREs in einer inaktiven geschlossenen Konformation halten (Lupashin und Waters, 1997; Yang et al.; 2000).

„Tethering“-Faktoren sind Ankopplungsfaktoren, die vermutlich spezifisch das „docking“ eines Vesikels mit seiner Zielmembran vermitteln. Diese Faktoren wurden mittlerweile bei verschiedenen Transportschritten isoliert (Übersichten bei Pfeffer, 1999, Guo et al., 2000). Uso1p ist ein zytosolisches Protein, das Homodimere ausbildet (Sapperstein et al., 1996; Yamakawa et al., 1996). Das Protein agiert im ER-Golgi Transport vor dem SNARE-Interaktions- 
schritt (Barlowe, 1997; Cao et al., 1998). Es wird vermutet, daß seine Membrananlagerung durch Ypt1p vermittelt wird. TRAPP (,transport protein particle“) ist ein multimerer Proteinkomplex bestehend aus zehn Untereinheiten, der an GolgiMembranen assoziiert ist (Sacher et al., 1998). In einem in vitro Transportassay konnte gezeigt werden, daß dieser Komplex ebenfalls für das „tethering“ von ER-Vesikeln mit Golgi-Membranen zuständig ist (Barrowman et al., 2000). Ein weiterer Komplex aus Sec34p und Sec35p scheint auch im ER-Golgi Transport beim ,tethering“ involviert zu sein (VanRheenen et al., 1998; VanRheenen et al., 1999; Kim et al., 1999). Wie TRAPP, Uso1p und Sec34/35p mechanistisch ihre Funktion ausüben, ist noch nicht genau geklärt. Für den Golgi-ER retrograden Transport wurde bisher noch kein ,tethering“-Faktor entdeckt.

\subsection{SNARE-Proteine der ER-Golgi-Recyclingmaschinerie in Hefe}

Es sollen nun im folgenden SNARE-Proteine, die bei der ER-Golgi-Recyclingmaschinerie in Hefe eine Rolle spielen, etwas detaillierter vorgestellt werden, da in dieser Arbeit die verschiedenen Mechanismen der zuvor beschriebenen Maschinerie untersucht wurden (siehe Tabelle 2).

Darunter befinden sich die zwei Syntaxine (t-SNAREs) Sed5p und Ufe1p und die drei Proteine der Synaptobrevin-Familie Sec22p, Bos1p und Bet1p. Außer Sec22p werden alle genannten SNAREs durch für die Hefe essentielle Gene kodiert.

\begin{tabular}{cccc}
\hline SNARE & $\begin{array}{c}\text { vorherrschende } \\
\text { Lokalisation }\end{array}$ & $\begin{array}{c}\text { Protein- } \\
\text { familie }\end{array}$ & $\begin{array}{c}\text { Klassifizierung } \\
\text { historisch/nach SNARE-Motiv }\end{array}$ \\
\hline \hline Sec22p & ER & Synaptobrevin & v-SNARE/R-SNARE \\
Bos1p & ER & Synaptobrevin & v-SNARE/Q-SNARE \\
Bet1p & Golgi & Synaptobrevin & v-SNARE/Q-SNARE \\
Sed5p & Golgi & Syntaxin & t-SNARE/Q-SNARE \\
Ufe1p & ER & Syntaxin & t-SNARE/Q-SNARE \\
\hline
\end{tabular}

Tabelle 2: Übersicht über die Lokalisation und Klassifizierung von SNAREs, die im ER-Golgi Transport in Hefe involviert sind.

Es wurden zwei SNARE-Komplexe im ER-Golgi Transport charakterisiert. Der erste wurde durch Immunpräzipitation von Sed5p in einer sec18-1 Mutante gefunden und enthält die Proteine Sly1p, Sec17p, Bos1p, Gos1p, Ykt6p, Sec22p, Bet1p und Sft1p (Hardwick et al., 1992; Søgaard et al., 1994). Gos1p, Sft1p und 
Ykt6p sind ebenfalls SNAREs, für die eine Funktion im retrograden Transport von späteren Golgi-Kompartimenten vorgeschlagen wird (Banfield et al., 1995). Ykt6p gehört zwar zur Familie der Synaptobrevine, stellt aber eine Ausnahme dar, da es im Gegensatz zu den übrigen hier genannten SNAREs keine Transmembrandomäne besitzt. Stattdessen ist Ykt6p durch einen Prenylrest in der Membran verankert, und es ist deshalb fraglich, ob es sich hierbei um ein klassisches SNARE-Protein handelt (McNew et al., 1997). Sed5p bildet zusätzlich mit Vtilp, einem SNARE im späten sekretorischen Transportweg, einen SNARE-Komplex aus (Lupashin et al., 1997; Fischer von Mollard et al., 1997). Da Sed5p mit insgesamt sieben SNAREs in wahrscheinlich drei verschiedenen SNARE-Komplexen interagiert, wird deutlich, daß SNAREs nicht allein für die Spezifität des vesikulären Transports verantwortlich sein können. Ufe1p stellt das t-SNARE des retrograden Golgi-ER Transports dar (Lewis und Pelham, 1996). Es wurde in einem Komplex mit Sec20p, einem Transmembranprotein des ER, das eine amphipatische Helix enthält, aber kein klassisches SNARE ist, und Sec22p, das vermutlich als v-SNARE in diesem Transportschritt fungiert, gefunden (Lewis et al., 1997). Ufe1p besitzt eine weitere Funktion in der homotypischen ER-Fusion, bei der es das einzige gefundenen SNARE darstellt und vermutlich durch Ausbildung eines t-t-SNARE-Komplexes die Fusion vermittelt (Patel et al., 1998).

Da Sec22p, Bos1p, Bet1p und Sed5p zwischen ER und Golgi zirkulieren, ist es anhand von Komplexbildung schwierig zu entscheiden, zu welchem Zeitpunkt das jeweilige SNARE tatsächlich agiert, oder ob es gerade zu seinem Zielkompartiment transportiert wird (Ballensiefen et al., 1998; Ossipov et al., 1999; Wooding und Pelham, 1998). Um dieses Problem zu lösen, wurden verschiedene in vitro Transportassays entwickelt. Bei dem von C. Barlowe entwickelten anterograden Transportassay werden zunächst COPII-Vesikel von ER-Donormembranen rekonstituiert und isoliert. Diese werden anschließend mit GolgiAkzeptormembranen sowie Uso1p, Sec18p und LMA1 zur Fusion gebracht. Die Fusionseffizienz wird mit Hilfe von radioaktiv markiertem pro- $\alpha$-Faktor verfolgt, der in die COPII Vesikel verpackt wird und der nur bei erfolgter Fusion im Golgi

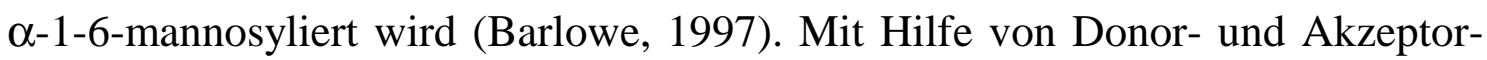
membranen von SNARE-Mutantenstämmen konnte überprüft werden, welches SNARE beim anterograden Transport eine Rolle spielt. Es stellte sich heraus, daß Bos1p und Bet1p als v-SNAREs und Sed5p als t-SNARE fungieren (Cao et al., 2000). Für den retrograden Golgi-ER Transport wurde ebenfalls ein System etabliert, das auf der Verwendung des mit dem HDEL-Rückführungssignal versehenen pro- $\alpha$-Faktor basiert (Spang und Schekman, 1998). Hier konnte gezeigt 
werden, daß Sec22p und überraschenderweise auch Bet1p als v-SNARE und Ufe1p als t-SNARE agieren. Die Annahme, daß Bet1p sowohl im anterograden als auch im retrograden ER-Golgi Transport eine Rolle spielt, ist plausibel, da Sec22p für die Hefe nicht essentiell ist und Bet1p somit seine Funktion übernehmen könnte. Etwas kontroversere Ergebnisse wurden mit einem Liposomenfusionsassay erhalten, bei dem mit Lipiden und aufgereinigten SNARE-Proteinen künstliche Vesikel, die SNAREs inkorporiert haben, hergestellt und zur Fusion gebracht werden (Weber et al., 1998). Hier konnte nur eine Fusion beobachtet werden, wenn sich Sed5p, Bos1p und Sec22p zusammen auf dem Akzeptorliposom und Bet1p allein auf dem Donorliposom befanden. Alle anderen statistisch möglichen Kombinationen führten nicht zur Fusion der Liposomen (McNew et al., 2000; Parlati et al., 2000).

\subsection{Zielsetzung und Konzept dieser Arbeit}

In Hefe werden alle bisher untersuchten ER-Proteine, die zum Golgi gelangen, mit Hilfe von COPI-Vesikeln zum ER zurücktransportiert. Bisher ist aber noch ungeklärt, wie die unterschiedlichen Proteine in die Vesikel dirigiert werden.

Durch Verwendung eines Sec22- $\alpha$-Hybridproteins konnte in unserer Arbeitsgruppe gezeigt werden, daß auch Sec22p, ein überwiegend im ER lokalisiertes v-SNARE des frühen sekretorischen Transportwegs, mit Hilfe von COPI-Vesikeln zum ER zurückgelangt (Ballensiefen et al.; 1998). Es enthält jedoch keines der in Kap. 1.2.2.2 beschriebenen Rückführungssignale. Ziel dieser Arbeit war es daher, Proteinkomponenten $\mathrm{zu}$ isolieren, die an dem Recyclingprozeß des Sec22p beteiligt sind.

In der vorliegenden Arbeit sollte ein Ansatz gewählt werden, um Proteine zu finden, die mit dem Recycling von Sec22p interferieren. Es ist bekannt, daß zelluläre Transportprozesse durch Überproduktion bestimmter Proteine, die selbst im vesikulären Transport involviert sind, gehemmt werden können. Dies äußert sich häufig in einem verlangsamten oder sogar blockierten Zellwachstum. Beispiele hierfür sind Sec12p (Nishikawa et al., 1994), Sec16p (Espenshade et al., 1995), Sec23p (Kurihara et al., 2000), Sed5p (Hardwick und Pelham, 1992; Wooding und Pelham, 1998) und Arf1p (Kahn et al., 1995). Darüber hinaus kann sogar die Überproduktion von Proteinabschnitten ausreichend für eine Hemmung des vesikulären Transports und des Zellwachstums sein (Sweet und Pelham, 1993; Roth et al. 1998). Die Überexpression von Hefegenen kann man durch die Verwendung von genomischen Fragmenten in sogenannten „multi-copy“- 
Vektoren erzielen. Es handelt sich hierbei um episomale Vektoren, die den Replikationsursprung des Hefe $2 \mu$-Plasmides tragen und deswegen in Hefen in sehr hoher Kopienzahl vorliegen. Eine Erhöhung der Proteinproduktion kann auch durch Benutzung von Zentromer tragenden „single-copy“-Vektoren erreicht werden, die die kodierende Region eines Gens unter der Kontrolle eines starken Promotors enthalten (Espinet et al., 1995).

In dieser Arbeit sollte systematisch nach Genen gesucht werden, die bei Überexpression die vorherrschende ER-Lokalisation von Sec22p und anderen integralen Membranproteinen, die ein KKXX-Motiv tragen, stören. Aus den erwähnten Gründen lag es nahe, daß es sich dabei um Komponenten einer spezifischen Recyclingmaschinerie handeln könnte. Um solche Hefeklone zu identifizieren, sollten Wildtyp-Hefezellen entweder mit einer „multi-copy“-Genbank oder mit „multi-copy“-Plasmiden, die ein bereits bekanntes Gen enthalten, transformiert werden. Die Analyse sollte zum einen mit dem Sec22- $\alpha$-Hybridprotein als Reporter und zum anderen mit dem in Kap. 1.2.2.2 beschriebenen Ste2-Wbp1p-Reporter, der ein KKXX-Motiv enthält, durchgeführt werden. Somit könnte der signalvermittelte Rücktransport über das KKXX-Motiv mit dem von Sec $22 p$ verglichen werden. Ziel war es, ein Protein zu finden, welches durch Überproduktion die Recyclingprozesse beider Reporter stört. Kann der Effekt, der durch dieses Protein hervorgerufen wird, durch die Überproduktion eines anderen Proteins wieder aufgehoben werden, könnte dies auf eine Wechselwirkung zwischen dem Reporter und dem zweiten Protein hinweisen. Dieses könnte somit im Zusammenhang mit einem Rezeptor für die Sortierung von Sec22p stehen.

In einem weiteren Ansatz sollte das Zwei-Hybrid System, ein Selektionsverfahren, das Protein-Protein-Wechselwirkungen innerhalb der Hefe sichtbar machen kann, angewendet werden, um Proteine, die mit Sec22p interagieren zu identifizieren. 


\section{Material}

\subsection{Hefe- und Bakterienstämme}

\section{Saccharomyces cerevisiae:}

\begin{tabular}{|c|c|c|}
\hline Stamm & Merkmale & Quelle \\
\hline Msuc-2D & MAT $\alpha$ ura3 his3 leu2 & H. D. Schmitt, diese Abt. \\
\hline Ste2-4B & $\begin{array}{l}\text { MATa, barl-1, ste } 2:: L E U 2, \text { STE2-WBP1::URA3, } \\
\text { ura3 leu2 his3 lys } 2\end{array}$ & H. D. Schmitt, diese Abt. \\
\hline Y190 & $\begin{array}{l}\text { MATa gal4 gal80 trp1-901 ade2-101 ura3-52 leu2-3,- } \\
112 \text { URA3::GAL } \rightarrow \text { lacZ, LYS2::GAL } \rightarrow \text { HIS3 cyh }\end{array}$ & S. J. Elledge, Houston \\
\hline RC898 & MATa bar1-1 sst2-1 leu1 trp5 ade2 can1 & H. Riezmann, Basel \\
\hline TNY14 & $\begin{array}{l}\text { MAT } \alpha, \text { mf } \alpha 1:: A D E 2, \text { mf } \alpha 2:: T R P 1, \text { barl::LYS2, ura3, } \\
\text { lys2, leu2, his3, ade2, trp1 }\end{array}$ & diese Arbeit \\
\hline TNY26 & $\begin{array}{l}\text { MAT } \alpha, m f \alpha 1:: A D E 2, \text { mf } \alpha 2: \because T R P 1 \\
\text { barl::LYS2::CYC1-SEC22-c-myc- } \alpha \text {, ura3, lys2, leu2, } \\
\text { his3, ade2, trp1 }\end{array}$ & diese Arbeit \\
\hline TNY116 & $\begin{array}{l}\text { MATa, ura3, leu2, his } 3, \text { trp } 1, \text { lys } 2, \text { ade } 8 \\
\text { sfb2::KanMX4, barl::LYS } 2\end{array}$ & diese Arbeit \\
\hline TNY118 & $\begin{array}{l}\text { MATa, ura3, leu2, his3, trp1, lys2, sfb3::LEU2, } \\
\text { bar1::LYS2 }\end{array}$ & diese Arbeit \\
\hline Sec22-3 1B & 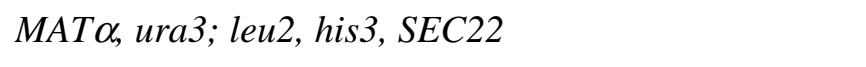 & H. D. Schmitt, diese Abt. \\
\hline Sec22-3 5D & MAT $\alpha$, ura3; leu2, his $3, \sec 22-3$ & H. D. Schmitt, diese Abt. \\
\hline MLY-100 & $\begin{array}{l}\text { MAT } \alpha, \text { ura3, ade2, his, trp1, ufe 1::TRP1, inklusive } \\
\text { pUFE315 }\end{array}$ & M. Lewis, Cambridge \\
\hline MLY-101 & $\begin{array}{l}\text { MAT } \alpha, \text { ura3, ade2, his, trp1, ufe } 1:: T R P 1, \text { inklusive } \\
\text { pUT1 }\end{array}$ & M. Lewis, Cambridge \\
\hline TNY51 & MAT $\alpha$, sed5-1, ura3, leu2, his, trp1, lys2, ade2 & $\begin{array}{l}\text { H. R. B. Pelham, } \\
\text { Cambridge }\end{array}$ \\
\hline FL74 & $M A T \alpha$, ret3-1, ura3, his & F. Letourneur, Lyon \\
\hline TNY139 & MATa, ret1-2, ura3, leu2, his, lys 2 & S. Schröder, diese Abt. \\
\hline TNY140 & MATa, sec27-1, ura3, leu2, his, lys2 & S. Schröder, diese Abt. \\
\hline YRXS12 & MAT $\alpha$, acc1-7-1, ura3, leu2, his 3, ade 2 & S. D. Kohlwein, Graz \\
\hline AUY004 & $\begin{array}{l}\text { MATo, acc1 }{ }^{C S}, \text { leu2-3, 112, ura3-1, his3-11, } \\
15 \text { can1-100, trp1 }\end{array}$ & S. D. Kohlwein, Graz \\
\hline SLUA1-4D & MATa, ura3, leu2, SEC22::HIS3, trp1, lys2, ade2 & U. Andag, diese Abt. \\
\hline
\end{tabular}




\section{Escherichia coli:}

\begin{tabular}{|c|c|c|}
\hline Stamm & Merkmale & Quelle \\
\hline DH5 $\alpha$ & $\begin{array}{l}\text { FlendAl hsdR17 }\left(r_{K}^{-} m_{K}^{+}\right) \text {supE44 glnV44 thi-1 recAl } \\
\text { gvrA }\left(\text { Nal }^{r}\right) \text { relA1 } \Delta(\text { lacZYA-argF }) \text { U169 deoR } \\
(\phi 80 \text { dlac }(\text { lacZ)M15) }\end{array}$ & Gibco BRL, Eggenstein \\
\hline HB101 & 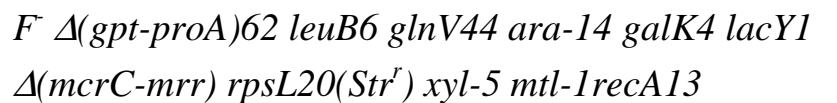 & Gibco BRL, Eggenstein \\
\hline
\end{tabular}

\subsection{Verwendete Plasmide}

\begin{tabular}{|c|c|c|}
\hline Plasmid & Beschreibung & Quelle \\
\hline pTN-Bank & $\begin{array}{l}\text { pRS323-genomische Hefe-DNA-Genbank, HIS3, } \\
2 \mu\end{array}$ & diese Arbeit \\
\hline pTN85 & pRS323-FUN9, HIS3, $2 \mu$ & diese Arbeit \\
\hline pTN85 & pRS323-FUN9, HIS3, $2 \mu$ & diese Arbeit \\
\hline pTN86 & pRS323-YBR044c, HIS3, $2 \mu$ & diese Arbeit \\
\hline pTN87 & pRS323-YKL063c, HIS3, $2 \mu$ & diese Arbeit \\
\hline pTN88 & pRS323-RET2, HIS3, $2 \mu$ & diese Arbeit \\
\hline pTN89 & pRS323-RET1, HIS3, $2 \mu$ & diese Arbeit \\
\hline pTN90 & pRS323-RET2 $\triangle C T, H I S 3,2 \mu$ & diese Arbeit \\
\hline pTN77 & $\mathrm{pRS} 323, H I S 3,2 \mu$ & R. Grabowski, diese Abt. \\
\hline pTN96 & pRS323-FUN9-QGSQ, HIS3, $2 \mu$ & diese Arbeit \\
\hline pWB-Acyc $\alpha$ & CYC1-SEC22-c-myc- $a, U R A 3,2 \mu$ & W. Ballensiefen, diese Abt. \\
\hline pTN79 & pRS323-SEC22, HIS3, $2 \mu$ & diese Arbeit \\
\hline pTN80 & pRS323-SEC22-3, HIS3, $2 \mu$ & diese Arbeit \\
\hline pRO64 & YEP511-SEC22 $\triangle C T, L E U 2,2 \mu$ & Rainer Ossig, diese Abt. \\
\hline pTN78 & pRS323-UFE1, HIS3, $2 \mu$ & diese Arbeit \\
\hline pTN81 & pRS323-BOS1, HIS3, $2 \mu$ & diese Arbeit \\
\hline pTN82 & pRS323-SED5, HIS3, $2 \mu$ & diese Arbeit \\
\hline pHF25 & YEP511-BET1, LEU2, $2 \mu$ & R. Ossig, diese Abt. \\
\hline pTN131 & pYX122-SED5, HIS3, ARS/CEN & diese Arbeit \\
\hline pHF34 & pYX122, HIS3, ARS/CEN & $R \& D$ yeast vectors, Ingenius \\
\hline pTN113 & pRS323-SED5-SLY1, HIS3, $2 \mu$ & diese Arbeit \\
\hline pTN114 & pRS323-SED5-SLY1-20, HIS3, $2 \mu$ & diese Arbeit \\
\hline pTN115 & pRS323-SED5-SEC24, HIS3, $2 \mu$ & diese Arbeit \\
\hline pTN116 & pRS323-SED5-UFE1, HIS3, $2 \mu$ & diese Arbeit \\
\hline
\end{tabular}


Fortsetzung der Tabelle:

\begin{tabular}{|c|c|c|}
\hline Plasmid & Beschreibung & Quelle \\
\hline pTN149 & pRS323-SED5-SFB3, HIS3, $2 \mu$ & diese Arbeit \\
\hline pTN155 & pRS323-SED5-SFB2, HIS3, $2 \mu$ & diese Arbeit \\
\hline pTN198 & pRS323-SED5-SEC22-3, HIS3, $2 \mu$ & diese Arbeit \\
\hline pTN199 & pRS323-SED5-SEC22, HIS3, $2 \mu$ & diese Arbeit \\
\hline pTN200 & pRS323-SEC23, HIS3, $2 \mu$ & R. W. Peng, diese Abt. \\
\hline pHDS334 & pUG36, URA3, CEN6/ARS4 & J. Hegemann, Düsseldorf \\
\hline pTN159 & pUG36-SEC22, URA3, CEN6/ARS4 & diese Arbeit \\
\hline pUT1 & ufe 1-1, LEU2, CEN4/ARSH6 & M. Lewis, Cambridge \\
\hline pUFE315 & UFE1, LEU2, CEN4/ARSH6 & M. Lewis, Cambridge \\
\hline pTN142 & pAS2-SEC22 $\triangle T M D, T R P 1,2 \mu$ & diese Arbeit \\
\hline pTN181 & $\mathrm{pAS} 2, T R P 1,2 \mu$ & S. Elledge, Housten, USA \\
\hline $\mathrm{pBH}$ & pGAD-GH-c-DNA-Genbank, $L E U 2,2 \mu$ & B. Horazdovsky, Dallas, USA \\
\hline pTN166 & pGAD-GH-ACCI $^{C T}$ (AS 2004-2234), LEU2, $2 \mu$ & Genbankklon aus pBH \\
\hline pTN143 & pACTII, $L E U 2,2 \mu$ & S. Elledge, Housten, USA \\
\hline pHM138 & pAS1-YPT1, TRP $1,2 \mu$ & X. Yang, diese Abt. \\
\hline pHM209 & pAS1-YPT31, TRP $1,2 \mu$ & X. Yang, diese Abt. \\
\hline pHM139 & pAS1-YPT6, TRP1, $2 \mu$ & X. Yang, diese Abt. \\
\hline pHM140 & pAS1-YPT7, TRP $1,2 \mu$ & X. Yang, diese Abt. \\
\hline pHM554 & pAS2-BET5, TRP $1,2 \mu$ & H. Matern, diese Abt. \\
\hline pTN202 & $\mathrm{pAS} 2-S E C 22, T R P 1,2 \mu$ & D. Ossipov, diese Abt. \\
\hline pHM571 & pAS2-SED5 $\triangle T M D, T R P 1,2 \mu$ & R. W. Peng, diese Abt. \\
\hline pTN145 & pAS2-UFE1 $\triangle T M D, T R P 1,2 \mu$ & R. W. Peng, diese Abt. \\
\hline pTN158 & pEG-KT, $U R A 3,2 \mu$ & D. Mitchell, Iowa, USA \\
\hline pTN161 & pEG-KT-ACCI ${ }^{C T}$ (AS 2004-2234), URA3, $2 \mu$ & diese Arbeit \\
\hline pTN162 & pEG-KT-SEC22 $\triangle T M D, U R A 3,2 \mu$ & diese Arbeit \\
\hline pTN189 & pEG-KT-BET1 $1 T M D, U R A 3,2 \mu$ & diese Arbeit \\
\hline pTN190 & pEG-KT-UFE1 $\triangle T M D, U R A 3,2 \mu$ & diese Arbeit \\
\hline pTN191 & pEG-KT-SED5 $\triangle T M D, U R A 3,2 \mu$ & diese Arbeit \\
\hline pTN192 & pEG-KT-BOS1 $1 \triangle T M D, U R A 3,2 \mu$ & diese Arbeit \\
\hline pTN193 & pEG-KT-SEC22NT(AS 1-125), URA3, $2 \mu$ & diese Arbeit \\
\hline pTN194 & pEG-KT-SEC22 CC (AS 126-186), URA3, $2 \mu$ & diese Arbeit \\
\hline pTN175 & pEG-KT-VAM3 $\triangle T M D, U R A 3,2 \mu$ & T. Lazar, diese Abt. \\
\hline pTN176 & pEG-KT-PEP12 $\triangle T M D, U R A 3,2 \mu$ & M. Götte, diese Abt. \\
\hline pTN165 & $\begin{array}{l}\text { pUG36- } A C C 1^{C T} \text { (AS 2004-2234), URA3, } \\
C E N 6 / A R S 4\end{array}$ & diese Arbeit \\
\hline
\end{tabular}




\subsection{Verwendete Oligonukleotide}

Die verwendeten Oligonukleotide wurden bei der Firma NAPS in Göttingen in Auftrag gegeben. Es wurde in aller Regel ein Synthesemaßstab von $0.2 \mu \mathrm{mol}$ gewählt. Das Oligonukleotid wurde in Lösung mit einer Konzentration von $0.1 \mathrm{nmol} / \mu \mathrm{l}$ geliefert. Für PCR-Analysen und DNA-Sequenzierungen wurden Verdünnungen von $10 \mathrm{pmol} / \mu \mathrm{lbzw} .1 \mathrm{pmol} / \mu \mathrm{l}$ angesetzt.

\begin{tabular}{|c|c|c|}
\hline Nr. & Sequenz des Oligonukleotids & Zweck \\
\hline T3 & 5'-ATT AAC CCT CAC TAA AG-3' & T3-Sequenzierprimer \\
\hline $\mathrm{T} 7$ & 5'-AAT ACG ACT CAC TAT AG-3' & T7-Sequenzierprimer \\
\hline TN19 & 5'-GCG CCA CGG CGG CGC CGT AG-3' & $\begin{array}{l}\text { Klonierung FUN9QGSQ, } \\
\text { NarI-Schnittstelle }\end{array}$ \\
\hline TN20 & $\begin{array}{l}5^{\prime}-\mathrm{CTC} \text { TCG AGC TCC TAC TGG CTC TCC TGG } \\
\text { CCC CAG AT-3' }\end{array}$ & $\begin{array}{l}\text { Klonierung FUN9QGSQ, 3’- } \\
\text { Ende }\end{array}$ \\
\hline TN32 & $\begin{array}{l}5^{\prime} \text {-TCT CTG AAT TCA TGA ACA TAA AGG ATA } \\
\text { GAA CTT C-3' }\end{array}$ & $\begin{array}{l}\text { Klonierung TPI-SED5, 5'- } \\
\text { Ende }\end{array}$ \\
\hline TN33 & $\begin{array}{l}5^{\prime} \text {-TCT CTA AGC TTA ATT GAC TAA AAC CCA } \\
\text { AAT AAC-3' }\end{array}$ & $\begin{array}{l}\text { Klonierung TPI-SED5, 3'- } \\
\text { Ende }\end{array}$ \\
\hline TN35 & 5'-GTT TGT ATT CTT TTC TTG C-3' & $\begin{array}{l}\text { Sequenzierprimer, bindet an } \\
\text { TPI-Promotor }\end{array}$ \\
\hline TN66 & $5^{\prime}$-ACC TAG TGC CGT ACA GCA C-3' & $\begin{array}{l}\text { Sequenzierprimer, bindet an } \\
\text { SED5 }\end{array}$ \\
\hline TN42 & $\begin{array}{l}5^{\prime} \text {-CTC TCG GAT CCA TGA TAA AGT CAA CAC } \\
\text { TAA TCT AC-3' }\end{array}$ & $\begin{array}{l}\text { Klonierung GFP-SEC22, 5'- } \\
\text { Ende }\end{array}$ \\
\hline TN43 & $\begin{array}{l}5^{\prime} \text {-CTC TCG AAT TCC TAT TTG AGG AAG ATC } \\
\text { CAC CAG-3' }\end{array}$ & $\begin{array}{l}\text { Klonierung GFP-SEC22, 3'- } \\
\text { Ende }\end{array}$ \\
\hline TN44 & 5'-CAA TCT TAA ACA ATG ACG-3' & Sequenzierprimer, pUG36 \\
\hline TN45 & 5'-CCC TCC CGC ACT TAC ATT-3' & Sequenzierprimer, pUG36 \\
\hline TN51 & $\begin{array}{l}5^{\prime} \text {-CTC TCG AAT TCA CTG TAT GAC TTT TTT } \\
\text { GTC A-3' }\end{array}$ & $\begin{array}{l}\text { Klonierung GST-Sec22NT, 3'- } \\
\text { Ende }\end{array}$ \\
\hline TN52 & $\begin{array}{l}5^{\prime} \text {-CTC TCG GAT CCA AGA AAG TTC AGG ACA } \\
\text { ATT TGG-3' }\end{array}$ & $\begin{array}{l}\text { Klonierung GST-Sec22CC, 5'- } \\
\text { Ende }\end{array}$ \\
\hline TN53 & $\begin{array}{l}5^{\prime} \text {-CTC TCC CAT GGA TCC AAC TAT CAA CGC } \\
\text { TGA C-3' }\end{array}$ & $\begin{array}{l}\text { Klonierung GST-Acc1 }{ }^{\mathrm{CT}} \mathrm{p}, 5^{\prime}- \\
\text { Ende }\end{array}$ \\
\hline TN54 & $\begin{array}{l}5^{\prime}-\mathrm{CTC} \text { TCG TCG ACT TAT TTC AAA GTC TTC } \\
\text { AAC AA-3' }\end{array}$ & $\begin{array}{l}\text { Klonierung GST-Acc1 }{ }^{\mathrm{CT}} \mathrm{p}, 3^{\prime}- \\
\text { Ende }\end{array}$ \\
\hline TN55 & $\begin{array}{l}5^{\prime} \text {-CTC TCC CCG GGA ATG ATA AAG TCA ACA } \\
\text { CTA ATC TAC-3' }\end{array}$ & $\begin{array}{l}\text { Klonierung GST- } \\
\text { Sec22 } 2 \text { TMD, } 5^{\prime} \text {-Ende }\end{array}$ \\
\hline
\end{tabular}


Fortsetzung der Tabelle:

\begin{tabular}{|c|c|c|}
\hline Nr. & Sequenz des Oligonukleotids & Zweck \\
\hline TN56 & 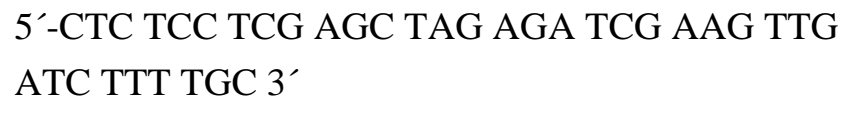 & $\begin{array}{l}\text { Klonierung GST- } \\
\text { Sec22 } 2 \text { TMD, } 3^{\prime} \text {-Ende }\end{array}$ \\
\hline TN57 & $\begin{array}{l}5^{\prime}-\mathrm{CTC} \text { TCC CCG GGA ATG AAC GCT CTT TAC } \\
\text { AAC CAT G-3' }\end{array}$ & $\begin{array}{l}\text { Klonierung GST-Bos1 } \Delta \mathrm{TMD} \text {, } \\
5^{\prime} \text {-Ende }\end{array}$ \\
\hline TN58 & $\begin{array}{l}5^{\prime}-\mathrm{CTC} \text { TCC TCG AGC TAT TTA TCT TTG AAC } \\
\text { ACC CGT TTA TTG-3' }\end{array}$ & $\begin{array}{l}\text { Klonierung GST-Bos1 } \Delta \mathrm{TMD} \text {, } \\
\text { 3'-Ende }\end{array}$ \\
\hline TN59 & 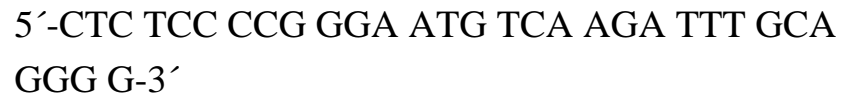 & $\begin{array}{l}\text { Klonierung GST-Bet1 } \Delta \mathrm{TMD} \text {, } \\
\text { 5'-Ende }\end{array}$ \\
\hline TN60 & $\begin{array}{l}5^{\prime}-\mathrm{CTC} \text { TCC TCG AGC TAT TTT ATA CTG ATC } \\
\text { CCA GAT CTT C-3' }\end{array}$ & $\begin{array}{l}\text { Klonierung GST-Bet1 } \Delta \mathrm{TMD} \text {, } \\
\text { 3'-Ende }\end{array}$ \\
\hline TN61 & $\begin{array}{l}5^{\prime} \text {-CTC TCC CCG GGA ATG AAC ATA AAG GAT } \\
\text { AGA ACT TCA } 3^{\prime}\end{array}$ & $\begin{array}{l}\text { rung GST-Sed5 } \Delta \text { TMD, } \\
\text { e }\end{array}$ \\
\hline TN62 & $\begin{array}{l}5^{\prime}-\mathrm{CTC} \text { TCC TCG AGC TAT CTA TTA CTC TTT } \\
\text { ATC CAG TCG A-3' }\end{array}$ & $\begin{array}{l}\text { Klonierung GST-Sed5 } \Delta \text { TMD, } \\
\text { 3'-Ende }\end{array}$ \\
\hline TN63 & $\begin{array}{l}5^{\prime}-\mathrm{CTC} \text { TCC CCG GGA ATG ATG TCT GAT TTA } \\
\text { ACA CCA ATA-3' }\end{array}$ & $\begin{array}{l}\text { Klonierung GST-Ufe1 } \Delta \mathrm{TMD} \text {, } \\
5^{\prime} \text {-Ende }\end{array}$ \\
\hline TN64 & $\begin{array}{l}5^{\prime}-\mathrm{CTC} \text { TCC TCG AGC TAG TGG TCA TTT TAG } \\
\text { CAG TTC TTC-3' }^{\prime}\end{array}$ & $\begin{array}{l}\text { Klonierung GST-Ufe1 } \Delta \mathrm{TMD} \text {, } \\
\text { 3'-Ende }\end{array}$ \\
\hline TN65 & $5^{\prime}$-CTA AGC ATG TGA TAC ATC CGC-3' & Sequenzierprimer UFE1 \\
\hline TN67 & $5^{\prime}$-ACG ACG TGC CTC GGT CCA-3' & Sequenzierprimer ACC1 \\
\hline
\end{tabular}

\subsection{Medienzusätze}

\begin{tabular}{ll}
\hline Medienzusatz & Lieferant \\
\hline $\begin{array}{l}\text { Bacto-Agar, Bacto-Pepton, Bacto-Trypton, } \\
\text { Bacto-Yeast-Extract und Bacto-Yeast Nitrogen }\end{array}$ & Difco, Detroit, MI, USA \\
Base w/o Amino Acids & \\
Ampicillin Natriumsalz & Appli Chem, Biolith Diagnostica, Göttingen \\
Oxoid-Agar, Bacteriological Agar No. 1 & Oxoid Basingstoke, UK \\
Adeninsulfat und Uracil & Merk AG (Darmstadt) \\
Aminosäuren (Histidin, Leucin, Lysin, & Serva, Heidelberg \\
Tryptophan, Cystein und Methionin) & \\
Geneticin & GibcoBRL Life Technologies \\
Kanamycin & Serva, Heidelberg \\
3-Amino-1,2,4-Triazol (3-AT) & Sigma-Aldrich Chemie GmbH, Deisenhofen \\
\hline
\end{tabular}




\subsection{Enzyme und Kits}

\begin{tabular}{ll}
\hline Enzyme und Kits & Lieferant \\
\hline $\begin{array}{l}\text { B-Glucuronidase/Arylsulfatase aus Helix } \\
\text { pomatia }\end{array}$ & Boehringer Mannheim \\
$\begin{array}{l}\text { Vent-DNA-Polymerase und Deep-Vent-DNA- } \\
\text { Polymerase aus Thermococcus litoralis }\end{array}$ & New England Biolabs, Schwalbach \\
Taq-DNA-Polymerase & Perkin Elmer \\
Zymolyase-6000 aus Arthrobacter luteus & Seikagaku Kogyo Company, Tokyo \\
Lytikase (Grad: "partially purified") aus & Sigma, Deisenhofen \\
Arthrobacter luteus & \\
Restriktionsendonukleasen und DNA & Roche, Mannheim und New England Biolabs, \\
modifizierende Enzyme & Schwalbach \\
QIAquick Gel Extraction Kit & Quiagen, Düsseldorf \\
Original TA-Cloning Kit & Invitrogen, USA, Californien \\
Oligonukleotid-labeling Kit & Pharmacia \\
ECL-Western blotting detection reagents & NEN Life Science Products, Belgium \\
\hline
\end{tabular}

\subsection{Chemikalien}

Es wurden handelsübliche Chemikalien der Qualitätsstufe p. A. der Firmen J. T. Baker (Deventer, Holland), Serva (Heidelberg), Merk AG (Darmstadt) und Sigma-Aldrich Chemie GmbH (Deisenhofen) verwendet. Zusätzlich wurden spezielle Chemikalien von folgenden Firmen bezogen:

\begin{tabular}{ll}
\hline Chemikalie & Lieferant \\
\hline $\begin{array}{l}\text { Farbmarkierter Proteingrößenstandard für } \\
\text { Acrylamidgele (“Rainbow-standard”) }\end{array}$ & Amersham Buchler, Braunschweig \\
$\begin{array}{l}\text { Isopropyl-ß-D-thiogalaktopyranosid (IPTG) } \\
\text { Desoxynukleosidtriphosphate (dNTPs) }\end{array}$ & Biomol, Ilvesheim \\
$\begin{array}{l}\text { 5-Brom-4-Chlor-3-Indolyl-ß-D- } \\
\text { galactopyranosid (X-Gal), 2-Nitrophenyl-ß-D- }\end{array}$ & Rochenentec, Belgien \\
galactopyranosid (ONPG) & \\
AGFA G150 Röntgenfilm-Entwikler und & A. Topf, Bielefeld \\
AGFA G354 Rapid Fixierer & \\
Glutathion Sepharose 4B & Pharmacia Biotech \\
\hline
\end{tabular}




\subsection{Antikörper}

\begin{tabular}{ll}
\hline Antikörper & Hergestellt von \\
\hline Polyklonaler Anti-CPY-Antikörper & Diese Arbeitsgruppe \\
Polyklonaler Anti-ALP-Antikörper & Diese Arbeitsgruppe \\
Polyklonaler Anti-Kex2p-Antikörper & Diese Arbeitsgruppe \\
Polyklonaler Anti-Sed5p-Antikörper & Diese Arbeitsgruppe \\
Polyklonaler Anti-Sec22p-Antikörper & R. Ossig bzw. R Grabowski, diese \\
& Arbeitsgruppe \\
Polyklonaler Anti-Bos1p-Antikörper & Diese Arbeitsgruppe \\
Polyklonaler Anti-Bet1p-Antikörper & Diese Arbeitsgruppe \\
Polyklonaler Anti-Ufe1p-Antikörper & M. Lewis, London \\
Polyklonaler Anti-Emp47p-Antikörper & Stephan Schröder; diese Arbeitsgruppe \\
Polyklonaler Anti-Kar2p-Antikörper & Diese Arbeitsgruppe \\
Polyklonaler Anti-Ypt7p-Antikörper & Diese Arbeitsgruppe \\
Polyklonaler Anti-GST-Antikörper & Diese Arbeitsgruppe \\
Polyklonaler Anti-Acc1p-Antikörper & S. D. Kohlwein, TU-Graz \\
Polyklonaler Anti-c-myc-Antikörper (A14) & Santa Cruz, Biotechnologie, Santa Cruz; USA \\
Cy3-konjugierter, sekundärer Antikörper (vom & Sigma, Deisenhofen \\
Schaf, Anti-Kaninchen-IgG) & \\
Peroxidase-konjugierter, sekundärer & Amersham Buchler, Braunschweig \\
Antikörper (vom Esel, Anti-Kaninchen-IgG) & \\
Peroxidase-konjugierter, sekundärer & Amersham Buchler, Braunschweig \\
Antikörper (vom Schaf, Anti-Maus-IgG) & \\
\hline
\end{tabular}

\subsection{Verbrauchsmaterialien}

\begin{tabular}{ll}
\hline Verbrauchsmaterialien & Lieferant \\
\hline Whatman 541 Filter & Whatman, Maidstone, England \\
$\begin{array}{l}\text { Nitrocellulose-Membranfilter BA 85, } \\
\text { Nylonmembranfilter Nytran und Bio-Trap- } \\
\text { Membranen BT1 und BT2 }\end{array}$ & Schleicher \& Schüll, Dassel \\
Polypropylenröhrchen, $15 \mathrm{ml}-$ und 30 ml- & Becton-Dickinson, Heidelberg \\
Falcon & \\
Qiagen-Säulen & Qiagen, Düsseldorf \\
Reaktionsgefäße, $0.5 \mathrm{ml}, 1.5 \mathrm{ml}$ und 2.0 ml & Eppendorf, Hamburg \\
Röntgenfilme Biomax & Eastman Kodak, Rochester, NY, USA \\
Kulturschalen & Nunc, Wiesbaden \\
\hline
\end{tabular}




\subsection{Radiochemikalien}

\begin{tabular}{ll}
\hline Radiochemikalie & Lieferant \\
\hline $\operatorname{Tran}^{35} \mathrm{~S}$-labeling Mix & ICN $(14 \mathrm{mCi} / \mathrm{ml})$ \\
\hline
\end{tabular}

\subsection{Geräte}

\begin{tabular}{ll}
\hline Geräte & Lieferant \\
\hline Allgemeine Glaswaren & Schütt, Göttingen \\
Autoklav "Sanoclav" & Wolf, Geislingen \\
Brutschränke & Heraeus, Hanau \\
Eppendorf-Thermomixer und Eppendorf-Tischzentri- & Schütt, Göttingen \\
fuge & \\
Elektroporationsgerät & BioRad, Richmond, USA \\
Inkubationsschüttler & New Brunswick, Edison, USA \\
Mikromanipulator & Singer Instruments, Watchet, England \\
Mikroskope & Leitz, Wetzlar bzw. Zeiss, Göttingen \\
PCR-Gerät, Hybaid Omn-E & MWG-Biotech, Ebersberg \\
PCR-Gerät, RoboCycler 40 Gradient & Stratagene \\
Photometer Uvikon 860 & Kontron Instruments, Eching \\
Röntgenfilmentwicklermaschine Gevamatik 60 & AGFA Gevaert, Hannover \\
Transilluminatoren 302 und 366 nm & Bachofer, Reutlingen \\
Vortex GenieTM & Bender \& Holbein, Zürich, Schweiz \\
Lumi-Imager & Roche, Mannheim \\
Zentrifugen Sorvall RC-5B, RC-3B und entsprechende & DuPont Instruments, Bad Homburg \\
Rotoren & \\
\hline & \\
\hline
\end{tabular}




\section{Methoden}

\subsection{Kulturbedingungen für Escherichia coli}

\subsubsection{Nährmedien für $E$. coli}

L-Broth-Medium:

$\begin{array}{ll}\text { Hefeextrakt } & 5 \mathrm{~g} / \mathrm{l} \\ \text { Trypton } & 10 \mathrm{~g} / \mathrm{l} \\ \mathrm{NaCl} & 5 \mathrm{~g} / \mathrm{l} \\ \mathrm{NaOH} & 5 \mathrm{ml} / \mathrm{l}\end{array}$

Antibiotika:

Ampicillin $(30 \mathrm{mg} / \mathrm{ml}$ in 50\% EtOH) $\quad 60 \mu \mathrm{g} / \mathrm{ml}$

Die Medien wurden $20 \mathrm{~min}$ bei $120^{\circ} \mathrm{C}$ autoklaviert und bei $4{ }^{\circ} \mathrm{C}$ gelagert. Für Agarplatten wurde dem Medium $20 \mathrm{~g} / \mathrm{l}$ Agar zugesetzt. Nach dem Autoklavieren und Abkühlen auf ca. $42^{\circ} \mathrm{C}$ wurde gegebenenfalls Ampicillin zugegeben, Platten gegossen und nach dem Erstarren bei $4{ }^{\circ} \mathrm{C}$ gelagert.

Minimalmedium M9(5X)

$\begin{array}{ll}\mathrm{Na}_{2} \mathrm{HPO}_{4} & 30 \mathrm{~g} / \mathrm{l} \\ \mathrm{KH}_{2} \mathrm{PO}_{4} & 15 \mathrm{~g} / 1 \\ \mathrm{NH}_{4} \mathrm{Cl} & 5 \mathrm{~g} / 1 \\ \mathrm{NaCl} & 2.5 \mathrm{~g} / \mathrm{l}\end{array}$

Die Stocklösung wurde 20 min bei $120^{\circ} \mathrm{C}$ autoklaviert und bei RT gelagert. Zur Herstellung von M9-Agarplatten wurden $12 \mathrm{~g}$ Agar in $475 \mathrm{ml} \mathrm{H}_{2} \mathrm{O}$ für $20 \mathrm{~min}$ bei $120^{\circ} \mathrm{C}$ autoklaviert. Nach Abkühlung auf $50^{\circ} \mathrm{C}$ wurden folgende sterile Lösungen zugegeben:

5× M9-Minimalmedium $120 \mathrm{ml}$

Glucose $(40 \%(\mathrm{w} / \mathrm{v})) \quad 3 \mathrm{ml}$

$1 \mathrm{M} \mathrm{MgSO}_{4} \quad 0.6 \mathrm{ml}$

Thiamin $(5 \mathrm{mg} / \mathrm{ml}) \quad 60 \mu \mathrm{l}$

Prolin $(40 \mathrm{mg} / \mathrm{ml}) \quad 0.6 \mathrm{ml}$ 


\subsubsection{Anzucht von $E$. coli-Kulturen}

Mit einer sterilen Impföse wurde eine Einzelkolonie von einer Platte aufgenommen und damit ein Reagenzglas mit $5 \mathrm{ml}$ LB-Medium inokuliert oder ein Teil einer Dauerkultur auf einer Agarplatte ausgestrichen. Zur Kultivierung von Transformanden enthielt das Medium ein geeignetes Antibiotikim (z. B. Ampicillin). Die Platten wurden bei $37^{\circ} \mathrm{C}$ inkubiert und Flüssigkulturen zusätzlich mit mindestens 210 upm geschüttelt. Dauerkulturen wurden angelegt, indem $0.5 \mathrm{ml}$ einer Übernachtkultur mit $0.5 \mathrm{ml}$ sterilem Glycerin vermischt wurden. Diese konnten dann bei $-80{ }^{\circ} \mathrm{C}$ eingefroren werden.

\subsection{Kulturbedingungen für Saccharomyces cerevisiae}

\subsubsection{Nährmedien für Hefe Kulturen}

YEPG (YEPGal):

$\begin{array}{ll}\text { Hefeextrakt } & 10 \mathrm{~g} / \mathrm{l} \\ \text { Pepton (Nr. 140) } & 20 \mathrm{~g} / 1 \\ \text { Glucose (Galaktose) } & 20 \mathrm{~g} / 1 \\ \text { Adeninsulfat }(1 \mathrm{~g} / \mathrm{l}) & 5 \mathrm{ml} / 1 \\ \text { Uracil }(1 \mathrm{~g} / \mathrm{l}) & 5 \mathrm{ml} / 1\end{array}$

Die entsprechenden Medien ohne Adenin und Uracil werden als PM-bzw, PMGal-Medien bezeichnet.

SD-Minimalmedium:

Yeast Nitrogen Base $1.6 \mathrm{~g} / \mathrm{l}$

Ammoniumsulfat $\quad 5 \mathrm{~g} / \mathrm{l}$

Glukose $\quad 20 \mathrm{~g} / \mathrm{l}$

Dem SD-Minimalmedium wurden je nach Bedarf folgende Zusätze zugefügt:

Adeninsulfat $\quad 20 \mathrm{mg} / \mathrm{l}$

Uracil $20 \mathrm{mg} / \mathrm{l}$

L-Histidin- $\mathrm{HCl} \quad 20 \mathrm{mg} / \mathrm{l}$

L-Leucin $\quad 30 \mathrm{mg} / \mathrm{l}$

L-Lysin- $\mathrm{HCl} \quad 20 \mathrm{mg} / \mathrm{l}$

L-Tryptophan $\quad 20 \mathrm{mg} / 1$ 
Sporulationsmedium:

KOAc

$10 \mathrm{~g} / \mathrm{l}$

Für Agarplatten wurde dem Medium $20 \mathrm{~g} / \mathrm{l}$ Agar zugestzt. Die Medien wurden 20 min bei $120^{\circ} \mathrm{C}$ autoklaviert, Agarplatten gegossen und bei $4{ }^{\circ} \mathrm{C}$ gelagert.

\subsubsection{Anzucht von Hefekulturen}

Hefekulturen wurden aus einer Dauerkultur oder von einer Einzelkolonie in Flüssigkultur angeimpft oder auf Agarplatten angelegt. Als Kohlenstoffquelle diente entweder Glukose oder Galaktose. Wenn nicht anders vermerkt, wurden die Hefekulturen bei $30^{\circ} \mathrm{C}$ inkubiert. Zur Selektion von Hefezellen wurde ein entsprechendes Minimalmedium eingesetzt. Zur Induktion der Sporulation von diploiden Hefezellen wurden logarithmisch wachsende Hefekulturen auf KOAc-Agarplatten ohne Stickstoffquelle gegeben und 3-5 d bei $30{ }^{\circ} \mathrm{C}$ oder $25{ }^{\circ} \mathrm{C}$ inkubiert. Dauerkulturen wurden angelegt, indem $0.5 \mathrm{ml}$ einer Übernachtkultur mit $0.5 \mathrm{ml}$ sterilem Glycerin vermischt wurden. Diese konnten dann bei $-80{ }^{\circ} \mathrm{C}$ eingefroren werden.

\subsection{Molekularbiologische Methoden}

\subsubsection{Präparationen von DNA}

\subsubsection{Analytische Plasmidisolierung aus $E$. coli-Zellen}

GTE-Puffer:

$\begin{array}{ll}\text { Glucose } & 50 \mathrm{mM} \\ \text { Tris/HCl } & 25 \mathrm{mM} \\ \text { EDTA } & 10 \mathrm{mM} \\ \text { pH } & 8\end{array}$

Alkali-SDS-Lösung:

Kaliumacetat-Lösung:

$\begin{array}{llll}\mathrm{NaOH} & 0.2 \mathrm{M} & \mathrm{KOAc} / \mathrm{HOAc} & 5 \mathrm{M} \\ \mathrm{SDS} & 1 \%(\mathrm{w} / \mathrm{v}) & \mathrm{pH} & 4.8\end{array}$


Die im folgenden beschriebene Methode zur Isolierung von analytischen Mengen bakterieller Plasmid-DNA basiert auf einer Vorschrift von Birnboim und Doly (1979) und wurde leicht modifiziert. Sie wurde hauptsächlich zur qualitativen Analyse mehrerer Einzelklone nach einer Transformation verwendet.

Rekombinante Einzelkolonien wurden in $1.5 \mathrm{ml}$ L-Broth-Amp-Medium in einem 2 ml-Eppendorfgefäß angeimpft und über Nacht bei $37^{\circ} \mathrm{C}$ unter Schütteln inkubiert. Gleichzeitig wurde die Einzelkolonie auf L-Broth-Amp-Agarplatten überimpft, ebenfalls über Nacht bei $37^{\circ} \mathrm{C}$ inkubiert und anschließend bei $4{ }^{\circ} \mathrm{C}$ gelagert. Die in Flüssigkultur herangewachsenen Bakterien wurden für $1 \mathrm{~min}$ in einer Tischzentrifuge bei $16.000 \times g$ abzentrifugiert. Das Zellpellet wurde in $100 \mu \mathrm{l}$ GTE-Puffer resuspendiert. Anschließend wurde $200 \mu \mathrm{l}$ Alkali-SDSLösung dazugegeben und 5 min bei RT inkubiert. Die Extrakte mit den lysierten Zellen wurden anschließend durch Zugabe von $150 \mu$ l eiskalter KaliumacetatLösung neutralisiert. Nach Inkubation für 10 min auf Eis wurden die Zellysate für 5 min bei $16.000 \times g$ zentrifugiert. Aus den klaren Überständen wurde die Plasmid-DNA durch Zugabe von $1 \mathrm{ml} 100 \%$ igem EtOH gefällt, $10 \mathrm{~min}$ bei $16.000 \times g$ abzentrifugiert und einmal mit $500 \mu 170 \%$ igem EtOH gewaschen. Das Pellet wurde anschließend für $5 \mathrm{~min}$ im $37^{\circ} \mathrm{C}$-Block bei offenem Gefäß getrocknet und in $50 \mu \mathrm{l}$ TE-Puffer mit RNase $(10 \mu \mathrm{g} / \mathrm{ml})$ gelöst. Die DNA-Proben konnten bei $-20^{\circ} \mathrm{C}$ eingefroren und gelagert werden. Für Restriktionsanalysen wurden jeweils $5 \mu \mathrm{l}$ dieser Lösungen verwendet.

\subsubsection{Präparative Plasmidisolierung aus $E$. coli-Zellen}

Mit dieser Methode zur Plasmidisolierung wurden größere DNA-Mengen präpariert. 200-500 ml einer über Nacht Kultur mit E. coli-Transformanden wurden geerntet und die Zellen durch alkalische Lyse unter Verwendung von Puffern nach dem Qiagen-Protokoll (Diagen, Düsseldorf) aufgeschlossen. Zur Isolierung und Aufreinigung der DNA wurden die mitgelieferten AnionenaustauscherSäulen und Puffer der Firma Diagen verwendet. Durch diese präparative Plasmidisolierung konnten 100-500 $\mu$ g DNA gewonnen werden. Die DNA wurde in 200-500 $\mu \mathrm{l} \mathrm{H}_{2} \mathrm{O}$ aufgenommen und bei $-20{ }^{\circ} \mathrm{C}$ gelagert. 


\subsubsection{Photometrische Bestimmung der DNA-Konzentration}

Die Lichtabsorption von Nukleinsäuren bei einer Wellenlänge von $260 \mathrm{~nm}$ wurde zur Bestimmung der DNA-Konzentrationen genutzt. Eine Absorbtion von 1.0 bei $260 \mathrm{~nm}$ entspricht einer DNA-Konzentration von $50 \mathrm{mg} / \mathrm{ml}$ für DoppelstrangDNA, $40 \mathrm{mg} / \mathrm{ml}$ für Einzelstrang-DNA oder RNA und $20 \mathrm{mg} / \mathrm{ml}$ für Oligonukleotide (Sambrook et al., 1989). Aromatische Aminosäuren und Phenol absorbieren Licht bei $280 \mathrm{~nm}$. Der Quotient aus $\mathrm{OD}_{260}$ und $\mathrm{OD}_{280}$ stellt daher einen relativen Wert für die Reinheit der DNA oder RNA dar. Relativ saubere DNAbzw. RNA-Präparationen bezitzen einen Quotient $\mathrm{OD}_{260} / \mathrm{OD}_{280}$ von 1.8-2.0 (Sambrook et al., 1989).

\subsubsection{Enzymatische Behandlung von DNA}

\subsubsection{Fragmentierung von Doppelstrang-DNA mit Restriktionsenzymen}

Restriktionsendonukleasen wurden eingesetzt, um definierte DNA-Fragmente für Klonierungsansätze herzustellen und um bei analytischen Anwendungen bestimmte Restriktionsmuster in der Plasmid-DNA zu identifizieren. Restriktionsenzyme, die von verschiedenen Bakterienstämmen synthetisiert werden, erkennen jeweils spezifische Sequenzmotive der DNA und spalten die Doppelstränge an genau festgelegten Positionen. Bei der Spaltung können, je nach Enzym, glatte DNA-Enden (blunt ends) oder Fragmente mit 3'- oder mit 5'-überhängenden, kohäsiven Enden (sticky ends) entstehen. Dabei ist immer das 3'-Hydroxylende frei, während das 5'-Ende die verbleibende Phosphatgruppe trägt (Roberts, 1984).

Die verwendeten Restriktionsenzyme wurden nach den jeweiligen Angaben der Hersteller in entsprechenden Pufferlösungen eingesetzt. Es wurden 1-3 u Enzym für die Spaltung von $1 \mu \mathrm{g}$ DNA in einem Reaktionsvolumen von 10-50 $\mu \mathrm{l}$ eingesetzt. Für präparative Zwecke wurde die verwendete Enzymaktivität und das Volumen des Reaktionsansatzes entsprechend der DNA-Menge erhöht. Die Inkubation erfolgte für 1-3 $\mathrm{h}$ bei der vom Hersteller angegebenen Temperatur. 


\subsubsection{Behandlung von linearisierter DNA mit alkalischer Phosphatase}

10× Phosphatasepuffer:

$\begin{array}{ll}\text { Tris/HCl } & 100 \mathrm{mM} \\ \mathrm{ZnCl}_{2} & 10 \mathrm{mM} \\ \mathrm{MgCl}_{2} & 10 \mathrm{mM} \\ \mathrm{pH} & 8\end{array}$

Die alkalische Phosphatase (Calf Intestinal, CIP, Boehringer Mannheim) katalysiert die Abspaltung der endständigen 5'-Phosphatgruppe von DNA- und RNAFagmenten. Das Enzym wurde bei einigen Klonierungen eingesetzt, um eine Religation des Vektors mit glatten oder kompatiblen kohäsiven Enden ohne ein eingefügtes DNA-Fragment zu verhindern und somit die Effizienz der Ligation zu erhöhen.

Etwa $2 \mu \mathrm{g}$ linearisierte DNA wurden in $45 \mu \mathrm{l} \mathrm{H}_{2} \mathrm{O}$ aufgenommen und $5 \mu \mathrm{l}$ $10 \times$ Dephosphorylierungspuffer zugesetzt. Nach Zugabe von $0.02 \mathrm{u}$ alkalischer Phosphatase wurde der Ansatz $30 \mathrm{~min}$ bei $37^{\circ} \mathrm{C}$ inkubiert. Die alkalische Phosphatase wurde anschließend durch Einstellen einer Endkonzentration von $5 \mathrm{mM}$ EDTA pH 8 und Erhitzen für $10 \mathrm{~min}$ auf $75^{\circ} \mathrm{C}$ inaktiviert. Das inaktivierte Enzym wurde mit Hilfe des QIAquick-Systems der Firma Qiagen von der DNA getrennt (siehe Kap. 3.3.6).

\subsubsection{Auffüllen von 5'-überhängenden DNA-Enden}

dNTP-Mix: $\quad$ je 5 mM dATP, dCTP, dGTP und dTTP

$\underline{10 \times \text { Klenow-Puffer: }}$

$\begin{array}{ll}\text { Tris/HCl } & 0.5 \mathrm{M} \\ \mathrm{MgCl}_{2} & 0.1 \mathrm{M} \\ \text { DTT } & 1 \mathrm{mM} \\ \mathrm{pH} & 7.2\end{array}$

Das Klenow-Fragment entsteht bei der proteolytischen Spaltung der DNA-Polymerase I (Klenow und Henningsen, 1970). Es wurde benutzt, wenn nicht zueinander passende, 5'-überhängende Enden von DNA-Fragmenten miteinander ligiert werden sollten. Das Enzym füllt an 5'-überhängenden DNA- 
Enden den Gegenstrang mit komplementären dNTPs auf, so daß glatte Enden entstehen.

2-3 $\mu \mathrm{g}$ linearisierte DNA wurden in $35 \mu \mathrm{l} \mathrm{H}_{2} \mathrm{O}$ und $5 \mu \mathrm{l} 10 \times$ KlenowPuffer aufgenommen und mit $5 \mu \mathrm{l}$ dNTP-Mix versetzt. Nach Zugabe von $1 \mathrm{u}$ Klenow-Enzym pro $\mu$ g DNA wurden die Ansätze $15 \mathrm{~min}$ bei $30{ }^{\circ} \mathrm{C}$ inkubiert. Die Polymerase wurde anschließend durch Einstellen einer Endkonzentration von $10 \mathrm{mM}$ EDTA pH 8 und Erhitzen für 10 min auf $75^{\circ} \mathrm{C}$ inaktiviert. Das inaktivierte Enzym wurde mit Hilfe des QIAquick-Systems der Firma Qiagen von der DNA abgetrennt (siehe Kap. 3.3.6).

\subsubsection{Gelelektrophoretische Auftrennung von DNA}

Die Agarose-Gelelektrophorese wurde zur Reinigung, Trennung und Identifizierung von zirkulärer Plasmid-DNA und DNA-Fragmenten benutzt. Aufgrund der negativen Ladung ihrer Phosphatgruppen wandern die DNA-Moleküle im elektrischen Feld. Wird die angelegte Spannung gering gehalten, so ist die Wanderungsgeschwindigkeit von linearer, doppelsträngiger DNA in einem Agarosegel dem Logarithmus ihres Molekulargewichts umgekehrt proportional (Helling et al., 1974). Die Größe der DNA-Fragmente konnte durch den Vergleich mit Standard-DNA-Fragmenten definierter Größe abgeschätzt werden. Eine Abschätzung der Menge der aufgetragenen DNA konnte durch einen Vergleich der Intensität der Ethidiumbromidfärbung erfolgen.

\subsubsection{Analytische und präparative Agarose-Gelelektrophorese}

TAE-Puffer:

Tris/HOAc

$\mathrm{NaOAc}$

EDTA

$\mathrm{pH}$
Auftragspuffer:

$40 \mathrm{mM}$

$20 \mathrm{mM}$

$1 \mathrm{mM}$

7.2

Ethidiumbromidbad:

Ethidiumbromid
Bromphenolblau

$0.25 \%(\mathrm{w} / \mathrm{v})$

Xylencyanol

$0.25 \%(\mathrm{w} / \mathrm{v})$

Glycerin $10 \%(\mathrm{w} / \mathrm{v})$

Zur analytischen und präparativen Trennung von DNA-Fragmenten wurden Agarose-Flachbettgele benutzt. Je nach Größe der zu trennenden DNA-Moleküle 
wurde eine Agarosekonzentration von 0.7-2.0\% Agarose gewählt. Die Agarose wurde durch Aufkochen in TAE-Puffer gelöst und in eine entsprechende Gelkammer gegossen. Durch das Aufsetzen eines Kammes wurden Taschen für den Probenauftrag freigehalten. Die DNA-Proben wurden mit 1/5 Volumen Auftragspuffer versetzt und in die Taschen des mit Laufpuffer überschwemmten Gels pipettiert. Zusätzlich wurde ein Molekulargewichts-Standard $(1 \mu \mathrm{g}$ EcoRI/HindIII- oder BstEII-geschnittene Doppelstrang-DNA des Phagen Lambda) aufgetragen. Als Elektrophoresepuffer wurde 1× TAE-Puffer verwendet. Die elektrophoretische Trennung wurde bei konstanter Spannung von 70-130 V durchgeführt. Anschließend wurde das Agarosegel in einem Ethidiumbromidbad 15 min inkubiert, um die aufgetrennten DNA-Fragmente anzufärben. Diese konnten danach durch Bestrahlung mit UV-Licht $(302 \mathrm{~nm})$ sichtbar gemacht werden. Präparative Gele wurden für möglichst kurze Zeit langwelligerem UV-Licht (366 nm) ausgesetzt, um Schäden in der DNA-Struktur zu vermeiden.

\subsubsection{Isolierung von DNA aus präparativen Gelen}

Zur Isolierung von DNA aus Agarose-Gelen wurde das QIAquick-System der Firma Qiagen nach Angaben des Herstellers angewendet. Das DNA-Fragment wurde aus dem Agarosegel herausgeschnitten und in ein Eppendorf-Reaktionsgefäß überführt. Nach Zugabe des Puffers QBT (3faches Gelvolumen) wurde das Gelstück durch Inkubation für 10 min unter Schütteln bei $50{ }^{\circ} \mathrm{C}$ geschmolzen. Die zu isolierende DNA wurde an die im Kit vorhandenen zentrifugierbaren Säulen gebunden, zweimal mit je $800 \mu 1$ des Puffers PE gewaschen und nach dem Trocknen mit 30-50 $\mu 1$ Wassser oder Puffer EB eluiert. Mit diesem Verfahren konnte bis zu $5 \mu \mathrm{g}$ DNA aufgereinigt werden.

\subsubsection{Klonierung rekombinanter DNA in $E$. coli}

Die Vektoren wurden für die Ligation durch geeignete Restriktionsenzyme linearisiert. Entstanden durch das Restriktionsenzym glatte oder kompatible kohäsive Enden, wurden die 5'-Phosphatreste an den Enden der Vektor-DNA entfernt, um eine Religation des Vektors ohne den Einbau eines DNA-Fragments zu verhindern. Die zu klonierende DNA wurde mit geeigneten Restriktionsendonukleasen geschnitten und isoliert. Wenn keine komplementären Schnittstellen des Vektors 
und des DNA-Fragments vorhanden waren, wurden 5'-überhängende Enden mit Klenow-Enzym aufgefüllt.

\subsubsection{Ligation von DNA-Doppelstrang-Fragmenten}

Linearisierte DNA-Moleküle können durch die Bildung von Phosphodiesterbindungen zwischen benachbarten 3'-Hydroxyl- und 5'-Phosphatenden miteinander verbunden werden. Die T4-DNA-Ligase katalysiert diese Reaktion unter Hydrolyse von ATP. Der Ligationsansatz enthielt 50-100 ng linearisierte VektorDNA, einen 3-10fachen molaren Überschuß des zu integrierenden DNA-Fragments, $2 \mu \mathrm{l}$ des vom Hersteller mitgelieferten 10×Ligase-Puffers und $1 \mathrm{u}$ T4-DNA-Ligase in einem Gesamtvolumen von $20 \mu \mathrm{l}$. Die Ansätze wurden mindestens $1-20 \mathrm{~h}$ bei $16^{\circ} \mathrm{C}$ inkubiert und konnten dann direkt zur Transformation von kompetenten $E$. coli eingesetzt werden.

\subsubsection{Herstellung transformationskompetenter $E$. coli-Zellen}

RF-I-Puffer:

KOAc

$\mathrm{RbCl}$

$\mathrm{MnCL}_{2}$

$\mathrm{CaCl}_{2}$

$\mathrm{LiCl}$

Glycerin

$\mathrm{pH}$

anschließend sterilfiltriert
RF-II-Puffer:

MOPS $\quad 10 \mathrm{mM}$

$\mathrm{CaCl}_{2} \quad 75 \mathrm{mM}$

Glycerin

$15 \%(\mathrm{w} / \mathrm{v})$

$\mathrm{pH}$

7.0

Zur Aufnahme von rekombinanter Plasmid-DNA durch Transformation müssen E. coli-Zellen zunächst vorbereitet werden (Cohen et al., 1972). behandelt. $1 \mathrm{ml}$ einer E. coli-Übernachtkultur wurde in $300 \mathrm{ml} \mathrm{LB}$-Medium gegeben und bei $37^{\circ} \mathrm{C}$ bis zu einer Zelldichte von $0.5-0.6 \mathrm{OD}_{600}$ angezüchtet. Durch Zentrifugation für 10 min bei $4000 \times g$ und $4{ }^{\circ} \mathrm{C}$ wurden die Zellen geerntet. Bei allen folgenden Schritten wurden die Zellen ständig auf Eis gekühlt. Das Zellpellet wurde in $90 \mathrm{ml}$ RF-I resuspendiert und für 90-120 min auf Eis inkubiert. Nach einer weiteren Zentrifugation bei $4000 \times g$ und $4{ }^{\circ} \mathrm{C}$ wurden die Zellen in $12 \mathrm{ml}$ 
RF-II aufgenommen. $300 \mu$ l-Aliquots wurden in Eppendorfgefäße gegeben, durch flüssigen Stickstoff schockgefroren und bei $-80{ }^{\circ} \mathrm{C}$ gelagert.

\subsubsection{Transformation von $E$. coli-Zellen}

Die tiefgefrorenen, kompetenten E. coli-Zellen wurden auf Eis aufgetaut. Pro Transformationsansatz wurden etwa $100 \mu \mathrm{l}$ Zellsuspension verwendet. Nach Zugabe von $10 \mu \mathrm{l}$ des Ligationsansatzes oder 10-20 ng Plasmid-DNA wurden die Zellen zunächst $30 \mathrm{~min}$ auf Eis inkubiert und anschließend $2 \mathrm{~min}$ bei $42{ }^{\circ} \mathrm{C} \mathrm{im}$ Heizblock erhitzt („Hitzeschock“). Nach Zugabe von $1 \mathrm{ml}$ L-Broth-Medium und Inkubation für 30-60 min bei $37^{\circ} \mathrm{C}$ unter leichtem Schütteln, konnte davon ausgegangen werden, daß die transformierten Zellen das plasmidkodierte Resistenzgen exprimieren. Durch eine Zentrifugation bei 5000×g wurden die Zellen abzentrifugiert, in $100 \mu \mathrm{l}$ L-Broth-Medium resuspendiert und auf L-Broth-Agarplatten mit Ampicillin verteilt. Die Platten wurden über Nacht bei $37^{\circ} \mathrm{C}$ inkubiert. Die gewachsenen Klone konnten für eine analytische Plasmidisolation angeimpft werden (siehe Kap. 3.3.1.1) und anschließend durch Restriktionsanalyse auf Anwesenheit der rekombinanten Plasmid-DNA überprüft werden.

\subsubsection{DNA-Amplifikation mit der Polymerase-Kettenreaktion}

Die Polymerase-Kettenreaktion (PCR) ist ein zyklischer Prozess, bei dem sich die Zahl der synthetisierten DNA-Moleküle mit jedem durchlaufenden Zyklus verdoppelt. Im ersten Schritt eines Zyklus wird die doppelsträngige DNA, welche als Matrize dient, durch Erhitzen denaturiert. Daraufhin wird der Reaktionsansatz soweit abgekühlt, daß sich die eingestzten Oligonukleotid-Primer jeweils an die komplementären DNA-Abschnitte anlagern können. Die Oligonukleotide sind so gewählt, daß sie flankierend zu dem zu amplifizierenden DNA-Abschnitt jeweils mit dem kodierenden bzw. dem nicht-kodierenden DNA-Strang hybridisieren können. Die DNA-Polymerase verlängert im letzten Schritt eines Zyklus diese Startermoleküle durch den Einbau von Desoxynukleotiden. Erneute Denaturierung leitet den nächsten Zyklus ein. Die PCR wurde zur gerichteten Mutagenese, z. B. zum Einführen von Mutationen bzw. Schnittstellen, zur Amplifikation bestimmter DNA-Abschnitte, sowie zur analytischen Überprüfung von Ligationen und Genom-Integrationen eingesetzt. 
Die PCR wurde entweder mit der Deep-Vent-DNA-Polymerase (New England Biolabs, Schwalbach) oder der AmpliTaq-Polymerase (Perkin Elmer, USA) unter Verwendung der mitgelieferten $10 \times$ konzentrierten Puffer durchgeführt. Die Deep-Vent-DNA-Polymerase besitzt eine 3'-Exonukleaseaktivität und weist daher eine höhere Genauigkeit während der Reaktion auf als die Taq-DNAPolymerase. Als DNA-Matrize für die Polymerase-Reaktion diente entweder Vektor-DNA oder genomische Hefe-DNA. Es wurden 20-100 ng der entsprechenden Vektor- bzw. 1-3 $\mu$ g chromosomale DNA und jeweils 50 pmol der beiden Oligonukleotide pro $100 \mu$ l Reaktionsansatz eingesetzt. Nach der PCRAmplifikation wurden $10 \mu \mathrm{l}$ des Reaktionsansatzes mittels Agarose-Gelelektrophorese analysiert, um die Anwesenheit des Produkts zu überprüfen. Das restliche PCR-Produkt konnte für weitere Klonierungsschritte eingesetzt werden.

$\begin{array}{ll}\text { Reaktionsansatz: } & \\ \text { Vektor-DNA }(10 \mathrm{ng} / \mu \mathrm{l}) & 2 \mu \mathrm{l} \\ \text { Oligonukleotid } 1(10 \mathrm{pmol} / \mu \mathrm{l}) & 5 \mu \mathrm{l} \\ \text { Oligonukleotid 2 }(10 \mathrm{pmol} / \mu \mathrm{l}) & 5 \mu \mathrm{l} \\ \text { dNTP-Mix (je } 5 \mathrm{mM}) & 4 \mu \mathrm{l} \\ 10 \times \text { PCR-Reaktionspuffer } & 10 \mu \mathrm{l} \\ \mathrm{H}_{2} \mathrm{O} & 76 \mu \mathrm{l} \\ \text { DNA-Polymerase } & 1 \mathrm{u}\end{array}$

Reaktionsbedingungen Standardprogramm:

1 Zyklus: $\quad$ Denaturierung: $\quad 94^{\circ} \mathrm{C}, 3 \mathrm{~min}$

Hybridisierung: $53^{\circ} \mathrm{C}, 2 \mathrm{~min}$

Polymerisation: $72{ }^{\circ} \mathrm{C}, 2 \mathrm{~min}$

30 Zyklen: $\quad$ Denaturierung: $94^{\circ} \mathrm{C}, 30 \mathrm{~s}$

Hybridisierung: $53^{\circ} \mathrm{C}, 1 \mathrm{~min}$

Polymerisation: $72{ }^{\circ} \mathrm{C}, 2 \mathrm{~min}$

1 Zyklus: $\quad$ Denaturierung: $94^{\circ} \mathrm{C}, 30 \mathrm{~s}$

Hybridisierung: $53^{\circ} \mathrm{C}, 1 \mathrm{~min}$

Polymerisation: $72{ }^{\circ} \mathrm{C}, 10 \mathrm{~min}$ 


\subsection{Methoden zur Hefegenetik}

\subsection{1 klassische Transformation von Hefezellen}

TE-Puffer:

$\begin{array}{ll}\text { Tris/HCl } & 10 \mathrm{mM} \\ \text { EDTA } & 1 \mathrm{mM} \\ \mathrm{pH} & 8.0\end{array}$

PEG-Lösung:

PEG 6000

$\mathrm{LiOAc}$ in TE-Puffer

\section{Lithiumacetatlösung:}

LiOAc $0.1 \mathrm{M}$

in TE-Puffer

Die Hefetransformation wurde nach einer Methode von Ito et al. (1983) durchgeführt. Die Behandlung der Hefezellen mit Alkali-Kationen, wie z. B. Lithiumionen macht die Zellwand für DNA-Moleküle durchlässig, so daß die Hefezellen Plasmid-DNA aufnehmen können. Auch lineare DNA-Fragmente können auf diese Weise in Hefezellen transformiert werden und können danach durch homologe Rekombination in das Hefegenom integriert werden (Rothstein, 1983). Zur Selektion der transformierten Zellen auf Minimalmedium enthielten die verwendeten DNA-Vektoren ein entsprechendes Markergen (wie z. B. LEU2, URA3 oder das Kanamycin-Resistenzgen $K A N^{R}$ ).

Hefezellen wurden während der logarithmischen Wachstumsphase $\left(\mathrm{OD}_{600}=1\right)$ geerntet und einmal mit TE-Puffer gewaschen. Danach wurden die Hefezellen mit einer Konzentration von etwa $2 \mathrm{OD}_{600} / 100 \mu \mathrm{l}$ in LithiumacetatLösung resuspendiert und $1 \mathrm{~h}$ bei $30^{\circ} \mathrm{C}$ unter leichtem Schütteln inkubiert (Im Falle von temperatursensitiven Stämmen wurden die einzelenen Schritte bei $25{ }^{\circ} \mathrm{C}$ durchgeführt). Zu jeweils $100 \mu \mathrm{l}$ Zellsuspension wurde 1-2 $\mu \mathrm{g}$ DNA gegeben. Als Kontrolle diente ein Ansatz ohne DNA. Nach 30 min Inkubation bei $30{ }^{\circ} \mathrm{C}$ wurde $1 \mathrm{ml}$ PEG-Lösung zugegeben und erneut eine Stunde bei $30{ }^{\circ} \mathrm{C}$ inkubiert. Anschließend folgte ein Hitzeschock für $10 \mathrm{~min}$ bei $42{ }^{\circ} \mathrm{C}$. Die Zellen wurden 5 min bei 5000×g abzentrifugiert und die PEG-Lösung möglichst vollständig entfernt. Die Hefezellen wurden in $100 \mu 1$ TE-Puffer aufgenommen und auf eine selektive Agarplatten ausplattiert. Nach Inkubation für $2-3 \mathrm{~d}$ bei $30{ }^{\circ} \mathrm{C}$ bzw $25^{\circ} \mathrm{C}$ konnten Einzelkolonien auf andere Agarplatten bzw. Flüssigmedien überimpft und ihre Eigenschaften analysiert werden. 


\subsubsection{Elektroporation von $S$. cerevisiae}

Um eine höhere Transformationseffizienz zu erzielen, konnte Plasmid-DNA auch mit einem Gene Pulser (Bio-Rad, USA) durch Elektroporation in die Hefezellen eingeschleust werden. Eine logarithmisch wachsende $200 \mathrm{ml}$ Hefekultur wurde abzentrifugiert, viermal mit sterilem, kaltem $\mathrm{H}_{2} \mathrm{O}$ und anschließend mit $1 \mathrm{M}$ Sorbitol gewaschen. Die Zellen wurden in $200 \mu \mathrm{l}$ kaltem $1 \mathrm{M}$ Sorbitol aufgenommen und mit 1-5 $\mu \mathrm{g}$ Plasmid-DNA gemischt. Die Elektroporation wurde bei $1.5 \mathrm{kV}, 20 \mu \mathrm{F}$ und $200 \mathrm{~W}$ durchgeführt. Anschließend wurden die Zellen in $200 \mu 11 \mathrm{M}$ Sorbitol aufgenommen und auf selektiven Agarplatten ausplattiert.

\subsubsection{Plasmidisolation aus $S$. cerevisiae}

Aufschluß-Puffer:

$\begin{array}{ll}\text { Tris/HCl } & 10 \mathrm{mM} \\ \mathrm{NaCl} & 100 \mathrm{mM} \\ \text { EDTA } & 1 \mathrm{mM} \\ \text { SDS } & 1 \%(\mathrm{w} / \mathrm{v}) \\ \text { Triton-X-100 } & 2 \%(\mathrm{w} / \mathrm{v}) \\ \mathrm{pH} & 8.0\end{array}$

$2 \mathrm{ml}$ stationär gewachsene Hefekultur wurden für $1 \mathrm{~min}$ bei $16.000 \times g$ abzentrifugiert und das Zellpellet in $200 \mu \mathrm{l}$ Aufschlußpuffer resuspendiert. Nach Zugabe von $200 \mu \mathrm{l}$ Äquivalent säuregewaschener Glasperlen und $200 \mu \mathrm{l}$ Phenol/Chloroform (1:1), wurde die Suspension für 2 min gevortext. Zur Trennung der wässrigen Phase von der organischen Phase, den Glasperlen und den unaufgebrochenen Zellen wurde für 5 min bei $16.000 \times g$ zentrifugiert. Die wässrige Phase wurde vorsichtig abgehoben und die DNA durch Zugabe von $600 \mu 1$ 100\%igem EtOH ausgefällt. Das Präzipitat wurde für $10 \mathrm{~min}$ bei $16.000 \times g$ abzentrifugiert und Salze durch zweimaliges Waschen mit je $500 \mu 170 \%$ igem EtOH entfernt. Das Pellet wurde getrocknet und in $50 \mu 1 \mathrm{H}_{2} \mathrm{O}$ gelöst. Jeweils $5 \mu \mathrm{l}$ des Ansatzes wurden zur Transformation von kompetenten E. coli eingesetzt, um das Plasmid für weitere Analysen zu amplifizieren. 


\subsubsection{Präparation von genomischer Hefe-DNA}

Eine $50 \mathrm{ml}$ Übernacht-Hefekultur wurde durch Zentrifugation bei $3000 \times g$ für 5 min geerntet und das Zellpellet einmal mit $5 \mathrm{ml} 1 \mathrm{M}$ Sorbitol gewaschen. Nach erneuter Zentrifugation wurden die Zellen in $2.7 \mathrm{ml} 1 \mathrm{M}$ Sorbitol und $0.3 \mathrm{ml}$ 0.5 M EDTA pH 8 aufgenommen. Durch Zugabe von $2000 \mathrm{u}$ Lytikase und Inkubation für 30 min bei $37{ }^{\circ} \mathrm{C}$ wurden die Zellen sphäroblastiert. Die Sphäroblasten wurden bei $500 \times g$ abzentrifugiert und das Pellet in $5 \mathrm{ml} 50 \mathrm{mM}$ Tris- $\mathrm{HCl} / 20 \mathrm{mM}$ EDTA/pH 7.5 suspendiert. Für den Zellaufschluß wurde $500 \mu 1$ 10\% SDS zugegeben und 30 min bei $65{ }^{\circ} \mathrm{C}$ inkubiert. Das Ausfällen der Proteine erfolgte durch Zugabe von $1.5 \mathrm{ml} 5 \mathrm{M} \mathrm{KOAc}$ und Inkubation für $1 \mathrm{~h}$ auf Eis. Das Präzipitat wurde durch Zentrifugation für 20 min bei 14.000 upm sedimentiert, der Überstand in ein neues Reaktionsgefäß überführt und die in ihm enthaltene DNA und RNA durch Zugabe von 14 ml 100\%igen EtOH gefällt. Das Präzipitat wurde für $30 \mathrm{~min}$ bei $14.000 \times \mathrm{g}$ abzentrifugiert und in $3 \mathrm{ml}$ TE-Puffer aufgenommen. Durch Zugabe von $150 \mu \mathrm{l}$ RNase $(1 \mathrm{mg} / \mathrm{ml})$ wurde die mitgefällte RNA bei $37^{\circ} \mathrm{C}$ für 30 min abgebaut. Anschließend wurde durch Zugabe von $3.5 \mathrm{ml}$ Isopropanol die DNA präzipitiert und durch Zentrifugation für 30 min bei 14.000 upm sedimentiert. Das DNA-Pellet wurde wiederum in $500 \mu 1$ TE-Puffer gelöst und konnte für PCR-Reaktionen oder zur Herstellung einer genomischen Hefe-DNA-Genbank eingesetzt werden.

\subsubsection{Kreuzung von Hefezellen}

S. cerevisiae-Hefestämme können sich unter optimalen Wachstumsbedingungen sowohl als diploide, als auch als haploide Zellen vegetativ vermehren. Wird eine diploide Zellkultur unter Stickstoff-Mangelbedingungen inkubiert, so treten die Hefezellen in den meiotischen Zyklus ein. Dabei wird ein Ascus mit vier haploiden Sporen gebildet, der auch als Tetrade bezeichnet wird. Zerlegt man die Tetrade durch Mikromanipulation in vier voneinander getrennte Sporen, können diese als haploide Kulturen weiterwachsen. Die aus den Sporen hervorgehenden haploiden Zellen haben unterschiedliche Paarungstypen, jeweils zwei Sporen sind vom Typ a (MATa) bzw. vom Typ $\alpha$ (MAT $\alpha$ ). Eine Konjugation von haploiden Hefezellen geschieht nur bei einer Mischung von Zellen mit unterschiedlichen Paarungstypen. Die Verschmelzung der Zellen führt zur Bildung einer diploiden Zygote. Die im Labor verwendeten heterothallischen Hefestämme behalten ihren 
Paarungstyp stabil bei und können daher dauerhaft als haploide Kultur angezüchtet werden.

Hefestämme mit unterschiedlichen Paarungstypen wurden mit einer sterilen Impföse strichförmig auf eine YEPG-Platte ausgebracht und am unteren Ende mit der Impföse vermischt. Nach Inkubation über Nacht bei $25{ }^{\circ} \mathrm{C}$ wurden die gewachsenen Zellen auf SD-Minimalmedium zur Selektion der diploiden Zellen überstempelt und erneut über Nacht bei $25^{\circ} \mathrm{C}$ inkubiert. Wenn keine passenden Phänotypen zur Selektion der diploiden Hefezellen nutzbar waren, so wurden zwei vereinzelte Zellen mit unterschiedlichem Paarungstyp mit Hilfe eines Mikromanipulators direkt nebeneinander auf eine Agarplatte gelegt. Nur wenn die Verschmelzung der Zellen und die Bildung der Zygote mit einem Lichtmikroskop eindeutig beobachtet werden konnte, wurden die diploiden Zellen weiter kultiviert.

\subsubsection{Sporulation von Hefezellen}

Eine $5 \mathrm{ml}$ Übernachtkultur des zu sporulierenden diploiden Hefestamms wurden bei $3000 \times g$ abzentrifugiert, das Zellpellet in $5 \mathrm{ml}$ YEPGal-Medium resuspendiert und die Kultur für weitere 2-3 h geschüttelt. Die Inkubation in Galaktose erhöht die Sporulationsbereitschaft der diploiden Zellen. Anschließend wurden die Zellen erneut abzentrifugiert und der Mediumüberstand dekantiert. Die pelletierten Hefezellen konnten mit dem im Zentrifugenröhrchen verbliebenen Medium resuspendiert werden. Die konzentrierte Zellsuspension wurde als Tropfen auf eine Kaliumacetat-Agarplatte (siehe Kap. 3.2.1) gegeben. Nach Inkubation der Hefen für 3-5 d bei $25{ }^{\circ} \mathrm{C}$ konnte die erfolgte Ausbildung der Asci mit Hilfe eines Lichtmikroskops kontrolliert werden.

\subsubsection{Analyse von Hefetetraden}

Bei der Tetradenanalyse wurden die vier Sporen eines Ascus mit der feinen Glasspitze eines Mikromanipulators isoliert und einzeln auf YEPG-Agarplatten ausgelegt. Nachdem die Sporen zu Zellkolonien herangewachsen waren, konnte der Phänotyp der jeweils vier zusammengehörenden Meioseprodukte analysiert werden.

Sporulierte Hefezellen wurden mit einer Impföse in eine Lösung aus $10 \mu 1$ ß-Glucuronidase/Arylsulfatase und $500 \mu \mathrm{l} \mathrm{dH}_{2} \mathrm{O}$ gegeben. Eine Inkubation für 
15-30 min bei RT bewirkte einen partiellen Abbau der Ascuswände. $20 \mu \mathrm{l} \mathrm{der}$ Zellsuspension wurden vorsichtig an den Rand einer YEPG-Agarplatte aufgebracht. Unter dem Lichtmikroskop wurden Tetraden mit der Glasspitze eines Mikromanipulators vorsichtig isoliert. Die vier Sporen wurden einzeln an definierten Positionen auf der Agarplatte ausgelegt. Die Platten wurden zum Auskeimen der Sporen für 2-4 d bei $25^{\circ} \mathrm{C}$ inkubiert. Nachdem Kolonien gewachsen waren, wurden diese auf Selektivplatten zur Verfolgung der Markergene und auf frische YEPG-Platten zur Überprüfung des Wachstumsverhaltens bei kritischen Temperaturen (z. B. $16^{\circ} \mathrm{C}$ und $37^{\circ} \mathrm{C}$ ) überstempelt.

\subsubsection{Nachweis von sekretiertem $\alpha$-Pheromon durch den „Halo“6-Test}

Um die Sekretion des $\alpha$-Pheromons nachzuweisen, wurde der Halo(Hof)-Test verwendet (Ciejek und Thorner 1979, Julius et al., 1984). Zunächst wurden $1 \mathrm{~g}$ Agar in $100 \mathrm{ml}$ YEPG-Medium durch kurzes Aufkochen in der Mikrowelle und vorsichtiges Schwänken gelöst. Anschließend wurde das Medium in einem Wasserbad auf $42{ }^{\circ} \mathrm{C}$ abgekühlt und mit $1 \mathrm{OD}_{600}$ logarithmisch wachsender RC898-Hefezellen vermischt. Die Zellsuspension wurde möglichst dünn in Kulturschalen gegossen. Die Agarplatten sind ca. $10 \mathrm{~d}$ bei $4{ }^{\circ} \mathrm{C}$ lagerungsfähig.

Die Sensitivität des MATa Testerstammes beruht auf Mutationen im BARI - und im SST2-Gen. Der Stamm RC898 endozytiert das durch den Agar diffundierende $\alpha$-Pheromon, kann aber aufgrund der defekten Gene das Anhalten in der mitotischen G1-Phase nicht aufheben. Dadurch bildet sich um $\alpha$-Pheromon sezernierende Hefestämme ein klarer Hof (Halo).

\subsubsection{Paarungstest}

Um die Fehllokalisation des Ste2-Wbp1p-Fusionsproteins zur Plasmamembran festzustellen, wurde ein sogenannter Paarungstest nach Letourneur et al. (1994) durchgeführt. Dazu wurden entweder eine genomische Hefe-DNA-Genbank oder bestimmte auserwählte Gene in pRS323 kloniert und in den Stamm Ste2-4B transformiert. Die Transformanden wurden flächig auf entsprechende Selektivplatten ausgestrichen, $1 \mathrm{~d}$ bei $30{ }^{\circ} \mathrm{C}$ inkubiert und anschließend auf YEPGPlatten, auf denen ein Zellrasen mit MAT $\alpha-Z e l l e n$ (hier: Msuc 2D) ausplattiert wurde, replikaplattiert. Die Platten wurden anschließend zur Paarung der beiden 
Stämme für $6 \mathrm{~h}$ bei $30^{\circ} \mathrm{C}$ inkubiert. Die Zellen wurden dann zur Selektion der Diploide auf SD-Platten überstempelt und für 2-3 d bei $30{ }^{\circ} \mathrm{C}$ inkubiert.

Die Fehllokalisation des Ste2-Wbp1p-Reporters zur Plasmamembran spiegelt sich in der Bildung der Diploiden wider. Hat ein Genprodukt keine Auswirkungen auf die Lokalisation des Reporters, werden aufgrund der Sterilität des Ste2-4B Stammes keine Diploide gebildet.

\subsubsection{Bestimmung des Wachstums von Hefezellen auf Agarplatten}

Zur Kontrolle des Wachstumsverhalten wurden Hefezellen zunächst in Flüssigkultur in Vollmedium oder Minimalmedium bei $25^{\circ} \mathrm{C}$ oder $30^{\circ} \mathrm{C}$ angezüchtet. Anschließend wurde eine Verdünnungsreihe der Stämme hergestellt, so daß die höchsten Konzentrationen einer Zelldichte von $1 \mathrm{OD}_{600} / \mathrm{ml}$ entsprachen. Diese Zellsuspension wurde nun sukzessiv 1:5 verdünnt. Von den Verdünnungen wurde jeweils $10 \mu \mathrm{l}$ als Tropfen auf Vollmedium-Agarplatten aufgebracht und die Platten wurden bei unterschiedlichen Temperaturen $\left(16{ }^{\circ} \mathrm{C}, 25^{\circ} \mathrm{C}, 30^{\circ} \mathrm{C}, 32^{\circ} \mathrm{C}\right.$ und $37^{\circ} \mathrm{C}$ ) inkubiert. Das Wachstum der Mutanten wurde je nach Inkubationstemperatur nach 1-3 d im Vergleich zu Wildtyp-Zellen dokumentiert.

\subsection{Biochemische Methoden}

\subsubsection{Alkalischer Aufschluß von Hefezellen und TCA-Präzipitation der Proteine}

Lyse-Puffer:

TCA-Lösung:

$\begin{array}{ll}\mathrm{NaOH} & 2 \mathrm{M} \\ \beta \text {-Mercaptoethanol } & 5 \%(\mathrm{w} / \mathrm{v})\end{array}$

TCA $100 \%(\mathrm{w} / \mathrm{v})$

Logarithmisch wachsende Hefezellen wurden durch Zentrifugation bei $5000 \times g$ geerntet und jeweils $5 \mathrm{OD}_{600}$-Einheiten Zellen in $200 \mu \mathrm{l}$ eines alkalischen LysePuffers suspendiert. Nach einer Inkubation von $10 \mathrm{~min}$ bei RT wurden die Proteine durch Zugabe von $24 \mu 1$ 100\%iger TCA-Lösung innerhalb von $10 \mathrm{~min}$ auf Eis gefällt. Die Proteine wurden abzentrifugiert $(16.000 \times \mathrm{g}, 5 \mathrm{~min})$ und die verbleibende TCA im Pellet durch Zugabe von $10 \mu \mathrm{l} 1.5 \mathrm{M}$ Tris pH 8.5 neutralisiert. Anschließend wurde das Pellet in $20 \mu \mathrm{l}$ Laemmli-Auftragspuffer pro 
$\mathrm{OD}_{600}$-Einheit Zellen gelöst und $5 \mathrm{~min}$ im Heizblock bei $95{ }^{\circ} \mathrm{C}$ erhitzt. Die Proben konnten nun direkt für eine SDS-PAGE-Analyse eingesetzt werden.

\subsubsection{Messung der Proteinkonzentration}

Die Bestimmung der Proteinkonzentration erfolgte entweder durch eine Abschätzung der Proteinmenge im Polyacrylamidgel oder nach einer Methode von Bradford (1976). Diese Methode beruht auf der Eigenschaft des CoomassieFarbstoffs, sein Absorbtionsmaximum durch die Bindung an Proteine von einer Wellenlänge von $465 \mathrm{~nm}$ auf $595 \mathrm{~nm}$ zu verschieben. Die quantitative Bestimmung wurde mit einer Färbelösung und nach der Vorschrift der Firma Biorad (Richmond, USA) durchgeführt. Eichkurven wurde unter der Verwendung definierter Konzentartionen von Rinderserumalbumin (BSA) hergestellt.

\subsubsection{Trennung von Proteinen durch SDS-PAGE}

Laemmli-Auftragspuffer (2x):

Elektrophoresepuffer:

$\begin{array}{llll}\text { Tris/HCl } & 0.1 \mathrm{M} & \text { Glycin } & 0.19 \mathrm{M} \\ \beta \text {-Mercaptoethanol } & 2 \%(\mathrm{w} / \mathrm{v}) & \text { Tris-Base } & 25 \mathrm{mM} \\ \text { Glycerin } & 20 \%(\mathrm{w} / \mathrm{v}) & \text { SDS } & 0.1 \%(\mathrm{w} / \mathrm{v}) \\ \text { Bromphenolblau } & 0.002 \%(\mathrm{w} / \mathrm{v}) & & \\ \mathrm{pH} & 8.0 & & \end{array}$

Acrylamid-Stammlösung (30\%):

Acrylamid

$29.2 \%(\mathrm{w} / \mathrm{v})$

Sammelgel (5\%):

Bisacrylamid

$0.8 \%(\mathrm{w} / \mathrm{v})$

Acrylamid-Stammlsg. $1.7 \mathrm{ml}$

Tris/HCl, pH $6.5 \quad 2.5 \mathrm{ml}$

$\mathrm{H}_{2} \mathrm{O} \quad 5.7 \mathrm{ml}$

10\%ige SDS-Lösung $100 \mu \mathrm{l}$

Trenngel (12.5\%):

Trenngel (8\%):

Acrylamid-Stammlsg. $10 \mathrm{ml}$

Acrylamid-Stammlsg. $6.5 \mathrm{ml}$

Tris/HCl, $\mathrm{pH} 8.8 \quad 6 \mathrm{ml}$

$\mathrm{H}_{2} \mathrm{O} \quad 7.5 \mathrm{ml}$

Tris/HCl, $\mathrm{pH} 8.8 \quad 6 \mathrm{ml}$

10\%ige SDS-Lösung $250 \mu \mathrm{l}$

$\mathrm{H}_{2} \mathrm{O} \quad 11 \mathrm{ml}$

10\%ige SDS-Lösung $250 \mu \mathrm{l}$ 
Färbe-Lösung:

$\mathrm{MeOH}$

HOAc

Serva Blau R250
Entfärbe-Lösung:

$\mathrm{MeOH}$

$45 \%(\mathrm{v} / \mathrm{v})$

$\mathrm{HOAc}$

Die elektrophoretische Beweglichkeit von Proteinen in einer Acrylamid-Gelmatrix ist von ihrer Größe und Form abhängig und wird durch die Nettoladung des Proteins bestimmt. Das anionische Detergenz Natriumdodecylsulfat (SDS) wird von Proteinen in großer Menge gebunden und bewirkt in Gegenwart von Thiolreagenzien wie $\beta$-Mercaptoethanol zumeist eine vollständige Denaturierung der Proteine. Die Ladungen der Sulfatgruppen des gebundenen SDS führen zu einer stark negativen Gesamtladung des SDS-Proteinkomplexes, so daß die Ladung des nativen Proteins vernachlässigbar wird. Die Wanderungsgeschwindigkeit von Proteinen in der SDS-Polyacrylamid-Gelelektrophorese (SDS-PAGE) wird somit hauptsächlich durch den Siebeffekt der Gelmatrix und die angelegte Stromstärke bestimmt und korreliert sehr gut mit dem Molekulargewicht der Proteine.

Die SDS-PAGE wurde als diskontinuierliche Gelelektrophorese mit Trenn- und Sammelgel mit unterschiedlicher Konzentrations- und Pufferzusammensetzung nach dem von Laemmli (1970) beschriebenen System durchgeführt. Die SDS-PAGE wurde mit vertikalen Plattengelen $(170 \times 180 \times 1.5 \mathrm{~mm})$ und einer Acrylamidkonzentration des Trenngels von 7-17.5\%, je nach Molekulargewicht der zu untersuchenden Proteine, durchgeführt. Das Trenngel wurde nach Zugabe von $240 \mu \mathrm{l}$ APS (10\% (w/v)) und $12 \mu 1$ TEMED zwischen zwei Glasplatten bis etwa $3 \mathrm{~cm}$ unterhalb des Glasplattenrandes gegossen. Anschließend wurde das Trenngel mit Isopropanol überschichtet, um eine glatte Oberfläche zu erhalten. Nach der Polymerisation wurde das Isopropanol sorgfältig entfernt. Das Sammelgel wurde nach Zugabe von $30 \mu$ APS und $10 \mu 1$ TEMED bis zum oberen Rand der Glasplatten gegossen. Ein $1.5 \mathrm{~mm}$ dicker Probenkamm wurde zur Aussparung der Auftragstaschen in den oberen Gelrand eingesetzt. Nach der erfolgten Polymerisation wurden der Probenkamm sowie der untere Abstandhalter entfernt. Das zwischen den Glasplatten fixierte Gel konnte nun in eine passende Elektrophorese-Kammer eingespannt werden, so daß der obere und der untere Gelrand mit Elektrophorese-Puffer überschichtet werden konnte. Die Proteinproben wurden vor dem Auftrag mit dem gleichem Volumen $2 \times$ Laemmli-Auftragspuffer versetzt und zur vollständigen Denaturierung $5 \mathrm{~min}$ in Heizblock bei $95^{\circ} \mathrm{C}$ erhitzt. Die Elektrophorese erfolgte bei einer konstanten Stromstärke von $50 \mathrm{~mA}$ und wurde beendet, sobald der im Auftragspuffer enthaltene Farbmarker Brom- 
phenolblau die untere Kante der Gelmatrix erreicht hatte. Anschließend wurden die Glasplatten abgelöst und das Gel unter leichtem Schütteln in der Färbelösung inkubiert. Durch Waschen in einer Entfärbelösung konnte der Coomassie-Farbstoff aus der Gelmatrix wieder gelöst werden.

\subsubsection{Nachweis von Proteinen auf Nitrozellulose-Filtern}

\subsubsection{Transfer von Proteinen auf Nitrozellulose-Filter (,Westernblot ${ }^{66}$ - Verfahren)}

Transfer-Puffer:

$\begin{array}{ll}\text { Tris-Base } & 20 \mathrm{mM} \\ \text { Glycin } & 150 \mathrm{mM} \\ \text { MeOH } & 20 \%(\mathrm{w} / \mathrm{v})\end{array}$

Der elektrophoretische Transfer aufgetrennter Proteine auf eine NitrozelluloseMembran folgte der Vorschrift von Burnette (1981). Er ermöglicht den Nachweis von Proteinen mit spezifischen Antikörpern. Nach der SDS-PAGE wurden das nicht gefärbte Gel, die zugeschnittene Nitrozellulose und das Chromatographiepapier in Transferpuffer getränkt und schichtweise, gemäß der Western-BlotMethode (Burnette, 1981), übereinander gelegt. In einer speziellen Western-Blot Apparatur, die mit Transferpuffer gefüllt wurde, erfolgte der Transfer der Proteine aus der Gelmatrix auf den Nitrozellulose-Filter bei einer angelegten Stromstärke von 30-100 mA innerhalb von 2-16 h.

\subsubsection{Ponceau-Färbung von Nitrozellulose-Filtern}

Ponceau-Rot-Lösung:

$\begin{array}{lc}\mathrm{MeOH} & 40 \%(\mathrm{v} / \mathrm{v}) \\ \mathrm{HOAc} & 15 \%(\mathrm{v} / \mathrm{v}) \\ \text { Ponceau-Rot } & 2.5 \mathrm{~g} / \mathrm{l} \\ \text { anschließend sterilfiltriert }\end{array}$

Um die Qualität der Proteintrennung im SDS-PAGE und des Transfers auf Nitrozellulose zu testen, wurden die Proteine durch Ponceau-Rot reversibel angefärbt. Hierzu wurde die Membran für 2-5 min in Ponceau-Rot-Lösung geschwänkt und 
anschließend vorsichtig mit $\mathrm{dH}_{2} \mathrm{O}$ entfärbt, bis die Proteinbanden deutlich sichtbar wurden. Von der gefärbten Membran wurde zur Dokumentation und Quantifizierung eine Auflichtaufnahme am Lumiimager gemacht.

\subsubsection{Immunologischer Nachweis von Proteinen auf Nitrozellulose-Filtern (Immunoblot-Analyse)}

PufferA:

Tris/HCl

$\mathrm{NaCl}$

Tween 20
$10 \mathrm{mM}$

$0.9 \%(\mathrm{w} / \mathrm{v})$

$0.05 \%(\mathrm{v} / \mathrm{v})$
Puffer B:

SDS

$0.2 \%(\mathrm{w} / \mathrm{v})$

$\mathrm{NaCl}$

$0.9 \%(\mathrm{w} / \mathrm{v})$

Triton-X-100

$0.5 \%(\mathrm{v} / \mathrm{v})$

Stripp-Puffer:

Tris/HCl

SDS

$\beta$-Mercaptoethanol

$\mathrm{pH}$
$62.5 \mathrm{mM}$

$2 \%(\mathrm{w} / \mathrm{v})$

$100 \mathrm{mM}$

6.7

Zur Absättigung von unspezifischen Bindungsstellen wurde der NitrozelluloseFilter 20 min bei RT in Puffer A unter leichtem Schütteln inkubiert. Danach wurde der Filter in 10-30 ml Puffer A, versetzt mit 5\% (w/v) Magermilchpulver mit einer entsprechenden Menge eines spezifischen Antiserums, für 1-3 h bei RT oder für $10-12 \mathrm{~h}$ bei $4{ }^{\circ} \mathrm{C}$ geschüttelt. Der Filter wurde dann je 10 min in Puffer A, Puffer B und wieder in Puffer A gewaschen. Die Markierung der gebundenen Antikörper erfolgte durch einstündige Inkubation des Filters in 10-30 ml Puffer A versetzt mit 5\% (w/v) Magermilchpulver und 2-6 $\mu 1$ eines Peroxidase-gekoppelten sekundären Antikörpers (Esel-Anti-Kaninchen-IgG-Antikörper). Danach wurde der Filter nochmals wie oben beschrieben gewaschen.

Der Nachweis der immunreaktiven Proteine auf dem Nitrozellulose-Filter wurde unter Anwendung eines Reaktionssystems zur Chemilumineszenz (ECLSystem, NEN Life Science Products, Belgium) durchgeführt. Hierzu wurde die Membran mit einem 1:1 Gemisch aus den beiden ECL-Lösungen (je 1-2 ml) für 1 min benetzt. Zur Detektion und Auswertung der entstehenden Chemilumineszens wurde ein Lumiimager der Firma Roche, Mannheim verwendet.

Die Antikörper der ersten immunologischen Reaktion lassen sich durch eine Inkubation mit Stripp-Puffer für $1 \mathrm{~h}$ bei $50{ }^{\circ} \mathrm{C}$ wieder entfernen, so daß die Membran mit einem weiteren Antikörper inkubiert werden konnte. 


\subsubsection{Expression von GST-Fusionsproteinen in S. cerevisiae}

Lysis-Puffer:

$\begin{array}{ll}\text { Hepes/KOH } & 20 \mathrm{mM} \\ \text { KOAc } & 150 \mathrm{mM} \\ \mathrm{MgCl}_{2} & 5 \mathrm{mM} \\ \text { EDTA } & 1 \mathrm{mM} \\ \text { Triton-x-100 } & 1 \%(\mathrm{w} / \mathrm{v}) \\ \mathrm{pH} & 7.2\end{array}$

Die Expression von GST-Fusionsproteinen in S. cerevisiae erfolgte mit Hilfe des Vektors pEG-KT (Mitchell et al., 1993). Die Proteinexpression erfolgt in diesem Vektor unter der Kontrolle des GAL-Promotors. Nach Transformation des Hefestammes Sec22-3 1B mit dem rekombinanten Plasmid wurde von einer Einzelkolonie eine $5 \mathrm{ml}$ Kultur in PM-Medium beimpft und bei $30^{\circ} \mathrm{C}$ inkubiert. Mit diesen Zellen wurde eine $250 \mathrm{~m} 1$ Kultur PMGal-Medium beimpft und weitere $24 \mathrm{~h}$ bei $30^{\circ} \mathrm{C}$ inkubiert. Daraufhin wurden die Zellen durch Zentrifugation für $15 \mathrm{~min}$ bei $4000 \times g$ pelletiert. Das Pellet wurde in $5 \mathrm{ml}$ Lysis-Puffer resuspendiert und $1.5 \mathrm{ml}$ Aliquots entweder sofort weiterverarbeitet (siehe Kap. 3.5.6) oder in $2 \mathrm{ml}$ Reaktionsgefäßen in flüssigem Stickstoff schockgefroren und bei $-80^{\circ} \mathrm{C}$ gelagert.

\subsubsection{Aufreinigung von GST-Fusionsprotein-Komplexen (GST-,,pull-down"-Experiment)}

Lysis-Puffer:

$\begin{array}{ll}\text { Hepes/KOH } & 20 \mathrm{mM} \\ \text { KOAc } & 150 \mathrm{mM} \\ \mathrm{MgCl}_{2} & 5 \mathrm{mM} \\ \text { EDTA } & 1 \mathrm{mM} \\ \text { Triton-x-100 } & 1 \%(w / v) \\ \text { pH } & 7.2\end{array}$

Dem Puffer wurde zur Aufreinigung ein Proteaseinhibitor-Cocktail der Firma Roche, Mannheim zugesetzt. Für unterschiedliche Waschbedingungen wurde die Salzkonzentration durch Zugabe von $200-800 \mathrm{mM} \mathrm{NaCl}$ erhöht. Um Einflüsse von Substanzen wie z. B. Palmitoyl-CoA auf die Komplexstabilität zu testen, 
wurden diese sowohl während des Zellaufschlusses als auch bei den einzelnen Waschungen zugesetzt.

Ein Aliquot einer Zellsuspension aus Kap. 3.5 .5 wurde 2 min bei $5000 \times g$ abzentrifugiert und in $400 \mu$ l Lysis-Puffer mit Proteaseinhibitoren resuspendiert. Nach Zugabe von $400 \mu$ l Äquivalent säuregewaschener Glasperlen wurde für 2 min gevortext und die Proben anschließend auf Eis für 2 min gekühlt. Dieser Vorgang wurde zweimal wiederholt. Die Glasperlen sowie Zelltrümmer wurden durch eine Zentrifugation bei $16.000 \times g$ für 10 min bei $4{ }^{\circ} \mathrm{C}$ abgtrennt Das Pellet wurde nochmals durch Resuspension in $400 \mu \mathrm{l}$ Lysispuffer mit Proteaseinhibitoren und anschließender Zentrifugation extrahiert. Die beiden löslichen Überstände wurden vereinigt und auf exakt $1 \mathrm{ml}$ Gesamtvolumen mit Lysispuffer eingestellt. Nach Zugabe von $200 \mu \mathrm{l}$ äquilibrierte Glutathion-Sepharose (50\% slurry), wurde der Ansatz für $2 \mathrm{~h}$ bei $4{ }^{\circ} \mathrm{C}$ auf einem Drehrad inkubiert. Die Sepharose mit den gebundenen GST-Fusionsprotein-Komplexen wurde bei $5000 \times g$ für 1 min abzentrifugiert. Der Überstand wurde mit $2 \times$ Laemmli-Puffer vermischt und im Heizblock für 5 min auf $95{ }^{\circ} \mathrm{C}$ erhitzt. Die Sepharose wurde fünfmal mit je $1 \mathrm{ml}$ Lysis-Puffer gewaschen und die Proteine durch Zugabe von $100 \mu 1$ Laemmli-Puffer und Erhitzen für 5 min auf $95^{\circ} \mathrm{C}$ von der Sepharose eluiert. Wurden unterschiedliche Salzkonzentrationen bei den Waschungen getestet, wurde der Ansatz nach Inkubation für $2 \mathrm{~h}$ bei $4{ }^{\circ} \mathrm{C}$ in vier Teile geteilt, die dann jeweils paralell weiterverarbeitet wurden. Das Volumen für die Elution der Proteinkomplexe von der Sepharose wurde entsprechend reduziert.

\subsubsection{Immunpräzipitation von radioaktiv markierten Proteinen aus Zellextrakten (,Pulse-Chase“-Experiment)}

10× „, chase“-Lösung:

$\begin{array}{ll}\text { Methionin } & 100 \mathrm{mM} \\ \text { Cystein } & 10 \mathrm{mM} \\ \text { Glukose } & 2 \%(\mathrm{w} / \mathrm{v}) \\ \text { Hefeextrakt } & 4 \%(\mathrm{w} / \mathrm{v})\end{array}$

Tween-20-Harnstoff-Puffer:

$\begin{array}{ll}\text { Tris/HCl } & 100 \mathrm{mM} \\ \mathrm{NaCl} & 200 \mathrm{mM} \\ \text { Harnstoff } & 2 \mathrm{M} \\ \text { Tween-20 } & 0.5 \%(w / \mathrm{v})\end{array}$

TBS:

$\begin{array}{ll}\text { Tris/HCl } & 50 \mathrm{mM} \\ \mathrm{NaCl} & 150 \mathrm{mM} \\ \text { EDTA } & 0.1 \mathrm{mM} \\ \mathrm{pH} & 7.5\end{array}$


Tween-20-IP-Puffer:

$\begin{array}{ll}\text { Tris/HCl } & 50 \mathrm{mM} \\ \mathrm{NaCl} & 150 \mathrm{mM} \\ \text { Tween-20 } & 0.5 \%(\mathrm{w} / \mathrm{v}) \\ \text { EDTA } & 0.1 \mathrm{mM} \\ \mathrm{pH} & 7.5\end{array}$

Boiling-Puffer:

$\begin{array}{ll}\text { Tris/HCl } & 50 \mathrm{mM} \\ \text { EDTA } & 1 \mathrm{mM} \\ \text { Harnstoff } & 6 \mathrm{M} \\ \text { SDS } & 1.0 \%(\mathrm{w} / \mathrm{v}) \\ \text { pH } & 7.5\end{array}$

Um den Transport und die spezifische Prozessierung eines Proteins innerhalb einer Zelle zu verfolgen, wurden ,pulse-chase“-Experimente durchgeführt. Hefezellen, die in Methionin und Cystein freiem Medium gewachsen waren, konnten während eines definierten Zeitraums mit radioaktivem ${ }^{35} \mathrm{~S}$-Methionin und ${ }^{35}$ S-Cystein markiert werden (,,pulse“). Der Einbau der radioaktiven Aminosäuren in die Proteine wurde durch Zugabe einer hohen Konzentration unmarkierter Aminosäuren in den Reaktionsansatz beendet, und die Eigenschaften des radioaktiv markierten Protein-Pools nach unterschiedlichen Zeitpunkten untersucht (,,chase“). Damit ein spezifisches Protein mit dieser Methode verfolgt werden konnte, wurde es durch Immunpräzipitation isoliert.

Hefezellen wurden für die Immunpräzipitation der Carboxypeptidase $\mathrm{Y}$ (CPY), der Alkalischen Phosphatase (ALP) und des Sec22-myc- $\alpha$-Fusionsproteins radioaktiv markiert. Hefekulturen bzw. entsprechende Transformanden wurden über Nacht in SD-Medium mit 0.2\% Hefeextrakt angezüchtet. Die Zellen wurden am nächsten Morgen auf eine Zelldichte von $0.2 \mathrm{OD}_{600} / \mathrm{ml}$ vedünnt und für 2 weitere Genaration bis zu einer Zeldichte von $0.8 \mathrm{OD}_{600} / \mathrm{ml}$ geschüttelt. Die gewünschte Zellzahl ( $1 \mathrm{OD}_{600} /$ Zeitpunkt $)$ wurde gerntet, einmal mit $5 \mathrm{ml}$ SD-Medium gewaschen und in $180 \mu \mathrm{l}$ SD-Medium pro $1 \mathrm{OD}_{600}$ Zellen aufgenommen. Die Suspensionen wurden für 5-10 min bei der gewünschten Temperatur des Experiments (in der Regel $30^{\circ} \mathrm{C}$ ) inkubiert. Nach dieser Adaptionszeit wurde $\mathrm{zu}$ jedem Ansatz $10-20 \mu \mathrm{Ci}$ pro $1 \mathrm{OD}_{600}$ Zellen Trans ${ }^{35}$ S-Label (Gemisch aus ${ }^{35} \mathrm{~S}$-Cystein und ${ }^{35} \mathrm{~S}$-Methionin, $10 \mathrm{mCi} / \mathrm{ml}$ ) zugegeben und für weitere $10 \mathrm{~min}$ bei der gewünschten Temperaturen inkubiert.

Direkt nach Zugabe von $20 \mu 1$,,chase“-Lösung pro 1 OD $_{600}$ Zellen, wurde jeweils ein $200 \mu$ l Aliquot als Null-Wert entnommen und in ein auf Eis gekühltes Reaktionsgefäß mit $20 \mu 1$ 100\%iger TCA-Lösung pipettiert. Der restliche Teil der Ansätze wurde weiter inkubiert, nach $15 \mathrm{~min}, 30 \mathrm{~min}$ und $45 \mathrm{~min}$ jeweils ein Aliquot entnommen und genauso verfahren wie mit dem Null-Wert-Aliquot. Die einzelnen Proben wurden mindestens 15-20 min auf Eis inkubiert und anschließend für $5 \mathrm{~min}$ bei $16.000 \times g$ zentrifugiert. Das TCA-Pellet wurde zweimal mit je $1 \mathrm{ml}$ eiskaltem Aceton gewaschen, um überschüssiges TCA zu entfernen, 
und für 10 min bei RT unter dem Abzug getrocknet. Falls notwendig konnten diese Pellets für einige Tage bei $-20^{\circ} \mathrm{C}$ gelagert werden.

Das Pellet wurde in $100 \mu$ l Boiling-Puffer resuspendiert und nach Zugabe von $100 \mu 1$ Äquivalent säuregewaschener Glasperlen für 1 min gevortext. $\mathrm{Zu}$ jeder Probe wurde $900 \mu 1$ Tween-20-IP-Puffer mit $1 \mathrm{mg} / \mathrm{ml}$ BSA gegeben und sorgfältig gemischt. Die Suspension wurde $15 \mathrm{~min}$ bei $16.000 \times g$ zentrifugiert. Um zu vermeiden, daß jegliches Pelletmaterial in die nachfolgende Immunpräzipitation gelangt, wurden nur $900 \mu 1$ des Überstandes in ein neues Reaktionsgefäß pipettiert.

Für die Immunpräzipitation wurde das entsprechende Antiserum (in der Regel $10 \mu \mathrm{l}$ ) und $50 \mu \mathrm{l}$ mit Tween-20-IP-Puffer äquilibrierte Protein-ASepharose (30\% slurry) zu den Proben hinzugefügt und mindestens 2-4 h oder über Nacht bei $4{ }^{\circ} \mathrm{C}$ auf dem Drehrad inkubiert.

Die Proben wurden für 1 min bei $10.000 \times g$ zentrifugiert. Der Überstand konnte entweder sofort für die nächste Immunpräzipitation verwendet werden oder in flüssigem Stickstoff schockgefroren werden und für einige Zeit bei $20{ }^{\circ} \mathrm{C}$ gelagert werden. Die Protein-A-Sepharose wurde mit je $1 \mathrm{ml}$ Tween-20-IPPuffer, Tween-20-Harnstoff-Puffer, erneut Tween-20-IP-Puffer und TBS gewaschen. Die Proteine wurden durch Zugabe von $50 \mu 1$ Laemmli-Auftragspuffer und Erhitzen für 5 min auf $95^{\circ} \mathrm{C}$ von der Sepharose eluiert.

Aliquots wurden über ein Polyacrylamidgel aufgetrennt (siehe Kap. 3.5.3). Nach der Elektrophorese wurde das Gel zur Überprüfung der Immunpräzipitation (Detektion der schweren IgG-Ketten) für 15 min in Färbe-Lösung angefärbt und für 45 min in Entfärber-Lösung entfärbt. Anschließend wurde das Gel zur Verstärkung des radioaktiven Signals in Amplify der Firma Amersham Buchler, Braunschweig für 30 min geschwenkt. Nach dem Trocknen unter Vakuum wurde das Gel mit einem Röntgenfilm in eine lichtdichte Kassette geschlossen. Nach Lagerung von $2-7 \mathrm{~d}$ bei $-80^{\circ} \mathrm{C}$ konnte der Röntgenfilm entwickelt werden.

\subsection{Zwei-Hybrid-System}

Diese genetische Methode zur Identifizierung von Protein-Interaktionen in vivo detektiert die Rekonstitution eines funktionellen Gal4-Proteins, eines Transkriptionsfaktors aus S. cerevisiae. Dieser besteht aus zwei funktionellen Domänen: Der N-terminalen DNA-bindenden Domäne und der C-terminalen transaktivierenden Domäne. Werden diese beiden Domänen durch die Interaktion zweier Fusions-Proteine in räumliche Nähe gebracht entsteht wieder ein funktioneller 
Transkriptionsfaktor, es kommt zur Expression des lacZ-Reportergens und Hefekolonien werden im X-Gal-Filtertest blau. Wird mit der DNA-bindenden Domäne ein bekanntes Protein fusioniert, kann dieses, als Köder („bait“) bezeichnete Protein benutzt werden, um eine Zwei-Hybrid Genbank zu durchmustern.

\subsubsection{Transformation einer c-DNA-Genbank}

Lithium-Sorbitol:

$\begin{array}{llll}\text { Tris/HCl } & 10 \mathrm{mM} & \text { Tris/HCl } & 10 \mathrm{mM} \\ \text { LiOAc } & 100 \mathrm{mM} & \text { PEG } 4000 & 40 \%(\mathrm{w} / \mathrm{v}) \\ \text { EDTA } & 1 \mathrm{mM} & \text { LiOAc } & 100 \mathrm{mM} \\ \text { Sorbitol } & 1 \mathrm{M} & \text { EDTA } & 1 \mathrm{mM} \\ \mathrm{pH} & 8.0 & \mathrm{pH} & 8.0\end{array}$

Die c-DNA-Bank wurde uns freundlicherweise von B. F. Horazdovsky zur Verfügung gestellt und ist in den Vektor pGAD-GH kloniert.

Für die c-DNA-Bank-Transformation des Y190 Hefestammes, welcher das Gal4-Sec22 $\Delta$ TMD-Hybrid-Protein exprimierte, wurde eine $200 \mathrm{ml}$ Übernachtkultur in SD-Medium (-Trp) bei $30{ }^{\circ} \mathrm{C}$ angezüchtet. Die Zellen wurden in $500 \mathrm{ml}$ Vollmedium so verdünnt, daß sie nach 2 Generationen eine Dichte von $\mathrm{OD}_{600}$ 0.5-0.8 besaßen. Die Zellen wurden geerntet, mit $100 \mathrm{ml} \mathrm{H}_{2} \mathrm{O}$ gewaschen und in $5 \mathrm{ml}$ Lithium-Sorbitol resuspendiert. Nach Inkubation für $30 \mathrm{~min}$ bei $30^{\circ} \mathrm{C}$ wurden die Zellen abzentrifugiert, in $625 \mu \mathrm{l}$ Lithium-Sorbitol aufgenommen, in $100 \mu 1$ Aliquots aufgeteilt und auf Eis gelagert. Für die Träger-DNA wurden $20 \mathrm{mg}$ Kalbsthymus-DNA in $1 \mathrm{ml} \mathrm{H}_{2} \mathrm{O}$ für 7-10 min gekocht und $200 \mu \mathrm{l}$ dieser Lösung mit $800 \mu \mathrm{l}$ Lithium-Sorbitol bei RT gemischt. Nach Abkühlen der Kalbsthymus-DNA-Lösung auf RT wurden $100 \mu \mathrm{g}$ c-DNA-Bank hinzugegeben. $100 \mu 1$ der auf Eis gelagerten kompetenten Hefezellen wurden mit gleicher Menge des DNA-Gemisches für $30 \mathrm{~min}$ bei $30^{\circ} \mathrm{C}$ und leichtem Schütteln inkubiert. Nach Zugabe von $900 \mu 1$ PEG-Lösung wurde für weitere 30 min bei $30^{\circ} \mathrm{C}$ inkubiert. Nach einem Hitzeschock für 5 min bei $42^{\circ} \mathrm{C}$, konnte ein $5 \mu$ l Aliquot zur Dokumentation der Transformationseffizienz auf SD-Platten (-Trp, -Leu) ausplattiert werden. Die übrigen Zellen wurden vereinigt und zur Regeneration für 1-3 h in $100 \mathrm{ml}$ YEPG-Medium bei $30{ }^{\circ} \mathrm{C}$ inkubiert. Anschließend wurde die Kultur geerntet, in $6 \mathrm{ml}$ SD-Medium aufgenommen, je $300 \mu \mathrm{l}$ auf großen Platten ( $\varnothing 14.5 \mathrm{~cm}$, SD-His, -Trp, -Leu) mit $30 \mathrm{mM}$ 3-Amino-1,2,4-Triazol (3-AT) verteilt und 5-7 $\mathrm{d}$ bei $30{ }^{\circ} \mathrm{C}$ inkubiert. 


\subsubsection{X-Gal-Filtertest zur Identifizierung interagierender Proteine}

$\begin{array}{ll}\text { Z-Puffer: } & \\ \mathrm{Na}_{2} \mathrm{HPO}_{4} & 60 \mathrm{mM} \\ \mathrm{NaH}_{2} \mathrm{PO}_{4} & 40 \mathrm{mM} \\ \mathrm{KCl} & 10 \mathrm{mM} \\ \mathrm{MgSO}_{4} & 1 \mathrm{mM} \\ \mathrm{pH} & 7.0\end{array}$

Die Zugabe von $270 \mu 1 \beta$-Mercaptoethanol und $1 \mathrm{ml} \mathrm{X-Gal} \mathrm{(20} \mathrm{mg/ml} \mathrm{DMSO)je}$ $100 \mathrm{ml}$ Z-Puffer erfolgte stets frisch vor jedem Test.

Auf Agarplatten gewachsene Kolonien können in dem X-Gal-Filtertest auf ihre ß-Galalaktosidase-Aktivität und somit auf das Vorhandensein interagierender Proteine getestet werden. Hierzu wurde ein Nylon-Filter auf die Kolonien gelegt und vorsichtig wieder abgezogen. Die transferierten Zellen wurden durch Einfrieren in flüssigem Stickstoff und anschließendem Auftauen auf RT permeabilisiert und in eine Petrischale mit Z-Puffer getränktem Whatman-Papier gelegt. Die Kolonien, die nach einer Inkubation von 1-12 h eine blaue Färbung zeigten, wurden nach erneutem Ausstreichen auf Agarplatten einem zweiten Filtertest unterzogen. Die Kolonien, die auch im zweiten Test B-Galaktosidase-Aktivität aufwiesen, wurden weiter untersucht.

Aus den potentiell positiven Hefeklonen wurden die beiden Plasmide isoliert (siehe Kap. 3.4.3). Durch Transformation in den E. coli Stamm HB101, der eine leuB Mutation trägt, konnte durch Komplementation des LEU2-Gens auf M9-Platten, selektiv das Genbankplasmid pGAD-GH amplifiziert werden. Die so isolierte DNA wurde in den Hefestamm Y190 mit dem Köderplasmid pAS-GAL4-Sec22 $\triangle \mathrm{TMD}$ retransformiert und mit mehreren Transformanden ein erneuter Filtertest durchgeführt, um die Zahl der positiven Kandidaten weiter einzuengen. Nachdem die Plasmide der verbliebenen positiven Kandidaten einer Sequenzanalyse unterzogen wurden, konnte das für die Interaktion verantwortliche Gen durch Sequenzvergleich mit der Hefegenomdatenbank (SGD) bestimmt werden. 


\subsection{Zellbiologische Methoden}

\subsubsection{Immunfluoreszenzanalysen von Hefezellen}

PBS/Sorbitol:

$\begin{array}{ll}\mathrm{NaCl} & 137 \mathrm{mM} \\ \mathrm{KCl} & 2.7 \mathrm{mM} \\ \mathrm{Na}_{2} \mathrm{HPO}_{4} & 4.3 \mathrm{mM} \\ \mathrm{KH}_{2} \mathrm{PO}_{4} & 1.4 \mathrm{mM} \\ \text { Sorbitol } & 10 \%(\mathrm{w} / \mathrm{v}) \\ \mathrm{pH} & 7.0\end{array}$

Lytikase-Lösung (1 ml):

$\begin{array}{ll}\text { Lytikase } & 10 \mu \mathrm{l} \\ \begin{array}{l}\beta \text {-Mercaptoethanol } \\ \text { in PBS/Sorbitol }\end{array} & 1.4 \mu \mathrm{l}\end{array}$

Einbettmedium:

$\begin{array}{ll}\text { Phenylendiamin } & 100 \mathrm{mg} \\ \text { PBS } & 10 \mathrm{ml}\end{array}$

Fixativ:

$\begin{array}{ll}\text { Paraformaldehyd } & 3.5 \%(\mathrm{w} / \mathrm{v}) \\ \text { in PBS/Sorbitol } & \\ \text { DAPI-Stocklösung } & \\ \text { DAPI } & 1 \mathrm{mg} / \mathrm{ml}\end{array}$

Block-Lösung:

$\begin{array}{ll}\text { BSA } & 1 \%(\mathrm{w} / \mathrm{v}) \\ \text { Triton-X-100 } & 0.5 \%(\mathrm{v} / \mathrm{v}) \\ \text { in PBS/Sorbitol } & \end{array}$

der $\mathrm{pH}$ wurde mit $0.5 \mathrm{M} \mathrm{Na}_{2} \mathrm{CO}_{3}$ auf 8.5-9.5 eingestellt

Glycerin ad $100 \mathrm{ml}$

Entsprechende Transformanden wurden über Nacht in SD-Medium angezüchtet. Die Zellen wurden in YEPG-Medium so verdünnt, daß sie nach 2 Generationen eine Dichte von 0.8-1.0 $\mathrm{OD}_{600}$ besaßen. Jeweils $3.5 \mathrm{OD}_{600}$ wurde geerntet, in $400 \mu \mathrm{l}$ Fixativ resuspendiert und für $2 \mathrm{~h}$ bei RT inkubiert. Die fixierten Zellen wurde bei $500 \times g$ für 2 min abzentrifugiert, mit je $1 \mathrm{ml}$ PBS/Sorbitol gewaschen und in $100 \mu 1$ Lytikase-Lösung aufgenommen. Durch Inkubation der Suspension unter leichtem Schütteln bei $30^{\circ} \mathrm{C}$ wurden die Zellen sphäroblastiert. Die Sphäroblasten wurden durch eine Zentrifugation bei $500 \times g$ für 1 min geerntet, mit $1 \mathrm{ml} \mathrm{PBS/Sorbitol} \mathrm{gewaschen} \mathrm{und} \mathrm{anschließend} \mathrm{in} 50 \mu 1$ PBS/Sorbitol resuspendiert.

Je $15 \mu 1$ der Sphäroblastensuspension wurde je Loch auf einen mit Poly-LLysin beschichteten 10-Loch-Objektträger gegeben. Nach $10 \mathrm{~min}$ haben sich die Zellen aud der Öberfläche angeheftet und die überstehende Flüssigkeit konnte abgesaugt werden. Zur Absättigung unspezifischer Bindungsstellen wurde je $20 \mu \mathrm{l}$ Block-Lösung für $10 \mathrm{~min}$ auf die angehefteten Zellen gegeben. 
Anschließend wurde der gewünschte Primärantikörper, gelöst in Block-Lösung, auf die Zellen gegeben und für 1-2 h bei RT in einer Feuchthaltekammer inkubiert.

Nachdem der Objektträger fünfmal mit je $20 \mu 1 /$ Loch PBS/Sorbitol gewaschen wurde, wurden die Zellen mit Sekundärantikörper (Cy3- oder Cy2-konjugiertes Schaf-anti-Kaninchen bzw. anti-Maus-IgG), in Block-Lösung gelöst, für $30 \mathrm{~min}$ in einer lichtgeschützten Feuchthaltekammer inkubiert. Da dieser Antikörper besonders lichtempfindlich ist, wurden alle folgenden Schritte möglichst im Dunkeln durchgeführt. Es folgten 10 Waschschritte mit je $20 \mu 1$ PBS/Sorbitol je Loch, wobei jede Inkubation jeweils 2-3 min andauerte. Die Zellen wurden nun mit $20 \mu \mathrm{l}$ Einbett-Medium überschichtet, dem zuvor $1 \mu \mathrm{l} / \mathrm{ml}$ DAPI-Stocklösung zugesetzt wurde, und durch ein entsprechendes Deckglas versiegelt. Überschüssiges Einbett-Medium wurde vorsichtig entfernt.

Die so behandelten Zellen wurden mikroskopisch untersucht und waren einige Tage bei $4{ }^{\circ} \mathrm{C}$ im Dunkeln lagerungsfähig.

\subsubsection{Subzelluläre Fraktionierung von Hefekompartimenten mittels Sucrosegradient}

Puffer A:

$\mathrm{Hepes} / \mathrm{KOH}$

$\mathrm{MgCl}_{2}$

Sorbitol

$\mathrm{NaN}_{3}$

$\mathrm{NaF}$

Cycloheximid

$\mathrm{pH}$
$10 \mathrm{mM}$

$1 \mathrm{mM}$

$1 \mathrm{M}$

$10 \mathrm{mM}$

$10 \mathrm{mM}$

$20 \mu \mathrm{g} / \mathrm{ml}$

7.5

$\underline{\text { Reduzierungspufferpuffer: }}$

Puffer A

MESNA

$100 \mathrm{mM}$

Sphäroblastierungspuffer:

Puffer A

Lytikase

$10 \mathrm{U} / \mathrm{OD}_{600}$

Harnstoff-Auftragspuffer (2x):

$\begin{array}{ll}\text { Harnstoff } & 6 \mathrm{M} \\ \text { Tris/HCl } & 50 \mathrm{mM} \\ \text { SDS } & 2 \%(\mathrm{w} / \mathrm{v}) \\ \text { Bromphenolblau } & 0.1 \mathrm{mg} / \mathrm{ml} \\ \mathrm{pH} & 8.0\end{array}$

Es wurde eine leicht modifizierte Variante des von Schröder et al. (1995) beschriebenen Protokolls durchgeführt. Die entsprechenden Hefezellen wurden 
über Nacht bei $25^{\circ} \mathrm{C}$ in PM-Medium bis zu einer $\mathrm{OD}_{600}$ von 0.35 angezüchtet. $600 \mathrm{ml}$ dieser Zellkultur wurden geerntet und in $100 \mathrm{ml}$ PM-Medium, das mit $20 \mu \mathrm{g} / \mathrm{ml}$ Cycloheximid versetzt wurde, resuspendiert. Die Kultur wurde in zwei gleiche Teile geteilt, wobei ein Teil weiterhin bei $25^{\circ} \mathrm{C}$ inkubiert wurde und der andere Teil in einem Wasserbad bei $35^{\circ} \mathrm{C}$. Nach $1 \mathrm{~h}$ wurden die Zellen geerntet und weitere Energieproduktion inhibiert, indem die Zellen in $10 \mathrm{ml}$ Puffer A resuspendiert wurden. Die Zellen wurden erneut abzentrifugiert und zur Reduzierung der Zellwand in $10 \mathrm{ml}$ Reduzierungspuffer aufgenommen und für $10 \mathrm{~min}$ bei RT inkubiert. Anschließend wurden die Zellen geerntet, mit $10 \mathrm{ml}$ Puffer A gewaschen, in $1 \mathrm{ml}$ Speroblastierungspuffer resuspendiert und $30 \mathrm{~min}$ bei $30^{\circ} \mathrm{C}$ unter leichtem Schütteln inkubiert. Die so entstandenen Sphäroblasten wurden für 1 min bei $500 \times g$ abzentrifugiert und mittels osmotischer Lyse durch Aufnahme in

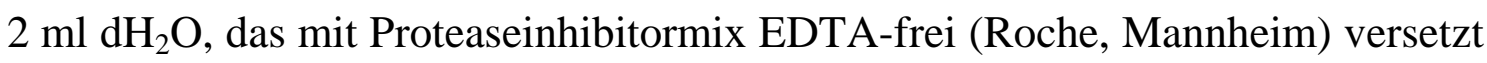
wurde, aufgebrochen. Die Lyse-Effizienz betrug etwa $80 \%$. Das Lysat wurde durch dreimalige Zentrifugation für 1 min bei $500 \times g$ von unaufgebrochenen Sphäroblasten befreit, was durch mikroskopische Analyse überprüft wurde. $1.5 \mathrm{ml}$ der Lysate wurde jeweils auf einen vorbereiteten 11-stufigen Sucrosedichtegradienten (von 18\% (w/v) bis 60\% (w/v) Sucrose; je $1 \mathrm{ml}$ ) aufgetragen, der für $2.5 \mathrm{~h}$ bei $100.000 \times g$ in einem Beckman SW40-Rotor zentrifugiert wurde (Schröder et al., 1995). Danach wurden von oben nach unten 1 ml-Fraktionen abgenommen, wobei die letzte Fraktion auf exakt $1 \mathrm{ml}$ mit $\mathrm{dH}_{2} \mathrm{O}$ aufgefüllt wurde. Jede Fraktion wurde mit $1 \mathrm{ml}$ Harnstoff-Auftragspuffer versetzt und für $10 \mathrm{~min}$ bei $50{ }^{\circ} \mathrm{C}$ inkubiert. Die Analyse der Proteine erfolgte durch SDS-PAGE und nachfolgendem Immunoblot-Verfahren (vgl. Kap. 3.5.3, Kap. 3.5.4). 


\section{Ergebnisse}

\subsection{Durchmusterung einer Genbank}

\subsubsection{Verwendung des Ste2-Wbp1p-Reporters}

Wie bereits in Kapitel 1.2.2.2 beschrieben, gibt es verschiedene Signale, die eine Rückführung von ER-Proteinen aus dem Golgi vermitteln. Um Proteine zu identifizieren, die die dilysinabhängige Rückführung zum ER stören (KKXX-Motiv), wurde eine geringfügig modifizierte Variante des von Letourneur et al. (1994) entwickelten Tests verwendet. Der Reporter dieses Systems ist ein Fusionsprotein bestehend aus dem $\alpha$-Faktor-Rezeptor (Ste2p) und dem C-Terminus der Oligosaccharyltransferaseuntereinheit Wbplp (Abbildung 2).

A

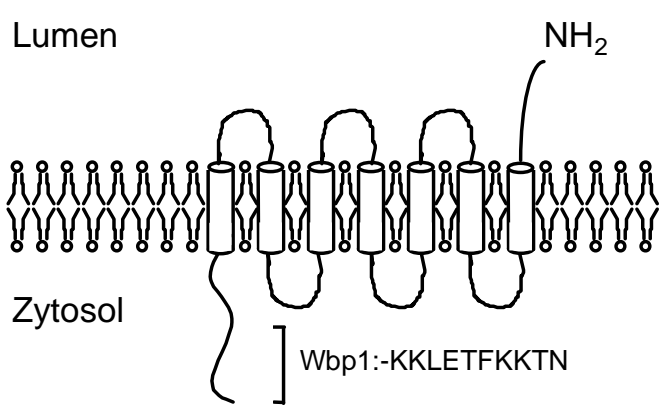

B

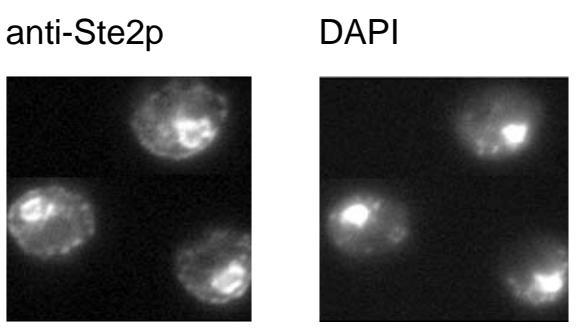

Abbildung 2: A Schematische Darstellung des verwendeten Ste2-Wbp1p-Reporters. B Immunfluoreszenz des Ste2-Wbp1p-Reporters in Wildtyp Zellen. Die Lokalisation des Zellkerns wurde durch die DAPI-Anfärbung der Kern-DNA überprüft. Der anti-Ste2p-Antikörper erkennt den Ste2-Wbp1p-Reporter, der in perinukleären ER-Strukturen lokalisiert ist.

Ste2p, ein Protein mit sieben Transmembrandomänen, wird in MATa Hefezellen auf der Zelloberfläche exprimiert und ist als $\alpha$-Faktor-Rezeptor essentiell für die Paarung mit MAT $\alpha$ Zellen. Wird an den C-Terminus von Ste2p die zytoplasmatischen Domäne von Wbp1p, die ein funktionelles Dilysinsignal enthält, fusioniert, bleibt das so veränderte Protein im ER. Hefezellen, bei denen das chromosomale STE2-Gen durch den Ste2-Wbp1p-Reporter ersetzt ist, weisen einen Paarungsdefekt auf, der auf dem effizienten „Retrieval“ des Reporters zum ER beruht. Wird diese Maschinerie gestört, so wird der Reporter zur Plasmamembran fehllokalisiert und die Paarung mit MAT $\alpha$ Zellen kann erfolgen. Durch Abstem- 
peln auf Agarplatten, die mit einem MAT $\alpha$-Testerstamm beschichtet sind, können Mutanten leicht identifiziert werden. Während Letourneur et al. (1994) und Cosson et al. (1996) dieses System benutzten, um Hefemutanten zu untersuchen, wurde dieser Test in der vorliegenden Arbeit verwendet, um Gene zu finden, deren Proteinprodukte bei Überproduktion das Zurückführen des Ste2-Wbp1p-Reporters zum ER stören (siehe Kap. 1.5).

$\mathrm{Zu}$ diesem Zweck wurde der Hefestamm Ste2-4B mit genomischen HefeDNA-Genbanken transformiert. Die Genbanken wurden durch unterschiedliche Restriktion genomischer Hefe-DNA und anschließender Klonierung aller Fragmente $>3.5 \mathrm{kB}$ in den ,multi-copy“-HIS3-Vektor pRS323 generiert. Anhand dieser Metode wurden 45 verschiedene kleine Genbanken hergestellt. Durch die Verwendung einer Vielzahl von paarweisen Kombinationen unterschiedlichster Restriktionsendonukleasen sollte sichergestellt werden, daß möglichst alle Hefegene mit ausreichender Wahrscheinlichkeit in einer der Genbanken repräsentiert sind. Die mit Plasmiden aus diesen Genbanken transformierten Hefen wurden auf Selektivplatten (SD-His) ausplattiert und nach $24 \mathrm{~h}$ Wachstum dem Paarungstest unterworfen (siehe Kap. 3.4.9).

Von ungefähr 7000 getesteten Transformanden, waren nur 17 Klone in der Lage, Diploide auszubilden. Von diesen wurde die Plasmid-DNA isoliert und in den Hefestamm Ste2-4B rücktransformiert, um zu beweisen, daß der gemessene Effekt tatsächlich von der Plasmid-DNA abhängt und nicht durch zufällige Veränderung des verwendeten Hefestamms hervorgerufen wird. Nach dieser Kontrolle zeigten noch sieben Klone die erwünschte Ausbildung von Diploiden. Durch Sequenzierung der Plasmid-DNA mit den Oligonukleotiden T3 und T7 konnte der Anfang und das Ende des inserierten genomischen Hefe-DNA-Fragmentes bestimmt werden. Durch Vergleich mit der Hefegenomdatenbank SGD wurden alle Gene bestimmt, die auf den einzelnen DNA-Fragmenten lokalisiert sind (siehe Tabelle 3).

Da sich auf einigen Genabschnitten mehrere Leserahmen befanden wurden potentielle Kandidaten durch Subklonierung vereinzelt und erneut getestet. Gene, die offensichtlich nicht direkt mit dem ER-Golgi-Transport zusammenhingen wie z. B. BDF1, dessen Genprodukt bei der Sporulation eine Rolle spielt, oder RME1, ein Transkriptionsfaktor, der die Meiose von Diploiden reprimiert, wurden nicht näher untersucht. Es kristallisierten sich vier verschiedene Leserahmen als mögliche Kandidaten heraus, die durch Überproduktion einen Recyclingdefekt hervorrufen: YKL063c, YBR044c, FUN9 und RET2. Das Genprodukt von RET2 ist Ret2p ( $\delta$-COP), ein Protein der COPI-Vesikelhülle (siehe Kap. 1.2.2.1). Das RET2-Gen war auf dem klonierten DNA-Fragment nicht vollständig erhalten 
(Abbildung 5). Die Funktion der Genprodukte der übrigen drei Leserahmen war zum Zeitpunkt der Durchführung des Paarungs-,,screen“ unbekannt.

\begin{tabular}{ccl}
\hline KIon Nr. & Chromosom & \multicolumn{1}{c}{ Gene } \\
\hline \hline 1 & $\mathrm{XII}$ & BDF1 \\
3 & $\mathrm{II}$ & $\underline{\text { KTR4, BEM1, DER1 }}$ \\
4 & $\mathrm{VII}$ & RME1; YGR046w \\
6 & $\mathrm{XI}$ & YKL063c \\
12 & $\mathrm{II} / \mathrm{XI}$ & MRPL13, YKR007w, RSC4, YBR044c \\
15 & $\mathrm{VI}$ & RET2, RPN12, HXK1 \\
17 & $\mathrm{I}$ & FUN9, CDC24 \\
\hline
\end{tabular}

Tabelle 3: Übersicht über die gefundenen Klone im Paarungs-,,screen“. Durch Sequenzanalysen konnte die Lokalisation des Genabschnitts im Genom sowie die darauf befindlichen offenen Leserahmen bestimmt werden. Befanden sich mehrere interessante Leserahmen auf dem Genabschnitt wurden diese durch Subklonierung vereinzelt. Unterstrichene Leserahmen zeigten keine Ausbildung von Diploiden, während fettgedruckte Leserahmen auch für sich alleine im Paarungstest positiv waren. Näheres siehe Text

YKL063c: Der Leserahmen kodiert für ein aus 167 Aminosäuren bestehendes Protein, das eine geringe Sequenzhomologie zu einem aus Säugern stammenden mikrotubuliassoziiertem Protein MAP 1B aufweist. Es enthält laut Computervorhersage eine Transmembrandomäne (Aminosäure 33-58). Das Ausmaß der Fehllokalisation des Ste2-Wbp1p-Reporters zur Plasmamembran ist im Gegensatz zu den anderen beiden Leserahmen YBR044c und FUN9 eher schwach ausgeprägt (Abbildung 3).

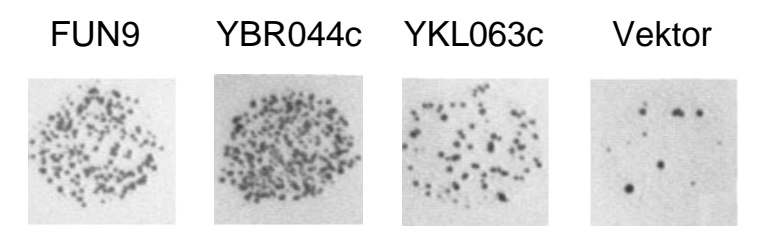

Abbildung 3: Der $\Delta$ ste2 Stamm Ste2-4B, welcher das Reporterprotein Ste2-Wbp1p exprimiert, wurde mit „multi-copy“-Plasmiden, die die angegebenen Leserahmen enthalten, transformiert. Die erhaltenen Transformanden wurden auf die Fähigkeit zur Ausbildung von Diploiden getestet, was ein Maß für die Fehllokalisation des Ste2-Wbp1p Reporters zur Plasmamembran darstellt. 
Die Deletion von YKL063c führte weder zur Letalität noch zu einem deutlich verminderten Wachstum bei $37^{\circ} \mathrm{C}$. Da die Überproduktion vonYKL063cp auch keinen Einfluß auf das Recycling des Sec22- $\alpha$-Reporters hatte (vgl. Kap. 4.1.2), wurde das Gen nicht weiter untersucht.

YBR044c: Ähnliche Ergebnisse wie mit YKL063c wurden mit dem Leserahmen YBR044c erzielt, der für ein 572 Aminosäure langes Protein kodiert. Das Genprodukt von YBR044c besitzt Ähnlichkeit zu einem mitochondrialen Hitzeschockprotein (Hsp60p). Später wurde es in einer Veröffentlichung als Tcm62p charakterisiert (Dibrov et al., 1998). Es stellt ein „Chaperon“ dar, das für die Assemblierung der mitochondriale Succinatdehydrogenase verantwortlich ist. Warum es einen so starken Einfluß im Paarungstest hat, ist nicht zu erklären

FUN9: Das Gen FUN9 kodiert für ein 415 Aminosäuren langes Protein mit zwei potentiellen Transmembrandomänen. Interessanterweise enthält dieses Protein am C-Terminus ein KKXX-Motiv (KKSQ), was die Vermutung nahe legt, daß es selbst ein Frachtmolekül des retrograden Transports darstellt. Seine Überproduktion würde somit eine Sättigung der KKXX-abhängigen Rückführungsmaschinerie hervorrufen. Der aus der ,,coatomer“-Bindung verdrängte Reporter würde dann zur Plasmamembran transportiert werden. Unter dieser Annahme müßte eine Überproduktion von Fun9p mit Mutationen im KKXX-Motiv die effiziente Rückführung des Ste2-Wbp1p-Reporter in das ER nicht stören. Wie in Abbildung $4 \mathrm{zu}$ sehen ist, wird die Fehllokalisation des Ste2-Wbp1p-Reporters zur Plasmamembran bei Überproduktion von Fun9-QGSQp zwar signifikant reduziert aber nicht vollständig aufgehoben. Das Protein hatte jedoch auf das Recycling von Sec22- $\alpha$ keinen Einfluß (vgl. Kap. 4.1.2).
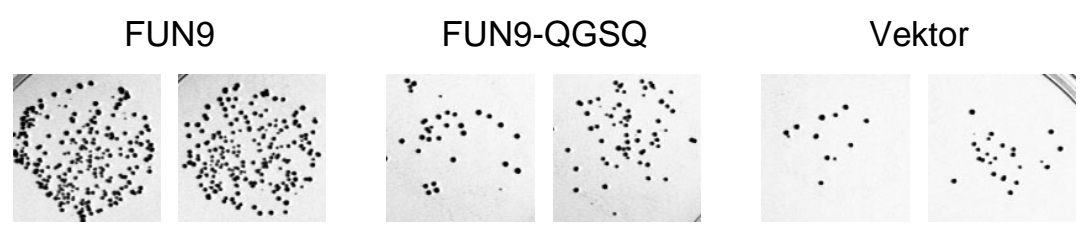

Abbildung 4: Der 4 ste2 Stamm Ste2-4B, der das Reporterprotein Ste2-Wbp1p exprimiert, wurde mit den Plasmiden pTN85, pTN92 und pTN77 transformiert. Die erhaltenen Transformanden wurden auf die Fähigkeit zur Ausbildung von Diploiden getestet, das ein Maß für die Fehllokalisation des Reporters zur Plasmamembran darstellt.

Kürzlich wurde dieses Protein in der Arbeitsgruppe von C. Barlowe tatsächlich auf Vesikeln gefunden und mit dem Namen Erv46p (ER vesicle protein of $46 \mathrm{kDa})$ versehen. 
RET2: Das einzige Gen, das bei der Durchmusterung der Genbank gefunden wurde, dessen Genprodukt nachweislich im vesikulären Transport involviert ist, war RET2. Dabei wurde zufällig eine Deletionsmutante isoliert, die für ein C-terminal um 16 Aminosäuren verkürztes Genprodukt kodiert (siehe Abbildung 5). Gleichzeitig waren vier Kodons an den verkürzten Leserahmen fusioniert, die von der Polylinkerregion des verwendeten Vektors stammen. Die Ursache für die Fusion der DNA-Sequenzen lag in der Verwendung einer natürlichen SacI-Restriktionsschnittstelle am C-Terminus des RET2-Gens. Wird das vollständige Wildtypprotein Ret2p ( $\delta-\mathrm{COP}$ ) überproduziert, ist im Gegensatz zu dem verkürzten Protein keine Fehllokalisation des Ste2-Wbp1p-Reporters nachweisbar. Genausowenig hatte die Überproduktion von Ret1p ( $\alpha$-COP), die gleichzeitig als Kontrolle diente, einen Effekt. Offensichtlich wird durch die Anwesenheit von Ret $2 \Delta \mathrm{CT}$ p die Architektur des COPI-Hüllproteinkomplexes stark beeinflußt und die Bindung an das KKXX-Motiv des Reporters und damit seine Rückführung in das ER verhindert. Eine direkte Interaktion mit dem KKXX-Motiv wurde der ,,coatomer“-Untereinheit $\gamma$-COP zugeschrieben (Harter et al., 1996). Diese bildet jedoch zusammen mit $\beta$-und $\zeta$-COP bei der Vesikelbildung einen Subkomplex aus (siehe Kap. 1.2.2.1). Es wäre folglich möglich, daß der Mechanismus der Aufnahme von KKXX-markierten Frachtmolekülen in COPI-Vesikel bei Überproduktion von Ret2 $\Delta$ CTp gestört ist. Ein ,coatomer-Komplex“, der aus einer ret2-1 Mutante isoliert wurde, kann allerdings in vitro noch an das KKXX-Motiv binden (Cosson et al, 1996). Welche Mutation in diesem Fall das ret2-1 Gen trägt, ist nicht veröffentlicht.

A
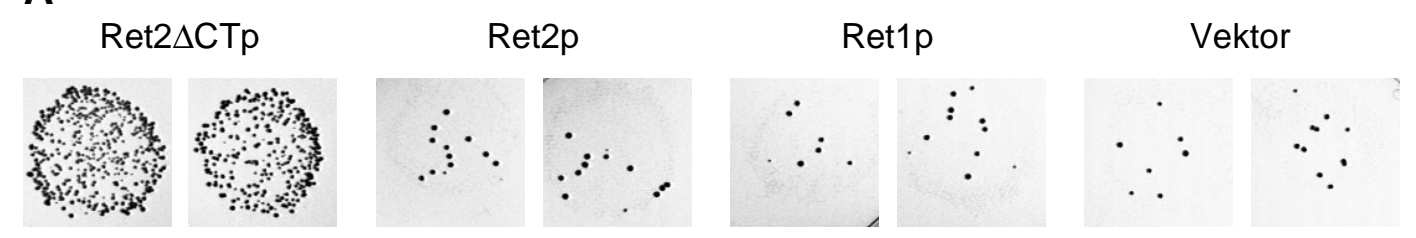

\section{B}

Ret2 $\Delta$ CTp 521 V M A D H D E L Q F A L *

Ret2p $521 \vee M A N D H D Q E L P Y D V I T S L K S D E Y L V Q$ *

Abbildung 5: A Der $\Delta$ ste2 Stamm Ste2-4B, der den Reporter Ste2-Wbp1p exprimiert, wurde mit den Plasmiden pTN88, pTN89, pTN90 und pTN77 transformiert und im Paarungstest getestet. B Vergleich der Aminosäuren des C-Terminus von Ret2p und der Stopmutante Ret2 $\triangle$ CTp, die durch eine zufällige Fusion von RET2 mit Sequenzen des Vektors generiert wurde. 


\subsubsection{Verwendung des Sec22- $\alpha$ Reporters}

Um Proteine zu identifizieren, die bei Überproduktion das Recycling von Sec22p zwischen ER und Golgi stören, wurde neben Ste2-Wbp1p der Sec22- $\alpha$ Reporter verwendet (Ballensiefen et al., 1998). Mit diesem Hybridprotein konnte Wolfgang Ballensiefen im Rahmen seiner Dissertation in vivo zeigen, daß Sec22p über COPI-Vesikel zum ER zurückgelangt. Bei den Untersuchungen zeigte sich weiterhin, daß Sec22p sogar aus dem späten Golgi in das ER zurücktransportiert wird.

Wie bereits in Kap. 1.4 beschrieben wurde, gehört das SNARE Sec22p zur Familie der Synaptobrevine und ist ein TypII-Transmembranprotein. Der größte Teil des Proteins ist ins Zytosol gerichtet und nur wenige Aminosäuren des C-Terminus befinden sich im ER-Lumen, so daß keine luminalen Modifikationen, z. B. eine Glykosylierung im Golgi, möglich sind. Deshalb läßt sich ein Sec22p-Molekül, das sich im ER aufhält, biochemisch nicht von einem Sec22pMolekül unterscheiden, das den Golgi-Komplex durchlaufen hat. Mit Hilfe des künstlich erzeugten Sec22- $\alpha$ Reporters ist dies möglich. Abbildung 6 soll die Strategie dieses Systems schematisch veranschaulichen.

Am 3'-Ende von SEC22 wurde eine Sequenz angehängt, die für folgende Peptidsegmente kodiert: ein c-myc-Epitop gefolgt von einer Kex2p-Schnittstelle und dem $\alpha$-Faktor-Pheromon. Dieser Sec22- $\alpha$ Reporter kann Sec22p funktionell ersetzen und weist die gleiche Lokalisation innerhalb der Zelle auf. Wird dieser Reporter aufgrund fehlender oder gestörter ER-Retention fehllokalisiert, passiert er den späten Golgi, wo sich die Kex2-Protease befindet. Dies hat zur Folge, daß Kex2p den $\alpha$-Faktor vom Reporter abspaltet und dieser ins Medium sezerniert wird. Daraus ergeben sich zwei Möglichkeiten die Fehllokalisation des Sec22- $\alpha$ Reporters in den späten Golgi nachzuweisen: 1) Der sezernierte $\alpha$-Faktor kann mittels Halotest (vgl. Kap. 3.4.8) auf Agarplatten nachgewiesen werden. 2) Der Reporter besitzt nach der $\alpha$-Faktor Abspaltung ein deutlich kleineres Molekulargewicht und kann durch Immunoblot-Analyse vom unprozessierten Sec22- $\alpha$ Reporter unterschieden werden. Der Nachweis kann entweder mit anti-Sec22pAntikörper oder mit anti-c-myc-Antikörper erfolgen.

Da es schwierig ist, den ausgeschiedenen $\alpha$-Faktor zu quantifizieren, sollte diese Methode nur zur Vorauswahl der einzelnen Klone benutzt werden (HaloTest). Die mögliche vermehrte Kex2p-Prozessierung des Reporters sollte anschließend durch Immunoblot-Analyse bestätigt werden. Der Hefestamm TNY14 wurde mit dem Plasmid pWB-Acyc $\alpha$, das für den Sec22- $\alpha$ Reporter kodiert, transformiert. 

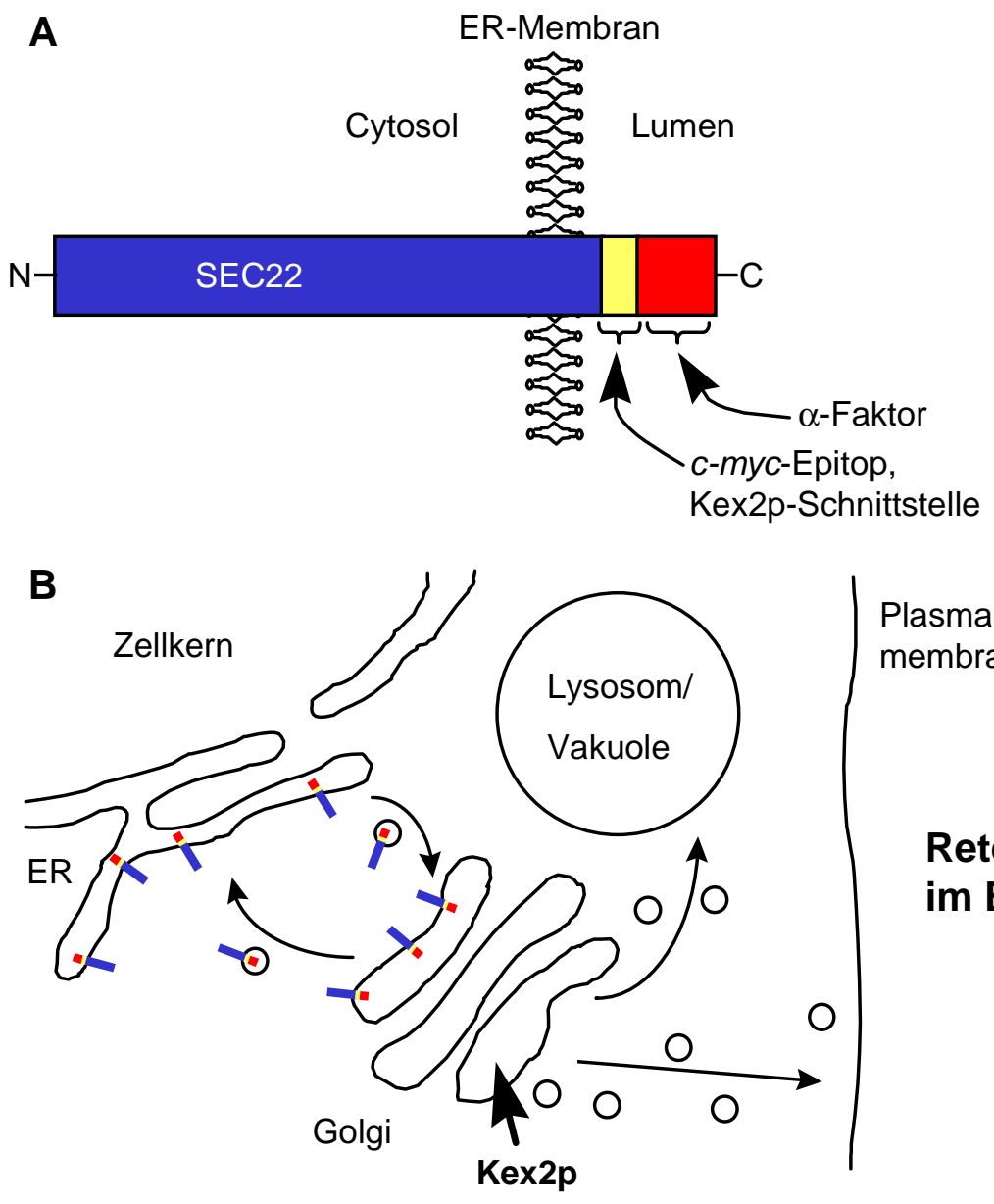

Plasma-

membran

C

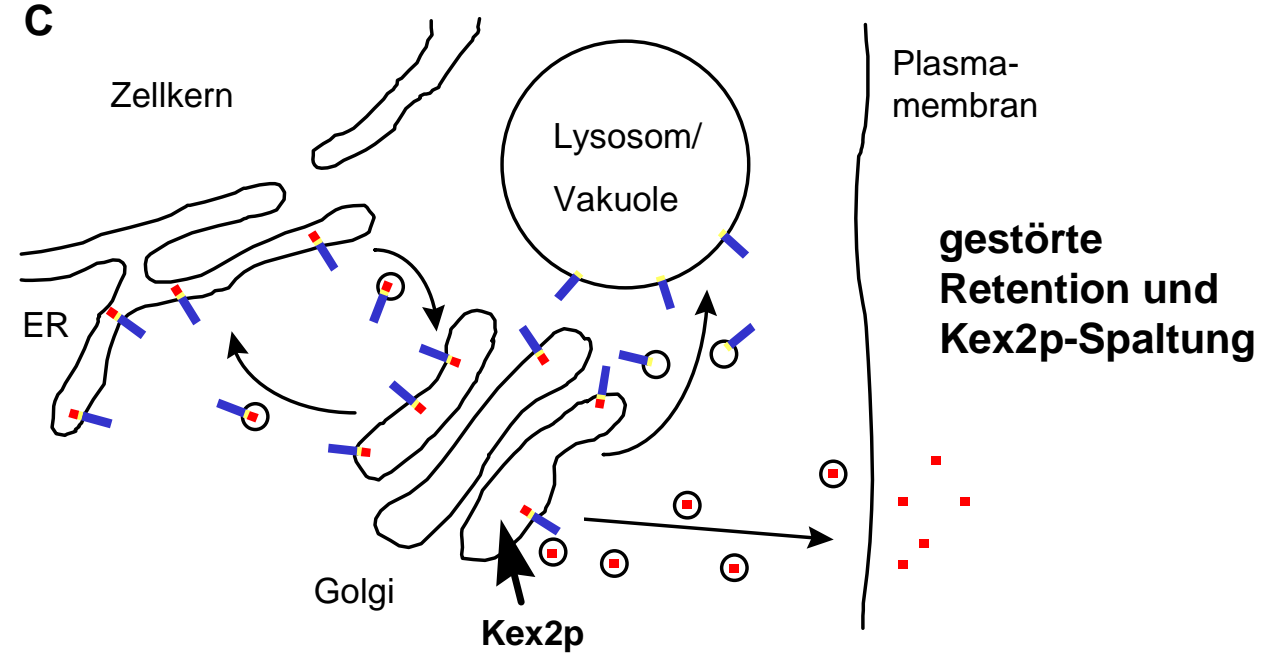

Abbildung 6: Schematische Darstellung des verwendeten Sec22- $\alpha$ Reporters (A) und seine Lokalisation in der Zelle bei funktionierender Retention (B). Wird das Recycling gestört, erfolgt eine Fehllokalisation des Sec22- $\alpha$ Reporters in den späten Golgi. Der $\alpha$-Faktor wird durch die Kex2-Protease abgespalten und sezerniert. Der prozessierte Reporter wird in der Vakuole abgebaut. 
Diese Transformanden zeigten bereits einen kleinen Hof (Halo) im Halo-Test. Nach zusätzlicher Transformation mit den hergestellten „,multi-copy“ Genbanken wurden Klone selektiert, die einen stark vergrößerten Hof im Halo-Test ausbildeten und somit potentielle Kandidaten mit vermehrtem Sec22- $\alpha$ Transport in den späten Golgi darstellten. Obwohl ca. 21.000 Transformanden getestet wurden, von denen zunächst 900 Kanditaten einen vergrößerten Hof bildeten, konnte letztendlich kein Gen isoliert werden, dessen Genprodukt auch in der Immunoblotanalyse eine vermehrte Prozessierung des Sec22- $\alpha$ Reporters durch Kex2p zeigte. In diesem Genbank-,,screen“ wurde allerdings viermal das Gen isoliert, das für den $\alpha$-Faktor selbst kodiert, was zum einen für das Selektionsverfahren über den Halo-Test spricht und zum anderen dafür, daß die Genbank vollständig war.

\subsection{Einfluß von SNARE-Proteinen auf die ER-Golgi-Recyclingmaschinerie}

Da mit Hilfe einer Genbank kein Gen gefunden wurde, das bei Überexpression das Recycling beider Reporter Ste2-Wbp1p und Sec22- $\alpha$ stört, wurden bekannte Proteine, die am ER-Golgi-Transport beteiligt sind, in beiden Testsystemen untersucht.

Zunächst wurde die Überproduktion von Sec22p selbst getestet. Diese Untersuchung erscheint in Bezug auf den Sec22- $\alpha$ Reporter zunächst trivial zu sein, stellt aber eine wichtige Kontrolle für das Testsystem dar. Es konnte bereits gezeigt werden, daß die Menge des Kex2p-Schnittprodukts mit steigender Expressionsrate des Sec22- $\alpha$ Reporters zunimmt (Ballensiefen et al., 1997). Durchläuft der Reporter den gleichen Recyclingweg wie das Sec22p selbst, so müsste auch eine erhöhte Sec22p-Expression eine Verdrängung des Reporters aufgrund einer Sättigung der Recyclingmaschinerie bewirken. Für diesen Versuch wurde der Hefestamm TNY26, bei dem der Sec22- $\alpha$ Reporter genomisch integriert wurde, mit dem Plasmid pTN79, das SEC22 in einem multi-copy Vektor enthält, transformiert. Tatsächlich konnte in der Immunoblot-Analyse eine vermehrte Kex2p-Prozessierung festgestellt werden (siehe Abbildung 8). Der

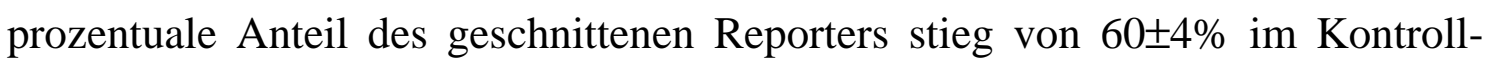
experiment ohne Überproduktion um etwa $15 \%$ bei Überproduktion von Sec22p an. Die relativ hohe Menge an Schnittprodukt im Kontrollexperiment ist darauf zurückzuführen, daß die Recyclingmaschinerie schon durch die Anwesenheit des Reporters übersättigt ist und der Reporter teilweise aus dem späten Golgi zum ER zurückgeführt werden kann (Ballensiefen et al., 1997). In der Immunoblotanalyse 
wird jedoch nur eine „steady-state“ Analyse der ständig fortlaufenden zellulären Recyclingprozesse vorgenommen. Um eine Aussage darüber $\mathrm{zu}$ erhalten, in welchem Zeitraum ein neusynthetisierter Pool von Reporterproteinen den späten Golgi erreicht und von der Kex2-Protease gespalten wird, wurden ,pulse-chase“Experimente durchgeführt.

In Abbildung 7 ist das Ergebnis des ,pulse-chase“-Experimentes mit und ohne Überproduktion von Sec22p dargestellt. Die Proteine des Hefestamms TNY26, der den Sec22- $\alpha$ Reporter exprimiert und die angegebenen ,multi-copy“ Plasmide enthält, wurden für zehn Minuten mit radioaktiven ${ }^{35} \mathrm{~S}$-Cystein und ${ }^{35}$ S-Methionin markiert (,„pulse“). Anschließend wurde die radioaktive Markierung durch Zugabe eines großen Überschusses nicht radioaktiver Aminosäuren beendet. Nach den angegebenen Zeiten (,chase“) wurden der Sec22- $\alpha$ Reporter und Sec22p durch Immunpräzipitation mit einem Gemisch aus anti-Sec22p- und anti-c-myc-Antikörper isoliert, durch SDS-PAGE getrennt und mittels Autoradiographie sichtbar gemacht. Im Kontrollexperiment (Vektor) liegt der Se22- $\alpha$ Reporter zum Zeitpunkt $\mathrm{t}=0 \mathrm{~min}$ ungeschnitten vor. Bereits nach 45 Minuten hat ein Teil des radioaktiv markierten Reporters den späten Golgi erreicht, etwa 25\% des Reporters liegen nun in Kex2p-prozessierter Form vor. Nach 90 Minuten sind ca. $50 \%$ des Reporters gespalten. Im Falle der Überproduktion von Sec $22 p$ erfolgt diese Prozessierung bedeutend schneller. Hier ist zum Zeitpunkt $\mathrm{t}=0$ schon eine geringe Menge des Sec22- $\alpha$ Reporters gespalten, nach 45 Minuten ist etwa $80 \%$ prozessiert und nach 90 Minuten liegt fast ausschließlich geschnittenes Material vor.

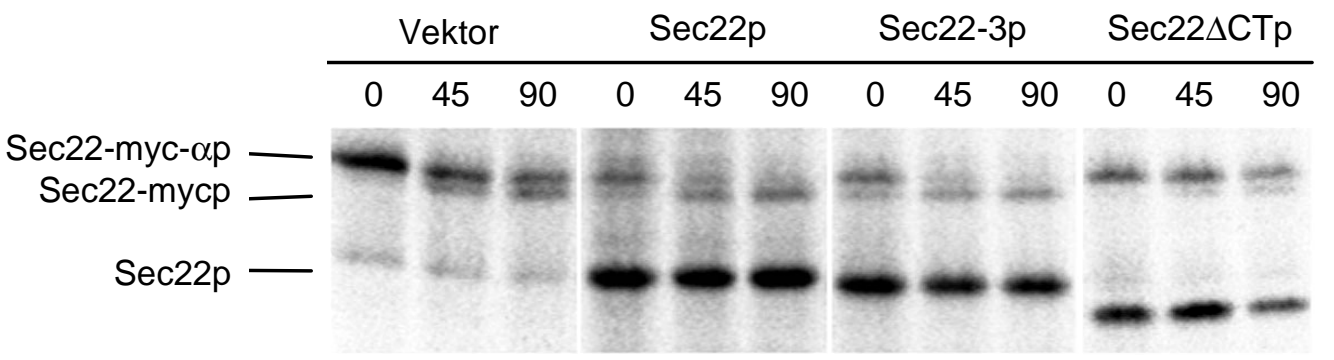

Abbildung 7: Der Stamm TNY26 wurde mit den „multi-copy“ Plasmiden pTN79, pTN77, pTN80 und pRO64, die für die angegebenen Proteine kodieren, transformiert. Mit den so erhaltenen Transformanden wurde ein „pulse-chase“-Experiment durchgeführt. Die fortschreitende Kex2p-Spaltung des Sec22- $\alpha$ Reporters wurde nach 0, 45 und 90 Minuten „chase“ analysiert. 
Gleichzeitig wurde bei diesem Experiment die Wirkung der Überproduktion von mutierten Sec22-Proteinen untersucht. Das Sec22-3p enthält an Position 157 einen Aminosäureaustausch von Arginin zu Glycin (R157G), die aus der temperatursensitiven sec22-3-Mutante stammt (Novick et al., 1980). Die Mutation betrifft die zentrale Aminosäure des SNARE-Motivs (R-SNARE) und führt im sec22-3 Stamm zu einem Block des Proteintransports zwischen ER und Golgi. Es stellt sich daher die Frage, ob der Grund für den Transportdefekt im sec22-3 Stamm in einem Recyclingdefekt des Sec22-3p liegt. Wäre dies der Fall, dann dürfte eine Überproduktion von Sec22-3p nicht in der Lage sein, den Sec22- $\alpha$ Reporter in den späten Golgi zu verdrängen. Dies trifft jedoch nicht zu, wie in Abbildung $7 \mathrm{zu}$ sehen ist. Der Einfluß von Sec22-3p auf den Transport von Sec22- $\alpha$ entspricht dem von Sec22p. Das Mutantenprotein Sec22 $\Delta$ CTp trägt eine Deletion der C-terminalen Transmembrandomäne. Da dieses Protein somit im Zytosol lokalisiert ist, besitzt es eine völlig andere Lokalisation in der Zelle als das Wildtypprotein, und der Sec22- $\alpha$ Reporter wird - wie erwartet - nicht in den späten Golgi verdrängt.

Dieses Ergebnis zeigt, daß die mit Hilfe von Immunoblot-Analyse festgestellte Steigerung der Kex2p-Prozessierung des Reporters durchaus signifikant war. Es läßt sich jedoch der zeitliche Verlauf wesentlich präziser mit „,pulsechase"-Experimenten analysieren. Die Annahme, daß auch die Anwesenheit großer Mengen von Sec22p zu einer Fehllokalisation des Sec22- $\alpha$ Reporters aufgrund einer Übersättigung der Recyclingmaschinerie führt, konnte somit eindeutig bestätigt werden. Die Recyclingkompetenz von Sec22-3p scheint nicht durch die Mutation R157G beeinflußt zu werden. Im Paarungstest hatten beide Proteine keinen Einfluß auf die Fehllokalisation des Ste2-Wbp1p Reporter (siehe Abbildung 8).

Anschließend wurden alle anderen SNAREs, die im ER-Golgi Transport involviert sind, untersucht (Tabelle 2). Sec22p konnte nun nach den vorherigen Untersuchungen als Positivkontrolle für die Fehllokalisation des Sec22- $\alpha$ Reporters verwendet werden. In Abbildung 8 sind die Ergebnisse, die mit beiden Tests (Immunoblot-Analyse und ,pulse-chase"-Experiment) erhalten wurden, zusammengestellt. Abbildung 8A zeigt den Einfluß der angegebenen SNAREs bei Überproduktion auf den Sec22- $\alpha$ Reporter in der Immunoblot-Analyse im „steady-state“. Ähnlich wie bei der Überproduktion von Sec22p, tritt auch bei der Überproduktion von Sed5p eine vermehrte Kex2p-Spaltung des Sec22- $\alpha$ Reporters auf. Während eine Überproduktion von Ufe1p keinen Einfluß auf die Prozessierung des Sec22- $\alpha$ Reporters hat, scheint die Überproduktion von Bet1p die Kex2p-Spaltung sogar zu inhibieren. Im ,pulse-chase“-Experiment (Abbildung 
8B) wurde dieses Ergebnis genauer untersucht. Es zeigte sich, daß außer Sec22p auch Sed5p bei Überproduktion zu einer erheblichen Beschleunigung der Kex2pProzessierung führt. Nach 90 Minuten ,chase“-Zeit liegt der radioaktiv markierte Pool des Reporters nahezu vollständig gespalten vor. Im Gegensatz dazu hatte die Überproduktion der SNAREs Bet1p, Bos1p und Ufe1p keinen Einfluß auf die Prozessierungsgeschwindigkeit des Sec22- $\alpha$ Reporters. Die Untersuchung mit dem Paarungstest ergab, daß die Überproduktion von Sed5p auch eine Fehllokalisation des Ste2-Wbp1p Reporters zur Plasmamembran zur Folge hatte (Abbildung 8C).

Damit war ein Protein gefunden, welches bei Überproduktion in beiden hier verwendeten Testsystemen eine Fehllokalisation des Reporters verursacht.
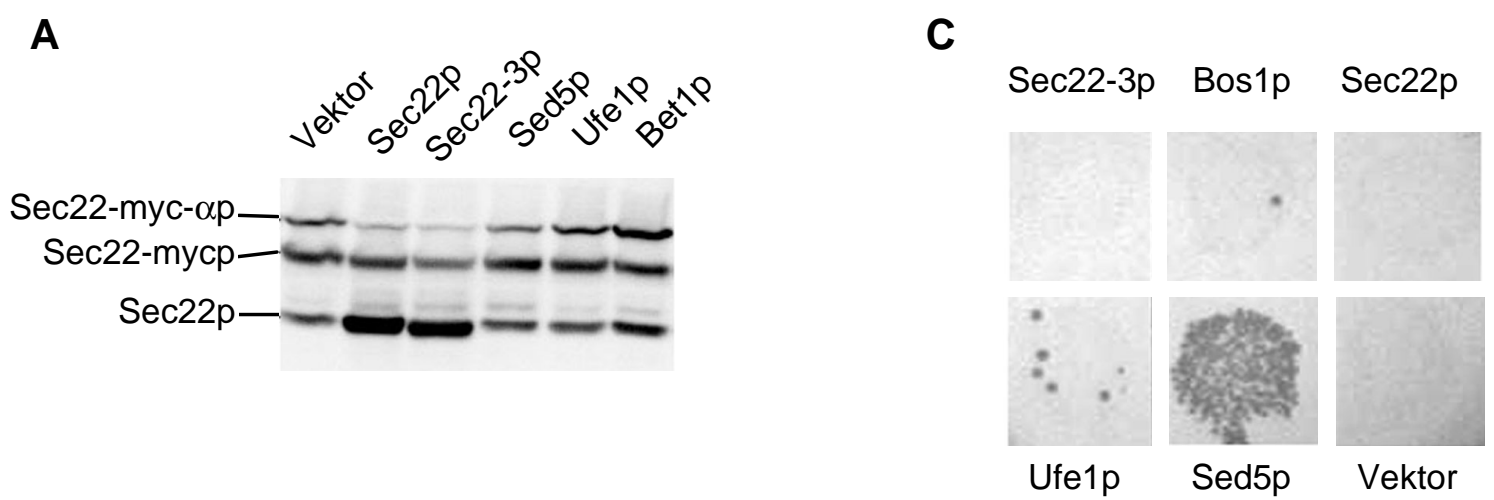

B

\begin{tabular}{|c|}
\hline Vektor \\
\hline
\end{tabular}

Sec22-myc- $\alpha$ -

Sec22-mycp-

Sec22p-

Abbildung 8: Untersuchung der Überproduktion der ER-Golgi SNAREs Sec22p, Bos1p, Bet1p, Ufe1p und Sed5p. A Durch Immunoblot-Analyse bestimmtes Ausmaß (,steady-state") der Kex2p-Prozessierung des Sec22- $\alpha$ Reporters. B Analyse der Kex2p-Spaltung des Sec22- $\alpha$ Reporters mittels "pulse-chase“-Experiment nach 0, 45 und 90 Minuten „chase“. C Ausbildung der Diploiden im Paarungstest. 


\subsection{Weitere Effekte der Überproduktion von Sed5p}

Sed5p, dem die Funktion des t-SNAREs beim anterograden ER-Golgi Transport zugeschrieben wird, wurde als Suppressor der Erd2p-Deletion (HDEL-Rezeptor) isoliert (Hardwick et al., 1992). Seine vorherrschende Lokalisation innerhalb der Zelle ist der Golgi. Es sind bereits einige Effekte beschrieben, die bei starker Überproduktion von Sed5p auftreten (Hardwick et al., 1992). Die Autoren haben jedoch mit wesentlich höheren Expressionsleveln gearbeitet. Sie verwendeten zwar auch einen „multi-copy“ Vektor, jedoch anstelle des SED5-Promotors den Triosephosphatisomerase (TPI) Promotor, der den Expressionslevel um etwa das Acht- bis Zehnfache gegenüber dem eigenen Promotor erhöht (eigene Untersuchungen). Unter diesen Bedingungen stellten sie fest, daß sich das Zellvolumen vergrößerte und die Teilungsgeschwindigkeit verlangsamte. Beide Phenomäne konnten in dieser Arbeit unter Verwendung eines „multi-copy“ Vektors mit SED5-Promotor nicht festgestellt werden. Mittels Elekronenmikroskopie konnten Hardwick et al. zeigen, daß die Zellen vermehrt vesikuläre Strukturen ausbilden. Zudem war die Effizienz des ER-Golgi Transportes reduziert, was zur Akkumulation der ER-Form der Carboxypeptidase Y (CPY) führte. Dieses letzte Resultat schien zunächst im Widerspruch zu den hier erhaltenen Ergebnissen zu stehen, da die Fehllokalisation des Sec22- $\alpha$ Reporters in den späten Golgi und des Ste2-Wbp1p Reporters zur Plasmamembran für einen erhöhten anterograden Vesikeltransport spricht.

Die hier verwendete Kombination „multi-copy“-Vektor $(2 \mu)$ und original SED5-Promotor erhöht den zellulären Expressionslevel von Sed5p etwa um das Dreifache und entspricht etwa der Hälfte des Expressionslevels von der Kombination ,single-copy“ Vektor (CEN/ARS) und TPI-Promotor (eigene Untersuchungen). Bei Verwendung von „multi-copy“-Plasmiden hat die stark variierende Kopienzahl der Vektoren zur Folge, daß die Kulturen immer eine Population von Zellen mit sehr unterschiedlichen Expressionsleveln der plasmidkodierenden Gene darstellen. Dagegen ist der entscheidende Vorteil bei der Verwendung von „single-copy“ Plasmiden, daß es zu einer gleichmäßigen Expression in allen Zelle kommt. Um eine einheitliche Expression zu erzielen, wurde SED5 mittels PCR in den ,single-copy“-Vektor pYX122, der den TPI-Promotor enthält, kloniert. Das Konstrukt kann Sed5p funktionell in dem temperatursensitiven sed5-1 Stamm ersetzen. Nach Transformation in die Hefestämme TNY26 und Ste2-4B wurden diese unter der so erhaltenen Überproduktion von Sed5p nochmals eingehend auf Transportdefekte analysiert. 
In Abbildung 9 ist das Ergebnis dieser Untersuchung dargestellt. Wie erwartet läßt sich auch hier eine Beschleunigung der Sec22- $\alpha$ Spaltung in der ,pulsechase" Analyse beobachten. Allerdings wurden in diesem Experiment die „,chase“-Zeiten etwas kürzer gewählt, um auch die Frachtmoleküle Alkalische Phosphatase (ALP) und Carboxypeptidase Y (CPY) zu untersuchen. Nach 45 Minuten „chase“ liegt der radioaktiv markierte Pool des Sec22- $\alpha$ Reporters im Gegensatz zur Kontrolle (Vektor) fast ausschließlich gespalten vor. Bei den anderen beiden analysierten Frachtmolekülen ALP und CPY ist hingegen der vesikuläre Transport zur Vakuole stark gehemmt. Im Kontrollansatz hat der gesamte radioaktiv markierte Pool von ALP und CPY bereits nach 15 Minuten die Vakuole erreicht (Ausbildung von mALP und mCPY), während bei Überproduktion von Sed5p noch nach 45 Minuten beide ER-Vorläuferformen pALP und p1CPY zu detektieren sind. Die Akkumulation von p1CPY, die bei Hardwick et al. (1992) beschrieben wurde, konnte hiermit bestätigt werden.

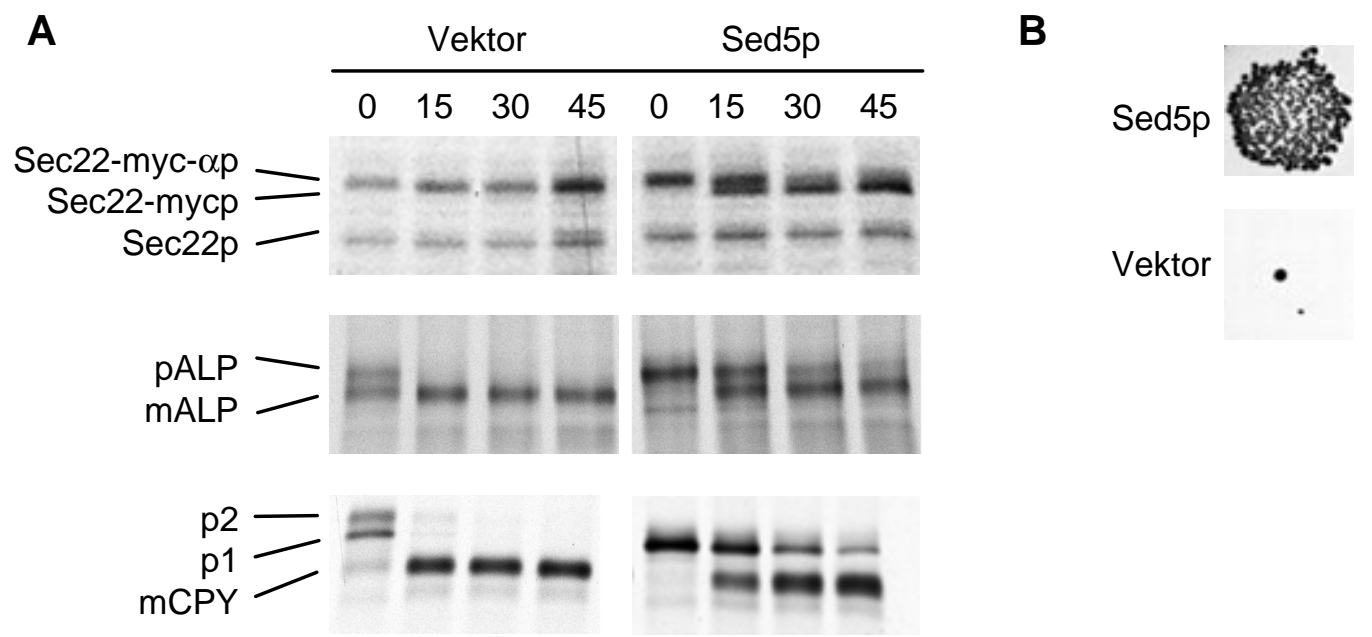

Abbildung 9: Untersuchung der Überproduktion von Sed5p vom „single-copy“ Plasmid mit TPI-Promotor. A Analyse der Kex2p-Spaltung des Sec22- $\alpha$ Reporters und der Maturierung von ALP und CPY mittels „pulse-chase“ Experiment nach 0, 15, 30 und 45 Minuten „chase“. B Ausbildung der Diploiden im Paarungstest.

\subsection{Die Suche nach Genen, deren Überexpression die negativen Effekte einer Überproduktion von Sed5p ausgleichen kann}

Es wurden Gene analysiert, die bei Überexpression die durch die Sed5p-Überproduktion verursachte Fehllokalisation des Sec22- $\alpha$ Reporters bzw. des 
Ste2-Wbp1p Reporters wieder aufheben können. Diese Gene könnten dies anhand verschiedener Mechanismen bewerkstelligen: 1) Das von ihnen kodierte Proteinprodukt bindet an Sed5p, so daß es seine negative Wirkung nicht entfalten kann. 2) Das Protein stimuliert den anterograden bzw. retrograden ER-Golgi Transport und gleicht somit den durch Sed5p hervorgerufenen Transportdefekt aus. 3) Das Protein bindet selektiv an Sec22p bzw. Ste2-Wbp1p und führt diese vom Golgi zum ER zurück. 4) Das Protein verlangsamt den ER-Export und somit auch die Fehllokalisation der beiden Reporter.

Es wurden hauptsächlich Gene untersucht, von denen bereits bekannt war, daß sie für Proteine kodieren, die mit Sed5p interagieren und im ER-Golgi Transport involviert sind. Für diese Experimente wurden SED5 und ein jeweils zweites Gen gemeinsam in denselben „,multi-copy“-Vektor kloniert, um zu gewährleisten, daß pro Zelle stets die gleiche Kopienanzahl der beiden Gene vorhanden ist. Die so erhaltenen Konstrukte wurden im Paarungstest auf die Fehllokalisation des Ste2-Wbp1p Reporters und im ,pulse-chase“-Experiment auf die Fehllokalisation des Sec22- $\alpha$ Reporters getestet. In Tabelle 4 ist eine Zusammenfassung dieser Experimente dargestellt.

\begin{tabular}{ccc}
\hline $\begin{array}{c}\text { überproduzierte } \\
\text { Proteine }\end{array}$ & $\begin{array}{c}\text { Fehllokalisation } \\
\text { von Ste2-Wbp1p }\end{array}$ & $\begin{array}{c}\text { Fehllokalisation } \\
\text { von Sec22- } \alpha\end{array}$ \\
\hline \hline Sed5p & ++ & ++ \\
Sed5p, Sly1p & + & ++ \\
Sed5p, SLY1-20p & ++ & ++ \\
Sed5p, Sec24p & + & ++ \\
Sed5p, Ufe1p & + & ++ \\
Sed5p, Sec22p & ++ & nicht getestet \\
Sed5p, Sec22-3p & - & nicht getestet \\
Sed5p, Sfb2p & - & - \\
Sed5p, Sfb3p & ++ & ++ \\
Sec23p & - & - \\
\hline
\end{tabular}

Tabelle 4: Übersicht über die überproduzierten Proteine und ihre Auswirkungen auf die Fehllokalisation des Ste2-Wbp1p Reporters und des Sec22- $\alpha$ Reporters, welche mit dem Paarungstest bzw. in „pulse-chase“-Experimenten untersucht wurden.

Bei der Analyse der Fehllokalisation des Ste2-Wbp1p Reporters konnte gezeigt werden, daß einige der hier untersuchten Proteine den Sed5p-Überproduktions- 
effekt reduzieren. Das zur Sec1-Familie gehörende Protein Sly1p, das an Sed5p bindet und es damit in einer inaktiven Konformation hält, kann die Paarungseffizienz der Zellen zwar nicht reduzieren, jedoch ist eine eindeutige Inhibierung der Fehllokalisation des Ste2-Wbp1p Reporters unter der Verwendung von SLY1-20p zu beobachten. Unter der Annahme der Bildung eines Komplexes zwischen Sly1p und Sed5p, scheint das mutierte Protein in vivo stärker an Sed5p zu binden. Das dominante Mutantengen SLY1-20 wurde bei der Suppressorsuche der YPT1-Deletion gefunden (Dascher et al., 1991). Vergleichbar ist die gleichzeitige Überexpression von SEC22 und SED5. Während das mutierte Protein Sec22-3p die durch Überproduktion von Sed5p hervorgerufene Paarung aufheben kann, zeigt das Wildtyp-Sec22p keine Veränderung im Paarungstest. Alle gerade beschriebenen Proteine reduzierten jedoch nicht die Fehllokalisation des Sec22- $\alpha$ Reporters.

Das einzige hier untersuchte Protein, das in beiden Reportersystemen für eine Aufhebung der Fehllokalisation sorgte, war Sfb2p (Abbildung 10). Sfb2p und Sfb3p sind homolge Proteine zu Sec24p, einem Bestandteil der COPII-Hülle. Auch Sfb2p und Sfb3p können wie Sec24p mit Sec23p einen stabilen Komplex ausbilden. Im Paarungstest zeigte außer Sfb2p auch Sec24p eine Inhibierung der Fehllokalisation des Ste2-Wbp1p Reporters, während die Überproduktion von Sfb3p zusammen mit Sed5p weiterhin zur Ausbildung von Diploiden führte (Abbildung 10B). Sec24p, Sfb2p und Sfb3p binden in vitro an Sed5p. Der primäre Effekt der Überproduktion von Sed5p könnte deshalb darin bestehen, daß sie zu einer Störung des Gleichgewichts zwischen Sec24p, Sfb2p, Sfb3p und Sec23p führt und die Menge an freiem, nicht Sec24/Sfb2/Sfb3p-gebundenem Sec23p erhöht. Es ist bekannt, daß eine Überproduktion von Sec23p toxisch sein kann (Kurihara et al., 2000). Deshalb wurde getestet, ob die Überproduktion von Sec23p ähnlich wie die von Sed5p alleine bereits zu einer Fehllokalisation beider Reporter führen kann. Dies war jedoch nicht der Fall.

In Abbildung 10A sind die ,pulse-chase“-Untersuchungen der Überproduktion von Sed5p in Kombination mit Sec24p, Sfb2p und Sfb3p abgebildet. Da in diesem Experiment „multi copy“-Plasmide verwendet wurden, also eine dreifache Überproduktion von Sed5p, sind die Transportdefekte von Sec22- $\alpha$, CPY und ALP etwas schwächer ausgeprägt als bei der achtfachen Überproduktion mit Hilfe des TPI-Promotors in Abbildung 9. Nach 45 Minuten ist bei alleiniger Sed5p-Überproduktion die radioaktive Form des Sec22- $\alpha$ Reporters zur Hälfte durch die Kex2-Protease gespalten. Dasselbe Ergebnis wurde auch bei der gleichzeitigen Überproduktion von Sec24p bzw. Sfb3p erhalten. Wird jedoch Sed5p zusammen mit $\mathrm{Sfb} 2 \mathrm{p}$ überproduziert, so liegt nach 45 Minuten der 
Sec22- $\alpha$ Reporter genau wie im Kontrollexperiment (Vektor) nahezu ungespalten vor. Abbildung 10C zeigt, daß dieses Phänomen nicht Ursache einer reduzierten Sed5p-Expression ist, denn die Expression von Sed5p bleibt auch bei Überproduktion von Sfb2p konstant, was durch Immunoblot-Analyse gezeigt wurde.

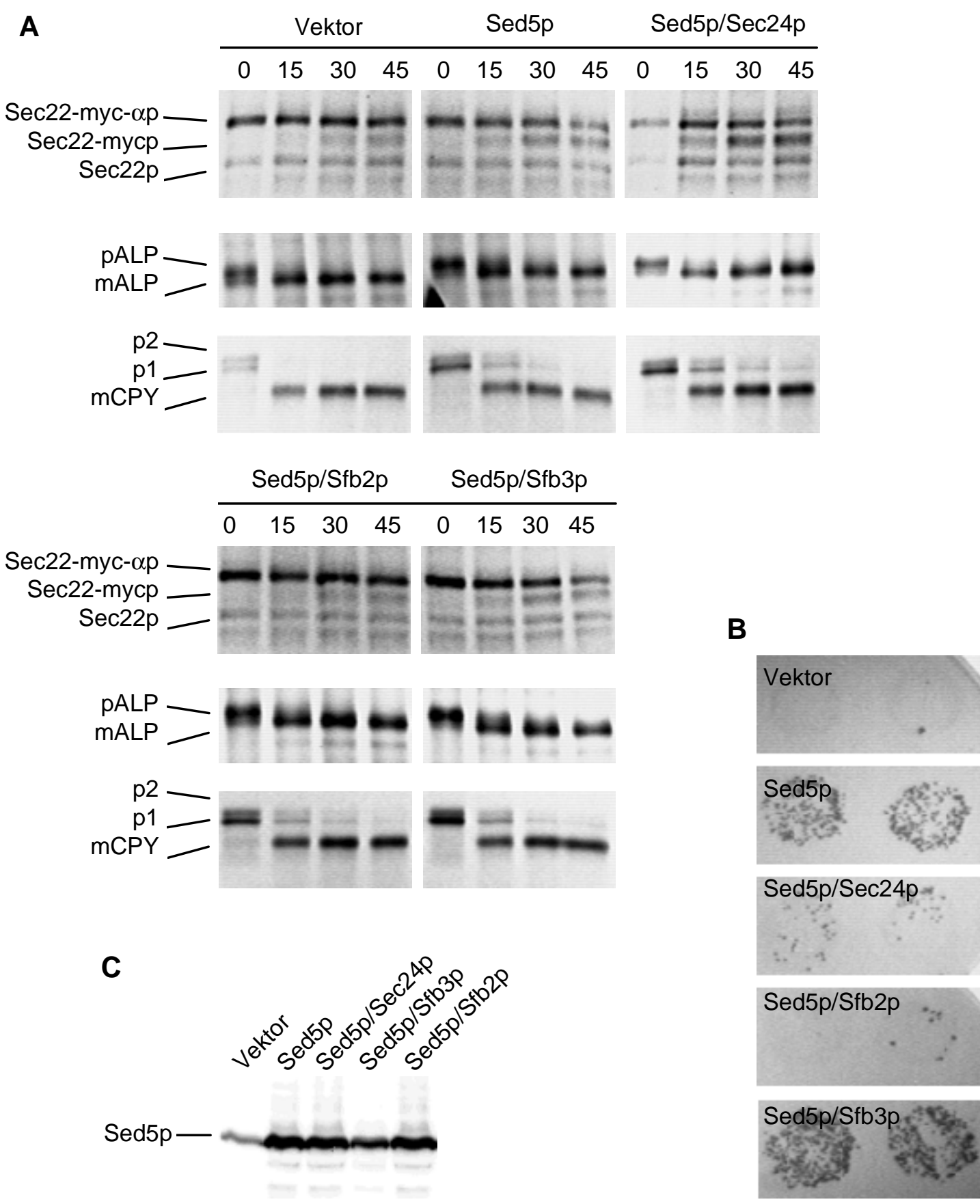

Abbildung 10: Untersuchung der Überproduktion von Sed5p in Kombination mit Sec24p, Sfb2p und Sfb3p. A Analyse der Kex2p-Spaltung des Sec22- $\alpha$ Reporters und der Maturierung von ALP und CPY mittels „pulse-chase“ Experiment nach 0, 15, 30 und 45 Minuten „chase“. B Ausbildung der Diploiden im Paarungstest $\mathbf{C}$ Analyse des Expressionlevels von Sed5p der Transformanden im Immunoblot-Analyse mit anti-Sed5p-Antikörper 
Somit war es gelungen, ein Protein zu finden, das die durch Sed5p Überproduktion hervorgerufenen „Recycling“-Defekte von Sec22- $\alpha$ und Ste2-Wbp1p aufheben konnte: $\mathrm{Sfb} 2 \mathrm{p}$.

\subsection{Welche Funktion hat Sfb2p?}

Sfb2p stellt wie Sfb3p ein nicht essentielles homologes Protein zu dem COPIIHüllprotein Sec24p dar. Es wird vermutet, daß es zusammen mit Sec23p eine neue Form der COPII-Vesikelhülle bildet. Folgende Ergebnisse wurden bis jetzt in verschiedenen Arbeitsgruppen zur Funktion von Sfb2p gewonnen (Peng et al., 2000; Pagano et al., 1999, Kurihara et al., 2000):

- Sfb2p bildet einen Komplex mit Sec23p aus. Der Sfb2p/Sec23p-Komplex kann in vitro zusammen mit Sar1p und dem Sec31p/Sec13p-Komplex Vesikel von Mikrosomen-Membranen abschnüren.

- Die so erhaltenen Vesikel besitzen dieselbe Dichte wie COPII-Vesikel und enthalten die v-SNAREs Sec22p und Bet1p als Frachtmoleküle. Von allen Proteinen der Syntaxin-Familie in Hefe bindet nur Sed5p in vitro an Sfb2p.

- Die Überproduktion von Sfb2p kann zwar den Wachstumsdefekt der temperatursensitiven Mutante sec24-11 suppremieren, aber nicht die Letalität einer Deletion von SEC24.

- In einem $4 s f b 2$ Stamm lassen sich keine Transportdefekte von CPY, ALP, Invertase und Gas1p feststellen. Dies ist jedoch in der Doppelmutante sec24-11/4sfb2 der Fall.

- Interessanterweise kann der Wachstumsdefekt der sec22-3 Mutante durch Überproduktion von $\mathrm{Sfb} 2 \mathrm{p}$ aufgehoben werden. Ein weiterer genetischer Zusammenhang zwischen Sfb2p und Sec22p besteht darin, daß eine Doppelmutante aus $\Delta s f b 2$ und $\sec 22-3$ nicht lebensfähig ist.

In dieser Arbeit wurde gefunden, daß die Überproduktion von $S f b 2 p$ die durch Sed5p-Überproduktion ausgelösten Transportdefekte bezüglich des Ste2-Wbp1p Reporters und des Sec22- $\alpha$ Reporters aufheben kann. Wenn die Überproduktion von Sfb2p tatsächlich einen Einfluß auf die Lokalisation des Sec22- $\alpha$ Reporters hat, nämlich seine Retention im frühen Golgi (reduzierte Kex2-Prozessierung), würde man erwarten, daß eine Deletion des Gens zu einem gegenläufigen Effekt führt (Zunahme der Kex2-Spaltung). Abbildung 11A zeigt die ImmunoblotAnalyse des Sec22- $\alpha$ Reporters im „steady-state“ in einem Wildtyp-, $\Delta s f b 2-$ und $\Delta s f b 3$-Stamm mit Hilfe von anti-Sec22p-Antikörper. Im Vergleich zum Wildtypstamm, bei dem etwa $60 \%$ Kex2p-Spaltung erfolgt, liegt im $\Delta s f b 2$-Stamm 
$80 \%$ des Sec22- $\alpha$ Reporter prozessiert vor. Im $\Delta s f b 3-$ Stamm scheint die Kex2pProzessierung sogar inhibiert zu werden, nur $20 \%$ des Reporters sind durch die Kex2-Protease gespalten worden. Die erhöhte Kex2p-Prozessierung könnte jedoch auch durch die Fehllokalisation der Protease in das ER bedingt sein. Deswegen wurde die Lokalisation von Sec22p zusätzlich durch das fluoreszierende Fusionsprotein GFP-Sec22p überprüft (Abbildung 11B), wodurch die Lokalisation von Sec22p in vivo bestimmt werden kann (vgl. Kap. 4.6).

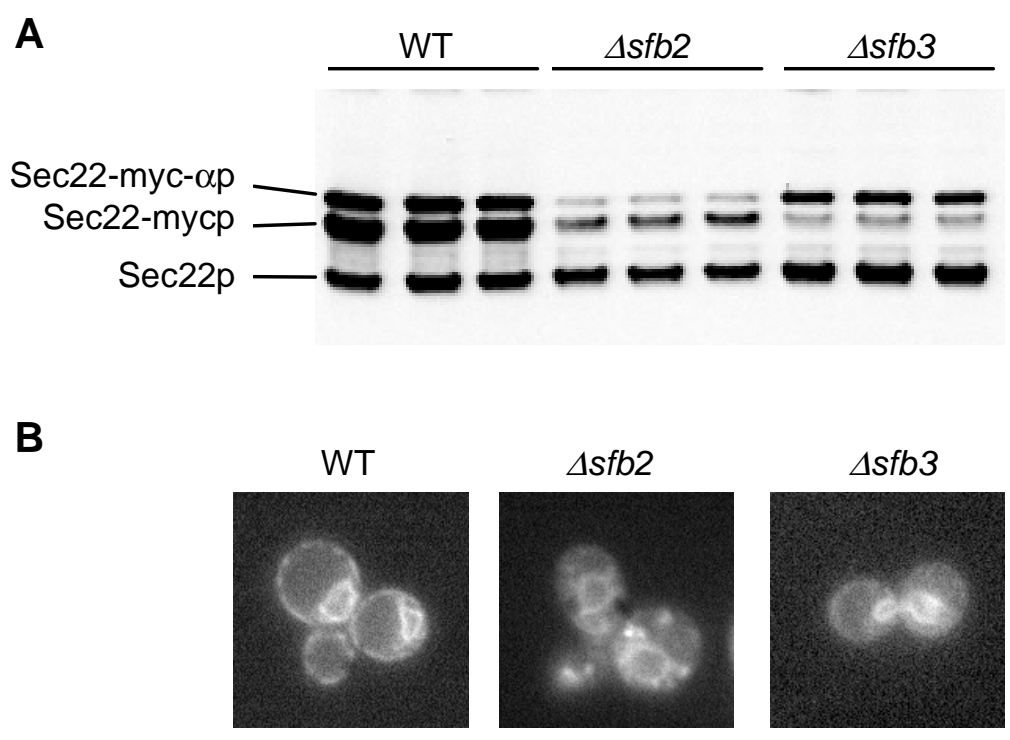

Abbildung 11: Die Stämme TNY14, TNY116 und TNY118 wurden entweder mit dem Plasmid pWBAcyc $\alpha$ oder mit pTN159 transformiert. A Analyse der Kex2p-Spaltung des Sec22- $\alpha$ Reporters durch Immunoblot-Analyse mit anti-Sec22-Antikörper. B Lokalisation des fluoreszierenden GFP-Sec22p Fusionproteins.

Im Wildtyp- sowie im $4 s f b 3$-Stamm befand sich GFP-Sec22p überwiegend in perinukleären ER-Strukturen und peripheren ER-Strukturen unterhalb der Plasmamembran, während mit diesem Fusionsprotein im $\Delta s f b 2$-Stamm verstärkt punktförmigen Golgi-Strukturen angefärbt wurden. Diese vermehrte GolgiLokalisation des GFP-Sec22p bestätigt die Annahme einer Fehllokalisation des Sec22p und nicht der Kex2-Protease, was somit zu einer gesteigerten Kex2pProzessierung des Sec22- $\alpha$ Reporters im späten Golgi führte (Abbildung 11A). 


\subsection{GFP-Sec22p - der in vivo-Reporter}

Eine relativ neue Methode, um dynamische Prozesse in der lebenden Zelle zu untersuchen, ist die Visualisierung von Proteinen durch die Fusion an das grün fluoreszierende Protein (GFP). GFP ist ein $27 \mathrm{kDa}$ Protein, stammt aus der Qualle Aequorea victoria und emittiert ohne jegliche Kofaktoren grünes Licht, nach Absorbtion von blauem Licht. Da GFP die Funktion der meisten Proteine nicht beeinflußt, wurden GFP-Fusionsproteine bereits in zahlreichen Untersuchungen als Reporterproteine in lebenden Zellen eingesetzt (Übersicht bei Lippincott-Schwartz et al., 1998).

In der Arbeitsgruppe von H. R. B. Pelham wurden bereits erfolgreich GFP-SNARE-Fusionsproteine (GFP-Sed5p und GFP-Sft1p) in Hefe für Untersuchungen eingesetzt. Ein Ergebnis dieser Experimente war, daß GFP-Sed5p zwischen Golgi und ER zirkuliert (Wooding und Pelham, 1998). In der vorliegenden Arbeit wurde Sec22p mit GFP fusioniert. Die Klonierung erfolgte mittels PCR in das Plasmid pUG36, das bereits GFP unter der Kontrolle des Methionin reprimierbaren MET25-Promotors enthält. Das exprimierte chimäre Protein ist funktionell, da es den temperatursensitiven Defekt einer sec22-3 Mutante aufheben kann. Ziel war es, die Lokalisation von Sec22p, die bisher nur in fixierten Zellen hauptsächlich mit Hilfe des Sec22- $\alpha$ Reporters untersucht wurde, in lebenden Zellen verschiedener Hefemutanten zu bestätigen. Man kann somit Artefakte durch die Fixierung der Zellen, die Zellwandentfernung und die Permeabilisierung durch Detergentien vermeiden.

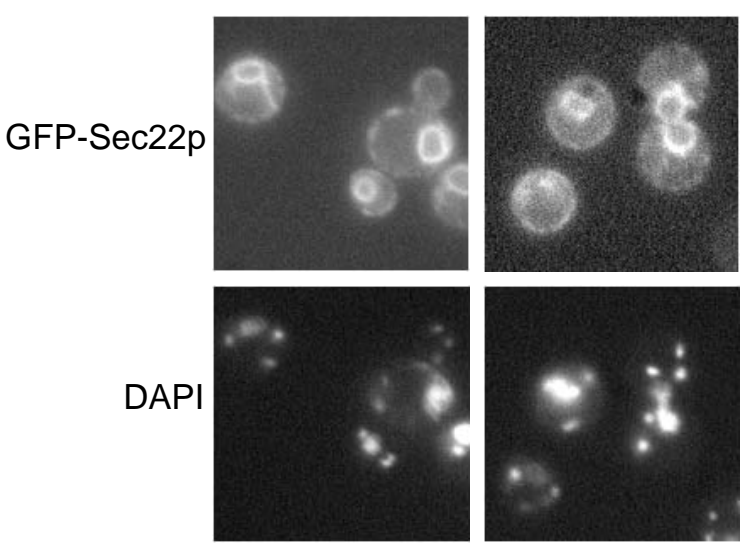

Abbildung 12: Fluoreszenzmikroskopie von Wildtypzellen, die GFP-Sec22p exprimieren. Die Lokalisation des Zellkerns wurde durch die DAPI-Anfärbung der DNA überprüft. 
Abbildung 12 zeigt eine typische ER-Lokalisation des Fusionproteins in Wildtypzellen. Es stellte sich heraus, daß die DAPI-Anfärbung der DNA im Zellkern lebender Zellen im Gegensatz zu fixierten und perforierten Zellen in der Immunfluoreszenz sehr ineffizient war. In unfixierten Zellen ließ sich häufig nur die mitochondriale DNA markieren. Deswegen wird diese Anfärbung in den übrigen Abbildungen nicht mehr gezeigt. Bei den fluoreszierenden ringförmigen Strukturen handelt es sich immer um das perinukleäre ER, in dem GFP-Sec22p lokalisiert ist.

Abbildung 13A zeigt Fluoreszenzaufnahmen einzelner Querschnitte durch die Zellen, die mit einem Raster-Laser-Mikroskop aufgenommen wurden. Diese Technik ermöglicht eine bedeutend bessere Auflösung der zellulären Strukturen. Mit Hilfe dieser Technik sind sogar die netzartiken ER-Strukturen unterhalb der Plasmamembran zu erkennen (Bild 1-3). Das ER um den Zellkern zeigt sich zunächst als ein leuchtender Fleck (Bild 1-5), der sich langsam zu einem Ring um den Zellkern öffnet (Bild 6 und 7) und anschließend wieder schließt (Bild 11 und 12). Abbildung 13B zeigt die durchschnittliche Intensität der Überlagerung der Schnitte. Diese wird ermittelt, indem jeweils nur der hellste Punkt der durch Übereinanderlegen der Bilder entstehenden Z-Achse auf die X-Y-Ebene projiziert wird. Dieses Bild entspricht optisch etwa einer Aufahme an einem nicht konfokalen Mikroskop.

A
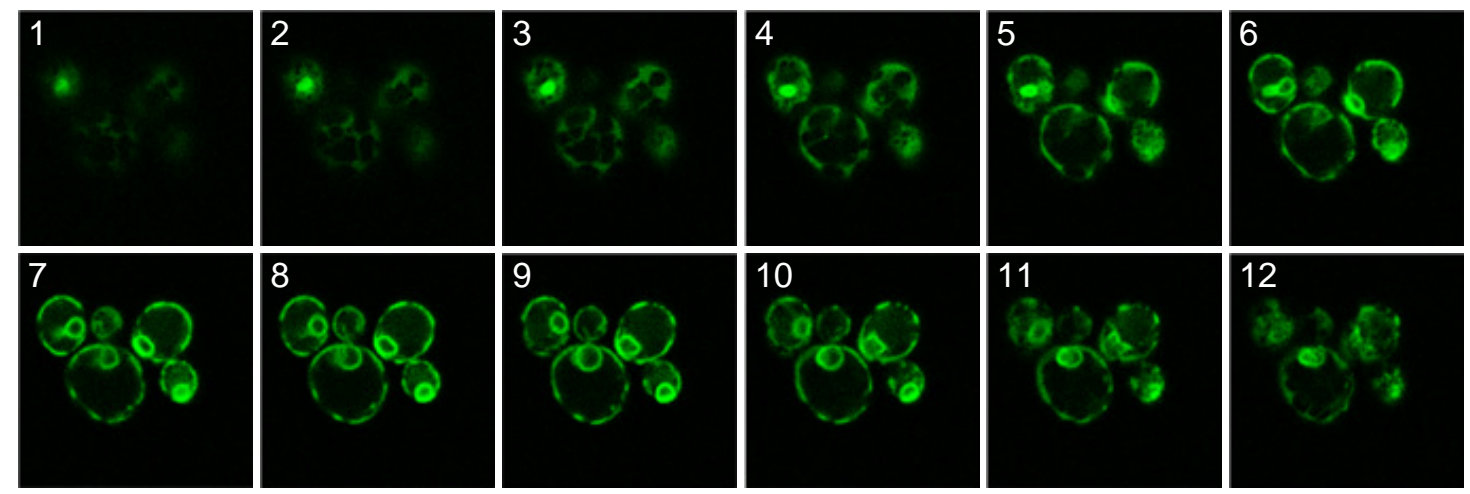

B

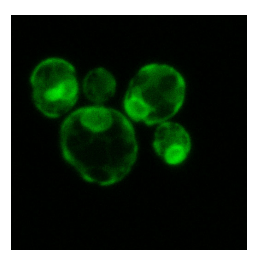

Abbildung 13: Analyse der Fluoreszenz von GFP-Sec22p im Wildtypstamm im Raster-LaserMikroskop. A Querschnittsaufnahmen durch die Zellen. B Durchschnitt der Überlagerung der Querschnitte. 
Wenn der GFP-Sec22p Reporter wie der Sec22- $\alpha$ Reporter zwischen ER und Golgi zirkuliert, müsste er sich bei einem Golgi-ER-Block in COPI-Mutanten im Golgi anreichern. Für diese Untersuchung wurde GFP-Sec22p in verschiedenen COPI-Mutanten exprimiert. Das Ergebnis ist in Abbildung 14 abgebildet. Die jeweiligen Stämme wurden bei $25^{\circ} \mathrm{C}$ und nach einer einstündigen Inkubierung bei $30^{\circ} \mathrm{C}$ im Mikroskop untersucht. Die Aufnahmen zeigen, daß sich im Gegensatz zum Wildtypstamm bei den COPI-Mutanten sec27-1 und ret1-2 schon bei $25{ }^{\circ} \mathrm{C}$ eine vermehrte punktförmige Lokalisierung des GFP-Sec $22 \mathrm{p}$ zeigt. Dieser Effekt wird besonders im sec27-1 Stamm durch die Temperaturerhöhung verstärkt. Im ret1-2 Stamm wird bei $30{ }^{\circ} \mathrm{C}$ sogar die Vakuole angefärbt. Der Wildtypstamm zeigt bei beiden Temperaturen ER-Färbung.

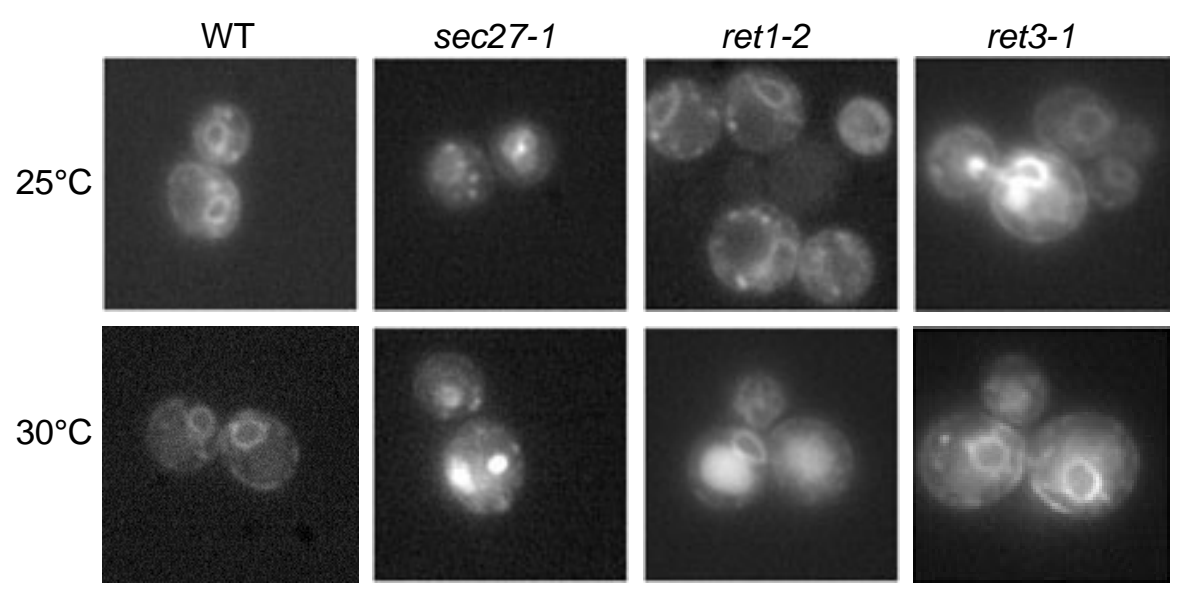

Abbildung 14: Fluoreszenzmikroskopie von Wildtypzellen und den COPI-Mutanten sec27-1, ret1-2 und ret3-1, die GFP-Sec22p exprimieren. Die Zellen wurden bei $25^{\circ} \mathrm{C}$ oder nach einer Inkubierung von einer Stunde auf $30^{\circ} \mathrm{C}$ im Mikroskop untersucht.

Besonders deutlich wurde die Anreicherung des GFP-Sec22p Reporters in punktförmigen Golgi-Strukturen, wenn das Fluoreszenzsignal mit dem Raster-LaserMikroskop analysiert wurde. Als Beispiel hierfür ist in Abbildung 15 die Lokalisation von GFP-Sec22p im SNARE-Mutantenstamm ufe1-1, der wie die COPIMutantenstämme für einen Golgi-ER Block sorgt, gezeigt. Der temperatursensitive Stamm zeigte im Gegensatz zum isogenen Wildtypstamm bereits bei der hier verwendeten Temperatur von $25^{\circ} \mathrm{C}$ eine eindeutige Fehllokalisation des GFP-Sec22p Reporters in den Golgi. Jede punktförmige Golgi-Struktur war nur in zwei bis drei aufeinander folgenden Querschnitten zu sehen. Da alle $0.2 \mu \mathrm{m}$ ein Querschnitt durch die Zellen aufgenommen wurde, läßt sich ihre Größe auf ungefähr $0.4 \mu \mathrm{m}^{2}$ schätzen. Dies zeigt, daß diese Strukturen bezüglich des 
Fluoreszenzsignals eine kugelförmige Raumstruktur einnehmen und keine langen zylinderförmigen Strukturen ausbilden, die in der konfokalen Schnittebene ebenfalls als Punkt erscheinen, aber durch die gesamte Zelle reichen.
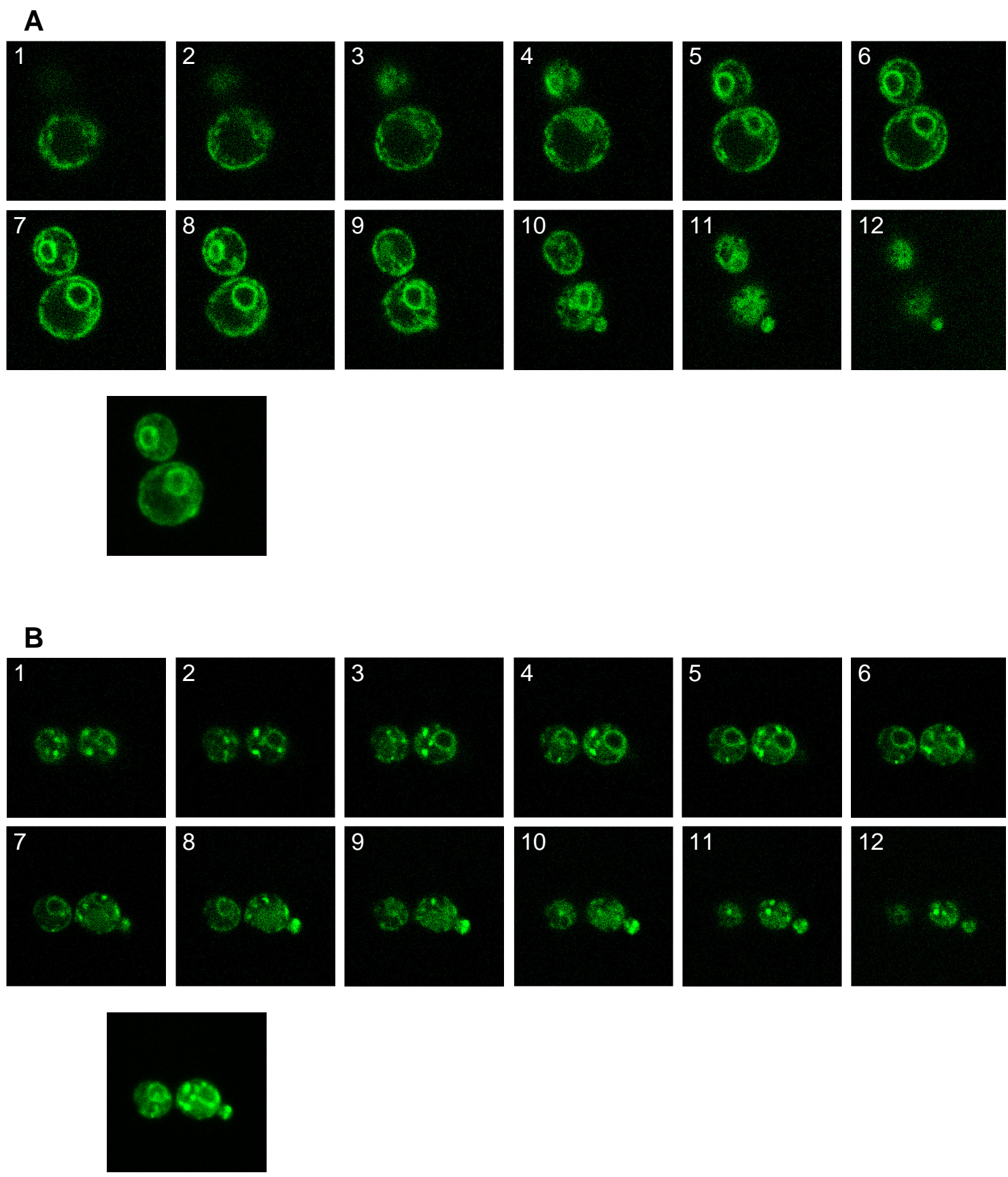

Abbildung 15: Analyse der Fluoreszenz von GFP-Sec22p im UFE1-Wildtypstamm MLY100 (A) und im ufe1-1-Mutantenstamm MLY101 (B) im Raster-Laser-Mikroskop bei $25^{\circ} \mathrm{C}$. Es sind jeweils die Querschnittsaufnahmen durch die Zellen und der Durchschnitt der Überlagerung der Querschnitte gezeigt. 
Zusammenfassend kann festgehalten werden, das alle Ergebnisse, die zuvor mit dem Sec22- $\alpha$ Reporter erhalten wurden, mit dem GFP-Sec22p Reporter in vivo bestätigt wurden. Er ist also ein äußerst nützliches Werkzeug, um in zukünftigen Projekten dynamische Recyclingprozesse in lebenden Zellen zu analysieren.

\subsection{Die Suche nach direkten Bindungspartnern von Sec22p mittels Zwei- Hybrid-System}

Mit Hilfe des Zwei-Hybrid-Systems können Protein-Protein-Interaktionen untersucht werden (Fields und Song, 1989). Es basiert auf dem generellen strukturellen Aufbau von Transkriptionsfaktoren. Diese besitzen zwei Domänen, eine DNA bindenen Domäne und eine transkriptionsaktivierende Domäne. Beide sind allein nicht funktionell, können jedoch in Nähe zueinander gebracht einen aktiven Transkriptionsfaktor rekonstituieren. Es werden zwei unabhängige chimäre Proteine generiert: Das Protein X wird an die Bindedomäne (BD) und das Protein $\mathrm{Y}$ an die Aktivierungsdomäne (AD) von Gal4 fusioniert. Die beiden Fusionsproteine werden in Hefe exprimiert. Kommt es zu einer Interaktion von Protein $\mathrm{X}$ mit Protein Y, werden die Gal4-AD und die Gal4-BD angenähert und der nun aktive Transkriptionsfaktor kann die Transkription eines zuvor in den Hefestamm eingebrachten Reportergens (z. B. HIS3, lacZ) aktivieren (Abbildung 16). Beide Reportergene stehen unter der Kontrolle der Aktivierungssequenz (UAS=upstream activator sequence) des Galktose regulierten GAL1-Gens. Mit diesem System können auf sehr einfache Weise Protein-Protein-Interaktionen von zwei spezifischen Proteinen untersucht werden, die man genauer charakterisieren möchte. Außerdem eignet sich diese Methode für die Suche neuer ProteinProtein-Interaktionen durch Verwendung einer c-DNA-Genbank, die mit der Gal4-AD fusioniert wurde, und eines Köderproteins, das mit der Gal4-BD fusioniert wurde.

In dieser Arbeit wurde das beschriebene System mit dem Gal4-Transkriptionsfaktor verwendet. Als Köderprotein diente die zytosolische Domäne von Sec22p. Die dafür kodierende DNA-Sequenz wurde mittels PCR amplifiziert und in den Vektor pAS2 kloniert, der bereits den Genabschnitt für die Gal4 BD enthält. Das Plasmid wurde in den Hefestamm Y190 transformiert, der so modifiziert ist, daß er die Analyse der Transkription der Reportergene HIS3 und lacZ erlaubt. Nachdem überprüft wurde, daß das generierte Fusionsprotein tatsächlich exprimiert wurde und es selbst keine Aktivierung der Transkription hervorruft, wurde in den Hefestamm zusätzlich eine Hefe-c-DNA-Genbank transformiert. Es 
wurden zwei unterschiedliche Genbanken verwendet. Eine wurde von H. Matern in unserer Arbeitsgruppe unter Verwendung des Vektors pACTII hergestellt; die zweite Genbank stammt von Dr. B. Horazdovsky (Univ. von Dallas, USA) und wurde in den Vektor pGAD-GH kloniert. Beide Genbanken enthalten die AD von Gal4. Es wurden insgesamt etwa 500.000 Transformanden zunächst auf die Expression des HIS3-Genprodukts durch einen Wachstumstest und anschließend auf die Anwesenheit der $\beta$-Galaktosidase, das Genprodukt des lacZ-Reportergens, getestet (vgl. Kap. 3.6).

A

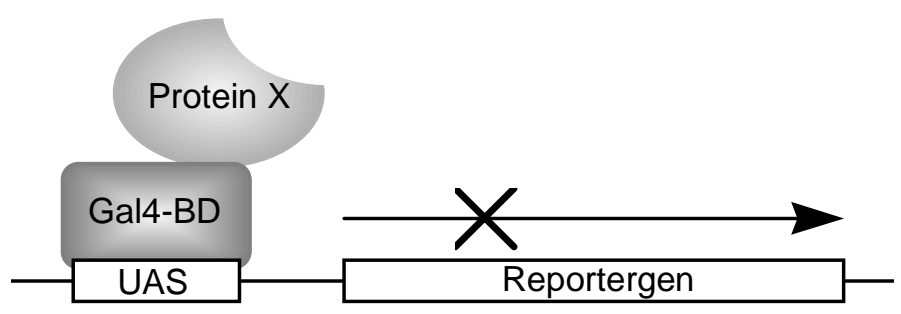

B

Protein $Y$

Gal4-AD
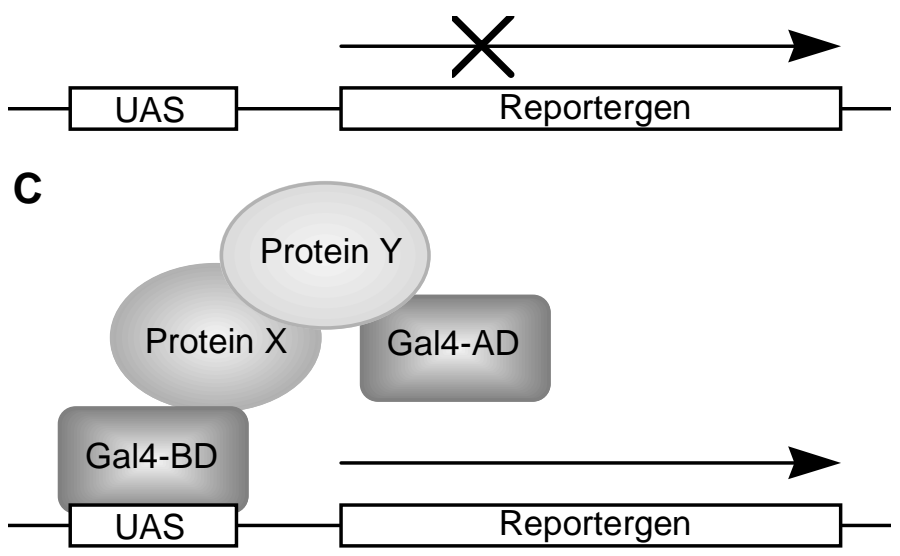

Abbildung 16: Prinzip des Zwei-Hybrid-Systems. Die beiden Fusionsproteine bestehend aus der Bindedomäne des Transkriptionsfaktors Gal4 (Gal4-BD) und einem Protein X oder aus der Aktivierungsdomäne des Transkriptionsfaktors Gal4 (Gal4-AD) und einem Protein Y werden in Hefe exprimiert. A In Abwesenheit von Gal4-AD interagiert Gal4-BD mit der DNA bindenden Region des Transkriptionsfaktors (UAS), kann aber die Transkription des Reportergens (z. B. HIS3, lacZ) nicht initiieren. B Gal4-AD kann ebenfalls in Abwesenheit von Gal4-BD nicht die Transkription aktivieren. $\mathbf{C}$ Die Interaktion von Protein $\mathrm{X}$ mit Protein $\mathrm{Y}$ bewirkt die Rekonstitution des aktiven Transkriptionsfaktors Gal4 und damit die Transkription des Reportergens. 
Zwölf Transformanden wurden selektiert, aus denen die Genbankplasmide isoliert wurden. Die Genbankplasmide wurden erneut in den Hefestamm Y190 transformiert, der das Köderprotein exprimierte. Drei Genprodukte der Genbankplasmide zeigten reproduzierbar nur in Anwesenheit der zytoplasmatischen Domäne von Sec22p eine Aktivierung der Transkription von lacZ und damit die Expression der $\beta$-Galactosidase.

Durch Sequenzierung der DNA und anschließendem Vergleich der Sequenz mit der Hefegenomdatenbank SGD, konnten die zugehörigen Gene und deren Genprodukte bestimmt werden. Dabei zeigte sich, daß zwei der drei Klone identisch waren. Es handelte sich um ein Fragment, das für die C-terminale Domäne der Acetyl-CoA-Carboxylase (Acc1p) in Hefe kodiert. Der dritte Klon kodierte für Map1p, eine Methioninaminopeptidase. Map1p spaltet N-terminale Methionine von Proteinen ab, die bestimmte Signalsequenzen tragen. Auch im Fall von Sec22p wird das Startmethionin der Translation nach der Synthese abgespalten. Da diese Interaktion bezüglich vesikulärer Transportprozesse als nicht relevant erschien, wurde sie nicht weiter untersucht. Weitaus interessanter erschien die Interaktion von Sec22p mit der C-terminalen Domäne von Acc1p. Sie wurde eingehender studiert.

\subsubsection{Acc1p}

ACC1 kodiert für die Acetyl-CoA Carboxylase (Acc1p) in Hefe und sorgt für die biotinabhängige Produktion von Malonyl-CoA aus Acetyl-CoA (Abbildung 17).
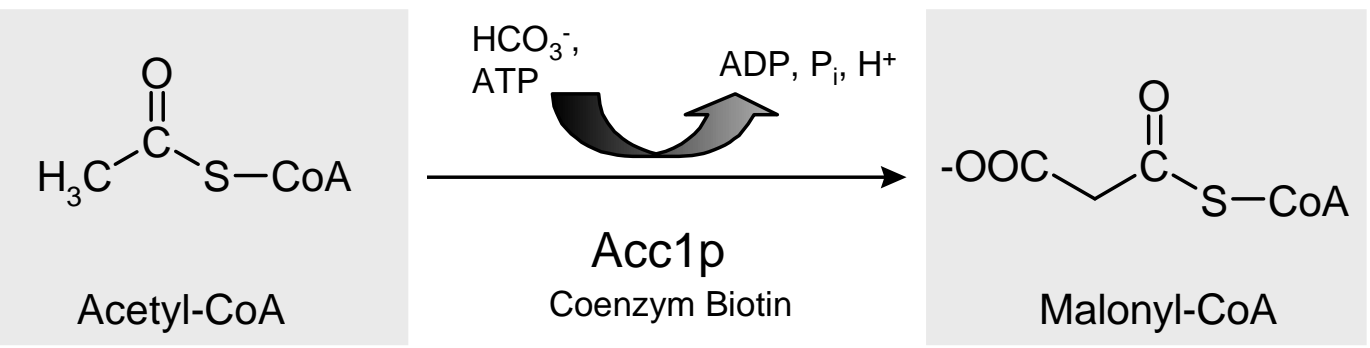

Abbildung 17: Von der Acetyl-CoA-Carboxylase (Acc1p) katalysierte Reaktion.

Da Malonyl-CoA der zentrale Baustein ist, mit dem Fettsäuren im Zytoplasma bis $\mathrm{zu}$ einer Kettenlänge von $\mathrm{C}_{16}$ neusynthetisiert und am ER zu langkettigen Fettsäuren bis zu einer Kettenlänge von $\mathrm{C}_{26}$ verlängert werden, stellt seine Synthese durch die Acc1p den ersten und limitierenden Schritt der Fettsäurebiosynthese 
dar. Aufgrund dieser zentralen Rolle im Fettaäurestoffwechsel ist es naheliegend, daß es sich bei der Acetyl-CoA Carboxylase um ein essentielles Enzym der Hefe handelt. Die subzelluläre Lokalisation des Acc1p, die früher als ausschließlich zytosolisch galt, wurde erst kürzlich in der Arbeitsgruppe von S. D. Kohlwein genauer untersucht (Ivessa et al., 1997). Dabei stellte sich heraus, daß ein Teil des Acc1p an der zytoplasmatischen Seite des ERs lokalisiert ist. Die Autoren mutmaßten, daß der C-terminale Abschnitt der Acc1p, der eine mögliche $\alpha$-helikale Struktur enthält, mit einem fiktiven Rezeptor auf der ER-Membranoberfläche interagiert.

A

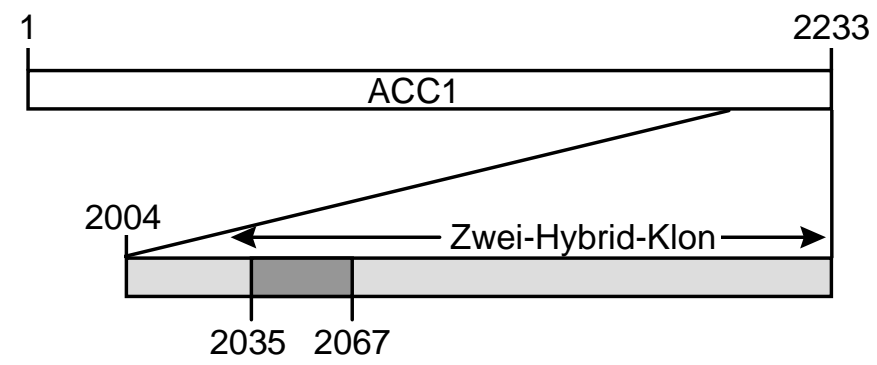

B

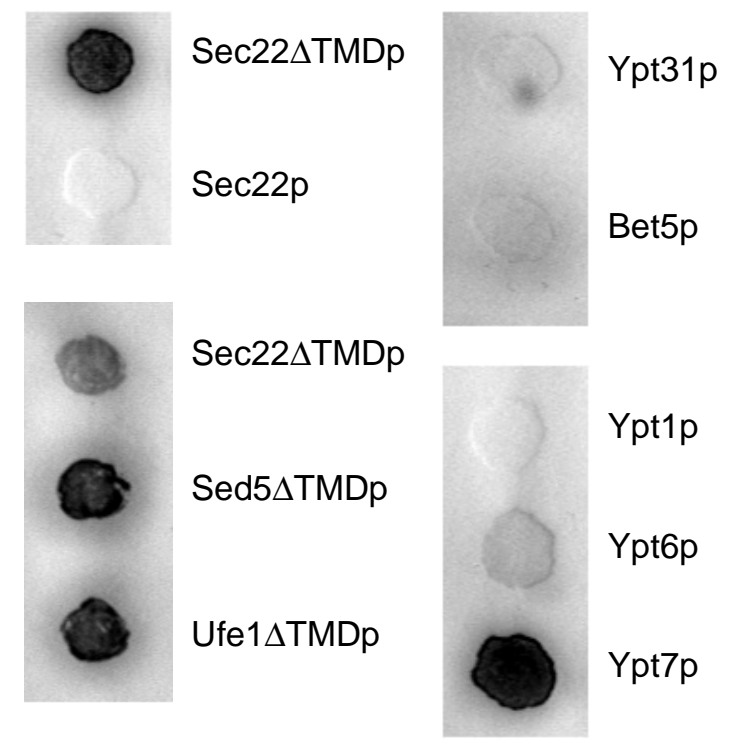

Abbildung 18: A Schematische Darstellung des in der Genbank gefundenen Acc1p-Fragments. Der Klon kodiert für den C-Terminus der Acc1p (AS 2004-2233), der eine $\alpha$-helikale "coiled-coil“ Domäne enthält (AS 2035-2067). B Nachweis der $\beta$-Galaktosidaseaktivität. Die angegebenen Proteine sind an Gal4-BD fusioniert worden und wurden auf Interaktion mit dem C-Terminus des Acc1p getestet. 
Der in dieser Arbeit isolierte Zwei-Hybrid-Klon kodierte nur für die letzten 230 Aminosäuren des insgesamt 2233 Aminosäuren langen und damit $250 \mathrm{kDa}$ Enzyms. Dieser Proteinabschnitt umfaßte die eben beschriebene $\alpha$-helikale Domäne (Abbildung 18A). Um zu überprüfen, wie spezifisch die Interaktion von Sec22 $\triangle \mathrm{TMDp}$ mit dem C-terminalen Acc1p-Fragment ist, wurden andere Proteine als Köderproteine eingesetzt. Die Stärke der Wechselwirkung mit dem C-terminalen Fragment von Acc1p wurde durch Sichtbarmachen der $\beta$-Galaktosidaseaktivität überprüft. Das Ergebnis ist an einigen Beispielen in Abbildung 18B dargestellt.

Interessanterweise war im Zwei-Hybrid-System keine Interaktion zwischen dem C-Terminus des Acc1p und dem gesamten Gal4-BD-Sec22p einschließlich seiner Transmembrandomäne $\mathrm{zu}$ beobachten. Aus den nachfolgenden Experimenten geht hervor, daß die Transmembrandomäne nicht die Interaktion inhibiert sondern daß vermutlich der sich bildende Proteinkomplex der beiden Fusionsproteine aufgrund der Transmembrandomäne von Sec22p nicht in der Lage ist, in das Innere des Kerns zu wandern und dort die Transkriptionsaktivierung der Reportergene auszulösen. Dies ist nicht trivial, denn es wurden schon einige Proteininteraktionen im Zwei-Hybrid-System nachgewiesen, bei denen die Proteine Transmembrandomänen besitzen. Wie in Abbildung 18B zu sehen ist zeigen auch die ER-Golgi t-SNAREs Ufe1p und Sed5p jeweils als Fusionsproteine mit Gal4-BD ohne Transmembrandomäne ein positives Signal. Weiterhin wurden einige zur Verfügung stehende Klone, die für Fusionsproteine aus Gal4-BD und GTPasen der Ypt-Familie kodieren, getestet. Die ER-Golgi GTPase Ypt1p und die Golgi GTPase Ypt31p waren negativ, jedoch interagierten Ypt7p und sehr schwach Ypt6p, zwei GTPasen im späten sekretorischen Transportweg. Ypt7p ist beispielsweise an dem Transportprozeß zur Vakuole beteiligt. Bet5p, eine Komponente des TRAPP-Komplexes (vgl. 1.3.2), war ebenfalls im Zwei-Hybrid-System mit dem Acc1p-Fragment negativ.

Das C-terminale Acc1p Fragment scheint also bezüglich des Zwei-HybridSystems nicht nur mit Sec22p zu interagieren, sondern auch mit einigen anderen am vesikulären Transportprozess beteiligten Proteinen. Da das Zwei-HybridSystem jedoch häufig zu falsch-positiven Ergebnissen führt, die nicht auf der Interaktion beruhen, mußte die gefundene Interaktion mit anderen Methoden bestätigt werden. 


\subsubsection{Untersuchung der Interaktion zwischen Acc1p und Sec22p}

Wenn die gefundene Interaktion von Sec22p mit Acc1p auch in vivo in der Hefe stattfindet, müsste es möglich sein die Acc1p in ihrer vollen Länge mit einem GST (Glutathion-S-Transferase)-Sec22p-Fusionsprotein aus Hefezellen mittels Affinitätschromatographie zu isolieren. Umgekehrt sollte auch der C-terminale Anteil des Acc1p fusioniert an GST in der Lage sein, einen Teil des endogenen Sec22p der Hefezellen zu binden. Zur Durchführung dieses Experiments wurden die kodierenden Sequenzen für den C-Terminus des Acc1p und der zytoplasmatischen Domäne von Sec22p mittels PCR in den Vektor pEG-KT kloniert, der bereits die kodierende Sequenz für GST hinter einem galaktoseinduzierbaren Promotor enthält, und jeweils in einen Wildtyp-Hefestamm transformiert. Die Fusionsproteine wurden exprimiert und die sich gebildeten Proteinkomplexe wie in Kap. 3.5.5 und 3.5.6 ausführlich beschrieben mit Hilfe von Glutathion-Sepharose aufgereinigt. Die Anwesenheit des jeweiligen Interaktionspartners konnte nun durch Immunoblot-Analyse überprüft werden. In Abbildung 19 ist das Ergebnis dieses sogenannten GST-,,pull-down“-Experiments dargestellt.

In Abbildung 19A wurde das Experiment mit GST-Sec22 2 TMDp durchgeführt. Die Expression und Aufreinigung von GST diente bei dieser Art von Experimenten immer als Negativkontrolle. Nachdem die Proteinkomplexe auf dem Säulenmaterial immobilisiert waren, wurde der Überstand entfernt (Ü). Das Waschen des Säulenmaterials erfolgte mit Waschpuffern unterschiedlicher Salzkonzentration, um zum einen unspezifische Wechselwirkungen anderer Proteine zu entfernen und zum anderen eine Aussage über die Bindungsstärke der Interaktionspartner zu bekommen. In der dargestellten Immunoblot-Analyse konnte nur bei Verwendung von GST-Sec22 $\triangle$ TMDp nicht aber bei der Negativkontrolle GST mit dem anti-Acc1p-Antukörper eine spezifische Bande von ca. $250 \mathrm{kDa}$ detektiert werden. Wurde die Salzkonzentration des Waschpuffers erhöht, nahm die Bandenintensität ab. Wird umgekehrt das Acc1p ${ }^{\mathrm{CT}}$-GST-Fusionsprotein im ,pull-down“-Experiment verwendet (Abbildung 19B), kann in der Immunoblot-Analyse eine Bande bei $25 \mathrm{kDa}$ mit Hilfe des anti-Sec22p-Antikörpers detektiert werden, die im Kontrollexperiment mit GST nicht vorhanden war. Die im Kontrollexperiment auftauchenden Banden bei etwa $27 \mathrm{kDa}$ beruhen auf einer Kreuzreaktion des anti-Sec22p-Antikörpers gegen GST. Sehr deutlich wird in diesem Experiment auch, daß es sich keineswegs um eine quantitative Bindung von Sec22p handelt, sondern nur ein gewisser Prozentsatz an das C-terminale Acc1p-Fragment bindet. Dies war auch zu erwarten, da die Funktion von Sec22p hauptsächlich die eines SNAREs im 
ER-Golgi Transport ist und es somit auch in SNARE-Komplexen assoziiert vorliegt. Ein Verlust der Bindung kann natürlich auch durch die einzelnen Waschungen herbeigeführt worden sein.

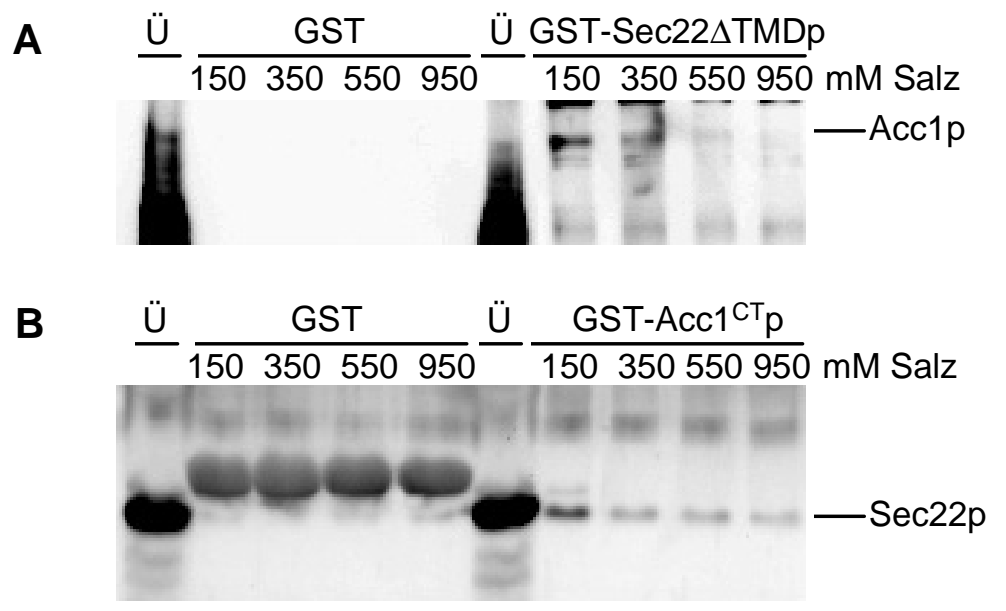

Abbildung 19: Immunoblot-Analyse eines GST-,pull-down“-Experiments. A GST und GST-Sec22 $\triangle T M D p$ wurden in Hefe exprimiert und nach Aufschluß der Hefezellen an GlutathionSepharose gebunden. Nach einer Inkubationsdauer von zwei Stunden bei $4{ }^{\circ} \mathrm{C}$ wurde der Überstand (Ü) entfernt und die Sepharose mit den daran gebundenen Protinkomplexen mit Waschpuffern unterschiedlicher Salzkonzentrationen gewaschen. Nach Elution der Proteine vom Säulenmaterial durch Aufkochen in Auftragspuffer wurden die einzelnen Proben durch Immunoblot-Analyse auf die Anwesenheit der Acc1p mit anti-Acc1p-Antikörper untersucht. B GST und GST-Acc ${ }^{\mathrm{CT}} \mathrm{p}$ wurden in Hefe exprimiert. Die Durchführung des Versuchs erfolgte wie unter A. Die einzelnen Proben wurden durch Immunoblot-Analyse auf die Anwesenheit von Sec22p mit anti-Sec22p-Antikörper untersucht.

Alle SNARE-Proteine bilden untereinander stabile Komplexe über die Interaktion ihre „,coiled-coil“ Domänen (SNARE-Motiv) aus. Diese ,,coiled-coil““ Domäne liegt bei Sec22p zwischen Aminosäure 126 und 189, unmittelbar vor Beginn der Transmembrandomäne (vgl. Abbildung 20A). Die N-terminale Domäne von Aminosäure 1-126 enthält in regelmäßigen Abständen die aromatischen Aminosäuren Tyrosin (Y) oder Phenylalanin (F). Über eine besondere Funktion diese Motivs ist jedoch nichts bekannt. Um zu überprüfen, welcher Proteinabschnitt von Sec22p an die Acc1p bindet wurden zwei weitere GST-Fusionsproteine hergestellt (vgl. Abbildung 20A). Das eine Fusionsprotein enthält nur die N-terminale Region von Sec22p (Sec22-NTp) und das andere nur die ,coiled-coil“ Domäne des Proteins (Sec22-CCp). Die Bindung dieser Proteinabschnitte an Acc1p wurde wie zuvor beschrieben in einem GST-,,pull-down“- 
Experiment mit anschließender Immunoblot-Analyse untersucht. Wie in Abbildung 20B deutlich zu erkennen ist, ist eine Bindung des Acc1p nur im Fall von GST-Sec22-CCp und der vollständigen zytoplasmatischen Domäne von Sec22p (GST-Sec22 $\triangle$ TMDp) detektierbar. Wird nur die N-terminale Domäne von Sec22p verwendet, erfolgt keine Bindung des Acc1p. Die Bindung an die „coiled-coil" Region von Sec22p ist jedoch sehr viel schwächer als bei Verwendung der vollständigen zytoplasmatischen Domäne von Sec22p. Dies deutet auf eine mögliche Stabilisierung der Bindung durch die N-terminalen Domäne hin.

$\mathrm{Da}$ an das C-terminale Acc1p-Fragment, das ebenso eine $\alpha$-Helix enthält, das vollständige Sec22p bindet, liegt die Vermutung nahe, daß die Interaktion der beiden Proteine durch die Wechselwirkungungen dieser beiden $\alpha$-helikalen Domänen erfolgt.

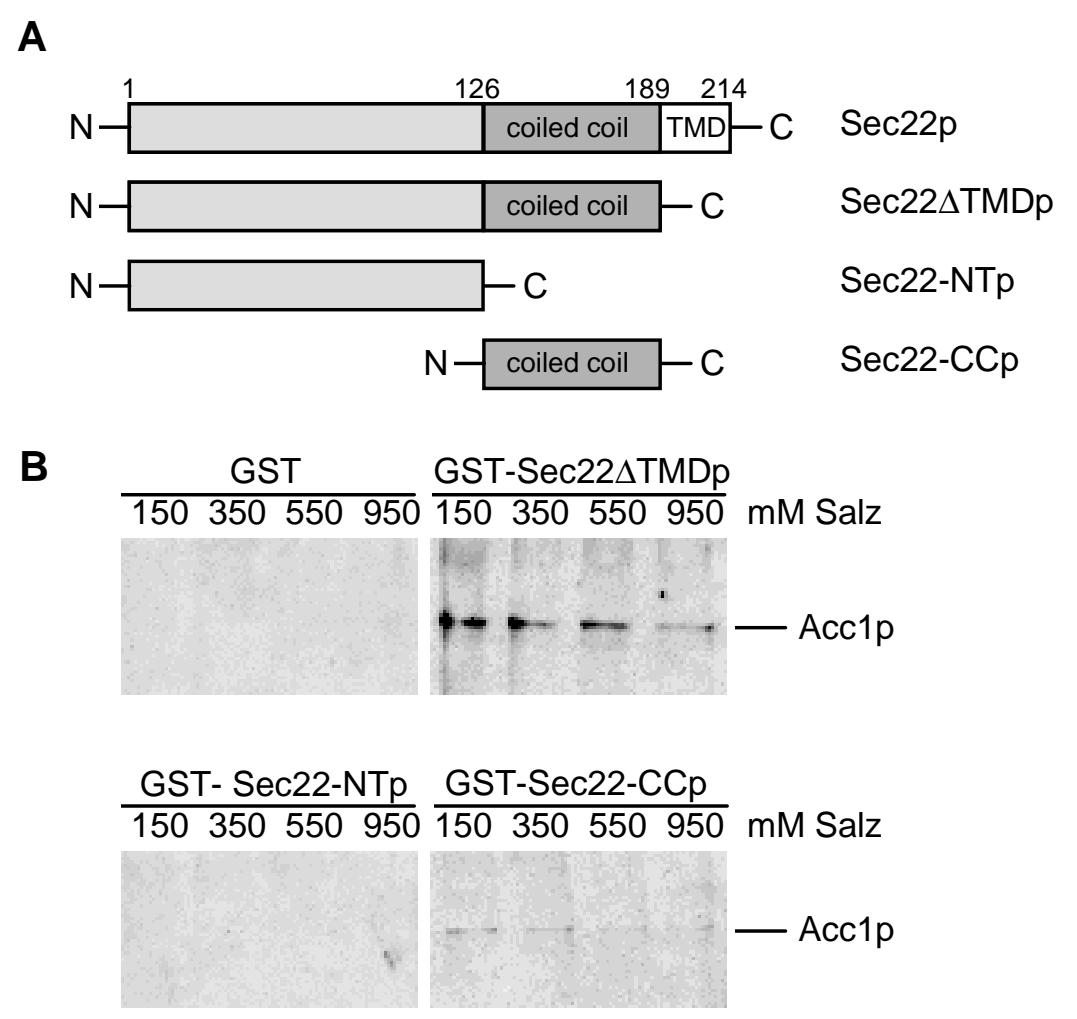

Abbildung 20: A Schematische Darstellung der Sec22p-Fragmente, die als GST-Fusionsproteine verwendet wurden. B Immunoblot-Analyse eines GST-,pull-down“-Experiments. GST, GST-Sec22 $\triangle T M D p$, GST-Sec22-NTp und GST-Sec22-CCp wurden in Hefe exprimiert. Die Durchführung des Versuchs erfolgte wie in Abbildung 19 und Kap. 3.5.6 beschrieben. Die einzelnen Proben wurden in der Immunoblot-Analyse auf die Anwesenheit von Acc1p mit antiAcc1p-Antikörper untersucht. 
$\alpha$-helikale Proteinstrukturen gehen häufig auch unspezifische Wechselwirkungen mit anderen $\alpha$-Helices ein. Deswegen wurden andere SNAREs untersucht, die ebenfalls ,,coiled-coil“-Strukturen ausbilden können.

\subsubsection{Untersuchung der Interaktion zwischen Acc1p und weiteren SNAREs}

Bereits im Zwei-Hybrid-System zeigten auch andere Proteine eine Interaktion mit dem C-Terminus von Acc1p (Abbildung 18). Darunter waren die beiden t-SNAREs Ufe1p und Sed5p. Es stellte sich die Frage, ob eventuell alle SNAREProteine mit dem C-Terminus des Acc1p interagieren. Dies würde auf eine unspezifische Bindungsreaktion hinweisen, die möglicherweise nur in diesem experimentellen Ansatz nachweisbar wäre, jedoch nicht durch in vivo Experimente. Um diese Frage zu klären, wurden weitere SNARE-Proteine ohne Transmembrandomäne als GST-Fusionsproteine generiert und in demselben experimentellen Ansatz, in dem die Interaktion von Sec22p mit Acc1p nachgewiesen werden konnte, analysiert. Dabei stellte sich heraus, daß es nicht möglich ist, GST-Sed5 $\Delta$ TMDp in Hefen zu exprimieren. Das Protein scheint bei hoher Expressionsrate, die bei der Expression von GST-Fusionsproteinen gewünscht ist, toxisch für die Zellen zu sein. Es wurde so stark abgebaut, daß das Experiment unter Verwendung von GST-Sed5 $\Delta$ TMDp nicht durchführbar war. In Abbildung 21 ist das Ergebnis der hier untersuchten SNARE-Proteine dargestellt.

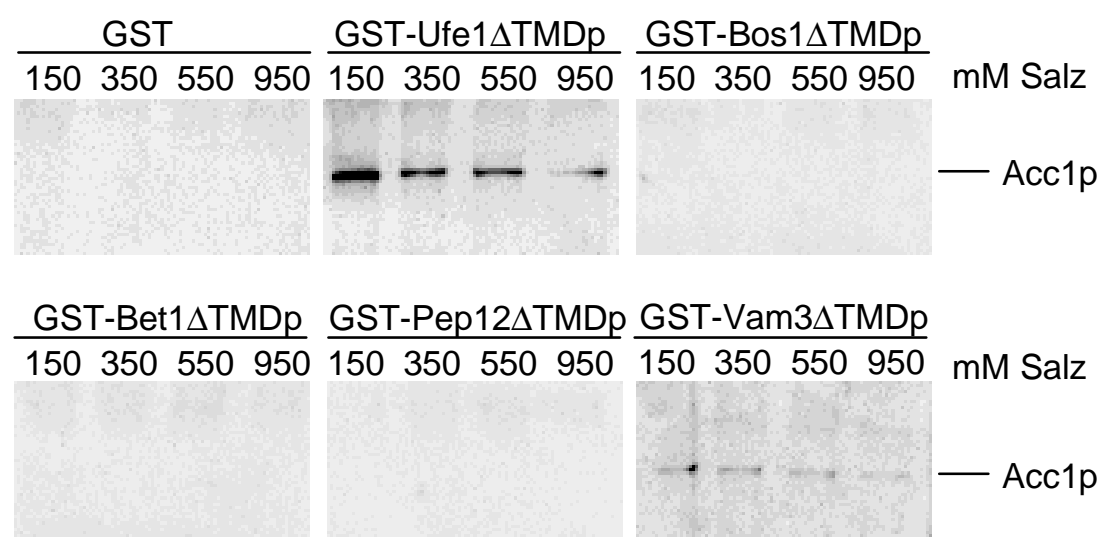

Abbildung 21: Immunoblot-Analyse eines GST-,pull-down“-Experiments. GST, GST-Ufe1 $\Delta$ TMDp, GST-Bos1 $\Delta$ TMDp, GST-Bet1 $\Delta$ TMDp, GST-Pep12 $\Delta$ TMDp und GST-Vam3 $\Delta$ TMDp wurden in Hefe exprimiert. Die Durchführung des Versuchs erfolgte wie in Abbildung 19 beschrieben. Die einzelnen Proben wurden durch Immunoblot-Analyse auf die Anwesenheit von Acc1p mit anti-Acc1p-Antikörper getestet. 
Von den drei zusätzlich zu Sec22p untersuchten ER-Golgi SNAREs Ufe1p, Bos1p und Bet1p konnte nur die zytoplasmatische Domäne von Ufe1p an Acc1p binden, was die im Zwei-Hybrid-System festgestellte Interaktion bestätigt. Das gebundene Acc1p konnte, wie auch bei Sec22p beobachtet, durch Erhöhung der Salzkonzentration im Waschpuffer z. T. von der GST-Sec22 $\Delta$ TMDp-Säulenmatrix gewaschen werden. Die Bindung zwischen GST-Ufe1 $\Delta$ TMDp und Acc1p in diesem experimentellen Ansatz scheint jedoch noch bei $550 \mathrm{mM}$ Salz stabil zu sein, was für eine spezifische Bindung spricht. Eine fehlende Bindung zwischen der zytoplasmatischen Domäne von Bos1p bzw. Bet1p und Acc1p beweist, daß dieses unter den hier verwendeten Bedingungen nicht unspezifisch an jedes SNARE bindet.

Im Zwei-Hybrid-System wurde eine sehr starke Interaktion zu Ypt7p, einer GTPase der Ypt-Familie, die bei Transportprozessen zur Vakuole fungiert, gefunden. Aus diesem Grund wurde das t-SNARE-Protein der Vakuole Vam3p $\mathrm{zu}$ den Untersuchungen hinzugezogen. Als Vergleich wurde die Interaktion von Acc1p zu einem weiteren SNARE des späten sekretorischen Transportwegs, dem endosomalen t-SNARE Pep12p, überprüft. Bei der Verwendung von GST-Vam3 $\Delta$ TMDp konnte tatsächlich eine sehr schwache Bindung zur Acc1p festgestellt werden; GST-Pep12 $\triangle$ TMDp hingegen interagierte nicht in diesem experimentellen Ansatz.

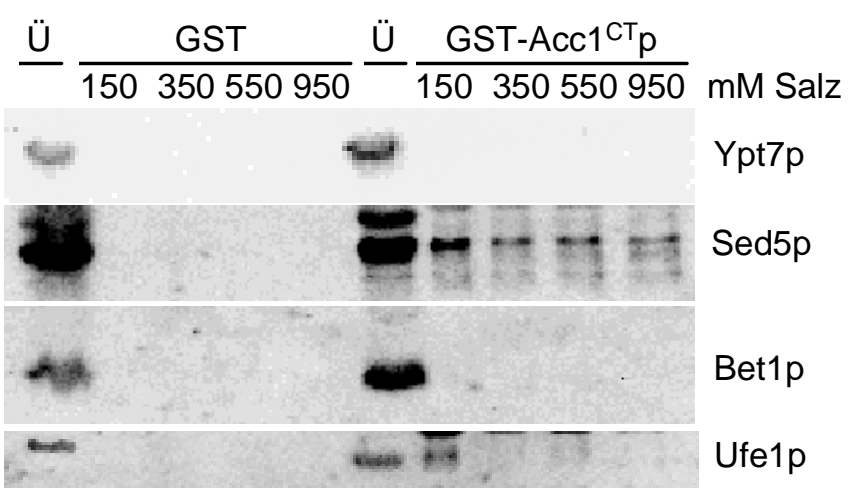

Abbildung 22: Immunoblot-Analyse eines GST-,pull-down“-Experiments. GST und GST-Acc ${ }^{\mathrm{CT}} \mathrm{p}$ wurden in Hefe exprimiert. Die Durchführung des Versuchs erfolgte wie in Abbildung 19 beschrieben. Die einzelnen Proben wurden durch Immunoblot-Analyse auf Anwesenheit der angegegbenen Proteine mit den entsprechenden Antikörpern getestet.

Um diese Ergebnisse zu verifizieren, wurden die Bindungsstudien in umgekehrter Konstellation, d. h. mit GST-markiertem Acc1 ${ }^{\mathrm{CT}} \mathrm{p}$ (GST-Acc1 ${ }^{\mathrm{CT}} \mathrm{p}$ ) wiederholt. 
Der Nachweis der Bindung von Wildtyp-SNARE-Proteinen an GST-Acc1 ${ }^{\mathrm{CT}} \mathrm{p}$ war jedoch aufgrund mangelhafter Qualität einiger anti-SNARE-Antikörper nur mit Einschränkungen möglich. In Abbildung 22 ist das Ergebnis dieser Untersuchungen zusammengefaßt.

Die Interaktion von Sed5p und Ufe1p und eine fehlende Interaktion von Bet1p mit dem C-terminalen Fragment des Acc1p bestätigen sowohl die zuvor mittels Zwei-Hybrid-System als auch die durch Experimente mit GST-SNAREFusionsproteinen erhaltenen Ergebnisse. Die Bindung von Sed5p scheint jedoch deutlich stärker zu sein als die von Ufe1p, da auch bei Erhöhung der Salzkonzentration im Waschpuffer bis auf ca. 1 M eine Sed5p-Bande detektiert werden konnte. Ypt7p konnte in diesem experimentellen Ansatz nicht nachgewiesen werden, obwohl aufgrund des Ergebnisses aus dem Zwei-HybridSystem eine Interaktion zu erwarten war. Es könnte sich also dabei um ein klassisches Zwei-Hybrid-System Artefakt oder aber um eine durch Vam3p vermittelte indirekte Wechselwirkung handeln. Dies muß noch geklärt werden. Anzumerken ist jedoch, daß der Zwei-Hybrid Klon mit dem C-terminalen Acc1pFragment bei einem ,screen“ mit einer Ypt7p-Mutante ebenfalls mittels ZweiHybrid-System isoliert wurde (T. Lazar, persönliche Mitteilungen).

Zusammenfassend ist festzuhalten, daß Acc1p mit den drei ER-Golgi SNAREs Sec22p, Ufe1p und Sed5p sowohl in Zwei-Hybrid-System als auch im GST-,,pull-down“-Experiment interagiert.

\subsubsection{Genetischer Zusammenhang zwischen SEC22 und ACC1}

Ein funktioneller Zusammenhang zwischen Proteinen, die miteinander wechselwirken, läßt sich auch mit genetischen Mitteln nachweisen. So kann die Kombination von Mutationen in den entsprechenden Genen zu einer Verstärkung des Wachstumsdefektes oder sogar zu Letalität führen. Voraussetzung dafür ist, daß man Punktmutationen oder Deletionsmutationen, die für sich alleine keinen oder nur einen schwach ausgeprägten Phänotyp zeigen, zu Verfügung hat. Da die Deletion des $A C C 1$-Gens für die Hefezelle letal ist, wurden für die genetischen Untersuchungen accl-Mutanten verwendet.

Es sind verschiedene ACC1-Mutantenallele bekannt. Die acc1-7-1-Mutante (mtr7) ist temperatursensitiv und wurde ursprünglich in einem ,screen“ für Mutanten gefunden, die einen defekten Kerntransport von mRNAs besitzen (Kadowaki et al., 1994). Erst die weitere Analyse dieser Mutante deckte die zweite essentielle Funktion der Acc1p auf. Sie beruht auf der Bereitstellung von 
Malonyl-CoA zur Herstellung langkettiger Fettsäuren $\left(\mathrm{C}_{16} \mathrm{zu} \mathrm{C}_{18}\right)$ und sehr langkettigen Fettsäuren $\left(C_{26}\right)$ (Schneiter et al., 1996; Schneiter und Kohlwein, 1997). $\mathrm{C}_{26}$-Fettsäuren sind Bestandteil von Ceramiden und ihre Synthese ist essentiell für die Hefezelle. Die $a c c 1^{C S}$-Mutante ist kältesensitiv und wurde in einem synthetischen Letalitäts-,,screen“ mit HPRl, dessen Genprodukt eine Funktion im Kerntransport besitzt, gefunden. Beide Mutanten zeigen bei nicht permissiver Temperatur ein verändertes Fettsäureprofil, das in einer dramatischen Erhöhung von $\mathrm{C}_{14: 1}$-Fettsäuren und einer Erniedrigung um das Zweifache an $\mathrm{C}_{26}$-Fettsäuren besteht. Weiterhin sind die $\mathrm{C}_{16: 0^{-}}$und $\mathrm{C}_{18: 0^{-}}$Fettsäurespiegel reduziert während der $\mathrm{C}_{16: 1}$-Fettsäurespiegel leicht erhöht ist. Die beiden Mutanten unterscheiden sich darin, daß die Wachstumsinhibition der kältesensitiven im Gegensatz zur temperatursensitiven Mutante nach Inkubation bei nicht permissiver Temperatur reversibel ist und nicht zum irreversiblen Zelltod führt. Die Positionen der Aminosäuremutation beider Mutanten-accl-Allele sind identifiziert. Sie sind in verschiedenen funktionellen Regionen des Acc1p lokalisiert. Bei der acc1-7-1-Mutante befindet sich die Mutation in der Biotinbindungsdomäne (F590S), während die $a c c 1^{C S}$-Mutante einen Aminosäureaustausch in der Transcarboxylasedomäne (G1783A) aufweist.

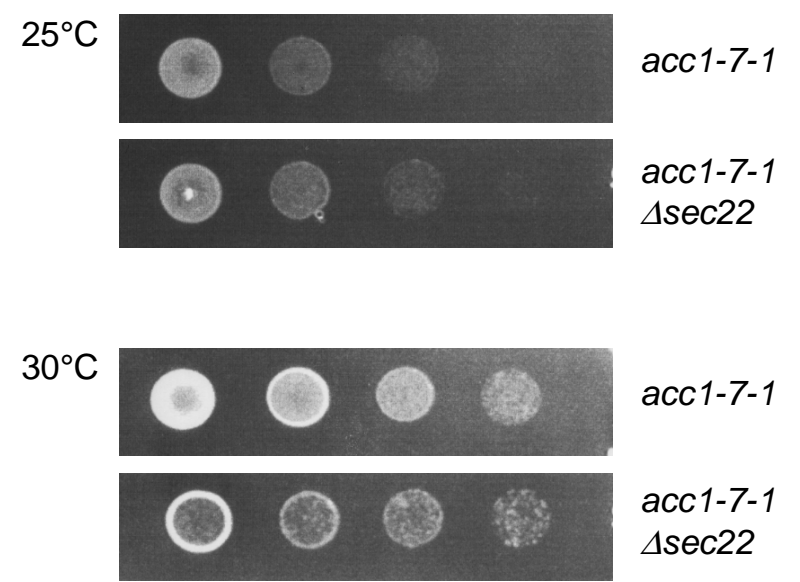

Abbildung 23: Wachstumstest der acc1-7-1 Mutante im Vergleich zur Doppelmutante acc1-7-1 $\Delta \sec 22$ bei $25^{\circ} \mathrm{C}$ und $30^{\circ} \mathrm{C}$. Die Zellen wurden in Flüssigkultur angezüchtet, gleiche Zellzahl in einer Verdünnungsreihe auf Agarplatten aufgetropft, und für ein bis zwei Tage bei der entsprechenden Temperatur inkubiert.

Da SEC22 für die Hefe nicht essentiell ist und die Deletion nur einen kältesensitiven Phenotyp hervorruft, konnten beide accl-Mutanten mit einem SEC22-Deletionsstamm gekreuzt werden. Die Tetradenanalyse der Kreuzung von 
$\Delta s e c 22$ mit acc1-7-1 zeigte zunächst keine Auffälligkeiten. Es konnten stets alle vier Tetraden eines Ascus bei $25{ }^{\circ} \mathrm{C}$ wachsen. Wie in dem Wachstumstest in Abbildung $23 \mathrm{zu}$ erkennen ist, zeigte sich aber ein verzögertes Wachstum der Doppelmutante acc1-7-1 4 sec22 bei $30^{\circ} \mathrm{C}$ im Vergleich zur acc1-7-1-Mutante. Eine SEC22-Deletion führt zu keiner Verringerung des Wachstums bei $30{ }^{\circ} \mathrm{C}$ (Ossig et al., 1991). Das bedeutet, daß die Temperatursensitivität der acc1-7-1-Mutante durch die Deletion von SEC22 verstärkt wird.

Noch deutlicher wird der genetische Zusammenhang zwischen Sec22p und Acc1p bei der Kreuzung der $a c c 1^{C S}$-Mutante mit $\Delta s e c 22$. Wie die Tetradenanalyse in Abbildung 24 zeigt, konnten nicht alle vier Tetraden eines Ascus wachsen. Häufig zeigte sich eine 2:2 Aufspaltung, bei der die beiden auskeimenden Sporen sowohl bei $25^{\circ} \mathrm{C}$ als auch bei $16^{\circ} \mathrm{C}$ wuchsen und somit keine Mutation enthielten. Die beiden nicht auskeimenden Sporen mußten also beide Mutationen enthalten. Keimten drei der vier Sporen aus, handelte es sich dabei um eine Wildtypspore (His, nicht kältesensitiv), eine $a c c 1^{C S}$-Spore (His`, kältesensitiv) und eine $\Delta s e c 22-$ Spore (His ${ }^{+}$, kältesensitiv). Die nicht auskeimende Spore musste also die Doppelmutation enthalten. Offensichtlich ist eine Doppelmutation von $\Delta s e c 22$ und $a c c 1^{C S}$ für die Hefe letal. Ein funktioneller Zusammenhang zwischen Sec22p und Acc1p läßt sich also auch auf genetischer Ebene feststellen.

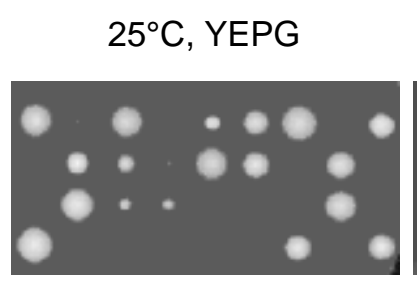

$25^{\circ} \mathrm{C}, \mathrm{SD}-\mathrm{HIS}$

$16^{\circ} \mathrm{C}, \mathrm{YEPG}$
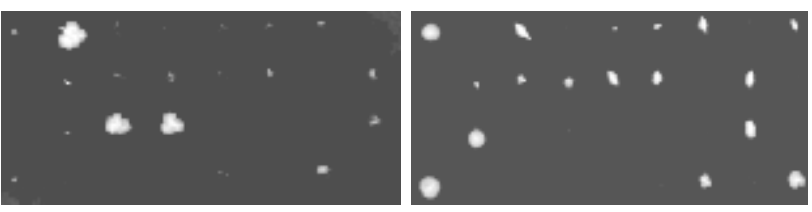

Abbildung 24: Tetradenanalyse der Kreuzung der acc1 ${ }^{c S}$-Mutante mit $\Delta s e c 22$ (ebenfalls cs). Die Tetraden wurden nach Wachstum bei $25^{\circ} \mathrm{C}$ auf YEPG-Platten auf die Anwesenheit der SEC22-Deletion auf SD-HIS-Platten getestet, sowie bei $16^{\circ} \mathrm{C}$ auf das kältesensitive Verhalten der einzelnen Mutationen.

\subsubsection{Lokalisation von Acc1p in Hefemutanten des vesikulären Transports}

Die Ergebnisse, die in den letzten Kapiteln beschrieben wurden, haben veranschaulicht, daß Acc1p mit Sec22p interagiert. Die Interaktion der beiden Proteine 
erfolgt über die C-terminale Domäne von Acc1p und die „coiled-coil“-Domäne von Sec22p. Da Acc1p teils zytosolisch, teilweise aber auch an die ER-Membran assoziiert vorliegt, liegt die Vermutung nahe, daß der C-terminale Anteil der Acc1p durch Bindung an das hauptsächlich im ER lokalisierte Sec22p bzw. Ufe1p die Membranassoziation vermittelt. Durch eine Konformationsänderung könnte sich Acc1p eventuell vom ER lösen und so seine Funktion im Zytosol ausüben. In der Immunfluoreszenz mit einem $c$-myc-markierten $A C C 1$-Konstrukt sind diese beiden Proteinpools jedoch schwer zu unterscheiden. Deswegen wurde ein GFP-Fusionsprotein generiert, das nur den C-terminalen Proteinabschnitt des Acc1p enthält. Dieses Fusionsprotein sollte es ermöglichen, den membranassoziierten Anteil der Acc1p zu betrachten und seine Lokalisation in Hefemutanten zu untersuchen. In Abbildung 25 sind die Fluoreszenzuntersuchungen des GFP-Acc1 ${ }^{\mathrm{CT}} \mathrm{p}$ im sec22-3- und $\Delta \sec 22-$ Stamm im Vergleich zum Wildtyp dargestellt.

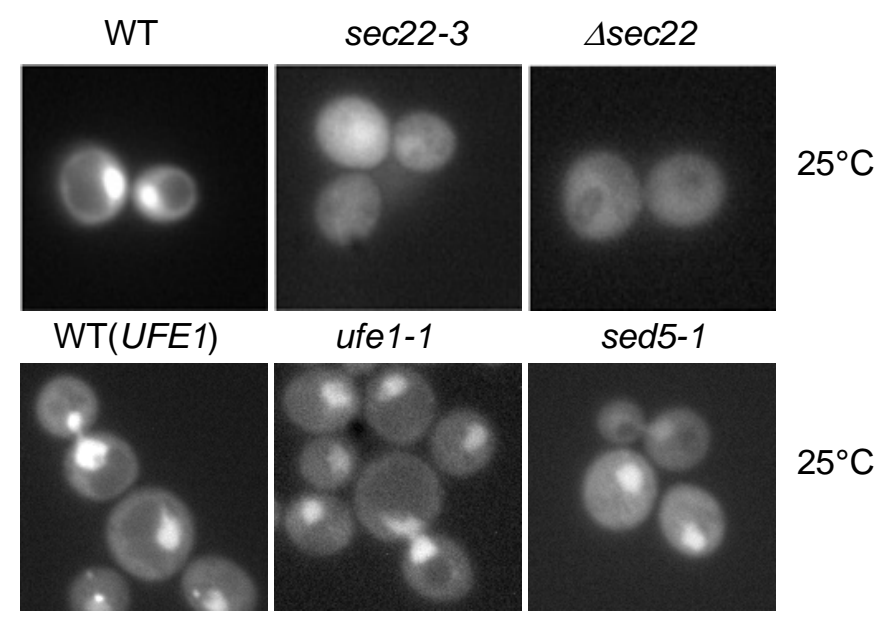

Abbildung 25: Analyse der Fluoreszenz von GFP-Acc ${ }^{\mathrm{CT}} \mathrm{p}$ im sec22-3-, 4 sec22-, ufe 1-1- und sed5-1-Stamm im Vergleich zum Wildtyp bei $25^{\circ} \mathrm{C}$.

Im Wildtypstamm war das Fusionsprotein GFP-Acc1 ${ }^{\mathrm{CT}}$ p sehr stark am Zellkern konzentriert. Da das Fluoreszenzsignal sehr intensiv war, konnte schwer bestimmt werden, ob es sich hierbei ausschließlich um eine Assoziation mit der am Zellkern befindlichen ER-Membran handelt oder auch der Zellkern angefärbt wurde. Des weiteren war eine schwache zytosolische Lokalisation zu erkennen, wobei die Vakuole deutlich ausgespart blieb. Bei Verwendung des sec22-3-Stamms sowie des Asec22-Stamms war überhaupt keine Konzentration der GFP-Acc ${ }^{\mathrm{CT}}$ p-Signals um den Zellkern feststellbar. Das Fusionsprotein zeigte vielmehr eine diffuse Verteilung in der Zelle. Auch eine Aussparung der Vakuole 
war nur sehr schwach zu erkennen. Interessanterweise trat dieser Effekt schon bei $25{ }^{\circ} \mathrm{C}$ auf, obwohl es sich bei sec22-3 um eine temperatursensitive Mutante handelt. Bei Verwendung der temperatursensitiven Stämme sed5-1 oder ufe 1-1 war dieses Phänomen nicht zu beobachten. Offensichtlich ist für die Lokalisation von GFP-Acc1 ${ }^{\mathrm{CT}} \mathrm{p}$ die Anwesenheit eines Wildtyp-Sec22p entscheident.
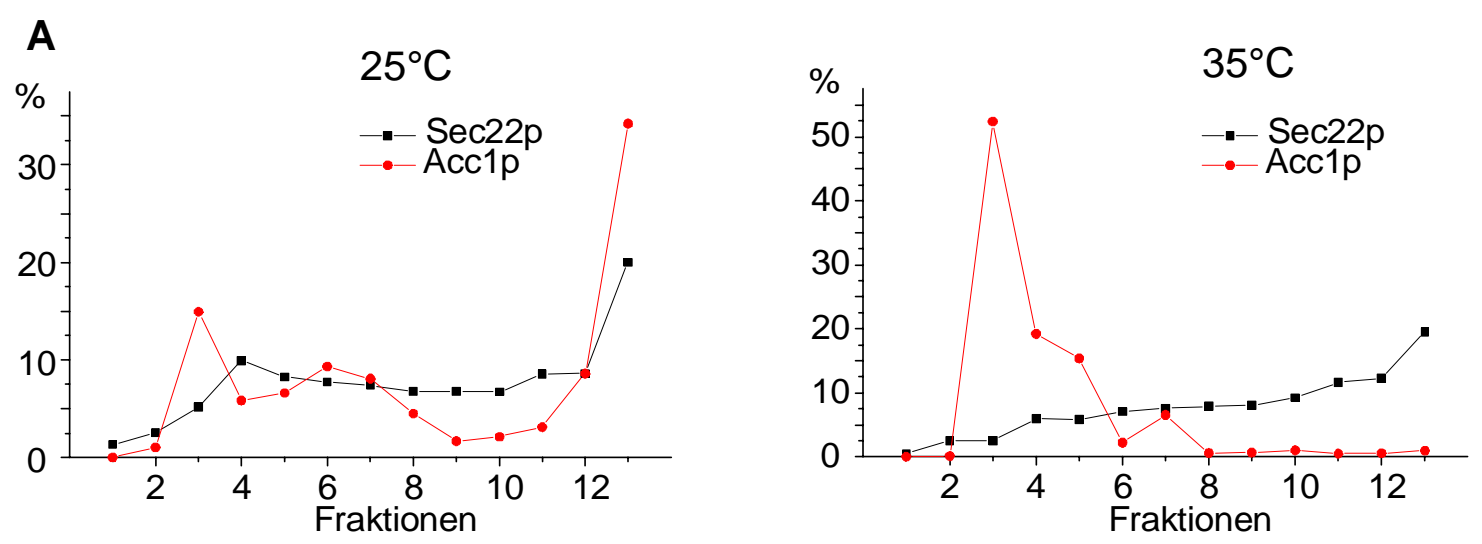

B
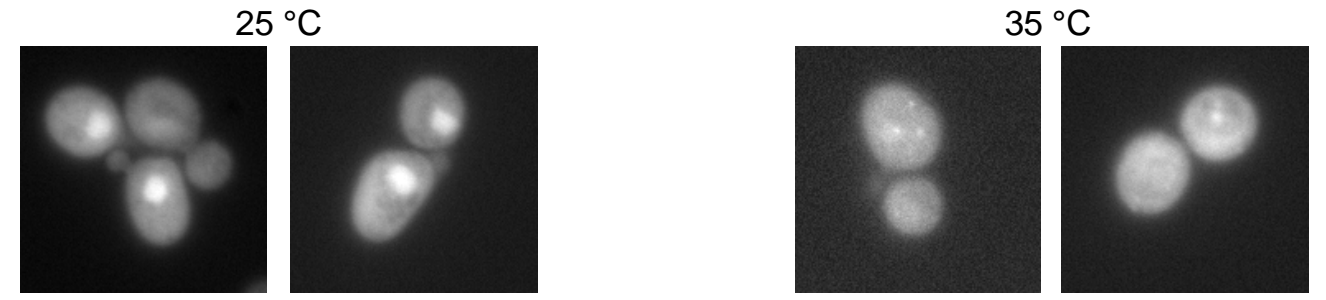

Abbildung 26: A Untersuchung der Lokalisation von Sec22p und Acc1p in einem sec23-1-Stamm mittels Zellfraktionierung durch Sucrosegradienten bei $25^{\circ} \mathrm{C}$ und $35^{\circ} \mathrm{C}$. Die Hefezellen wurden in Flüssigkultur bei $25^{\circ} \mathrm{C}$ angezüchtet und nach Zugabe von Cycloheximid, das die Proteinproduktion der Zellen inhibiert, für eine weitere Stunde bei 25 bzw. $35^{\circ} \mathrm{C}$ inkubiert. Die Zellen wurden wie in Kap. 3.7.2 ausführlich beschrieben geerntet, aufgeschlossen und die Organellen durch Dichtegradientenzentrifugation getrennt (Fraktion 1-3: Zytosol, Vesikel; Fraktion 4-9: Golgi; Fraktion 10-13: ER, Plasmamembran, Zellkern). B Analyse der Fluoreszenz von GFP-Acc $1^{\mathrm{CT}} \mathrm{p}$ im sec23-1-Stamm bei $25^{\circ} \mathrm{C}$ und nach einstündiger Inkubation bei $35^{\circ} \mathrm{C}$.

Um zu zeigen, daß die Lokalisation von GFP-Acc $1^{\mathrm{CT}} \mathrm{p}$ tatsächlich die Lokalisation von endogenem Acc1p widerspiegelt, wurde zum Vergleich die Lokalisation von Acc1p in einem Zellfraktionierungsexperiment untersucht. Durch die hier verwendete Zentrifugation in einem Sucrosegradienten konnten ER- und Plasmamembranen ( Fraktion 10-13), Golgi-Membranen ( Fraktion 4-9) sowie Zytosol und leichte Membranen, z. B. Vesikel ( Fraktion 1-3) 
aufgrund ihrer unterschiedlichen Dichte und der daraus resultierenden unterschiedlichen Sedimentationsgeschwindigkeit voneinander getrennt werden. In dem in Abbildung 26 dargestellten Beispiel wurde eine COPII-Mutante (sec23-1) verwendet, die bei nicht-permissiver Temperatur aufgrund fehlender COPII-Vesikelbildung den anterograden ER-Golgi Transport blockiert.

Bei $25^{\circ} \mathrm{C}$, d. h. bei fortlaufendem vesikulären Transport, befindet sich der größte Teil von Acc1p in ER-haltigen Fraktionen in Kolokalisation mit dem im ER-befindlichen Pool von Sec22p. Zwei weitere Maxima der Acc1p-Lokalisation befinden sich bei Fraktion 3 und Fraktion 6. Ersteres spiegelt wahrscheinlich den zytosolischen Anteil der Acc1p wider und letzteres eventuell einen weiteren membranassozierten Pool. Gleichzeitig läßt sich in der Fluoreszenzanalyse des GFP-Acc1 ${ }^{\mathrm{CT}} \mathrm{p}$ im sec23-1-Stamm bei $25^{\circ} \mathrm{C}$ eine Konzentrierung am Zellkern beobachten. Nach einstündiger Inkubation bei nicht permissiver Temperatur von $35{ }^{\circ} \mathrm{C}$ ist Acc1p zu 80\% in den oberen Fraktionen des Gradienten zu finden und nicht mehr in den ER-membranhaltigen Fraktionen 10-13. Somit ist auch die Kolokalisation mit Sec22p vollständig aufgehoben worden. Im Falle von Sec22p ist zu erkennen, daß eine Hemmung des anterograden ER-Golgi Transports dafür sorgt, daß der bei $25{ }^{\circ} \mathrm{C}$ in Fraktion 4-9 befindliche Golgi-Pool des Proteins bei $35{ }^{\circ} \mathrm{C}$ über den weiterhin funktionierenden retrograden Transport zunehmend in das ER zurückgeführt wird. Diese Umverteilung wurde schon in anderen Arbeiten nachgewiesen und diente in diesem Experiment als Kontrolle des ER-GolgiTransportblocks. In der Fluoreszenzanalyse des GFP-Acc1 ${ }^{\mathrm{CT}} \mathrm{p}$ wird deutlich, daß auch hier nach einer Stunde bei $35^{\circ} \mathrm{C}$ die Konzentrierung des Proteins am Zellkern aufgehoben ist.

Zusammenfassend kann festgehalten werden, daß die Lokalisation von Acc1p von der Anwesenheit des Wildtyp-Sec22p abhängt und durch ER-GolgiTransportdefekte beeinflußt wird.

\subsubsection{Regulation der Aktivität von Acc1p und Auswirkungen auf die Interaktion mit Sec22p}

In Prokaryonten wird für die Synthese von Malonyl-CoA aus Acetyl-CoA eine Assoziation von drei verschiedenen Proteinen benötigt, die die Biotincarboxylaseaktivität, die Biotinbindungsstelle und die Transcarboxylaseaktivität in einem heteromeren Komplex zur Verfügung stellen. Diese Reaktion wird in Hefe durch das trifunktionelle Enzym Acc1p katalysiert. Die Transkription von ACC1 wird positiv durch Ino2p/Ino4p und negativ durch Opi1p reguliert, die generelle 
Regulatoren der Transkription von Genen darstellen, die an der Phospholipidbiosynthese beteiligt sind (Hasslacher et al., 1993). Die $250 \mathrm{kDa}$ Acc1p ist als Tetramer funktionell, benötigt kovalent gebundenes Biotin als Coenzym und ihre Enzymaktivität wird durch kurzzeitige Phosphorylierung reguliert (Al-Feel et al., 1992; Witters et al., 1990). In Säugern wird die aktive ACC-Form durch filamentöse Strukturen charakterisiert, die in Hefe in ähnlicher Form nur bei Überproduktion des Enzyms zu beobachten sind. In einem Wildtyphefestamm ist Acc1p wie bereits beschrieben entweder zytosolisch lokalisiert oder mit dem ER assoziiert (Ivessa et al., 1997). Ob die ER-assoziierte Form als aktives Tetramer oder in einer inaktiven Form vorliegt, ist nicht bekannt. Es konnte jedoch gezeigt werden, daß die Membranassoziation zum einen durch die Enzymsubstrate ATP und Acetyl-CoA und zum anderen durch das Enzymprodukt Malonyl-CoA teilweise aufgehoben wird. Im Gegensatz zu dem schwachen Effekt von Citrat, einem Aktivator des Acc1p, zeigte der Inhibitor Palmitoyl-CoA einen sehr starken negativen Einfluß auf die Membranassoziation des Acc1p. In Gegenwart von Palmitoyl-CoA war Acc1p kaum membranassoziert. Die Autoren mutmaßten, daß das Monomer/Tetramer Gleichgewicht durch diese Substanzen beeinflußt wird und dies Auswirkungen auf die Membranassoziation hat (Ivessa et al. 1997).

Da Palmitoyl-CoA einen so starken negativen Einfluß auf die Membranassoziation des Acc1p hat, wurde sein Einfluß auf die Interaktion zu Sec22p und Ufe1p untersucht. Das Ergebnis ist in Abbildung 27 dargestellt.

Das Experiment wurde wie schon zuvor beschrieben durchgeführt. Die Fusionsproteine GST-Sec22 $\Delta$ TMDp und GST-Ufe1 $\Delta$ TMDp wurden in Hefen exprimiert, um ein GST-,,pull-down“-Experiment durchzuführen. Die Expression von GST diente wie üblich als Negativkontrolle. Für die Untersuchung des Einflusses von Palmitoyl-CoA wurde der Aufschlußpuffer sowie der Waschpuffer mit $50 \mu \mathrm{mol} / 1$ Palmitoyl-CoA versetzt. Diese Palmitoyl-CoAKonzentration wurde gewählt, da auch die Membranassoziationsexperimente der Acc1p in Ivessa et al., (1997) mit dieser Konzentration durchgeführt wurden.

Wie in Abbildung 27 deutlich zu erkennen ist, wird die Bindung zwischen Acc1p und GST-Sec22 2 TMDp in Anwesenheit von Palmitoyl-CoA stimuliert. Dies ist auch bei Verwendung von GST-Ufe1 $\Delta$ TMDp der Fall, jedoch ist hier Stimulation durch Palmitoyl-CoA schwächer ausgeprägt. Mit Avidin-Peroxidase wurde überprüft, ob das gebundene Enzym in biotinylierter Form vorliegt. Dies ist tatsächlich der Fall. Damit war ausgeschlossen, daß Sec22p in Anwesenheit des Acc1p-Inhibitors Palmitoyl-CoA ausschließlich biotinfreies, inaktives Acc1p bindet, das ebenfalls in der Zelle vorliegt. Ob das rekrutierte Enzym jedoch 
tatsächlich aktiv ist, hängt davon ab, ob es als monomere oder oligomere Form an Sec22p bzw. Ufe1p gebunden wird. Erste Untersuchungen zur Aktivitätsbestimmung des gebundenen Acc1p wurden durchgeführt, ergaben aber bisher kein aussagekräftiges Ergebnis, da die Menge des an GST-Sec22 $\Delta$ TMDp und GST-Ufe1 1 TMDp gebundenen Acc1p äußerst gering ist.

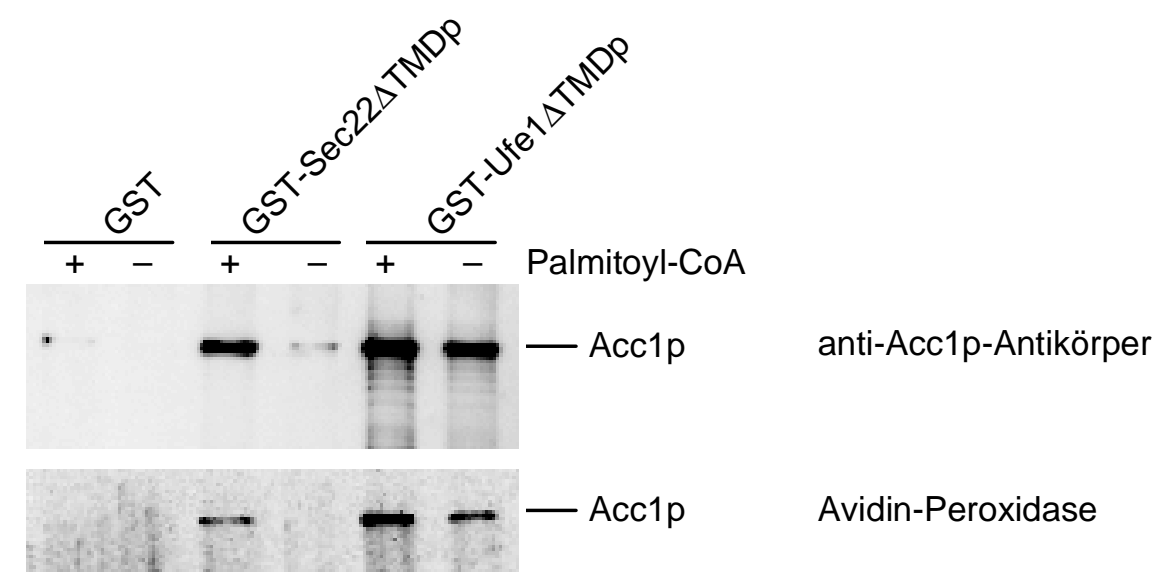

Abbildung 27: Immunoblot-Analyse eines GST-,„pull-down“-Experiments. GST, GST-Sec22 $\triangle T M D p$ und GST-Ufe1 $\Delta$ TMDp wurden in Hefe exprimiert, in An- und Abwesenheit von Palmitoyl-CoA aufgeschlossen und mit Glutathion-Sepharose inkubiert. Nach einer Inkubationsdauer von zwei Stunden bei $4{ }^{\circ} \mathrm{C}$ wurde der Überstand entfernt und die Glutathion-Sepharose mit den daran gebundenen Proteinkomplexen mit Waschpuffer mit und ohne Palmitoyl-CoA gewaschen. Nach Elution der Proteine vom Säulenmaterial durch Aufkochen in Auftragspuffer wurden die einzelnen Proben durch Immunoblot-Analyse auf die Anwesenheit der Acc1p mit anti-Acc1p-Antikörper und die Anwesenheit von biotinyliertem Acc1p mit Avidin-Peroxidase getestet. 


\section{Diskussion}

\subsection{Die Recycling-Maschinerie von Sec22p}

In dieser Arbeit wurden eingehende Untersuchungen zum Recycling-Verhalten von Sec22p, einem v-SNARE des ER-Golgi Transports in Hefe, durchgeführt. Dazu wurden Proteine in der Zelle überproduziert und die Lokalisation von Sec22p mit Hilfe des Sec22- $\alpha$ Reporters untersucht. Dieser Reporter enthält C-terminal und damit luminal ein $c$-myc-Epitop und die dreizehn Aminosäuren umfassende $\alpha-$ Faktorsequenz, die durch eine Kex2p-Schnittstelle voneinander getrennt sind. Eine Fehllokalisation des Sec22- $\alpha$ Reporters in den späten Golgi und eine damit verbundene vermehrte Kex2p-Prozessierung weist auf eine gestörte Recyclingmaschinerie hin. Um gleichzeitig auch die Auswirkungen der Überproduktion der verschiedenen Proteine auf den signalvermittelten Rücktransport einer anderen Proteinklasse zu untersuchen, den integralen Membranproteinen mit C-terminalen KKXX-Motiv, wurde der Ste2-Wbp1p Reporter verwendet. Bei gestörter ER-Retention wird dieses Fusionsprotein zur Plasmamembran fehllokalisiert. Die Effekte auf beide Reportersysteme wurde verglichen.

Wolfgang Ballensiefen hatte während seiner Dissertation den Sec22- $\alpha$ Reporter entwickelt. Er konnte zeigen, daß der Sec22- $\alpha$ Reporter funktionell aktiv ist, da mit diesem Reporter der temperatursensitive Phänotyp einer sec22-3-Mutante aufgehoben werden kann, und daß seine intrazelluläre Lokalisation mit der von Sec22p übereinstimmt. Unter Verwendung verschiedener Hefemutanten, die den retrograden Golgi-ER Transport blockieren, konnte er beweisen, daß der Reporter COPI-abhängig vom Golgi in das ER zurückgeführt wird. Zusätzlich wurde gezeigt, daß für diesen Prozeß das ER-t-SNARE Ufe1p sowie das Transmembranprotein Sec20p essentiell sind. Untersuchungen von unterschiedlichen Expressionsleveln des Sec22- $\alpha$ Reporters ergaben, daß die Kex2p-Prozessierung und damit die Fehllokalisation des Reporters mit Erhöhung des Expressionslevels zunimmt, was für eine Sättigung der Reporterrecyclingmaschinerie spricht. Nicht analysiert wurde jedoch, ob Sec22p und der Sec22- $\alpha$ Reporter tatsächlich über die gleiche Recyclingmaschinerie transportiert werden.

In dieser Arbeit konnte diese Annahme bestätigt werden, da auch eine Überexpression des Wildtyp-Sec22p den Sec22- $\alpha$ Reporter vermehrt in den späten Golgi verdrängen kann. Diese Übersättigung der Maschinerie kann auch 
durch Überproduktion des Sec22-3p erreicht werden. Das Sec22-3p, das aus der sec22-3-Mutante stammt, enthält an Position 157 Arginin statt Glycin (Novick et al., 1980). Die Mutation befindet sich in der „,coiled-coil“-Region von Sec22p und stellt die zentrale Aminosäure des SNARE-Motivs dar (Fasshauer et al., 1998). Der sec22-3 Stamm zeigt bei nicht permissiver Temperatur einen ER-Golgi Transportblock und staut $50 \mathrm{~nm}$ große Vesikel an (Kaiser und Schekman, 1990). Daß Sec22-3p genau wie Sec22p effizient den Sec22- $\alpha$ Reporter in den späten Golgi verdrängt, ist ein weiterer Beweis dafür, daß der Phänotyp des sec22-3 Stammes nicht durch die Recyclinginkompetenz des Sec22-3p zustande kommt, sondern durch eine gestörte SNARE-KomplexAusbildung, bei der SNARE-Motive eine entscheidene Rolle spielen (Søgaard et al., 1994). Dafür spricht auch, daß Sec22-3p in einem in vitro Experiment mit rekombinanten Proteinen, die aus E. coli aufgereingt wurden, nicht mehr an Sed5p binden kann (Sacher et al., 1997). Aus diesen Ergebnissen geht hervor, daß der Sec22p-Recyclingprozeß und die Sec22p-Funktion als SNARE von unterschiedlichen Faktoren abhängen. Andererseits bedingt natürlich auch ein effizientes Recycling von Sec22p die Bereitstellung von funktionellem Sec22p im richtigen Zellkompartiment. Da das Protein aber für die Hefe nicht essentiell ist, könnte ein Funktionsverlust bzw. Fehlen von Sec22p in diesem Kompartiment aufgrund gestörter Recyclingprozesse, ähnlich wie im SEC22-Deletionsstamm, durch andere Proteine kompensiert werden. Dies ermöglicht Untersuchungen des Recyclingprozesses ohne auf die Funktion von Sec22p angewiesen zu sein, würde aber möglicherweise eine Umverteilung anderer Proteine in der Zelle bewirken.

\section{2 Überproduktion von Sed5p stört das Recycling von Sec22p}

Es konnte ein Protein gefunden werden, daß bei Überproduktion sowohl mit dem Recyclingprozeß des Sec22- $\alpha$-Reporters interferiert als auch die ER-Retention des Ste2-Wbp1p-Reporters stört. Es handelt sich hierbei um das Golgi-t-SNARE Sed5p.

Sed5p wurde als Suppressor der ERD2-Deletion isoliert (Hardwick et al., 1992). Da Erd2p (HDEL-Rezeptor) für die Zurückführung HDEL-markierter Proteine vom Golgi in das ER zuständig ist, gab die Suppressorfunktion von Sed5p den ersten Hinweis auf den zellulären Ort seiner Funktion. Sed5p ist essentiell für das Wachstum von Hefe. Seine Notwendigkeit für die Zelle wird auch dadurch verdeutlicht, daß Sed5p mindestens sieben weitere SNAREs binden 
kann und dabei unterschiedliche Komplexe ausbildet. Einer dieser Komplexe enthält neben Sed5p noch Bos1p, Bet1p und Sec22p. Diese drei SNARE-Proteine sind im ER-Golgi Transport involviert und werden auf COPII-Vesikeln gefunden. Deshalb könnten diese als vesikelspezifische SNARE-Proteine, v-SNAREs, im vesikelvermittelten ER-Golgi Transport fungieren, während Sed5p die Funktion des „Target“-spezifischen SNARE-Proteins, t-SNAREs, des frühen Golgi übernimmt. In letzter Zeit wurden jedoch immer häufiger Hinweise gefunden, daß die einzelnen Golgi-Zisternen keineswegs als statische Organellen anzusehen sind, von denen Vesikel sowohl in Vorwärts- und Rückwärtsrichtung abknospen. Man glaubte bisher, daß die charakteristische Lipid- und Proteinzusammensetzung der frühen, mittleren und späten Golgi-Zisternen durch kontinuierlichen Vesikeltransport in beide Richtungen aufrecht erhalten würde. Nach neueren Erkenntnissen stellt man sich vor, daß Golgi-Zisternen de novo entstehen können und eine Reifung durchlaufen. Eine Vorstufe des frühen Golgi entstünde demnach durch homotypische Fusion einzelner am ER gebildeter Vesikel, die anschließend eine Reifung durchläuft. Voraussetzung hierfür ist, daß Golgi-residente Proteine während der Reifung jeweils aus der Golgi-Zisterne entfernt werden und zur nächsten heranreifenden Golgi-Zisterne zurückgeführt werden. Somit hätte vesikelvermittelter Transport zumindest beim rückwärtsgerichteten Transport eine wichtige Funktion. Dieses GolgiReifungsmodel wird durch Befunde, die mit Algen und Säugerzellen erhalten wurden, gestützt (Becker und Melkonian, 1996; Bonfanti et al., 1998). In Hefe wurde die Möglichkeit des Reifungsmodells noch nicht untersucht. Dafür sprechen würde aber, daß sich Sed5p nicht nur im frühen Golgi aufhält, sondern zwischen ER und Golgi zirkuliert (Wooding und Pelham. 1998). Daraus folgt, daß Sed5p auch auf Transportvesikeln lokalisiert ist und somit die homotypische Fusion der vom ER gebildeten Vesikel katalysieren könnte, um eine neue GolgiZisterne auszubilden. Dabei könnten ebenfalls die eben genannten SNAREs Bos1p, Bet1p und Sec22p als v-SNAREs involviert sein oder aber es käme möglicherweise zu einer Ausbildung von Sed5p-Oligomeren. Diese Ausbildung von Oligomeren trifft vermutlich auch für das t-SNARE Ufe1p während der homotypischen ER-Fusion zu (Patel et al., 1998). Allerdings müsste dann ein zusätzlicher Mechanismus verhindern, daß die am Golgi gebildeten Vesikel nicht miteinander fusionieren. Als Membrankomponente der neugebildeten GolgiZisterne könnte Sed5p dann ebenfalls als t-SNARE für Vesikel fungieren, die Golgi-residente Proteine von späten Golgi-Zisternen zurücktransportieren und vSNAREs, mit denen Sed5p SNARE-Komplexe ausbilden kann, exponieren. 
Wie lassen sich aber die in dieser Arbeit analysierten Folgen der Überproduktion von Sed5p erklären? Die Überproduktion von Sed5p bewirkt auf der einen Seite eine Verlangsamung des Transports von CPY und ALP, wobei jeweils die ER-Vorläuferformen akkumulieren. Andererseits kommt es zu einer Beschleunigung der Kex2p-Prozessierung des Sec22- $\alpha$ Reporters aufgrund einer Fehllokalisation in den späten Golgi und zu einer Fehllokalisation des Ste2-Wbp1pReporters zur Plasmamembran aufgrund einer gestörten ER-Retention.

Unter der Annahme des Golgi-Reifungsmodells würde eine Erhöhung der Sed5p-Expression möglicherweise eine vermehrte Ausbildung von Vorläufern neuer Golgi-Zisternen durch homotypische ER-Vesikel-Fusion bewirken. Dafür würden auch die Ergebnisse von Hardwick et al. (1992) sprechen, die bei ihren Untersuchungen der Überproduktion von Sed5p anhand von Elektronenmikroskopie-Aufnahmen eine vermehrte Bildung von vesikulären Strukturen und in der Immunfluoreszenz eine erhöhte Anzahl von punktförmigen Golgi-Strukturen feststellten. Diese Strukturen wären möglicherweise in ihrer Reifung gehemmt, da die nötigen Recyclingprozesse mit der Zunahme der vermehrt gebildeten frühen Golgi-Strukturen nicht schritthalten können. Faktoren, die für den Export von CPY und ALP nötig sind, akkumulieren im frühen Golgi und fehlen somit im ER. Das würde erklären, warum CPY und ALP länger im ER verweilen. Die Fehllokalisation des Sec22- $\alpha$ Reporters und des Ste2-Wbp1p Reporters ließe sich ebenfalls durch einen Reifungsdefekt der Golgi-Zisternen erklären: In der unmaturierten Golgi-Zisterne wären nicht alle Komponenten vorhanden, die für einen Rücktransport zum ER benötigt werden, z. B. Sortierungsfaktoren, die die oben genannten Reporter in COPI-Vesikel dirigieren. Somit würden die Reporter in den späten Golgi bzw. zur Plasmamembran transportiert, da der Rücktransport zum ER gestört ist.

Die Folgen der Sed5p-Überproduktion ließen sich jedoch auch durch eine Akkumulation von ER-Golgi Transportvesikeln, die nicht mit dem Golgi fusionieren können, erklären. Auch hier würden Proteine, die für den Rücktransport zum ER benötigt werden, nicht mehr ausreichend in den frühen Golgi transportiert. Es stellt sich hierbei aber die Frage, warum es bei längerer Inkubation nicht zu einem vollständigen ER-Golgi Transportblock kommt, denn Sed5p zierkuliert ebenfalls zwischen ER und Golgi und müsste folglich im ER akkumulieren. CPY und ALP werden zwar verlangsamt zur Vakuole transportiert, aber der Transport war nicht vollständig blockiert. In der Immunfluoreszenz konnten Hardwick et al. (1992) bei Überproduktion von Sed5p nur eine Zunahme punktförmiger GolgiStrukturen feststellen, die sie auf ER-Golgi Transportvesikel zurückführten, aber keine typischen ER-Strukturen. Es ist jedoch aus heutiger Sicht nicht möglich, 
Vesikel mittels Immunfluoreszenz in Hefe sichtbar zu machen. Die Beobachtungen sprechen vielmehr für eine vermehrte Ausbildung von Golgi-Strukturen.

Wenn durch die Sed5p-Überproduktion tatsächlich die Struktur des GolgiApparates beeinflußt wird, wäre es möglich, daß die Kex2-Protease, die den Sec22- $\alpha$ Reporter prozessiert, nicht mehr im späten Golgi lokalisiert ist. Aufgrund dieser Überlegungen, wurden subzelluläre Fraktionierungen mittels Sucrosegradientenzentrifugation von Hefezellen durchgeführt (nicht gezeigt). Eine Sed5p-Überproduktion führt nachweislich jedoch nicht zu einer Kex2pFehllokalisation. Die Protease ist stets in den Golgi-Fraktionen lokalisiert. Dies schließt jedoch nicht aus, daß eine Umverteilung von Kex2p zwischen frühem und spätem Golgi stattgefunden haben könnte, was mit dieser Methode nicht zu detektieren ist. Da aber der Ste2-Wbp1p Reporter, der ebenfalls für seine ER-Lokalisation eine intakte Retentionsmaschinerie benötigt, zur Plasmamembran fehllokalisiert wird, liegt die Vermutung nahe, daß die vermehrte Kex2p-Prozessierung des Sec22- $\alpha$ Reporters letztlich tatsächlich auf einen unzureichenden retrograden Golgi-ER Transport zurückzuführen ist.

\subsection{Sfb2p - ein Gegenspieler des Sed5p?}

Die Fehllokalisation des Sec22- $\alpha$ Reporters und des Ste2-Wbp1p Reporters, die durch die Sed5p-Überproduktion in der Zelle verursacht wurde, konnte durch gleichzeitige Erhöhung des Expressionslevels von Sfb2p wieder aufgehoben werden. Dieses Phänomen war spezifisch für die Transporteffekte der beiden Reporter, denn die durch Sed5p-Überproduktion hervorgerufene Verlangsamung des CPY- und ALP-Transports wurde nicht aufgehoben.

Sfb2p ist genau wie Sfb3p ein nicht essentielles Sec24p-Homolog, das Bestandteil einer COPII-ähnlichen Vesikelhülle ist. Beide Proteine wurden in unserer Abteilung als Sed5p-bindende Proteine Sfb2p bzw. Sfb3p (Sed5-bindingprotein) gefunden (Peng et al., 2000). Sfb2p wurde gleichzeitig im Arbeitskreis von R. Schekman als ein mit Sec16p interagierendes Protein Iss1p (interactor with SEC sixteen) in einem Zwei-Hybrid-,,screen“" gefunden. Sfb3p wurde in der Arbeitsgruppe von C. Kaiser durch einen synthetischen Letalitäts-,,screen“ als Lst1p (lethal with sec-thirteen) entdeckt (Kurihara et al., 2000; Roberg et al., 1999). Es konnte gezeigt werden, daß Sfb2p ebenso wie Sec $24 p$ mit Sec23p einen heteromeren Komplex ausbilden kann, der zusammen mit Sec13p/Sec31p

und der GTPase Sar1p das Vesikelabschnürung von isolierten Mikrosomenmembranen vermittelt. Es konnte hierbei kein wesentlicher Unter- 
schied zwischen den beiden Vesikelpopulation bezüglich ihrer Dichte oder der Zusammensetzung der Frachtmoleküle festgestellt werden. Beide Vesikelarten enthalten Sec22p und Bet1p sowie den löslichen $\alpha$-Faktor-Vorläufer gpoF (Kurihara et al., 2000). Frachtmoleküle, die in geringerer Konzentration in den Vesikeln vorliegen, wurden jedoch nicht analysiert. Dies könnten beispielsweise Sortierungsfaktoren sein, die nur in einer bestimmten Vesikelart transportiert werden. Ein Hefestamm mit SFB2-Deletion zeigte keine Transportdefekte bei den untersuchten Frachtmolekülen CPY, ALP, Invertase und Gas1p (Peng et al., 2000). Bezüglich dieser Frachtmoleküle verhält sich ein Stamm mit SFB3- Deletion ähnlich, jedoch ist ein spezifisches Frachtmolekül bekannt, daß unzureichend vom ER zur Plasmamembran transportiert wird: die Plasmamembran-ATPase Pma1p. Es wäre also möglich, daß auch in einem SFB2-Deletionsstamm ganz spezifische, bisher nicht determinierte Frachtmoleküle im ER zurückgehalten werden.

Wie kann man sich den suppremierenden Effekt der Überproduktion von Sfb2p bezüglich der Fehllokalisation der beiden Reporter vorstellen? Die einfachste Erklärung wäre, daß Sfb2p an Sed5p bindet und somit kompetitiv andere potentielle Bindungspartner verdrängt. Wenn diese Annahme richtig wäre, würde man erwarten, daß andere Proteine, die ebenfalls an Sed5p binden, den gleichen Effekt wie Sfb2p zeigen würden. Dies konnte jedoch nicht festgestellt werden (vgl. Tabelle 4). Sfb2p ist das einzige hier untersuchte Sed5p-bindende Protein, das einen Einfluß auf die Fehllokalisation beider Reporter hatte. Eine weitere mögliche Erklärung wäre, daß sich aufgrund der erhöhten Sfb2p-Expression mehr Vesikel am ER bilden können, die in ihrer Vesikelhülle anstelle des heteromeren Sec23p/Sec24p-Komplexes den Sec23p/Sfb2p-Komplex enthalten. Diese Vesikelpopulation transportiert möglicherweise spezifische Frachtmoleküle, die für die Retentionsmaschinerie des Ste2-Wbp1p Reporters und des Sec22- $\alpha$ Reporters benötigt werden. Diese Theorie würde mit der Annahme, daß eine Überproduktion von Sed5p zu einer Akkumulation von ER-Golgi Transportvesikeln führt, nicht harmonieren, denn warum sollten angestaute Vesikel, nur weil sie am ER mit einer anderen Vesikelhülle versehen waren, plötzlich fusionieren können. Es konnte schließlich gezeigt werden, daß die Hüllproteine des Vesikels vor der Fusion abdissoziieren (Orci et al., 1989). Andererseits könnten auch mitgeführte Frachtmoleküle eine effizientere Fusion bewirken. Kurihare et al. konnten jedoch zeigen, daß Vesikel, die entweder den Sec23p/Sec24p-Komplex oder den Sec23p/Sfb2p-Komplex enthalten, vergleichbare Mengen der SNARE-Proteine Sec22p und Bet1p mit sich führen. Zudem sind viele zur Fusion benötigten Proteine zytosolisch. Würde man aber annehmen, daß eine Überpro- 
duktion von Sed5p zu vermehrter Golgi-Zisternen-Bildung und den damit verbundenen Transportdefekten führt, könnten Sec23p/Sfb2p-Vesikel, die am ER vermehrt gebildet werden, weiterhin mit diesen Zisternen fusionieren. Unter der Annahme, daß solche Vesikel spezifische Frachtmoleküle mit sich führen, die für das Zurückführen des Sec22- $\alpha$ und des Ste2-Wbp1p Reporters benötigt werden, wäre die Rückführungsmaschinerie zum ER wieder hergestellt. Umgekehrt würde man in einem SFB2 Deletionsstamm erwarten, daß die beiden Reporter aufgrund des fehlenden Transports dieses fiktiven spezifischen Frachtmoleküls in den Golgi, vermehrt fehllokalisiert werden würden. Dies konnte tatsächlich in dieser Arbeit mit Hilfe des Sec22- $\alpha$ Reporters und des GFP-Sec22p Reporters gezeigt werden. Die Tatsache, daß im SFB2-Deletionsstamm auch der GFP-Sec22p Reporter vermehrt in Golgi-Strukturen lokalisiert ist, spricht für eine echte Fehllokalisation des Sec22- $\alpha$ Reporters und nicht für eine Umverteilung von Kex2p.

Die Fehllokalisation von Sec22p im SFB2 Deletionsstamm stellt auch eine Verbindung zu den bekannten genetischen Interaktionen von $S F B 2$ her. Interessanterweise sind die Doppelmutanten $4 s f b 2 / \sec 22-3$ und $4 s f b 2 / b e t 1-1$ nicht lebensfähig (Kurihara et al., 2000).

\subsection{Acc1p und der vesikuläre Transport}

In dieser Arbeit wurde mit Hilfe des Zwei-Hybrid-Systems nach Interaktionspartnern von Sec22p gesucht. Zu Beginn der Experimente war bekannt, daß Sec22p nicht mit den einzelnen Hüllproteinen der COPI-Vesikelhülle sowie mit den SNARE Proteinen Sed5p und Ufe1p in diesem System interagiert (R. Duden, persönliche Mitteilung, bzw. eigene Untersuchungen). Durch den Einsatz diese Systems sollten somit unbekannte Interaktionspartner gefunden werden. Es konnte unter Verwendung der zytoplasmatischen Domäne von Sec22p als Köder ein Klon aus einer c-DNA-Hefegenbank isoliert werden, der für die C-terminale Domäne der Acetyl-CoA-carboxylase (Acc1p) kodiert.

Acc1p katalysiert biotinabhängig die Synthese von Malonyl-CoA aus Acetyl-CoA. Aus Malonyl-CoA-Untereinheiten werden die Fettsäuren durch den zytosolischen Fettsäuresynthasekomplex (Fas1p/Fas2p) bis zu einer Kettenlänge von $\mathrm{C}_{16}$ synthetisiert. Die $\mathrm{C}_{16}$-Fettsäuren werden dann bis zu einer Kettenlänge von $\mathrm{C}_{26}$ durch Elongasen (Elo2p, Elo3p) am ER verlängert (Oh et al., 1997). Aus der Literatur geht hervor, daß Acc1p teilweise mit dem ER assoziiert ist (Ivessa et al., 1997). In seiner aktiven Form bildet Acc1p ein Tetramer aus, dessen Untereinheiten ein Molekulargewicht von 250 kDA aufweisen. Das Enzym enthält drei 
funktionelle Domänen: die Biotincarboxylase-, die Biotinbindungs- und die Transcarboxylasedomäne (Abbildung 28). Der mittels Zwei-Hybrid-System isolierte Klon enthält die C-terminale Domäne (AS 2004-2233), die eine potentielle „,coiled-coil“" Region und einen Teil der Transcarboxylase-Domäne beinhaltet.

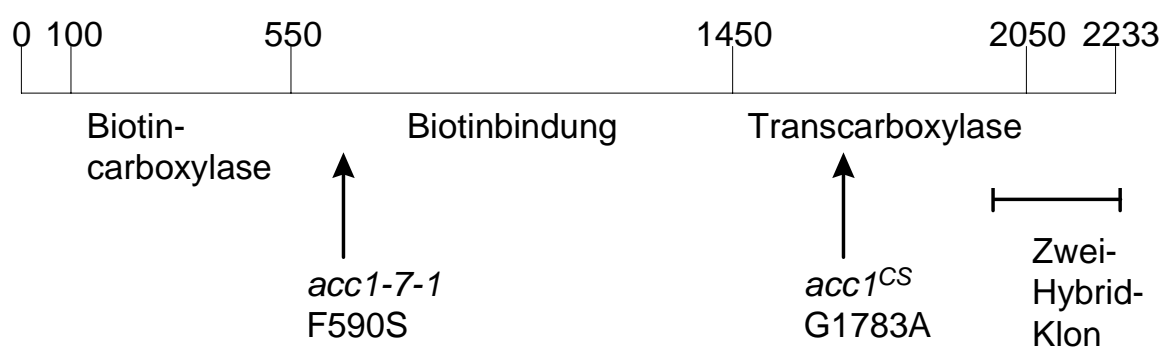

Abbildung 28: Schematische Darstellung der funktionellen Domänen des Acc1p. Die Aminosäurepositionen der Mutationen in dieser Arbeit verwendeter acc1-Allele (Al Feel et al., 1992; Schneiter et al., 2000) sowie des im Zwei-Hybrid-System gefundenen Proteinabschnitts sind eingetragen.

Es konnte in dieser Arbeit gezeigt werden, daß nicht nur die C-terminale Domäne des Acc1p mit Sec22p interagiert sondern auch das gesamte Enzym. Dabei ist die „coiled-coil“-Region des Sec22p allein ausreichend für eine Acc1p-Bindung (Abbildung 20). Da diese Region auch das sogenannte SNARE-Motiv enthält und für die Ausbildung von SNARE-Komplexen während des Fusionsprozesses von Vesikeln benötigt wird, stellt sich die Frage, unter welchen Voraussetzungen die Bindung zu Acc1p überhaupt erfolgen kann.

Von J. E. Gerst (1999) wurde ein Modell vorgeschlagen, in dem SNAREProteine einen Zyklus unterschiedlicher Konformationen durchlaufen (Abbildung 29): In Phase 1 bilden SNAREs cis-Komplexe auf derselben Membran aus. Dies kann sowohl auf der Vesikel- als auch Zielmembran erfolgen. Betrachtet man den retrograden Golgi-ER Transport, so könnten auf der Zielmembran beispielsweise Ufe1p mit Tip20p und Sec20p in einem Komplex arrangiert sein und auf dem Vesikel möglicherweise Sec22p mit Bet1p oder Sed5p, da diese zwischen ER und Golgi zirkulieren. Diese cis-SNARE-Komplexe dissoziieren nach Bindung von Sec18p und Sec17p (NSF und SNAP) unter anschließender ATP-Hydrolyse und gehen in den Übergangszustand der Phase 2 über (,priming“). Dieser erlaubt, daß die in Kapitel 1.3.2 beschriebene Bindung von SNARE-Modulatoren und das Erreichen eines stabilisierten Zustands (Phase 3). Nachdem die SNARE-Modulatoren das sogenannte „docking“ und 
„tethering“ der Vesikel zu ihrer jeweiligen Zielmembran vermittelt haben, wird die cis-SNARE-Interaktion aufgehoben und die SNAREs der Vesikel bilden trans-SNARE-Komplexe mit den SNAREs der Zielmembran (Phase 4), wodurch es letztlich zur Fusion der Vesikel mit der Zielmembran kommt und sich erneut cis-SNARE-Komplexe ausbilden (Phase 1). Die v-SNARE-Proteine (z. B. Sec22p) werden anschließend wieder zu ihrem Ausgangsort zurücktransportiert, während die t-SNAREs (z. B. Ufe1p) an der Akzeptormembran verbleiben.

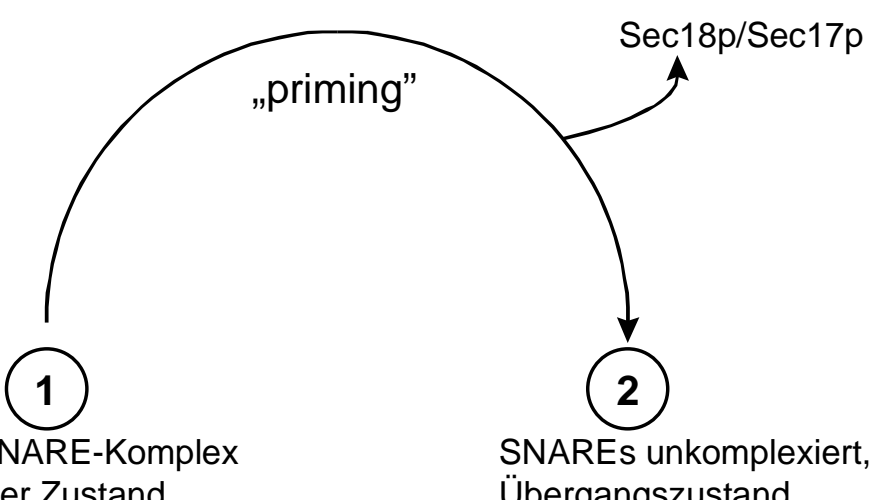

cis-SNARE-Komplex stabiler Zustand

Fusion $\uparrow$

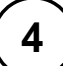

trans-SNARE-Komplex stabiler Zustand

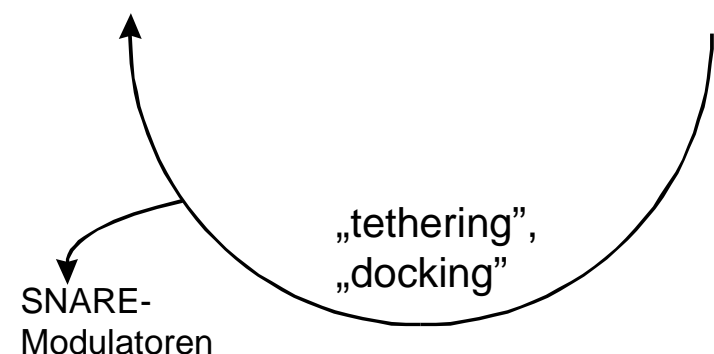

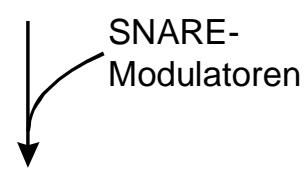

$3)$

SNAREs unkomplexiert, stabiler Zustand

Abbildung 29: SNARE-Zyklus, modifiziert nach J. E. Gerst (1999). Näheres siehe Text.

Unter Annahme dieses von J. E. Gerst vorgeschlagenen Modells, wird der Zeitpunkt, bei dem eine Bindung zwischen Acc1p und Sec22p möglich ist, durch die Phase 1 und Phase 2 repräsentiert. Da Phase 2 in diesem Modell nur einen Übergangszustand zu Phase 3 darstellt, ist die Interaktion zu Acc1p in dieser SNAREKonformation eher unwahrscheinlich. Wenn Acc1p eine Bindung mit Sec22p eingehen würde während dies als Untereinheit eines cis-SNARE-Komplex fungiert, dann wäre dies eine Erklärung für die in dieser Arbeit gefundene Bindung 
von Acc1p an Ufe1p und Sed5p, den möglichen Komponenten eines Komplexes mit Sec22p. Die Bindung von Acc1p an einen Proteinkomplex und nicht an monomere Proteine würde auch den Befund erklären, daß ein Defekt in nur einem Baustein des Komplexes, Sec22p, genügt, um die ER-Lokalisation von GFP-Acc $1{ }^{\mathrm{CT}} \mathrm{p}$ aufzuheben. Daß diese in vitro-Interaktion zwischen Acc1p und Sec22p auch in vivo vorhanden sein könnte, wird vor allen Dingen durch die genetische Interaktion von SEC22 und ACC1 gestützt. Eine Doppelmutante $a c c 1^{C S} 4 s e c 22$ ist nicht lebensfähig und eine Deletion von SEC22 in dem temperatursensitiven acc1-7-1-Stamm verstärkt dessen Wachstumsdefekt (vgl. Abbildung 23, Abbildung 24)

Wie ließe sich diese Bindung interpretieren? Da Sec22p bzw. Ufe1p hauptsächlich und Sed5p aufgrund seines Recycling-Verhaltens teilweise in der ER-Membran lokalisiert sind, liegt die Vermutung nahe, daß diese einen Rezeptor für die teilweise vorhandene ER-Lokalisation von Acc1p darstellen. Eine Kettenverlängerung der $\mathrm{C}_{16}$-Fettsäuren durch die mit dem ER assoziierten Elongasen Elo2p bzw. Elo3p benötigt Malonyl-CoA als Ausgangssubstanz. Eine Bindung an Sec22p/Ufe1p/Sed5p würde die Synthese von Malonyl-CoA durch Acc1p direkt am ER ermöglichen und somit die Synthese langkettiger Fettsäuren regulieren, die wiederum Bestandteile von Sphingolipiden sind.

Die Annnahme einer Rezeptorfunktion der SNAREs für Acc1p wird durch Experimente mit dem GFP-markierten C-terminalen Fragment von Acc1p bestätigt. Die Lokalisation dieses Fusionsproteins spiegelt die Verteilung des Acc1p innerhalb der Zelle wider, da bei einem Vergleich die Acc1p-Lokalisation in einem Sucrosedichtegradienten, der Hefeorganellen voneinander trennt, mit dem Fluoreszenzsignal des GFP-Acc ${ }^{\mathrm{CT}} \mathrm{p}$ innerhalb der Zelle korrelieren. Wenn das Fluoreszenzsignal sehr stark am Zellkern konzentriert ist, ist ein großer Anteil des Acc1p im Sucrosegradienten in den ER-Fraktionen detektierbar. Bei überwiegend zytosolischer Fluoreszenzsignale sind $80 \%$ des Acc1p auch in zytosolischen Fraktionen des Sucrosegradienten vorhanden. Dabei stellte sich heraus, daß sich Acclp bei blockiertem anterograden ER-Golgi Transport vom ER ins Zytosol umverteilt. Diese Umverteilung ist auch in einem SEC22 Deletionsstamm bzw. im temperatursensitiven sec22-3-Stamm bei $25^{\circ} \mathrm{C}$ zu beobachten, was für eine Rezeptorfunktion des Sec22p spricht. Da diese Umverteilung vom Kern ins Zytosol nicht in den SNARE-Mutantenstämmen ufe1-1 und sed5-1 auftritt, scheint Sec22p das zentrale Molekül des möglicherweise oligomeren Acc1p-Rezeptors zu sein.

Wenn die Lokalisation von Acc1p am ER eine regulative Funktion bezüglich der Synthese von langkettigen Fettsäuren und damit einen direkten Einfluß 
auf die Synthese von Lipiden hätte, würde man erwarten, daß eine Bindung an den ER-Rezeptor nur dann erfolgt, wenn eine Synthese von Malonyl-CoA am ER nötig ist. Dies wäre zum Beispiel der Fall, wenn die Zelle wächst und Zellwandund Zellmembransynthese aktiv sind. Blockiert man den anterograden ER-Golgi Transport, dann simuliert man den Stillstand von Wachstum und Sekretion. Tatsächlich wurde gefunden, daß Acc1p in Fraktionierungsexperimenten überwiegend zytosolisch ist. Einen weiteren Hinweis auf eine regulierte Bindung an den ER-Rezeptor liefern die Bindungsexperimente in Anwesenheit von Palmitoyl-CoA (Abbildung 27), die zeigen, daß die Bindung an GST-Sec22 $\Delta$ TMDp und GST-Ufe1 $\Delta$ TMDp stimuliert wird. Palmitoyl-CoA, ein Endprodukt der zytosolischen Fettsäurebiosynthese, ist gleichzeitig zusammen mit Malonyl-CoA Ausgangssubstanz für die Kettenverlängerung durch Elo2p bzw. Elo3p am ER. Die Konzentrierung dieser Ausgangssubstanzen am ER durch Bindung von Acc1p an Sec22p bzw. Ufe1p würde eine schnellere Kettenverlängerung bewirken. Im Widerspruch $\mathrm{zu}$ diesem vorgeschlagenen Mechanismus steht die Tatsache, daß Palmitoyl-CoA in vitro als Inhibitor von Acc1p fungiert. Jedoch muß die Annahme einer negativen Regulation der Malonyl-CoASynthese durch Palmitoyl-CoA eine regulatorische Funktion der beobachteten Bindung von Acc1p an Sec22p bezüglich der Kettenverlängerung nicht zwangsläufig ausschließen.

Ein Zusammenhang zwischen Lipiden und vesikulärem Transport wurde auch schon in anderen Arbeiten beobachtet. Beispielsweise gibt es hinreichende Beweise, daß phosphorylierte Produkte von Phosphatidylinositol bei der Regulation des Membrantransports in Hefe beteiligt sind (Übersicht bei Odorizzi et al., 2000). Ein indirekter Zusammenhang zwischen Sphingolipiden und der Membranfusion wurde durch Arbeiten mit den an der Exocytose in Hefe beteiligten v-SNAREs Snc1p un Snc2p erkannt (David et al., 1998). Hefen, die diese beiden SNAREs nicht enthalten, zeigen einen konditional letalen Phänotyp (Protopopov et al., 1993). Es konnten spontane Revertanten isoliert werden, die diesen Phänotyp aufheben. Dabei handelt es sich um Mutationen im ELO2- oder ELO3-Gen, die zu einer Inaktivierung der Genprodukte Elo2p bzw. Elo3p führen. Die Autoren mutmaßten, daß es durch Inaktivierung der für die Verlängerung von Fettsäuren verantwortlichen Enzyme zu einer reduzierten Sphingolipid- und Ceramidkonzentration kommt, wodurch der vesikuläre Transport zur Plasmamembran wiederhergestellt wird. Der Mechanismus für dieses Phänomen ist noch nicht bekannt, jedoch schlagen die Autoren vor, daß möglicherweise eine Veränderung der Membranzusammensetzung die Fusionskompetenz von Vesikeln 
variieren, die Sortierung anderer Proteine in Vesikel beeinflussen oder die t-SNARE-t-SNARE Wechselwirkung an der Plasmamembran verändern könnte.

Die in dieser Arbeit gefundene Interaktion von Acc1p mit Sec22p, Ufe1p bzw. Sed5p, die möglicherweise eine weitere Funktion als oligomerer ER-Rezeptor besitzen, könnte in unmittelbaren Zusammenhang mit den eben genannten Aspekten stehen. 


\section{Zusammenfassung}

Die Aufgabe der vorliegenden Arbeit war es, systematisch nach Genen zu suchen, die durch Überexpression die ER-Golgi-Recyclingmaschinerie von Sec22p und integralen Membranproteinen, die ein KKXX-Motiv tragen, beeinflussen. Stellvertretend für die Sec22p-Lokalisation wurde das Verhalten des Sec22- $\alpha$ Reporters untersucht, der sich wie Sec22p hauptsächlich im ER aufhält. Ein gestörter Recyclingmechanismus äußert sich in einer meßbaren Fehllokalisation des Sec22- $\alpha$ Reporters in den späten Golgi. Eine durch das KKXX-Motiv vermittelte ER-Retention wurde mit Hilfe des Ste2-Wbp1p Reporters analysiert, der bei gestörter Rückführung zum ER zur Plasmamembran fehllokalisiert wird. Mit Hilfe von „multi-copy“-Plasmiden wurde ein Gen isoliert, dessen Genprodukt bei Überproduktion den Recyclingmechanismus beider Reporter beeinflußt: Sed5p. Es handelt sich hierbei um ein für die Hefe essentielles t-SNARE, das im frühen Golgi lokalisiert ist. Aus früheren Untersuchungen (Hardwick et al., 1992) ist bekannt, daß lösliche Frachtmoleküle wie die Carboxypeptidase Y (CPY) und die Alkalische Phosphatase (ALP) unter diesen Bedingungen eine verlangsamte Kinetik des ER-Golgi Transports aufweisen. Die in der vorliegenden Arbeit durchgeführte eingehende Analyse der durch SED5-Überexpression hervorgerufenen Defekte wies auf Unterschiede im Transportverhalten zwischen löslichen und membranständigen Proteinen hin. Bei den untersuchten membranständigen Reportern Sec22- $\alpha$ bzw. Ste2-Wbp1p wurde der entgegengesetzte Effekt beobachtet: Sie wurden schneller transportiert. Dieser forcierte Transport der membranständigen Proteine konnte durch die Überproduktion von Sfb2p aufgehoben werden, während die verlangsamte Kinetik der lösliche Proteine (CPY und ALP) nicht beeinflußt wurde. Da Sfb2p eine Untereinheit eines neuartigen Hüllproteinkomplexes von am ER generierten Vesikeln ist, liegt die Vermutung nahe, daß in den Vesikeln, an deren Generierung Sfb2p beteiligt ist, spezielle Frachtmoleküle transportiert werden, die für eine effiziente Sortierung der eingesetzten Sec22- $\alpha$ bzw. Ste2-Wbp1p Reporter in Vesikel des retrograden Golgi-ER Transports sorgen. Die in einem SFB2-Deletionsstamm auftretende vermehrte Fehllokalisation sowohl des Sec22- $\alpha$ Reporters als auch von GFP-Sec22p in den Golgi unterstützt diese Vermutung. Somit konnte mit der vorliegenden Arbeit das Ziel erreicht werden, ein Protein zu finden, das spezifisch das Recyclingverhalten von Sec22p und Ste2-Wbp1p beeinflußt.

Weiterhin sollte mittels des Zwei-Hybrid-Systems nach neuen Interaktionspartnern von Sec22p gesucht werden. Es konnte mit der zytoplasmati- 
schen Domäne von Sec22p als Köder aus einer c-DNA-Genbank ein Klon isoliert werden, der für die C-terminale Domäne der Acetyl-CoA-Carboxylase (Acc1p) in Hefe kodiert. Acc1p synthetisiert Malonyl-CoA, eine Ausgangssubstanz für die zytosolische Fettsäurebiosynthese sowie für die Fettsäurekettenverlängerung durch Elongasen am ER. Die Interaktion zwischen Acc1p und Sec22p konnte sowohl mit GST-,,pull-down“-Experimenten in vitro als auch durch Kreuzungen von Mutantenstämmen genetisch bestätigt werden. Untersuchungen weiterer SNAREs ergaben, daß auch Ufe1p und Sed5p sowohl im Zwei-Hybrid-System als auch GST-,,pull-down“-Experimenten an Acc1p binden. Die Tatsache, daß Acclp teilweise am ER lokalisiert ist, läßt die Vermutung zu, daß die SNAREs, möglicherweise sogar als oligomerer Komplex, diese ER-Assoziation vermitteln. Dabei scheint das Vorhandensein eines Wildtyp-Sec22p entscheident für die Acc1p-Lokalisation am ER zu sein. Da Acc1p bei blockiertem ER-Golgi Transport hauptsächlich in zytosolischer Form vorliegt, läßt sich ein Zusammenhang zwischen vesikulärem Transport und Acc1p-Lokalisation herstellen. Es konnte gezeigt werden, daß Palmitoyl-CoA, eine Ausgangssubstanz der Fettsäurekettenverlängerung, die Bindung von Acc1p an die SNARE-Proteine Sec22p und Ufe1p verstärken kann. Diese Umverteilung von Acc1p vom Zytosol an das ER könnte somit eine wichtige regulative Funktion bei der Synthese längerkettiger Fettsäuren darstellen, was eventuell die Sphingolipid- und Ceramid-Synthese beeinflußt. 


\section{Literaturverzeichnis}

Al-Feel, W., S. S. Chirala and S. J. Wakil 1992. Cloning of the yeast FAS3 gene and primary structure of yeast acetyl-CoA carboxylase. Proc. Natl. Acad. Sci. U S A 89:4534-8.

Aridor, M., J. Weissman, S. Bannykh, C. Nuoffer and W. E. Balch 1998. Cargo selection by the COPII budding machinery during export from the ER. J. Cell Biol. 141:61-70.

Balch, W. E., J. M. McCaffery, H. Plutner and M. G. Farquhar 1994. Vesicular stomatitis-virus glycoprotein is sorted and concentrated during export from the endoplasmic reticulum. Cell 76:841-852.

Ballensiefen, W. 1997. Untersuchung der Lokalisation des Sec22-Proteins in Saccharomyces cerevisiae mit Hilfe von Hybridproteinen. Dissertation, Universität Göttingen

Ballensiefen, W., D. Ossipov and H. D. Schmitt 1998. Recycling of the yeast vSNARE Sec22p involves COPI-proteins and the ER transmembrane proteins Ufe1p and Sec20p. J. Cell Sci. 111:1507-20.

Banfield, D. K., M. J. Lewis and H. R. B. Pelham 1995. A SNARE-like protein required for traffic through the Golgi-complex. Nature 375:806-809.

Barlowe, C. 1997. Coupled ER to Golgi transport reconstituted with purified cytosolic proteins. J. Cell Biol. 139:1097-108.

Barlowe, C. and R. Schekman 1993. SEC12 encodes a guanine-nucleotideexchange factor essential for transport vesicle budding from the ER. Nature 365:347-349.

Barlowe, C., C. Denfert and R. Schekman 1993. Purification and characterization of Sarlp, a small GTP-binding protein required for transport vesicle formation from the endoplasmic reticulum. J. Biol. Chem. 268:873-879.

Barlowe, C., L. Orci, T. Yeung, M. Hosobuchi, S. Hamamoto, N. Salama, M. F. Rexach, M. Ravazzola, M. Amherdt and R. Schekman 1994. COPII: A membrane coat formed by sec proteins that drive vesicle budding from the endoplasmic reticulum. Cell 77:895-907. 
Barrowman, J., M. Sacher and S. Ferro-Novick 2000. TRAPP stably associates with the Golgi and is required for vesicle docking. EMBO J 19:862-9.

Becker, B. and M. Melkonian 1996. The secretory pathway of protists: spatial and functional organization and evolution. Microbiol Rev 60:697-721.

Bennett, M. K. and R. H. Scheller 1993. The molecular machinery for secretion is conserved from yeast to neurons. Proc. Natl. Acad. Sci. USA 90:25592563.

Boehm, J., F. Letourneur, W. Ballensiefen, D. Ossipov, C. Demolliere and H. D. Schmitt 1997. Sec12p requires Rer1p for sorting to coatomer (COPI)coated vesicles and retrieval to the er. J. Cell Sci. 110:991-1003.

Boehm, J., H. D. Ulrich, R. Ossig and H. D. Schmitt 1994. Kex2-dependent invertase secretion as a tool to study the targeting of transmembrane proteins which are involved in ER-Golgi transport in yeast. EMBO J. 13:3696-3710.

Bonfanti, L., A. A. Mironov Jr, J. A. Martinez-Menarguez, O. Martella, A. Fusella, M. Baldassarre, R. Buccione, H. J. Geuze, A. A. Mironov and A. Luini 1998. Procollagen traverses the Golgi stack without leaving the lumen of cisternae: evidence for cisternal maturation. Cell 95:993-1003.

Bradford, M. M. 1976. A rapid and sensitive method for the quantification of microgram quantities of protein utilizing the principle of protein dye binding. Anal. Biochem. 72:248-254.

Burnette, W. N. 1981. "Western blotting": electrophoretic transfer of proteins from sodium dodecyl sulfate-polyacrylamide gels to unmodified nitrocellulose and radiographic detection with antibody and radioiodinated protein A. Anal. Biochem. 112:195-203.

Campbell, J. L. and R. Schekman 1997. Selective packaging of cargo molecules into endoplasmic reticulum-derived COPII vesicles. Proc. Natl. Acad. Sci. USA 94:837-42.

Cao, X. and C. Barlowe 2000. Asymmetric Requirements for a Rab GTPase and SNARE Proteins in Fusion of COPII Vesicles with Acceptor Membranes. J Cell Biol. 149:55-66. 
Cao, X. C., N. Ballew and C. Barlowe 1998. Initial docking of er-derived vesicles requires Uso1p and Ypt1p but is independent of SNARE proteins. EMBO J. 17:2156-2165.

Chardin, P. and F. McCormick 1999. Brefeldin A: The advantage of being uncompetitive. Cell 97:153-155.

Ciejek, E. and J. Thorner 79. Recovery of S. cerevisiae a cells from G1 arrest by alpha factor pheromone requires endopeptidase action. Cell 18:623-35.

Cohen, S. N., A. C. Chang and L. Hsu 72. Nonchromosomal antibiotic resistance in bacteria: genetic transformation of Escherichia coli by R-factor DNA. Proc. Natl. Acad. Sci. U S A 69:2110-4.

Cosson, P. and F. Letourneur 1994. Coatomer interaction with di-lysine endoplasmic reticulum retention motifs. Science 263:1629-1631.

Cosson, P., C. Demolliere, S. Hennecke, R. Duden and F. Letourneur 1996. Delta-cop and zeta-cop, 2 coatomer subunits homologous to clathrinassociated proteins, are involved in ER retrieval. EMBO J. 15:1792-1798.

Dascher, C., R. Ossig, D. Gallwitz and H. D. Schmitt 1991. Identification and structure of four yeast genes $(S L Y)$ that are able to suppress the functional loss of YPT1, a member of the ras-superfamily. Mol. Cell Biol. 11:872-885.

David, D., S. Sundarababu, J. E. Gerst and J. E. Gerst 1998. Involvement of long-chain fatty-acid elongation in the trafficking of secretory vesicles in yeast. J. Cell Biol. 143:1167-1182.

Dibrov, E., S. Fu and B. D. Lemire 98. The Saccharomyces cerevisiae TCM62 gene encodes a chaperone necessary for the assembly of the mitochondrial succinate dehydrogenase (complex II). J Biol Chem 273:32042-8.

Donaldson, J. G., D. Cassel, R. A. Kahn and R. D. Klausner 1992. ADPribosylation factor, a small GTP-binding protein, is required for binding of the coatomer protein beta-cop to Golgi membranes. Proc. Natl. Acad. Sci. USA 89:6408-6412.

Duden, R., L. Kajikawa, L. Wuestehube and R. Schekman 1998. Epsilon-cop is a structural component of coatomer that functions to stabilize alpha-cop. EMBO J. 17:985-995. 
Duden, R., M. Hosobuchi, S. Hamamoto, M. Winey, B. Byers and R. Schekman 1994. Yeast beta- and beta'-coat proteins (cop). Two coatomer subunits essential for endoplasmic reticulum-to-Golgi protein traffic. J. Biol. Chem. 269:24486-95.

Espenshade, P., R. E. Gimeno, E. Holzmacher, P. Teung and C. A. Kaiser 1995. Yeast SEC16 gene encodes a multidomain vesicle coat protein that interacts with Sec23p. J. Cell Biol. 131:311-24.

Espinet, C., M. A. de la Torre, M. Aldea and E. Herrero 95. An efficient method to isolate yeast genes causing overexpression-mediated growth arrest. Yeast 11:25-32.

Fasshauer, D., R. B. Sutton, A. T. Brunger and R. Jahn 1998. Conserved structural features of the synaptic fusion complex: SNARE proteins reclassified as Q- and R-SNAREs. Proc. Natl. Acad. Sci. USA 95:1578115786.

Faulstich, D., S. Auerbach, L. Orci, M. Ravazzola, S. Wegehingel, F. Lottspeich, G. Stenbeck, C. Harter, F. T. Wieland and H. Tschochner 1996. Architecture of coatomer - molecular characterization of delta-cop and protein interactions within the complex. J. Cell Biol. 135:53-61.

Ferro-Novick, S. and R. Jahn 1994. Vesicle fusion from yeast to man. Nature 370:191-193.

Fields, S. and O. Song 89. A novel genetic system to detect protein-protein interactions. Nature 340:245-6.

Fischer von Mollard, G., S. F. Nothwehr and T. H. Stevens 1997. The yeast vSNARE Vti1p mediates two vesicle transport pathways through interactions with the t-SNAREs Sed5p and Pep12p. J. Cell Biol. 137:1511-24.

Gallwitz, D., C. Donath and C. Sander 1983. A yeast gene encoding a protein homologous to the human c-has/bas proto-oncogene product. Nature 306:704-707.

Gerst, J. E. 1999. SNAREs and SNARE regulators in membrane fusion and exocytosis. Cellular and Molecular Life Sciences 55:707-734.

Gimeno, R. E., P. Espenshade and C. A. Kaiser 1995. SED4 encodes a yeast endoplasmic-reticulum protein that binds Sec16p and participates in vesicle formation. J. Cell Biol. 131:325-338. 
Goldberg, J. 1999. Structural and functional analysis of the ARF1-ARFGAP complex reveals a role for coatomer in GTP hydrolysis. Cell 96:893-902.

Grabowski, R. and D. Gallwitz 1997. High-affinity binding of the yeast cisGolgi t-SNARE, Sed5p, to wild-type and mutant Sly1p, a modulator of transport vesicle docking. FEBS Letters 411:169-72.

Guo, W., M. Sacher, J. Barrowman, S. Ferro-Novick and P. Novick 2000. Protein complexes in transport vesicle targeting. Trends Cell Biol. 10:251255.

Hanson, P. I., R. Roth, H. Morisaki, R. Jahn and J. E. Heuser 1997. Structure and conformational changes in NSF and its membrane receptor complexes visualized by quick-freeze/deep-etch electron microscopy. Cell 90:523-35.

Hardwick, K. G. and H. R. B. Pelham 1992. SED5 encodes a 39-kD integral membrane protein required for vesicular transport between the ER and the Golgi complex. J. Cell Biol. 116 513-521.

Hardwick, K. G., J. C. Boothroyd, A. D. Rudner and H. R. B. Pelham 1992. Genes that allow yeast cells to grow in the absence of the HDEL receptor. EMBO J. 11:4187-4195.

Harter, C., J. Pavel, F. Coccia, E. Draken, S. Wegehingel, H. Tschochner and F. Wieland 1996. Nonclathrin coat protein gamma, a subunit of coatomer, binds to the cytoplasmic dilysine motif of membrane proteins of the early secretory pathway. Proc. Natl. Acad. Sci. USA 93:1902-1906.

Hasslacher, M., A. S. Ivessa, F. Paltauf and S. D. Kohlwein 93. Acetyl-CoA carboxylase from yeast is an essential enzyme and is regulated by factors that control phospholipid metabolism. J Biol Chem 268:10946-52.

Hayashi, T., H. Mcmahon, S. Yamasaki, T. Binz, Y. Hata, T. C. Südhof and H. Niemann 1994. Synaptic vesicle membrane fusion complex: Action of clostridial neurotoxins on assembly. EMBO J. 13:5051-5061.

Helling, R. B., H. M. Goodman and H. W. Boyer 1974. Analysis of endonuclease EcoRI fragments of DNA from 1 bacteriophages and other viruses by agarose gel electrophoresis. J. Virol. 14:1235-1244.

Higashio, H., Y. Kimata, T. Kiriyama, A. Hirata and K. Kohno 2000. Sfb2p, a yeast protein related to Sec24p, can function as a constituent of COPII coats required for vesicle budding from the endoplasmic reticulum. J. Biol. Chem. 275:17900-17908. 
Hosobuchi, M., T. Kreis and R. Schekman 1992. SEC21 is a gene required for ER to Golgi protein-transport that encodes a subunit of a yeast coatomer. Nature 360:603-605.

Ivessa, A. S., R. Schneiter and S. D. Kohlwein 1997. Yeast acetyl-CoA carboxylase is associated with the cytoplasmic surface of the endoplasmic reticulum. Eur. J. Cell Biol. 74:399-406.

Julius D., R. Schekman and Thorner J. 1984. Glycosylation and processing of prepro-alpha-factor through the yeast secretory pathway. Cell 36:309-318.

Kadowaki, T., M. Hitomi, S. Chen and A. M. Tartakoff 1994. Nuclear mRNA accumulation causes nucleolar fragmentation in yeast mtr2 mutant. Mol Biol Cell 5:1253-63.

Kahn, R. A., J. Clark, C. Rulka, T. Stearns, C. J. Zhang, P. A. Randazzo, T. Terui and M. Cavenagh 1995. Mutational analysis of Saccharomyces cerevisiae arf1. J. Biol. Chem. 270:143-150.

Kahn, R. A., P. Randazzo, T. Serafini, O. Weiss, C. Rulka, J. Clark, M. Amherdt, P. Roller, L. Orci and J. E. Rothman 1992. The amino terminus of ADP-ribosylation factor (arf) is a critical determinant of arf activities and is a potent and specific inhibitor of protein-transport. J. Biol. Chem. 267:13039-13046.

Kaiser, C. A. and R. Schekman 1990. Distinct sets of SEC genes govern transport vesicle formation and fusion early in the secretory pathway. Cell 61:723-733.

Kappeler, F., D. R. Klopfenstein, M. Foguet, J. P. Paccaud and H. P. Hauri 1997. The recycling of ERGIC-53 in the early secretory pathway. ERGIC53 carries a cytosolic endoplasmic reticulum-exit determinant interacting with COPII. J Biol Chem 272:31801-8.

Katz, L., P. I. Hanson, J. E. Heuser and P. Brennwald 1998. Genetic and morphological analyses reveal a critical interaction between the c-termini of 2 SNARE proteins and a parallel 4 helical arrangement for the exocytic SNARE complex. EMBO J. 17:6200-6209.

Kim, D. W., M. Sacher, A. Scarpa, A. M. Quinn and S. Ferro-Novick 1999. High-copy suppressor analysis reveals a physical interaction between Sec34p and Sec35p, a protein implicated in vesicle docking. Mol Biol Cell 10:3317-29. 
Klenow, H. and J. Henningsen 1970. Selective elimination of the exonuclease activity of the deoxyribonucleic acid polymerase from $E$. coli B by limitied proteolysis. Proc. Natl. Acad. Sci. USA 65:168-175.

Kosodo, Y., Y. Noda and K. Yoda 1998. Protein-protein interactions of the yeast Golgi t-SNARE Sed5 protein distinct from its neural plasmamembrane cognate syntaxin-1. Biochemical and Biophysical Research Communications 250:212-216.

Kuehn, M. J., J. M. Herrmann and R. Schekman 1998. COPII-cargo interactions direct protein sorting into ER-derived transport vesicles. Nature 391:187-90.

Kurihara, T., S. Hamamoto, R. E. Gimeno, C. A. Kaiser, R. Schekman and T. Yoshihisa 2000. Sec24p and Iss1p function interchangeably in transport vesicle formation from the endoplasmic reticulum in Saccharomyces cerevisiae. Mol Biol Cell 11:983-98.

Laemmli, U. K. 1970. Cleavage of structural proteins during the assembly of the head of the bacteriophage T4. Nature 227:680-685.

Lazar, T., M. Götte and D. Gallwitz 1997. Vesicular transport: how many ypt/rab-GTPases make a eukaryotic cell? Trends in Biochemical Sciences 22:468-72.

Letourneur, F. and P. Cosson 1998. Targeting to the endoplasmic-reticulum in yeast-cells by determinants present in transmembrane domains. J. Biol. Chem. 273:33273-33278.

Letourneur, F., E. C. Gaynor, S. Hennecke, C. Demolliere, R. Duden, S. D. Emr, H. Riezman and P. Cosson 1994. Coatomer is essential for retrieval of dilysine-tagged proteins to the endoplasmic reticulum. Cell 79:11991207.

Lewis, M. J. and H. R. B. Pelham 1992. Ligand-induced redistribution of the human KDEL receptor from the Golgi complex to the endoplasmic reticulum. Cell 68:353-364.

Lewis, M. J. and H. R. B. Pelham 1996. SNARE-mediated retrograde traffic from the Golgi-complex to the endoplasmic reticulum. Cell 85:205-215.

Lewis, M. J. and H. R. B. Pelham 1990. A Human Homologue of the Yeast HDEL Receptor. Nature 348:162-163. 
Lewis, M. J., D. J. Sweet and H. R. Pelham 1990. The ERD2 gene determines the specificity of the luminal ER protein retention system. Cell 61:13591363.

Lewis, M. J., J. C. Rayner and H. R. B. Pelham 1997. A novel SNARE complex implicated in vesicle fusion with the endoplasmic-reticulum. EMBO J. 16:3017-3024.

Lian, J. P., S. Stone, Y. Jiang, P. Lyons and S. Ferro-Novick 1994. Ypt1p implicated in v-SNARE activation. Nature 372:698-701.

Lippincott-Schwartz, J., N. Cole and J. Presley 1998. Unravelling Golgi membrane traffic with green fluorescent protein chimeras. Trends in Cell Biol. 8:16-20.

Lupashin, V. V. and M. G. Waters 1997. t-SNARE activation through transient interaction with a rab-like guanosine triphosphatase. Science 276:1255-8.

Lupashin, V. V., I. D. Pokrovskaya, J. A. McNew and M. G. Waters 97. Characterization of a novel yeast SNARE protein implicated in Golgi retrograde traffic. Mol Biol Cell 8:2659-76.

Malhotra, V., L. Orci, B. S. Glick, M. R. Block and J. E Rothman 1988. Role of an N-ethylmaleimide sensitive transport component in promoting fusion of transport vesicles with cisternae of the Golgi stack. Cell 54:221-227.

Mayer, A. and W. Wickner 1997. Docking of yeast vacuoles is catalyzed by the Ras-like GTPase Ypt7p after symmetric priming by Sec18p (NSF). J. Cell Biol. 136:307-17.

McNew, J. A., F. Parlati, R. Fukuda, R. J. Johnston, K. Paz, F. Paumet, T. H. Sollner and J. E. Rothman 2000. Compartmental specificity of cellular membrane fusion encoded in SNARE proteins. Nature 407:153-159.

McNew, J. A., M. Sogaard, N. M. Lampen, S. Machida, R. R. Ye, L. Lacomis, P. Tempst, J. E. Rothman and T. H. Söllner 1997. Ykt6p, a prenylated SNARE essential for endoplasmic reticulum-Golgi transport. J. Biol. Chem. 272:17776-83.

Mitchell, D. A., T. K. Marshall and R. J. Deschenes 1993. Vectors for the inducible overexpression of glutathione S-transferase fusion proteins in yeast. Yeast 9:715-22.

Munro, S. and H. R. Pelham 1987. A C-terminal signal prevents secretion of luminal ER proteins. Cell 48:899-907. 
Nakano, A. and M. Muramatsu 1989. A novel GTP-binding protein, Sar1p, is involved in transport from the endoplasmic reticulum to the Golgi apparatus. J. Cell Biol. 109:2677-2691.

Neer, E. J., C. J. Schmidt, R. Nambudripad and T. F. Smith 1994. The ancient regulatory-protein family of WD-repeat proteins. Nature 371:297300.

Nishikawa, S., A. Hirata and A. Nakano 1994. Inhibition of endoplasmic reticulum (er)-to-Golgi transport induces relocalization of binding-protein (bip) within the ER to form the bip bodies. Mol. Biol. Cell 5:1129-1143.

Nishimura, N. and W. E. Balch 1997. A di-acidic signal required for selective export from the endoplasmic-reticulum. Science 277:556-558.

Odorizzi, G., M. Babst and S. D. Emr 2000. Phosphoinositide signaling and the regulation of membrane trafficking in yeast. Trends in Biochemical Sciences 25:229-235.

Oh, C. S., D. A. Toke, S. Mandala and C. E. Martin 97. ELO2 and ELO3, homologues of the Saccharomyces cerevisiae ELO1 gene, function in fatty acid elongation and are required for sphingolipid formation. J Biol Chem 272:17376-84.

Orci, L., V. Malhotra, M. Amherdt, T. Serafini and J. E Rothman 1989. Dissection of a single round of vesicular transport: sequential intermediates for intercisternal movement in the Golgi stack. Cell 56:357-368.

Ossig, R., C. Dascher, H. H. Trepte, H. D. Schmitt and D. Gallwitz 1991. The yeast SLY gene-products, suppressors of defects in the essential GTPbinding Ypt1 protein, may act in endoplasmic reticulum-to-Golgi transport. Mol. Cell. Biol. 11:2980-2993.

Ossipov, D., S. Schröder-Köhne and H. D. Schmitt 1999. Yeast ER-Golgi vSNAREs Bos 1p and Bet1p differ in steady-state localization and targeting. J. Cell Sci. 112:4135-42.

Ostermann, J., L. Orci, K. Tani, M. Amherdt, M. Ravazzola, Z. Elazar and J. E. Rothman 1993. Stepwise assembly of functionally active-transport vesicles. Cell 75:1015-1025.

Pagano, A., F. Letourneur, D. Garcia-Estefania, J. L. Carpentier, L. Orci and J. P. Paccaud 1999. Sec24 proteins and sorting at the endoplasmic reticulum. J. Biol. Chem. 274:7833-7840. 
Palade, G. 1975. Intracellular aspects of the process of protein secretion. Science 189:347-358.

Palmer, D. J., J. B. Helms, C. J. M. Beckers, L. Orci and J. E. Rothman 1993. Binding of coatomer to Golgi membranes requires ADP-ribosylation factor. J. Biol. Chem. 268:12083-12089.

Parlati, F., J. A. McNew, R. Fukuda, R. Miller, T. H. Sollner and J. E. Rothman 2000. Topological restriction of SNARE-dependent membrane fusion. Nature 407:194-198.

Patel, S. K., F. E. Indig, N. Olivieri, N. D. Levine and M. Latterich 1998. Organelle membrane-fusion - a novel function for the syntaxin homolog Ufe1p in ER membrane-fusion. Cell 92:611-620.

Pelham, HR 1990. The retention signal for soluble proteins of the endoplasmic reticulum. Trends Biochem. Sci. 15:483-6.

Peng, R. W., A. De Antoni and D. Gallwitz 2000. Evidence for overlapping and distinct functions in protein transport of coat protein Sec $24 p$ family members. J. Biol. Chem. 275:11521-11528.

Pfeffer, S. R. 1999. Transport-vesicle targeting: tethers before SNAREs. Nature Cell Biology 1:E17-E22.

Pfeffer, S. R. and J. E. Rothman 1987. Biosynthetic protein transport and sorting by the endoplasmic reticulum and Golgi. Ann. Rev. Biochem. 56:829-852.

Poon, P. P., D. Cassel, A. Spang, M. Rotman, E. Pick, R. A. Singer and G. C. Johnston 1999. Retrograde transport from the yeast Golgi is mediated by two ARF GAP proteins with overlapping function. EMBO J. 18:555-564.

Protopopov, V., B. Govindan, P. Novick and J. E. Gerst 1993. Homologs of the synaptobrevin vamp family of synaptic vesicle proteins function on the late secretory pathway in Saccharomyces cerevisiae. Cell 74:855-861.

Pryer, N. K., N. R. Salama, R. Schekman and C. A. Kaiser 1993. Cytosolic Sec13p complex is required for vesicle formation from the endoplasmic reticulum invitro. J. Cell Biol. 120:865-875.

Rayner, J. C. and H. R. Pelham 1997. Transmembrane domain-dependent sorting of proteins to the ER and plasma membrane in yeast. EMBO J. 16:1832-41. 
Roberg, K. J., M. Crotwell, P. Espenshade, R. Gimeno and C. A. Kaiser 1999. LST1 is a SEC24 homologue used for selective export of the plasma membrane ATPase from the endoplasmic reticulum. J Cell Biol 145:659-72.

Roth, D., W. Guo and P. Novick 1998. Dominant-negative alleles of sec10 reveal distinct domains involved in secretion and morphogenesis in yeast. Mol. Biol. Cell 9:1725-1739.

Rothman, J. E. 1994. Mechanism of intracellular protein transport. Nature 372:55-63.

Rothstein, R. J. 1983. One-step gene disruption in yeast. Methods Enzymol. 101:202-211.

Sacher, M., S. Stone and S. Ferro-Novick 1997. The synaptobrevin-related domains of Bos1p and Sec22p bind to the syntaxin-like region of Sed5p. J. Biol. Chem. 272:17134-17138.

Sacher, M., Y. Jiang, J. Barrowman, A. Scarpa, J. Burston, L. Zhang, D. Schieltz, J. R. Yates, H. Abeliovich and S. Ferro-Novick 1998. TRAPP, a highly conserved novel complex on the cis-golgi that mediates vesicle docking and fusion. EMBO J. 17:2494-2503.

Salama, N. R., J. S. Chuang and R. W. Schekman 1997. SEC31 encodes an essential component of the COPII coat required for transport vesicle budding from the endoplasmic reticulum. Mol. Biol. Cell 8:205-17.

Salama, N. R., T. Yeung and R. W. Schekman 1993. The Sec13p complex and reconstitution of vesicle budding from the ER with purified cytosolic proteins. EMBO J. 12:4073-4082.

Sambrook, J., E. F. Fritsch and T. Maniatis 1989. Molecular cloning. Cold Spring Harbor New York Cold Spring Harbor Laboratory Press

Sapperstein, S. K., V. V. Lupashin, H. D. Schmitt and M. G. Waters 1996. Assembly of the ER to Golgi SNARE complex requires Uso1p. J. Cell Biol. 132:755-67.

Scheel, A. A. and H. R. B. Pelham 1996. Purification and characterization of the human KDEL receptor. Biochemistry 35:10203-10209.

Schimmöller, F., B. Singerkruger, S. Schroder, U. Kruger, C. Barlowe and H. Riezman 1995. The absence of Emp24p, a component of ER-derived COPII-coated vesicles, causes a defect in transport of selected proteins to the Golgi. EMBO J. 14:1329-1339. 
Schneiter, R. and S. D. Kohlwein 1997. Organelle structure, function, and inheritance in yeast: a role for fatty acid synthesis? Cell 88:431-4.

Schneiter, R., C. E. Guerra, M. Lampl, V. Tatzer, G. Zellnig, H. L. Klein and S. D. Kohlwein 2000. A novel cold-sensitive allele of the rate-limiting enzyme of fatty acid synthesis, acetyl coenzyme A carboxylase, affects the morphology of the yeast vacuole through acylation of Vac8p. Mol Cell Biol 20:2984-95.

Schneiter, R., M. Hitomi, A. S. Ivessa, E. V. Fasch, S. D. Kohlwein and A. M. Tartakoff 1996. A yeast acetyl coenzyme A carboxylase mutant links verylong-chain fatty acid synthesis to the structure and function of the nuclear membrane-pore complex. Mol Cell Biol 16:7161-72.

Schröder, S., F. Schimmöller, B. Singer-Krüger and H. Riezman 1995. The Golgi-localization of yeast Emp47p depends on its di-lysine motif but is not affected by the ret1-1 mutation in alpha-COP. J. Cell Biol. 131:895-912.

Semenza, J. C., K. G. Hardwick, N. Dean and H. R. B. Pelham 1990. ERD2, a yeast gene required for the receptor-mediated retrieval of luminal ER proteins from the secretory pathway. Cell 61:1349-1357.

Serafini, T., G. Stenbeck, A. Brecht, F. Lottspeich, L. Orci, J. E. Rothman and F. T. Wieland 1991. A coat subunit of Golgi-derived non-clathrincoated vesicles with homology to the clathrin-coated vesicle coat protein beta-adaptin. Nature 349:214-220.

Serafini, T., L. Orci, M. Amherdt, M. Brunner, R. A. Kahn and J. E. Rothman 1991. ADP-ribosylation factor is a subunit of the coat of Golgiderived cop-coated vesicles - a novel role for a GTP-binding protein. Cell 67:239-253.

Søgaard, M., K. Tani, R. R. Ye, S. Geromanos, P. Tempst, T. Kirchhausen, J. E. Rothman and T. Söllner 1994. A rab protein is required for the assembly of SNARE complexes in the docking of transport vesicles. Cell 78:937-948.

Söllner, T., S. W. Whitehart, M. Brunner, H. Erdjument-Bromage, S. Geromanos, P. Tempst and J. E. Rothman 1993. SNAP receptors implicated in vesicle targeting and fusion. Nature 362:318-324.

Sutton, R. B., D. Fasshauer, R. Jahn and A. T. Brunger 1998. Crystal structure of a SNARE complex involved in synaptic exocytosis at $2.4 \mathrm{~A}$ resolution. Nature 395:347-53. 
Sweet, D. J. and H. R. B. Pelham 1993. The TIP1 gene of Saccharomyces cerevisiae encodes an $80 \mathrm{kda}$ cytoplasmic protein that interacts with the cytoplasmic domain of Sec20p. EMBO J. 12:2831-2840.

Townsley, F. M., G. Frigerio and H. R. B. Pelham 1994. Retrieval of HDEL proteins is required for growth of yeast-cells. J. Cell Biol. 127:21-28.

Tsui, M. M. and D. K. Banfield 2000. Yeast Golgi SNARE interactions are promiscuous. J Cell Sci. 113:145-52.

VanRheenen, S. M., X. C. Cao, V. V. Lupashin, C. Barlowe and M. G. Waters 1998. Sec35p, a novel peripheral membrane protein, is required for ER to Golgi vesicle docking. J. Cell Biol. 141:1107-1119.

VanRheenen, S. M., X. Cao, S. K. Sapperstein, E. C. Chiang, V. V. Lupashin, C. Barlowe and M. G. Waters 1999. Sec34p, a protein required for vesicle tethering to the yeast Golgi apparatus, is in a complex with Sec35p. J Cell Biol 147:729-42.

Warren, G. and I. Mellman 1999. Bulk flow redux? Cell 98:125-127.

Waters, M. G., T. Serafini and J. E. Rothman 1991. Coatomer - a cytosolic protein complex containing subunits of non-clathrin-coated Golgi transport vesicles. Nature 349:248-251.

Weber, T., B. V. Zemelman, J. A. Mcnew, B. Westermann, M. Gmachl, F. Parlati, T. H. Söllner and J. E. Rothman 1998. SNAREpins - minimal machinery for membrane-fusion. Cell 92:759-772.

Weimbs, T., K. Mostov, S. H. Low and R. Hofmann 1998. A model for structural similarity between different SNARE complexes based on sequence relationships. Trends in Cell Biology 8:260-262.

Wilson, D. W., C. A. Wilcox, G. C. Flynn, E. Chen, W.-J. Kuang, W. J. Henzel, M. R. Block, A. Ullrich and J. E. Rothman 1989. A fusion protein required for vesicle-mediated transport in both mammalian cells and yeast. Nature 339:355-359.

Witters, L. A. and T. D. Watts 1990. Yeast acetyl-CoA carboxylase: in vitro phosphorylation by mammalian and yeast protein kinases. Biochem. Biophys. Res. Commun. 169:369-76.

Wooding, S. and H. R. B. Pelham 1998. The dynamics of Golgi protein traffic visualized in living yeast-cells. Mol. Biol. Cell 9:2667-2680. 
Yamakawa, H., D. H. Seog, K. Yoda, M. Yamasaki and T. Wakabayashi 1996. Uso1 protein is a dimer with 2 globular heads and a long coiled-coil tail. J. Struct. Biol. 116:356-365.

Yang, B., L. Gonzalez, R. Prekeris, M. Steegmaier, R. J. Advani and R. H. Scheller 1999. SNARE interactions are not selective - Implications for membrane fusion specificity. J. Biol. Chem. 274:5649-5653.

Yang, B., M. Steegmaier, L. C. Gonzalez Jr and R. H. Scheller 2000. Nsec1 binds a closed conformation of syntaxin1a. J. Cell Biol. 148:247-52.

Yoshihisa, T., C. Barlowe and R. Schekman 1993. Requirement for a GTPaseactivating protein in vesicle budding from the endoplasmic reticulum. Science 259:1466-1468. 


\section{Anhang}

\subsection{Verzeichnis der verwendeten Abkürzungen}

Neben den international gültigen physikalischen Einheiten und chemischen Symbolen fanden folgende Abkürzungen Verwendung:

\begin{tabular}{|c|c|}
\hline 3-AT & 3-Amino-1,2,4-triazol \\
\hline Ac & Acetyl \\
\hline AD & Aktivierungsdomäne \\
\hline ALP & Alkalische Phosphatase \\
\hline Amp & Ampicillin \\
\hline APS & Ammoniumperoxodisulfat \\
\hline AS & Aminosäure \\
\hline ATP & Adenosin- $5^{\prime}$-triphosphat \\
\hline BD & Bindedomäne \\
\hline BSA & Rinderserumalbumin \\
\hline CPY & Carboxypeptidase $Y$ \\
\hline DAPI & 4',6-Diamino-2-phenylindol-dihydrochlorid \\
\hline dATP & 2'-Desoxyadenosin-5'-triphosphat \\
\hline dCTP & 2'-Desoxycytidin-5'-triphosphat \\
\hline dGTP & 2'-Desoxyguanosin-5'-triphosphat \\
\hline DMSO & Dimethylsulfoxid \\
\hline DNA & Desoxyribonukleinsäure \\
\hline dNTP & 2'-Desoxynukleosid-5'-triphosphat \\
\hline DTT & Dithiothreitol \\
\hline dTTP & 2'-Desoxythymidin-5'-triphosphat \\
\hline EDTA & Ethylendiamintetraessigsäure \\
\hline ER & Endoplasmatisches Retikulum \\
\hline GAP & GTPase aktivierendes Protein \\
\hline GDP & Guanosin-5'-diphosphat \\
\hline GTP & Guanosin-5'-triphosphat \\
\hline GTP $\gamma S$ & Guanosin-5'-O-(3-thiotriphosphat) \\
\hline IPTG & Isopropylthio- $\beta$-D-galaktosid \\
\hline $\mathrm{Da}$ & Dalton \\
\hline $\mathrm{Me}$ & Methyl \\
\hline MESNA & 2-Mercaptoethansulfonsäure \\
\hline
\end{tabular}




$\begin{array}{ll}\text { MOPS } & \gamma \text {-Morpholino-propansulfonsäure } \\ \text { NEM } & \text { N-ethylmaleimid } \\ \text { NSF } & \text { NEM-sensitive-factor } \\ \text { OD } & \text { Optische Dichte } \\ \text { PBS } & \text { Phosphate-buffered-saline } \\ \text { PCR } & \text { Polymerase Kettenreaktion } \\ \text { PEG } & \text { Polyethylenglykol } \\ \text { RNA } & \text { Ribonukleinsäure } \\ \text { RNase } & \text { Ribonuklease } \\ \text { upm } & \text { Umdrehungen pro Minute } \\ \text { RT } & \text { Raumtemperatur } \\ \text { SDS } & \text { Natriumdodecylsulfat } \\ \text { SDS-PAGE } & \text { SDS-Polyacrylamid-Gel-Elektrophorese } \\ \text { SNAP } & \text { soluble-NSF-attachment-protein } \\ \text { SNARE } & \text { SNAP-receptor } \\ \text { TCA } & \text { Trichloressigsäure } \\ \text { TEMED } & N, N, N^{\prime}, N^{\prime} \text {-Tetramethylethylendiamin } \\ \text { TRAPP } & \text { transport-protein-particle } \\ \text { Tris } & \text { Tris-hydroxymethyl-aminomethan } \\ \text { u } & \text { unit (Einheit für die spezifische Enzymaktivität) } \\ \text { v/v } & \text { Volumen/Volumen-Verhältnis (volume/volume) } \\ \text { w/v } & \text { Gewicht/Volumen-Verhältnis (weight/volume) }\end{array}$




\section{Einbuchstabenkode für die Aminosäuren}

$\begin{array}{lll}\text { A } & \text { Ala } & \text { Alanin } \\ \text { C } & \text { Cys } & \text { Cystein } \\ \text { D } & \text { Asn } & \text { Asparaginsäure } \\ \text { E } & \text { Gln } & \text { Glutaminsäure } \\ \text { F } & \text { Phe } & \text { Phenylalanin } \\ \text { G } & \text { Gly } & \text { Glycin } \\ \text { H } & \text { His } & \text { Histidin } \\ \text { I } & \text { lle } & \text { Isoleucin } \\ \text { K } & \text { Lys } & \text { Lysin } \\ \text { L } & \text { Leu } & \text { Leucin } \\ \text { M } & \text { Met } & \text { Methionin } \\ \text { N } & \text { Asp } & \text { Asparagin } \\ \text { P } & \text { Pro } & \text { Prolin } \\ \text { Q } & \text { Glu } & \text { Glutamin } \\ \text { R } & \text { Arg } & \text { Arginin } \\ \text { S } & \text { Ser } & \text { Serin } \\ \text { T } & \text { Thr } & \text { Threonin } \\ \text { V } & \text { Val } & \text { Valin } \\ \text { W } & \text { Trp } & \text { Tryptophan } \\ \text { Y } & \text { Tyr } & \text { Tyrosin } \\ & & \end{array}$




\section{Danksagungen}

Herrn Prof. D. Gallwitz danke ich für die Betreuung dieser Arbeit.

Herrn Prof. A. Zeeck und Herrn Prof. H. Laatsch danke ich für ihre Zustimmung und Betreuung der Arbeit als Referenten und Korreferenten stellvertretend für den Fachbereich Chemie der Universität Göttingen.

Ganz besonders möchte ich mich bei Dr. Hans-Dieter Schmitt für die äußerst interessante Themenstellung, die stete Hilfsbereitschaft sowie für viele Ideen und Diskussionen, die zum Gelingen dieser Arbeit beigetragen haben, bedanken.

Bei meinen jetzigen und ehemaligen Laborkollegen Uwe Andag, Hannegret Frahm und Dr. Dmitri Ossipov möchte ich mich für die tatkräftige Unterstützung bedanken. Dabei gilt mein besonderer Dank Uwe Andag, der durch sein emsiges Korrekturlesen dieser Arbeit fast alle Fehler ausgebügelt hat (ER du Golgi).

Bei Dr. Stefan Jakobs möchte ich mich für die Hilfe bei den Aufnahmen am Raster-Laser-Mikroskop bedanken.

Bei Prof. S. D. Kohlwein und A. Ulrich (TU, Graz) möchte ich mich für den regen wissenschaftlichen Austausch zum Thema Acc1p und für die nette Aufnahme während meines einwöchigen Aufenthalts in Graz bedanken.

Hans-Peter Geithe danke ich für die zahlreichen DNA-Sequenzierungen sowie Ingrid Balshüsemann für die Überwindung bürokratischer Hürden.

Bei allen Kolleginnen und Kollegen der Abteilung Molekulare Genetik möchte ich mich für das angenehme Arbeitsklima und die gute Zusammenarbeit bedanken.

Weiterhin bedanke ich mich bei meinen Eltern, die mir das Studium der Chemie ermöglicht haben und allen Freunden, die mich während meines Studiums in Göttingen unterstützt haben. Dabei danke ich besonders Christian für die wichtigen Dinge im Leben. 


\section{Lebenslauf}

Name:

Tanja Neumann

Geburtsdatum: $\quad$ 14.08.1971

Geburtsort: Göttingen

Staatsangehörigkeit: deutsch

Familienstand: ledig

\section{Schulausbildung}

1977-1981 Grundschule Elliehausen

1981-1983 Kooperative Gesamtschule Göttingen-West

1983-1990 Otto-Hahn-Gymnasium Göttingen, Abschluß: Abitur

\section{Studium}

10/90-02/96 Studium der Chemie an der Georg-August-Universität Göttingen, Abschluß Diplom (Note: sehr gut)

01/95-02/96 Diplomarbeit in der Abteilung Klinische Biochemie der Georg-August-Universität Göttingen unter der Leitung von Prof. Dr. H.-D. Söling

Thema: Untersuchungen des Transports von Heparansulfatproteoglycanen vom Trans-Golgi-Netzwerk — Studien an permeabilisierten Leberzellen

seit 07/97 Promotionsarbeit in der Abteilung für Molekulare Genetik am Max-Planck-Institut für Biophysikalische Chemie unter der Leitung von Prof. Dr. D. Gallwitz, Betreuung durch Dr. H. D. Schmitt

Thema: Untersuchung von Proteinkomponenten der ERGolgi Recycling-Maschinerie von Hefe

\section{praktische Tätigkeiten}

05/96-06/97 Forschungstätigkeit in der Abteilung Physiologische Chemie an der Medizinischen Hochschule Hannover und der Bundesforschungsanstalt für Viruserkrankungen der Tiere in Tübingen, Leitung Prof. Dr. H. Niemann

02/96-04/96 Forschungstätigkeit in der Abteilung Klinische Biochemie der Georg-August-Universität Göttingen, Leitung Prof. Dr. H.-D. Söling 